



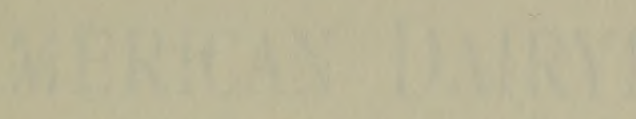





\title{
MERICAN DAIRYING:2
}

\author{
A MANUAL FOR
}

\section{Butter and Cheese Makers.}

BY

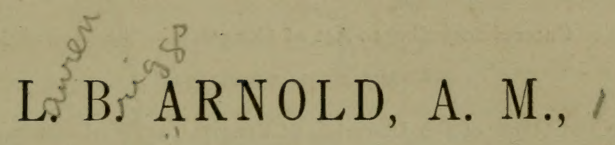

Secretary of the American Dairymen's Association,

Dairy Contributor to the New York Tribune, Lecturer on Dairy Husbandry, \&c.

ROCHESTER, N. Y.:

RURAL HOME PUBLISHING COMPANY.

$$
\text { I } 876 \text {. }
$$




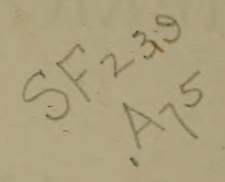

Entered according to Act of Congress, in the year 1876 , BY L. B. ARNOLD,

In the Office of the Librarian of Congress, at Washington, D. C.<smiles>[13CH3][13CH]([13CH3])[14CH3]</smiles>

JAMES Lennox, Electrotyper. 


\section{R E M A R K S.}

URGENT demands and frequent inquiries for a thoroughly practical work on American Dairying, together with continuous questions in regard to almost everything pertaining to the dairy, are the only apologies the author has to offer for this volume. In its preparation the aim has been to meet the wants indicated by the numerous inquiries that have from time to time reached him, and to so condense its contents as to keep its cost within the reach of every dairyman, and at the same time to give as full and fair an exposition as possible of the subject of dairying as developed by practical experience in factories and dairies in the United States and Canada. This effort has made it necessary to omit some details which might have been interesting, and often to be content with enunciating a general principle or fact without accompanying it with the evidence on which it was based.

The work is mainly the result of the investigations, observations and experiences of the author. He has avoided borrowing from foreign sources, preferring to confine himself to that with which he was familiar and of which he had knowledge-to that which is adapted to dairy husbandry in America-instead of drawing from outside and often doubtful sources, and speculating on what is conjectured or not positively known. The work is, therefore, not a compilation, but essentially original and American.

The author has also avoided adopting or recommending new and doubtful ideas and processes. If he cannot lead aright, he does not mean to lead astray. He is aware of the deficiencies and imperfections of the work, but he is not aware that it contains anything false or pernicious. Hoping it may meet the wants of the intelligent and rapidly increasing number of men and women engaged in the important interest of dairying in the United States and Canada, the author submits the result of his labors to their careful consideration and candid judgment.

L. B. A. 



\section{TABLE OF CONTENTS.}

AMERICAN DAIRY SYSTEM, Origin and Development of Associated Dairying, Influcnce of Dairy Production, Extent of -

DAIRY FARMING, Soiling Dairy Cows, Importance of Dairying upon Exhausted Soils, Influence of - _ _ _ - $\quad 24$ Manure on Dairy Farms, Importance of - _ _ - _ - - $\quad$ - 24

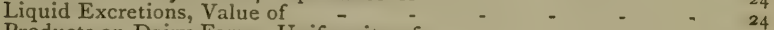
Products on Dairy Farms, Uniformity of - _ - - - - - $\quad 25$

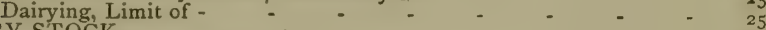

DAIRY STOCK

Dairy Breeds, Number of Ayrshires, Channel Island Cattle, Ayrshire Milk, Quality of Average Yield of Ayrshires Average Yield of Jerseys, Dutch or Holstein, Jersey Cheese, Analysis of Average Yield of Dutch Cows, Shorthorns,

Butter Globules in Shorthorn Milk, Character of Other Breeds, -

Thoroughbreds, Deficient Numbers of . Grades of Milking Breeds, Value of

HEREDI TARY DESCENT, Laws of, as Applied to Grades, How Qualities are Acquired and Lost. "Taking Back," When it Occurs, Law of Transmission, Importance of Breeding from Similar 'I'ypes, Milking Breeds, Perfection of Prepotency, First Effects of Old Creamer, Remarkable Yield, Jersey Cows, Remarkable Yield of Shorthorns Crossing on Native Stock, Effect of Selecting Dairy Stock, Milking Quality, Illustration of Value Dairy Coivs, Length of Period of Milking Dairy of A. L. Fish, Comparative Reliability of Different Breeds,

DAIRY CATTLE, Annual Demand for Where Selections Must Come From External Indications of Milking Capacity, Signs with No Significance, Signs which have Significance, Milk Mirror, Value of Skin, Significance of . Cellular Tissue, Significance of Breeds for Special Purposes, Small Breeds, Localities Adapted to Large Breeds, Localities Adapted to Poor Milker, Sample of (Illustrated),

PAGE.

- I3

14

I7

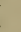


FOOD FOR DAIRY STOCK;

Circumstances which Affect Quantity Required, - - - - ${ }_{-} \begin{array}{r}65 \\ 65\end{array}$

Considerations of Cost, - _ _ _ - _ - - - - 65

Considerations Affecting Quality, - - - - - - - 66

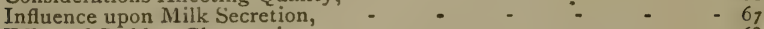

Effect of Sudden Changes in - - - - - - - - 68

Changing from Hay to Grass, .

Salt, Importance of - - - - - - - - - 69

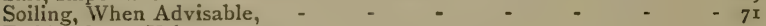

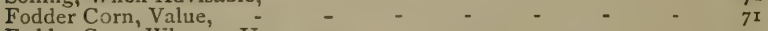

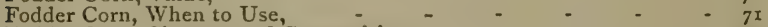

Fodder Corn, Character of Composition, - - - - - $\quad 72$

Lucern, - $\quad$ - $\quad$ - $\quad$ -

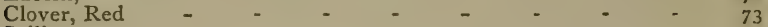

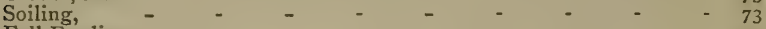

Fall Feeding, - $\quad$ - $\quad$ - $\quad$ - $\quad$ -

Bran, - - - - $\quad$ - $\quad$ - $\quad$ - $\quad$ -

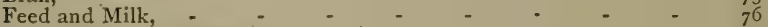

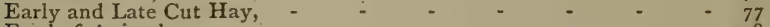

Food of Animals, - $\quad$ - $\quad$ - $\quad$ - $\quad$ -

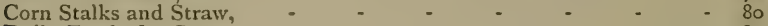

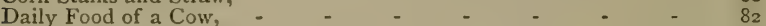

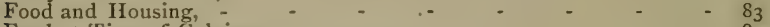

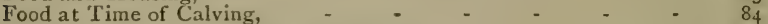

Condition of Food for Bovine Digestion, - _ _ - _ _ - - $\quad 86$

Digestive Apparatus of Ruminants, - $\quad$ - $\quad$ - $\quad$ - 86

The Course of Food, -

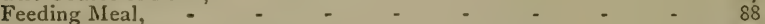

Food Experiments, - $\quad-\quad$ - $\quad$ - $\quad$ - $\quad$ - $\quad$ - $\quad$ - 89

Mode of Feeding of Ruminants, - - - - - - - $\quad$ - 90

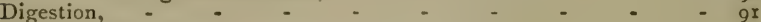

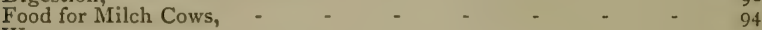

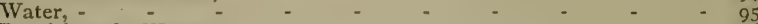

Provisions for Water,

THE DAIRY BARN,

Barn of Peter Mulks,

Provisions for Manure,

Stables and Milking,
Conveniences of Fodder,

THE OCTAGON BARN, - - - - - - - - - 108

The Octagon Form, - $\quad$ - $\quad$ - $\quad$ -

Barn of E. W. Stewart,

Adaptation of the Octagon, -

Concrete Wall,

Quick Lime Concrete, Proportions - - - - - - - - II6

Concrete Wall, Cost of - - _ _ _ _ - - - II7

REARING CALVES,

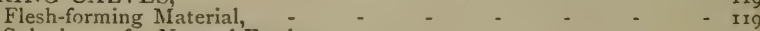

Substitutes for Natural Food, - - _ _ _ - _ - 121 MILK

Àlbuminoids in Milk, - _ _ _ _ _ _ _

Fats in Milk,

Milk Magnified,

Specific Gravity,

Sugar of Milk,

Saline Constituents of Milk,

Ash of Milk, Analysis of

Milk Secretion,

Mammary Gland, Development of

Mammary Gland, How Made,

Mammary Gland, Arterial Branches of

Lactiferous Vessels, Description of -

Lactiferous Reservoirs, 
MILK, How Cows Hold Up. Milk,

PAGE. Central Tendon Described,

Divisions of Udder Dissimilar,

Divisions of Udder into Lobules and Follicles, - - - -

Gland Cells, How Formed, -

Gland Cells, Changes in -

Gland Cells Similar to Milk Globules,

Milk Globules, Pellicle of, Not Caseine,

Milk Globules, Sometimes Fatless,

Milk Globules, with Broken Pellicle,

Colustrum, Formation of

Colustrum, Decrease of

Colustrum, Connection with Milk Globules, _ _ _ _ _ _ -

Colustrum, Analysis of -

Colustrum, Affected by Feed,

Udder Affected by Feed,

Milk, Changes in, After Parturition,

Milk, Quality Affected by Food,

Tables Showing Changes of Milk by Distance of Time from Calving, ${ }^{147}$

Milk, Quality Affected by Imperfect Nutrition, - _ - _ 149

Milking Function, How to Prolong it, - - - - - -

Milk Secretion, Effect of on Blood. - - - - - - $x^{x} 5^{x}$

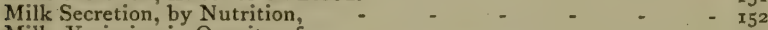

Milk, Variation in Opacity of - _ _ _ _ _ _ _ _ $\quad 153$

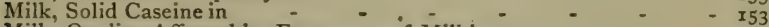

Milk, Quality Affected by Frequency of Milking, - _ _ - 154

Mllk, Quality Affected by Time between Milkings, _ - _ - 154

Milk, Difference between First and Last Drawn, - _ _ - $\quad 154$

Milk, Loss of by Absorption, - - _ _ _ _ - - 155

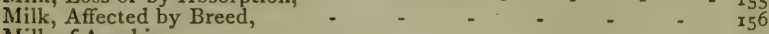

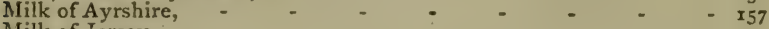

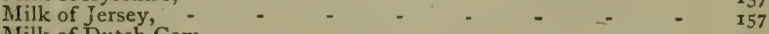

Milk of Dutch Cow, - _ _ _ _ _ _ _ _ - -

Milk of Shorthorn, - - - - - - - - 158

Milking,

Exciting Cows,

Treatment of Cows while Milking,

Manner of Milking,

Recularity and Cle - - - - - - - ${ }_{-162}$

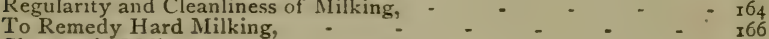

Changes in Milk, - - - - - - - - - -

Decomposition, -

Influence of Air on Milk, - - - _ - - - - -

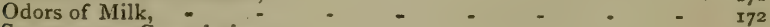

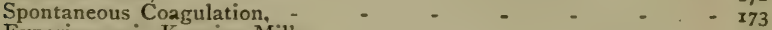

Experiences in Keeping Milk, - _ _ _ _ _ _ _ $\quad$ - 174

The Constituents of Milk, - - _ _ - _ _ _ - $\quad$ - 175

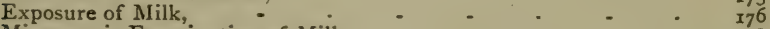

Microscopic Examination of Milk, - _ _ - _ - _ - - $\quad$ - 178

Milk from Unhealthy Sources, - _ _ _ _ _ _ $\quad$ - 180

Effect of Treatment, - - _ _ _ - - - - - - -

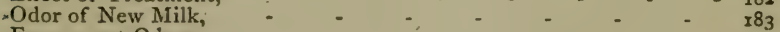

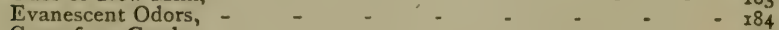

Gases from Curds, - $\quad$ - $\quad$ - $\quad$ - $\quad$ - $\quad$ - $\quad$ - 185

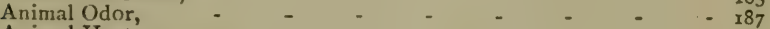

Animal Heat,

Milk in Warm Weather, - - - - - - - - -

Volatile Oil,

Feverishness,

Condition of Utensils,

Carrying Milk,

BUTTER MAKING, -

Vesscls for Seting - - - - - - - -

Cream, 
BUTTER MAKING, Specific Gravity of Cream, - _ - - - 205

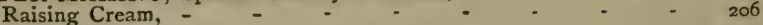

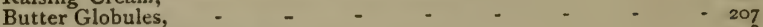

Fats in Cream, - - - - - - - 208

Difference in Gravities of Milk, - _ _ _ _ _ _ _ _ _ 210

Effects of Temperature, - - - - - - - - 211

Skimming, - - - - - - - - - - -

Preparing Cream for Churning, - _ _ _ _ - - $\quad$ - 217

When to Churn, - _ - _ _ _ - _ - - 218

Flecks in Cream, - $\quad$ - $\quad$ - $\quad$ - $\quad$ - $\quad$ -

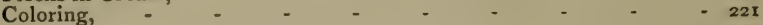

Churning - - - - - - - - - - 223

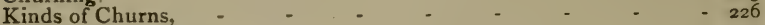

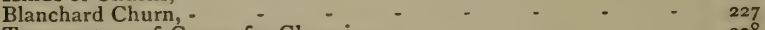

Temperature of Cream for Churning, - - - - - - 228

Washing Butter, - - - - - - - - - $\quad 230$

The Higgins Process of Manipulation, - - - - - - 232

Working Butter, - - . - - - - - 233

Butter Workers, - $\quad$ - $\quad$ - $\quad$ - $\quad$ -

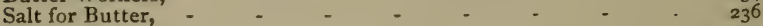

Salting Butter, - $\quad$ - $\quad$ - $\quad$ - $\quad$ -

Packing Butter, - $\quad$ - $\quad$ - $\quad$ - $\quad$ - $\quad$ - $\quad$ - 238

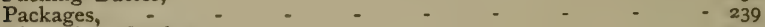

The Adams Package, - - $\quad$ - $\quad$ - $\quad$ - $\quad$ - 243

Milk Rooms, -

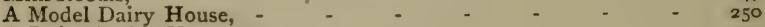

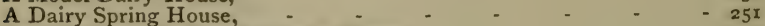

Prof. Wilkinson's Plan for Dairy House, - _ - - - - 253

Hardin's Method, -

Plan of Ice House, - $\quad$ - $\quad$ - $\quad$ - - 263

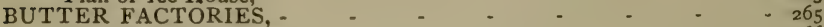

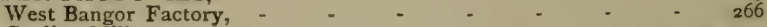

Cooling Milk, - $\quad$ - $\quad$ - $\quad$ - $\quad$ - $\quad$ - $\quad$ - 270

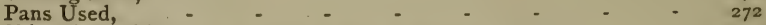

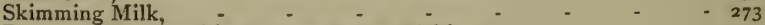

Processes Employed in Factory Butter Making, - _ - _ - 274

Temperatures, - - - - - _ _ - - - $\quad-277$

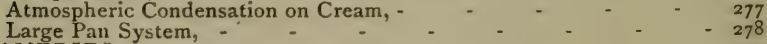

CREAMERIES, - - - - - - - - - - $\quad$ - 279

Elm Tree Creamery, - $\quad$ - $\quad$ - $\quad$ - $\quad$ - $\quad$ - $\quad$ - $\quad$ - $\quad$ - 282

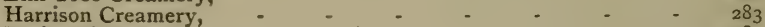

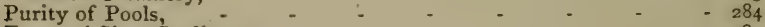

Fast and Slow Cooling, - _ _ _ _ _ _ _ - - 285

Economy in Labor, - $\quad$ - $\quad$ - $\quad$ - $\quad$ - $\quad$ - $\quad$ - 288

Economy in Cream, - $\quad$ - $\quad$ - $\quad$ - $\quad$ - 290

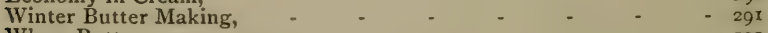

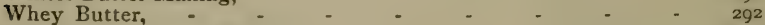

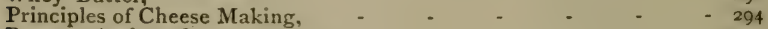

Rennet, Action of - - _ _ _ - - - 294

Effect of Heat in Cheese Making, - _ _ _ _ _ _ - 296

The Armstrong Vat, - : - - - - - . 300

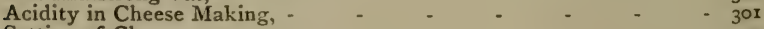

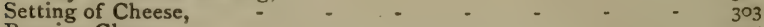

Pressing Cheese, - $\quad$ - $\quad$ - $\quad$ - $\quad$ - $\quad$ -

Curing Cheese, - - 305

CHEESE FACTORIES AND FACTORY MANAGEMENT, - - $\quad 307$

Willow Grove Factory, - - ? - ? - 303

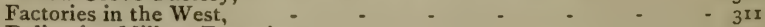

Delivering Milk to Factories, - - - - - - - $3^{12}$

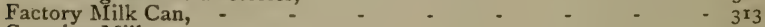

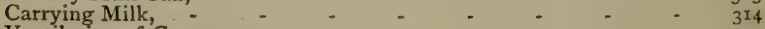

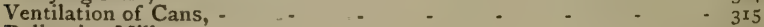

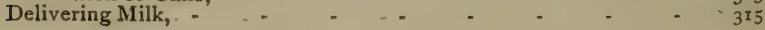


CHEESE FACTORIES AND FACTORY MANAGEMENT.

PAGE.

Motive Powers,

Methods of Heating,

Use of Vats,

Curd Cutters,

Curd Mill,

The Cheddar Process,

Treatment of Curd,

Working Tainted Milk,

Working Sour Milk,

Working Skim-milkCheese,

Oleomargarine Cheese,

The Ellsworth Method,

Hay Cheese,

Curing Early Cheese,

Pressing Cheese,

Time of Pressing,

Care of Cheese in the Curing Room,

Boxing Cheese for Market,

Farm Dairy Cheese Making,

APPENDIX,

Hot Iron Test,

Testing Milk at Factories,

Rennet,

Preparing Coloring for Cheese and Butter,

To Prepare Basket Annatto,

Boards of Trade,

Rules and Regulations for a Board of Trade

List of Apparatus,

Complete Outfit for a Cheese Factory of 400 Cows,

- 317

319

- 320

$32 \mathrm{I}$

- 324

326

- 327

328

- 330

331

- 334

334

- 336

337

- $33^{8}$

$34^{\circ}$

- $34 \mathrm{I}$

342

- 342

346

- 346

346

- 347

350

- 350

Form for Organizing a Dairy Manufacturing Company or Association,

Analysis of Cheese, - 


\section{INDEX TO ILLUSTRATIONS.}

Ayrshire Cow, Georgie,

Jersey Cow, Nella,

Dutch or Holsteın Cow, Maid of Twisk, -

Shorthorn Cow,

Milk Mirror, -

Barn of Peter Mulks,

Barn of Peter Mulks, Plan of

Bents of Keeler's Barn,

Basement of Mr. Stewart's Barn,

Octagon Barn,

Fats in Milk, -

Udder,

Teat with Irregular Interior,

Lobules,

Ultimate Follicles,

Milk Globule with Broken Pellicle

Enlarged Follicle,

Colustrum,

Colustrum

Fifth Milking,

Old Milk

Plug for Enlarging Teat,

Milk Cells,

Impurities in Milk,

Milk Globules,

Milk from Stagnant Water,

Milk from Distillers' Slops,

Milk Cooler,

Milk Vat,

Dash Churn,

Blanchard Churn,

Butter Worker,

The Adams Butter Package,

Chesebro's Butter Jar,

Plan of Spring House,

Sub-Earth Duct,

Hardin's Milk Cooler,

Plan of Ice House.

Butter Factory, West Bangor, N. Y - - - - 264

Butter Factory, West Bangor, N. Y., Ground Plan of - - - _ $\quad 260$

Elm Tree Creamery, Elevation of - _ _ _ _ _ _ _ _ _ 280

Elm Tree Creamery, Ground Plan of - _ _ _ _ _ _ _ $28 \mathrm{r}$

Harrison Creamery, - _ _ _ _ _ _ _ _ _ _ _ _ - 283

Heating Apparatus,

Willow Grove Factory,

Willow Grove Factory, Plan of

Iron-Clad Can,

Can Ventilating Device,

Economizer Engine,

Cheese Vat,

Curd Cutters,

Syphon,

Curd Mill,

Curd Sink on Castors, 


\title{
ORIGIN AND DEVELOPMENT.
}

\author{
OF THE
}

\section{AMERICAN DAIRY SYSTEM.}

From time immemorial the milk of domestic animals has been used as food for man, and its value as a wholesome and rich diet has been recognized from the earliest records, all the way down to the present date.

The cow has been the chief animal from which to derive milk; but the sheep and goat, the ass and horse, the buffalo and deer, have each also been drawn upon to furnish for the gratification of the human palate and the support of human life, the pabulum nature designed for their own offspring. The milk of these animals is still largely employed as food by different nations, but in American dairying, only cow's milk is used, and but very little milk from any other animal is ever used by, or even familiarly known to, the people of the United States. Cow's milk is therefore only treated of in this work.

Butter and cheese came later into use, but their origin, too, reaches so far back, that its precise date is lost in the dimness and obscurity of the distant past. 
Though for many centuries in use, and always esteemed as health-inspiring luxuries, the progress which has been made in preparing milk and its products for preservation and consumption, has been remarkably slow until within a very recent period. The slow advance in the quality and production of butter and cheese, is not without many parallels in rural industries. The modes of tilling the earth, the rearing of flocks and herds, and the culture of fruits and grains, have made equally slow advances.

In all the avocations of men in which the laborers work in positions so isolated as to fail of quickly catching any progressive steps their fellows may make, advancement is always slow. To make much progress men must work socially, so as to learn of each other. No one makes much progress by working alone. It was not, therefore, till associated dairying came into rogue, and the numerous associations for mutual instruction and investigation were established, that dairying in this country, made any marked advance. Since these agencies were adopted, it has on this continent shot ahead with a velocity that has astonished ourselves and attracted the attention of the civilized world.

It is not my purpose to trace the history of dairy husbandry through the long and devious course from its origin down to the present time. It must suffice for me to allude in the briefest way to the rise of the system now in general use in the United States and Canada, known as the American system of dairying, and to pass at once to a study of its practical workings and philosophy.

The system of associated dairying originated with Jesse Williams of Rome, N. Y., in $185 \mathrm{I}$. Its origin is 
Origin, \& c., of the American Dairy System.

regarded by many as accidental, but I do not so consider it.

We had arrived at a stage in the progress of dairy husbandry where a closer study of the art, especially of cheese-making, began to be arvakened, and men prominent for their skill and intelligence began to make their influence felt in the quality of cheese. Prominent among these early pioneers in the improvement of cheese-making were Harvey Farrington, who introduced and explained the use of acidity, and the effect of ripening milk for improving cheese; A. L. Fish, Harry Burrell, Jacob Ellison, R. D. Brown, Nathan Arnold, all of Herkimer Co., and many others who might be named. These men, who in advance of Mr. Williams, became noted for their skill in cheesemaking, are still living, and with the harness yet on, are still laboring in their old age, to advance the progressive movement they did much in their earlier days to inaugurate.

In 1844 a cheese factory was built in Groshen, Conn., by Lewis M. Norton, which is still in use by his descendant, Ed. Norton. The milk supplying this factory was coagulated at the farms, and the curd taken to the factory to be converted into cheese. It was an easy step from the association of curds to the association of milk.

The necessity of the plan introduced by Mr. Williams, was becoming so apparent and so strongly felt, that it could not much longer have escaped recognition had not his clear head and practical ability put it in successful operation. There is evidence of this in the fact that the fundamental idea of his plan had also occured to others in different parts of the country, 
and that a system, closely analagous, had been in operation in Switzerland for more than a century.

This view does not detract anything from the credit due to Mr. Williams as the originator of the American dairy system. 'His leadership in the matter is fully recognized and acknowledged, and it entitles him not only to the credit of originality but to the profound thanks of the whole dairy public for his timely inauguration of the most important improvement ever introduced in the dairy interest. The view I take of the part he played, makes him, like Ericson with his monitor, and as inventors generally are, a necessary link in the chain of progressive events.

The circumstance which gave rise to associated dairying, was the fact that the products of Mr. Williams' dairy would sell for a higher price than those of his son, living near by him. To secure for his son the same price he received for his own, he took his son's milk in with his own, who divided with him the cost of manufacturing and then shared with him pro rata, according to the pounds of milk each had furnished. This proved advantageous to both. It reduced the cost of manufacturing the milk of buth, and enhanced the price of the son's cheese. From this hint the milk of one neighbor after another was taken into the partnership, till the dairy house of Mr. Williams became the general manufactory for the milk of the dairies around him. Thus the original idea as introduced by Mr. Williams, embraced mingling the milk of several herds in one manufactory so that the best skill of the neighborhood could be applied to the whole. This idea is now receiving a more extended application. One expert now often controls the operations in a number of factories ranging from two to 
twenty or more. In this way the rare skill of superior experts, is made available to its utmost extent. This extension of skill is the all important characteristic of the factory system as distinguished from private dairies. An occasional expert may be found in family dairying, but it is not possible to find one in every family. The great bulk of products manufactured in dairies must be made by mediocre or inferior skill. But it is possible to find in a whole neighborhood one or more superior hands, and in the territory occupied by a number of factories it is always easy to find an expert whose skill can bring the products of all the factories he can preside over, up to the highest point of perfection known to the art.

This new departure in American dairying has done as much, if not more, to elevate the standard of American dairy products, than the original idea of associating dairies. As yet, this advantage has been chiefly applied to cheese-making, but there is an equal necessity for applying it to butter-making, and even a greater necessity, since the butter interest-is, at least, three times as large as the cheese interest.

\section{EXTENT OF PRODUCTION. .}

In consequence of the improved modes of manufacture recently introduced, the business of dairying has rapidly expanded. It is believed, however, rot to have reached the enormous magnitude some writers, - who have taken it for granted the national census of r870 was greatly at fault, have ascribed to it.

There can hardly be a doubt that inaccuracies of greater or less magnitude always creep into the statistics of the census marshals, but they are as likely to vary in one direction as another, and in the aggregate 
they give a good approximation to the truth. In regard to the statistics of the dairy it is certainly a very easy matter for marshals to get, very exactly, the number of cows in the country. As the enumeration of cows is as easy as that of the population, we may assume that item to be correct. The total for 1870 is put down at $8,935,232$. The amount of butter at $514,092,683$ lbs. This at the rate of roo lbs. to the cow, which, for the whole U. S., is a fair estimate,

Would use the milk of ............ . $5,40,926$ cows. $162,929,382 \mathrm{lbs}$. of cheese at $250 \mathrm{lbs}$. to the cow would use the milk of............. 65 I,709 "

$255,500,599$ gallons of milk sold of ......... 809,286 "6

Making a total of...............6,601,921

Subtracting this from the whole number of cows, we have $2,333,4$ I I cows to supply the home consumption of the farmers who produce milk, including their families and the help employed by them, which make up near one-third of the total population of the country. This is a moderate allowance of cows for supplying so large a number of people with milk. I am led to the belief, therefore, that the totals as put down in the last national census are substantially correct.

In 18,70 our exports were $\frac{7}{16}$ of our total product of cheese, and our home consumption $\frac{9}{16}$. If we suppose our home consumption has increased at the same rate as our export trade, it would make a present home cousumption of cheese of I $2,725,605$ pounds, and a total product of $204,446,555$ pounds. Owing to an increased area of dairying in the West, the consumption of cheese in the West and South, where most of the Western cheese finds a market, has been largely increased. Allowing twenty millions for this extra increase of home consumption, it will give us, in 
Origin, \&c., of the American Dairy System. 19

round numbers, a total annual product of cheese at present of $225,000,000$ pounds, which cannot be far from the truth.

Increasing the butter product at the same rate as that of cheese, we have 7 ro millions as the present annual product of butter. Unless the increase of cows since 1870 has been vastly greater than in any equal period in the past, the present number cannot vary much fron ten millions, the annual products of which would correspond closely to the above figures. I am aware that these estimates will lonk small to those who have had their imaginations stretched by the estimates of those who have based their calculations on a supposed per capita consumption of butter or cheese; and perhaps they ought to be somewhat enlarged, from the fact that in New York and Ohio especially, much of the milk which formerly made only butter, now makes cheese also from the same milk, thus increasing the aggregate product from a given number of cows; but it cannot swell the amount to anything like the estimates which have been current for the past few years.

The last national census does not show the per capita consumption of cheese in the United States to be as great as in some of the former ones, and there are good reasons why such a fact might be expected. In the first place, the factory cheese made for export is not suited to the taste of our people and it could not be expected that it would be consumed as freely as that which satisfied their taste better. In the second place, consumption has been stifled by crowding our markets with skim cheese, to a large extent insipid and indigestible, and such factory cheese as would not bear shipping. For these two reasons it is believed by 
many, and I think with reason, that the per capita consumption of cheese in the United States, instead of increasing as it ought, has been diminishing for several years.

\section{DAIRY FARMING.}

The introduction of the system of associated dairying, and the increased attention and study it has attracted to the dairy interest, are steadily making the business of dairy husbandry a leading branch of rural industry. The more thoroughly the matter is investigated the more clearly does it appear that the dairy affords many advantages over grain-raising and the other ordinary branches of farming, especially in particular localities; and as a natural consequence, this branch of farming is steadily gaining adherents in different parts of the country.

In favorable seasons, the annual returns from a grain farm and a dairy farm, do not foot up with a very wide difference; but that difference, whatever it may be, is generally in favor of the dairy. But it is not the extraordinary margin of profit afforded by dairy farming that is making so many converts to the cause. The inducements which cause so many to give a preference to this industry are various; and first among them is the greater certainty it affords of uniform results. All that portion of North America included in the north temperate zone, is subject to great climatic variations and sudden changes of 


\section{Dairy Farming.}

weather, which more or less affect and interfere with the farmer's crops. Drought, early or late frosts, excessive wet and cold, and storms of wind and hail, are ever-and-anon, the occasion of unfilled bins and empty pockets in one part of the country or another. On the prairies of the Western States, it is estimated that the corn crop, (probably the most reliable crop, in that section), is seriously injured on an average once in three years. And all over the Northern and Eastern States, crops are injuriously affected by drought or other cause, to serious extent once in about four years. Grass is more tenacious of life, and grows at a lower temperature than almost any other farm product. Nothing is so secure against varying climate and sudden changes of weather as grass; and as the operations of the dairy farmer are based on this crop, he can count on results much more nearly uniform than the grain-grower.

The increasing practice of soiling dairy cows during a part or the whole of the summer, is not only enhancing the proceeds of the dairyman, but is rendering him secure against the fluctuations of seasons, particularly against the almost never-failing recurrence of midsummer droughts. He is yearly appreciating more fully the fact that by growing deep rooted plants-such as corn, lucern and clover-he can cheaply provide an unfailing and abundant supply of excellent milk-producing food, which will carry his herd safely through long and severe droughts, that would dwarf his pastures and ruin his small grains. $\mathrm{He}$ can also, in the same way, eke out his winter's store. The practice of soiling taken in connection with the certainty of grass, spring and fall, gives him a guaranty of uniformity in his annual products, that 
hardly inures to any other farmer. Though his cattle are liable to accident and disease, the greater security which he thus enjoys against varying seasons and sudden freaks of weather, is equivalent to a considerble premium in favor of his mode of farming.

A second consideration in faror of dairy husbandry, is the greater uniformity in the price of butter and cheese, as compared with other farm products. The markets are often glutted with the different varieties of grain, meat, wool, \&c., the price running down below living rates, to be followed perhaps by inflation. In dairy products variations are not so great. Periods of activity and depression occur, but there are no such wide fluctuations as in the grain market. Great extremes cannot be reached in the dairy. The cows of a country cannot vary suddenly. It takes four or five years to produce a cow-and the market cannot be suddenly glutted. In fact, the cows in any country generally maintain nearly a uniform ratio with the number of inhabitants, varying very little, if at all. On this continent it has remained nearly the same from the earliest settlement of the country to the present time, varying little from twenty-three cows to one hundred inhabitants. A similar uniformity has prevailed in England and other countries of Europe. The relation, therefore, between the supply and demand of dairy products, cannot vary suddenly or very much. The relative proportions of butter and cheese may vary by reason of changes from the manufacture of one to the manufacture of the other; but an excess of cheese diminishes the product of butter, for the number of cows, and the aggregate of milk remaining the same, if more is devoted to cheese-making, less must be to butter-making, and vice versa. Prices run up and 
down as the supply of either varies, but dairymen oscillate so easily from the manufacture of one to the other, that no great excesses or deficiencies can well occur. These circumstances have a controlling influence, and will in the future, as they have done in the past, keep prices comparatively even. The greatest. variations are occasioned by good or bad seasons, when the aggregate of dairy products is swelled or diminished.

The difference in the severity of labor in grainraising and dairy farming has also, probably, some influence in inclining farmers to the dairy; but perhaps the strongest inducement is the little exhaustion it occasions to the fertility of the soil.

How the usual modes of farming exhaust the fertility of the soil is well known. The stores of plantfood which untold ages had accumulated in the virgin soil are sapped away in a few short years of subjugation to the plough. The depleting process seems destined to over-run the whole continent. It sweeps steadily on, keeping pace with the removal of the primeval forests, and leaves everywhere impoverished soils and diminished crops behind it. The exhaustion gnes on till the yield is reduced below profitable culture, when some new mode of operating must be adopted. There must be a resort to stock-raising, dairying, fallowing, rest, green crops, plastering or artificial manuring, to increase the yield to profitable results, for such results may always be accomplished. However low the fertility may be reduced there is always still left in the soil an immense wealth of plant food, though unavailable for present use, because locked up in insoluble compounds which require time and the action of the elements to unloose. Here then 
is a vast extent of land thus reduced, for the restoration of which dairy farming is most appropriate and inviting. It stops at once exhaustion, but does not stop income. It brings good returns from the first. Forage crops grow well where grain crops pay poorly. Seeding down to grass gives time for air and water, heat and frost, to gradually unlock the tenacious compounds which hold the mineral elements of plants, as with a firm grasp, and lets them loose for the rootlets to feed upon, or to accumulate in the soil for future use. It gives time for the absorbent properties of the soil to take in elements of fertility from the atmosphere, from the snows and rains, and from the dews of heaven. In this way a farm that has been run down may be made to grow rich, and a rich one richer. This problem is often worked out practically by farmers with such satisfactory results as to strongly induce others to "go and do likewise."

The manure-heap is the all-essential thing with the dairyman. His mode of farming allows him to consume the products of his farm on his own premises, and to return nearly all that is taken from the soil, back whence it came. There is a steady exhaustion going on upon a dairy farm as well as upon a grain farm, but it is small in comparison. It consists chiefly of phosphates that are carried away in the milk, and which may be easily restored with bone earth. The waste is so slow with ordinary care of the manure, that it is not usually felt for many years. By carefully saving all the liquid manure from the stables and the pens, the store which is already in the earth would hold out still longer. This a dairyman should always do. The liquid excretions of his animals are worth fully as much to the dairyman as the solid, because they 
contain just what dairy farming is all the time inclined to waste. To lose the liquid manure is to lose one-half the benefit to the farm from keeping a dairy. This fact is beginning to be pretty well appreciated. While dairymen are swelling the manure heap by every available means, they are at the same time adopting conveniences to save and utilize the valuable liquids which in former days were allowed to waste. And this increased economy in manures makes the contrast between a farm and a farmer growing rich and one that is growing poor, so great as to attract the attention of observant men, who become persuaded, and keep more stock and plough less.

An approximate certainty of uniform products and prices, a diminution of the severe labor of grain grown ing, a cessation of its exhaustion of the soil, and the retention upon the farm of nearly all its fertilizing material to aid in restoring an impoverished soil to a rich and productive one, are considerations which must in the future, as they do now, have great weight in leading intelligent farmers to exchange the plow for the milk pail. They are sufficient to warrant the inference that dairy farming is destined to follow in the wake of the grain grower, and, sweeping over the wide expanse of his westward march, to restore the lost fertility and bring back to productiveness the vast extent of land which his destructive habits have made poor. They will make dairy farming preferable to grain growing when the profits on dairy products shall fall to those of grain growing, and even below.

\section{- LIMIT TO DAIRYING.}

The first limitation to dairying is climate. If it is either too hot or to cold to keep cows comfortable 
and healthy, their milk will be faulty and its products poor. The climate in the northern part of the United States and southern part of Canada, is generally favorable. By protection against the heat of summer and the severity of winter, dairying may be successfully carried on some distance, either south or north of its natural' limit.

The second limitation is the supply of water. If an abundance of good, pure, fresh water, convenient of access, cannot be had, thoughts of dairying had better not be entertained. Pure water is a "sine qua non" in dairying. It must be running water, or at least fresh. Stagnant or even standing water should not be used: it is unsafe. Local limitations on this account often occur.

Groing southward, the want of a supply of running water through the summer season, will often be found to bar the extension of successful dairying before the limit by climate is reached. Were it not for the lack of running water three months in the year, the Blue Grass regions of Kentucky would be as accessible to the dairy as many of the counties in Pennsylvania and New York, where little else than butter and cheese are now produced. Immense tracts of lands both west and south are debarred from successful dairying, because, for one quarter of the year or more, they are without water, or without such as is suitable for the dairy. It will seldom be found a paying business to introduce dairying in any place where fresh running water is habitually wanting three or four months in the year.

The third limitation is the supply of food. The quality must be good, whatever it is. It is impossible to make good milk from poor material; and if such 
food cannot be supplied cheaply and abundantly it will restrict the operations of the dairy. The increasing value of land in the older settled portions of the continent, tends to increase the cost of cattle food, and to confine the limits of dairying on one side, while the increased occupation of new and cheap lands on the other, tends to the extension of the dairy in that direction. The immense extent of cheap land in the United States and Canada, will defy competition for an indefinite period, especially in the production of cheese.

Peculiarities of soil have been supposed to set the most rigid limits to dairying, especially to the cheese interest. But it is not easy to set definite bounds to the land from which good butter and cheese can only be made. Dairymen have been compelled to change their opinions in regard to the extent of dairying lands, and with more light they may have occasion for further modification. It is but a few years since the best informed dairymen believed that the limits of successful cheese-making were very narrow, and that the people of a fey favored localities anticipated they would enjoy for ever the privilege of supplying the world with cheese. It is but a few years ago that New York supplied Canada and the Western States with cheese, because it was then supposed that good cheese could not be made in either place. Now Canada is not only supplying herself, but is sending to England some fifty millions a year of better cheese than New York then sent to Canada, and the Western States are beginning to imitate the example of their Canadian neighbors. For the last three seasons Wisconsin cheese has been well received in the British markets, and during the past year, butter has been steadily 
sold by the Board of Trade in Elgin, Ill., by the thousand pounds, at higher figures than were made at the same time for equal quantities, in any of the Atlantic cities. The writer had the satisfaction of inspecting in the hot weather in June, 1875 , butter made at Marengo, Illinois, by Israel Bois \& Son, and at Elgin, by J. H. Wanzer, which it would not be easy to excel in any locality, and this with only the facilities common and available to almost the entire vast region of the Northwest.

In a letter to the Pennsylvania Dairymen's Association last winter, J. H. Reall of Philadelphia, an extensive dealer in dairy produce, declared the Marengo butter the best he had met with from any source.

Butter making it would seem can now be carried on successsfully anywhere that cows can be supplied with wholesome food and water, and where they can be maintained with a tolerable degree of health and comfort, and cheese appears to have no narrower limits. The condition and circumstances of the soil have, however, some influence upon the quality of milk and its products. In milk from low moist ground, for instance, the butyraceous and cheesy matter will be softer than in milk from land which is high or rolling. If the high land is sandy or gravelly, the contrast will be still greater. A difference has also been noticed in the products of milk from loamy soils, and those which are sandy or gravelly, both being alike rolling and the herbage the same.

It is evident that milk different in quality should be treated differently. And if the treatment and manufacture should in each case be varied to suit the variations in the milk, the probability is that the results in each case would prove alike atisfactory. 
My observations and experience incline to that belief.

The present state of the art of manufacturing cheese applies to milk from land of medium moisture, and does not succeed well with milk from soils very wet or very dry. In a more advanced stage, a wider range may be taken. But at present dairymen are advised to avoid extremes. Loamy soils with a rolling surface that will retain moisture without being wet; soils on which grass will remain fresh and green nearly the entire season, and on which a turf may be retained for a long series of years, produce butter and cheese of the best quality, and feed at the least cost, and are always to be preferred.

\section{DAIRY STOCK.}

Any breed of cattle worthy of being called a milking breed, ought to have the milking habit so well established in its blood, that over half of the cows belonging to it prove to be deep milkers. To fall short of this, would be to demonstrate that some other than the milking quality is the leading characteristic of the breed.

There are but three breeds of cattle in this country, which have attained to any considerable notoriety, that will stand this test. These are the Ayrshire, the Channel Island, and the Dutch or Holstein. But it is 
not my purpose to discuss at length the peculiarities of the different breeds, but to present only their more prominent characteristics so far as they will aid the dairyman in the selection of his herd. Besides, as this work is devoted to the practical operations of the dairy, the limited number of pages to which I am circumscribed, would not permit an extended consideration of breeds, were I disposed to go more into details.

\section{AYRSHIRES.}

This is a breed of cattle which has come to us from Scotland, and takes its name from the county of Ayr. There is some disagreement as to the ultimate origin of the breed; but this, to the practical man, is a matter of little consequence. The main thing which interests the dairyman is its possession of deep milking capacity, and the certainty with which this can be transmitted. These cattle have been long and successfully bred-by judicious selection and crossing, by liberal and appropriate food, and by care and constant milking-to meet this demand. Developing an aptitude for turning food into milk, naturally abates the aptitude for promoting an assimilation of flesh and fat and development of frame. The highest milking capacity is therefore rather unfavorable for size and strength of constitution, as in the milking season there is a tendency to convert everything into milk, instead of using it to build up and sustain bodily structure.

The Ayrshire cow is not large, but of fair size. It is a good cow that will weigh 1,000 pounds. Nor is she remarkable for symmetrical proportions. She has indeed a clean, well-formed head-rather broad between the horns and tapering toward the muzzle- 


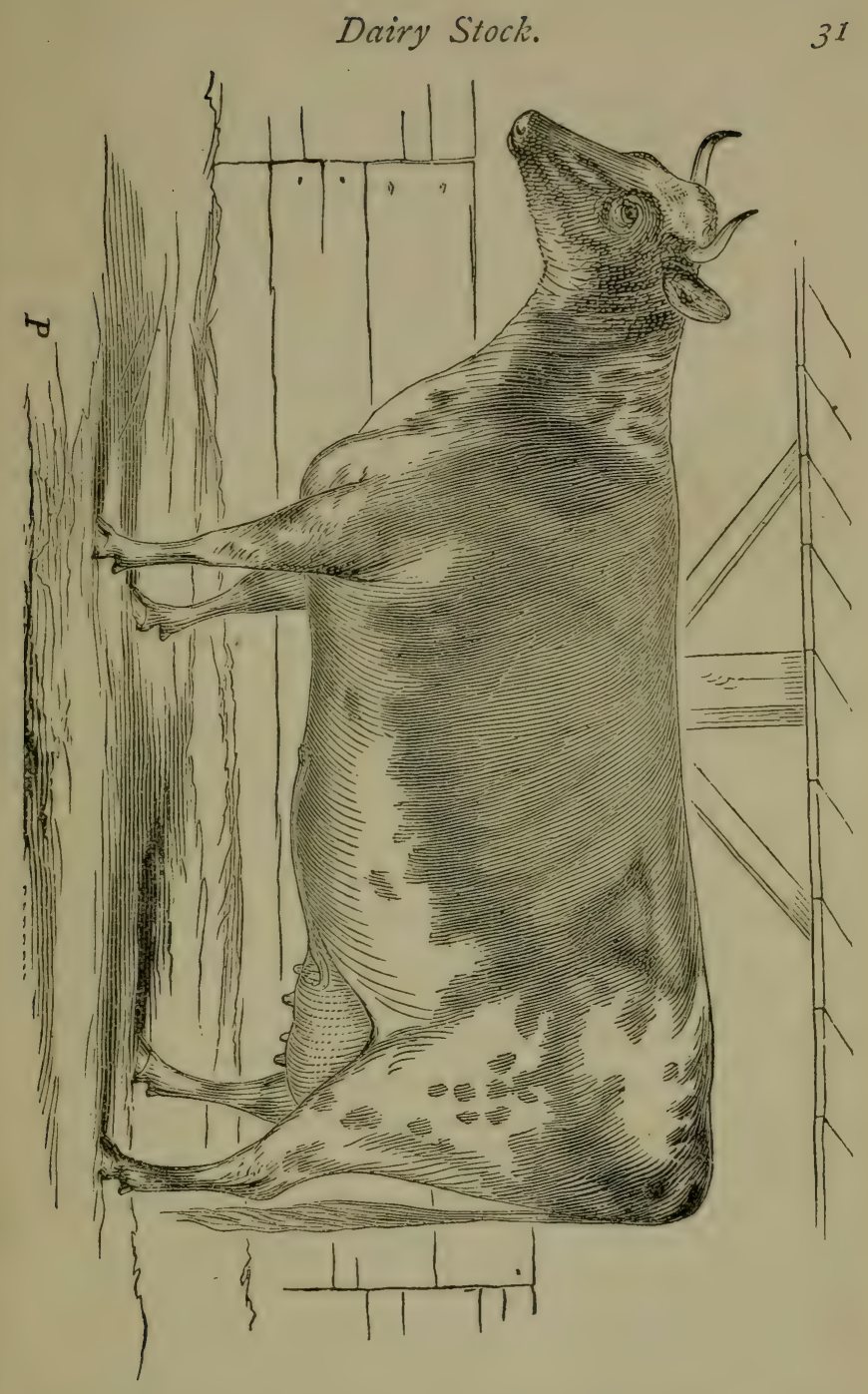

Ayrshire Cow, Imported "Georgie," No. I85 N. A. A. R., owned by Sturtevant Bros., Waushakum Farm, S. Farmingham, Mass. 
with a very intelligent and expressive eye. Her neck has a deep attachment to the shoulders, but is thin, long and symmetrical, and has a decidedly feminine appearance. Her fore-quarters are light, smooth and thin, and her hind-quarters deep and spreading-a form adapted to milk rather than "beef and beauty." One of the most striking characteristics of the Ayrshire cow is the size and shape of her udder and teats. Her udder is unlike that of any other cow; being flattened horizontally, but remarkably large and spreading sidewise; and while it extends far back, it has a very distinctive front development. Her small cylindrical teats are set far apart both ways, and are remarkable for their uniform size. She is supplied with an extraordinary number of small reservoirs, distributed through the udder, which enable it to distend and hold a very large mess, but it collapses to very narrow limits when empty-a peculiarity which generally attaches to deep milkers with a nervous and sensitive temperament. The milk mirrors are large and well formed. The one on the hinder part of the udder is broad and well up; the forward one spreads over the two front quarters of the udder, and extends well out upon the abdomen; the milk veins are also large. With a capacious digestive apparatus, a brilliant eye, and a lively expression in her red and white coat of hair-denoting health and vigorous digestion-she has all the insignia of a royal milker, so far as quantity is concerned. An average herd of Ayrshires, fairly fed and cared for, may be expected to give six times their weight of milk in a year, while individual cows will do very much more. It is doubtful whether there is any other breed of cows which will make as good an average yield in proportion to their weight. 
It is worthy of note that the Ayrshires were developed on a poor soil, yielding scanty pasturagewhich makes them all the more valuable as easy keepers-and that they have so long and carefully been bred for dairy purposes, that thay have failed to develop in almost every other direction.

The quality of Ayrshire milk well adapts it to cheese making. One strain of the breed is said to be well adapted to butter making; but I am not familiar with that strain. The milk which I have tested was well stocked with nitrogenous matter, and the fat globules were abundant, but of unequal size-making the cream rise unequally, and calling for skill in churning, to get all the butter. The yield is a pound of butter from 20 to 25 pounds of milk. A microscopic view of Ayrshire milk may be seen among the illustrations in the chapter on "Milk."

It is not to be expected that a single animal can be a full and perfect representative of all the points of a breed; but the portrait presented at the opening of this chapter gives a very fair idea of the average Ayrshire cow. She is ten years old, and weighs 1,080 pounds. Her annual yield has been from 6,000 to 8,000 pounds, her milk product tor 1874 -during which she was dry 22 days-being 8,27 I pounds.

The objections urged by some, against this breed are the moderate size, the shortness of the teats, a tendency to nervousness, and a suspected weakness of constitution. But they find numerous and ardent friends among dairymen who use them.

\section{CHANNEL ISLAND CATTLE.}

There is probably no breed of cattle which can boast of a longer devotion to milking habits than the 
American Dairying.

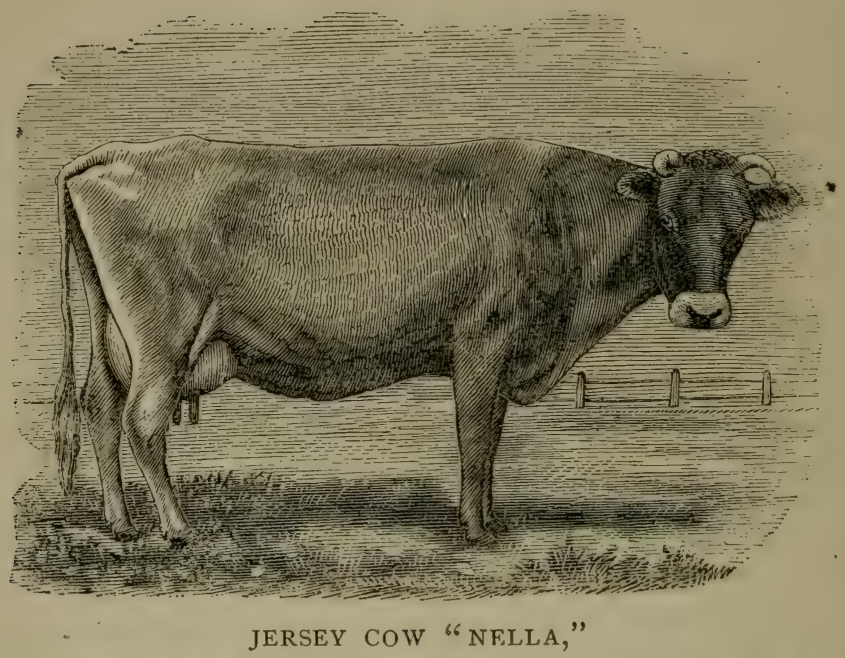

The property of W. L. \& W. Rutherford, Waddington, St. Lawrence Co., N. Y.

Channel Island cattle, the chief of which is the Jersey, known also in this country as the Alderney. Ever since their introduction upon the isles in the British channel, which is too long ago to be definitely traced, they have been unremittingly consccrated to the milk pail. These cattle, like the Ayrshires, show by their size and unpolished form how one leading characteristic, when it abstracts to itself an unequal share of pabulum, is developed at the expense of all others. Turning their food largely into rich milk, their bodies remain small and uncouth. Their size is diminutive, the average weight of a full grown cow being only about 800 or 900 pounds. The annexed cut shows a fair sample of the breed.

The quantity of milk they yield is not large, but fair. Good Jersey cows, if well fed and cared fur, 


\section{Dairy Stock.}

may be expected to give an average annual yield equal to five times the weight of their bodies. Their fort lies in the richness of their milk and the abundance and high color of their butter. The milk of different individuals varies in richness, as well as it does in all brceds, but it takes less of Jersey milk than of the milk of other breeds for a given quantity of butter-about I 3 of milk to one of butter. Eight to twelve quarts a day, in the best of the season, is a common yield.

The original of our illustration, eleven months after coming in, and after carying her calf four months, gave in August, on grass alone, 22 pounds of milk per day, which made 22 ounces of butter. In the flush of feed her mess was 37 pounds. This is probably a little above the average yield in quantity and richness of Jersey milk, but such results are quite common. Individuals run far beyond it. The milk of the cow "Pansy," a herd-book Jersey, the property of J. H. Sutliff, Ct., in one year made $574 \frac{5}{16}$ pounds of butter, a yield of which any of the larger breeds might well be proud.

The business of the Jersey cow is emphatically that of butter making - and she can be kept for nothing else so profitably. Her inilk, however, is rich in cheesy matter, and, contrary to the general belief, if I may judge from samples of cheese from Jersey milk which have recently been sent me from Maine, is capable of making as fine cheese as it does butter. Though it requires less milk to make a pound of cheese than it does of the milk of natives-about eight of milk for one of cheese-the quantity may be thought insufficient to yield a profitable income. It is a new feature, worthy of note in the uses of this breed of cattle, that their milk can, without waste of buttery 
matter, be converted successfully into a strictly fancy cheese, and as rich in fat as Stilton. Analyses of cheese from pure Jersey milk, recently made in Cornell University, have shown over 40 per cent. of fat.

Though the Jersey is not a handsome animal, it is not without something of beauty. Its ornamentation is in its head, which is always suggestive of the wild look of the deer and elk; and this with its finelywrought features and its intelligent placid and kindly eye, is the best and strongest mark of thorough breeding the animal bears. Iis constitution is fairly strong, and its digestion good, so that it is hardy and economises well the food it consumes. Its domesticity and quiet disposition, its gentleness and fondness of being petted, are much in favor of its usefulness as a milker. The large fat globules in their milk with an almost uniform size, so that the cream rises quickly and perfectly, and churns easily, also enhance their value. They are essential aids to profitable dairying. Against the many positive qualities of this breed of cows lie the objections of size and moderate measure of milk.

\section{DUTCH OR .HOLSTEIN.}

Fortunately the origin of a breed does not affect its characteristics, nor does its name detract from, or add to, its capacity to fill the milk pail. Though the name and origin of the cattle imported into this country from North Holland are disputed, there can be no dispute that they possess qualities which make them valuable to the dairymen. They possess large frames and vigorous constitutions, derived from the generous fecd of a generous soil for successive generations, and their flow of milk is liberal, amounting annually, according to different authorities, from $3 \frac{1}{2}$ to 4 times 


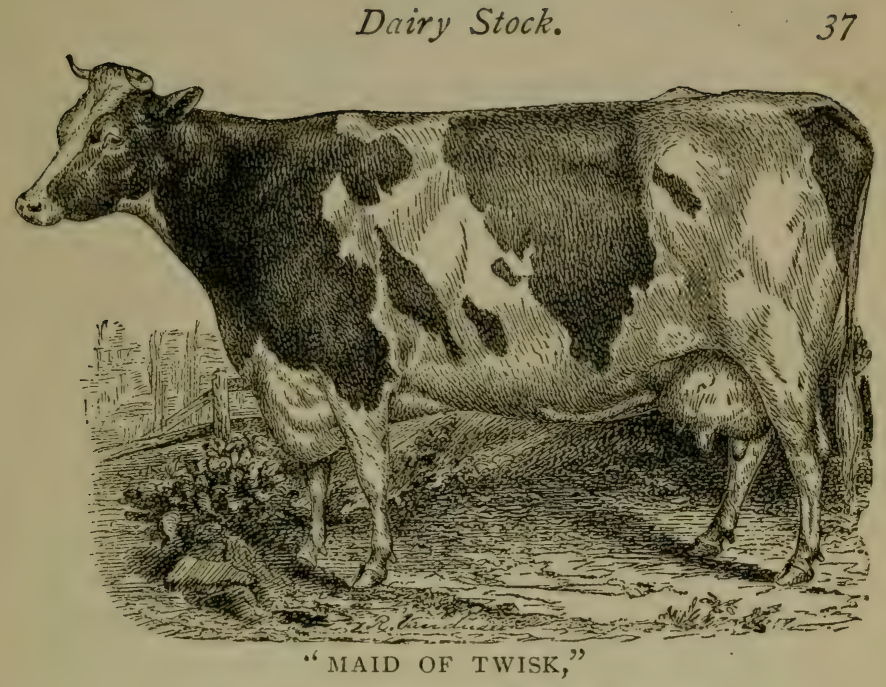

Property of Unadilla Dutch Stock Breeders' Association.

their own weight. Judging from the average of records I have met with, I should place the annual yield higher. The average cow of this breed will weigh near 1,500 pounds. The milk is rich in caseine and is fairly so in butter. The butter globules in their milk are very abundant and uniform in size, but small. It is therefore rather better adapted to cheese making and marketing than to butter making. Butter from the milk of Dutch cattle has, however, some special qualities. It stands up well against heat, and is said to be especially good for long keeping. The uniform smallness of the butter globules in their milk, though it makes the cream rise slowly, is a positive advantage in milk for marketing or cheese making. (See chapter on milk for microscopic views of Dutch or Holstein milk.)

In Holland the color of the breed under consideration, is a clear black and white; but in this country 
the black sometimes shades down to something like a reddish hue, while the white remains pure. These cattle are excellent for beef as well as milk, and the males are said to make good working oxen.

This breed of cattle has not, as yet, come into very extensive use; but the few that have been imported and bred have proved very satisfactory, especially for purposes of cheese making. For this, their milk seems specially adapted. I have had occasion to make several analyses of the milk of this breed, and in every instance have found it remarkably rich in cascine, fairly so in butter, but poor in sugar - an element not much needed in making either butter or cheese. The strength of their food seems to be well appropriated. They are liberal feeders, and give, in some instances, remarkable yields of milk. The illustration we give is a fair specimen of the appearance of the breed, both in form and color, but it does not indicate the size as compared with the illustrations of other breeds, it being drawn on a much smaller scale than that of the Ayrshire, on a preceding page. The subject of the illustration is more than the average milker. For seven months and thirteen days, beginning April 17 th, 1874 , she gave a total of 9,674 pounds-a daily average of $4 \mathrm{I} .52$ pounds. In 1875 , a period of seven months, beginning April roth and ending November roth, she gave 9,833 pounds--a daily average of 48.2 pounds-making an annual product of over six times the weight of her body.

In everything except color, the Holland cattle closely resemble the Shorthorns, and so much so as to suggest relationship. They appear as much alike as could be expected from the different ways in which they have been bred and fed. One has been fed on 
rich food to develop beef, and the breeding has also aimed in that direction. In the other, selections have been made with special reference to milk; and, as in the other dairy breeds, the animals have been chiefly supported by grazing-a circumstance that strongly favors their adaptation to our mode of dairying:

As an offset to the positive milking qualities of this breed of cattle, now aspiring to the favor of dairymen, no strong or specific objectiuns seẹm to be urged. There is, however, in the minds of some, a lurking query whether cattle coming from a climate mild and even as that of North Holland, and living upon the rich grass of that very fertile land, can successfully endure the poorer fare and the wide extremes of our more variable climate. But they have so far endured our climate well, and have given good satisfaction in all respects to those who have attempted to introduce them. Their milking quality seems to be less variable than that of most other breeds-being almost invariably large milkers.

\section{SHORT HORNS.}

I have preferred not to class the Shorthorns as a milking breed, simply because a majority of them are not good milkers, and not because there are not numerous good milkers in the breed. It is doubtful whether there has ever been any better milking stock than the original, Shorthorns, and they have still a most persistent tendency to transmit that quality to their descendants. If any proof of this were necessary, it can be found in the fact that while nine-tenths of the Shorthorns breeders, work with an eye single to "beef and beauty," and to breed out milk, strong 


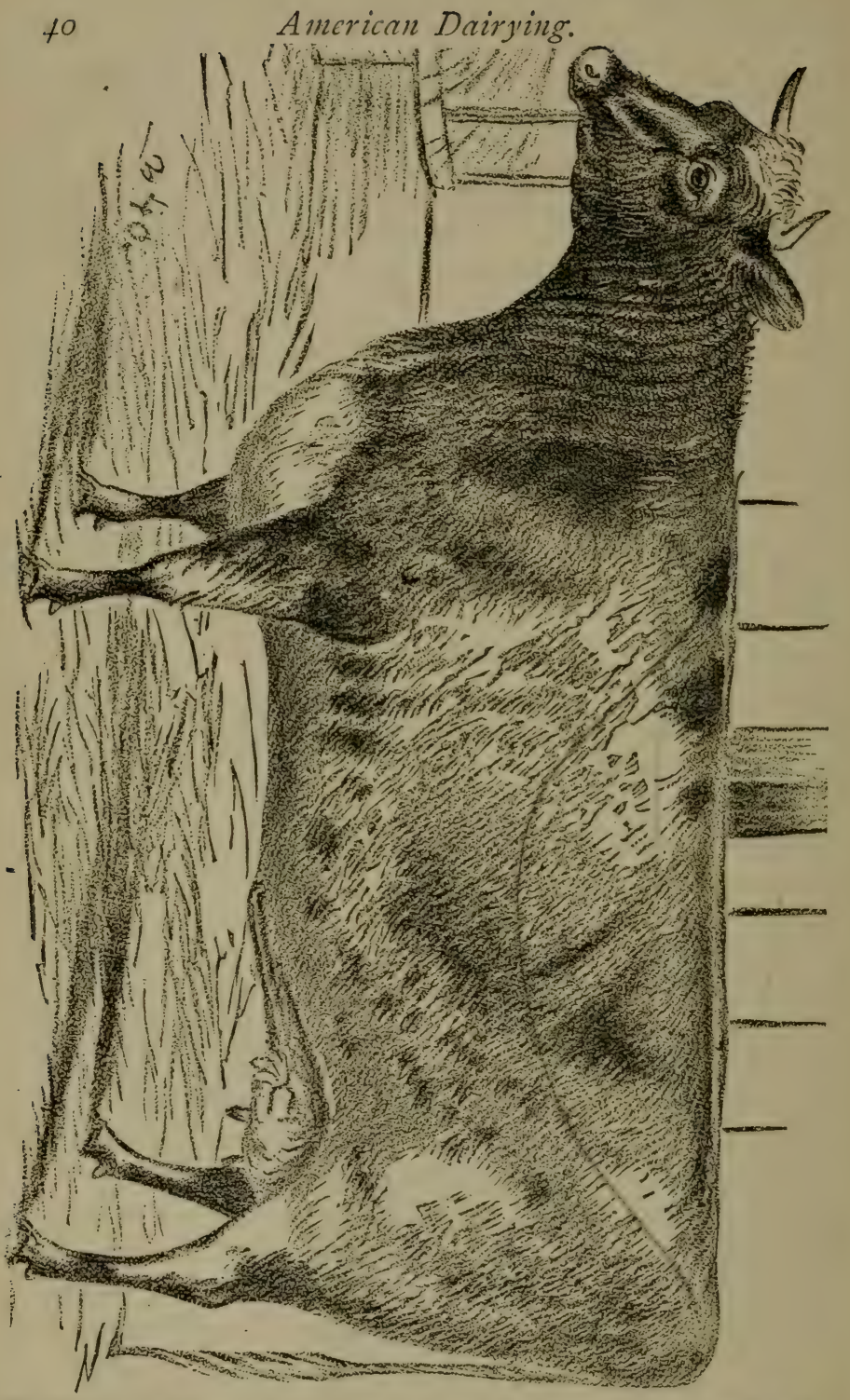

Short Horn Cow SoNsie ilth, the property of Gen. N. M. Curtis, Ogdensburg, N. Y. 
milking qualities are constantly cropping out in spite of all their efforts to repress it. Where a deep milking tendency has not been counteracted, or where it has been the least restrained, as in the Princess family, it has remained in nearly its original strength, and is transmitted with a most remarkable certainty. In some strains of Shorthorns blood, modern breeding has proved so skillful as to so completely wipe out the milking tendency, that cows in vigorous health and flesh sometimes fail to give milk enough to support a calf, and now and then one gives no milk at all. Beef is the all essential thing in the modern short horn. While we all admire the elegant forms, the well rounded proportions and the delicious flesh of the ponderous beasts, nevertheless, from a dairyman's stand point, it seems unfortunate that qualities so invaluable to his calling, should be turned out of their natural course and devoted to other purposes. When a milking strain is met with, the cows take rank with the best milkers.

The butter globules in the Shorthorns milk are generally not very high colored, 'but of good size, causing the cream to rise readily. The per cent. of cream, too, is liberal, and the quality of both good. The milk is about equally well adapted to butter, cheese, and marketing. Average weight $\mathrm{I}, 500$ pounds.

The main objection urged against the breed is, a tendency to convert food into fat and flesh, rather than into milk. The illustration on page 40 is one of the Princess blood, and is a fair average of the milking strains of this breed. She is six years old and dropped her last calf August 14 th, $1 S_{75}$, and gave an average daily mess till October 4 th, of a little over 40 pounds. In one week, beginning Oct. 4th, her daily average 
was $3 \delta_{2-7}$ pounds with I6 per cent. cream, as shown by the cream gauge. Her feed, like that of the preceding cows, was grass only. For those who desire to consider the element of beef in connection with milk, the short horns give the best satisfaction.

\section{OTHER BREEDS.}

There are several other breeds which have prominent milking qualities, quite as good, perhaps, as those already mentioned, but they are in such small supply in this country, as not to be relied on for general dairy purposes, such as the Swiss, Holderness, Kerry, \&c. And there are other breeds, in larger supply, which have many good milkers among them, as the Devons and the Herefords. Splendid milkers occur among these breeds, and the Devons, in particular, give milk of a choice quality, but for the general purposes of the dairy, they are defective in quantity.

At the present time, the best of the thorough breds cannot be much relied on for the general use of the dairy. In the first place, even those which are in the greatest supply, are held at prices too high for the dairyman to purchase simply for milking.

He may buy a few good animals and then raise others from these; but generally, this process is too slow for him. He wants cows at once, and they must be had at once from the best sources available. In such emergencies, he must fall back on the natives, so called. In these the chances are against him. The natives are a mixture of all breeds, with all sorts of milking tendencies, but the inferior are in excess. They have this advantage, however, over all other supplies: they form the great staple of neat stock; 
and if the dairyman can distinguish a good cow, when he- sees one, he can generally make selections at prices which he can afford.

\section{GRADES OF THE MILKING BREEDS.}

While the so called milking breeds constitute an item of great interest to dairymen generally, it must be borne in mind that thorough bred cows form a very insignificant part of the dairy cows of the countryprobably not much more than one per cent., and it must be a very long time hence, if ever, before any of the breeds named as prominent for milk producing, will constitute any considerable part of the aggregate of dairy stock in the United States.

Though we have little to hope for, especially in the immediate future, from thorough bred milkers, for direct and general use in dairies, we have much to hope from them by way of their grades. They have done much already in this direction, and from the readiness with which grades can be multiplicd, they can expand their usefulness almost indefinitely. From their more recent introduction into the country, the grades of the Dutch or Holstein cattle have not yet figured largely; but the Ayrshires, the Jersey and the Shorthorns grades are quite largely used for recruiting dairies, in preference to any other stock. They make the best of dairy cows, equaling and often surpassing 
their ancestors on either side. The splendid milkers

- developed among them and the general good quality they possess, the extent to which they are now used, and the facility and little cost with which they can be increased, make the grades of milking breeds of more immediate importance to the milk producer than the breeds themselves.

The estimation here awarded to this kind of dairy stock, and especially the intimation that we may fairly expect samples which will outdo their parents, may, to those who have not been familiar with them by use or observation, and who in a certain sense, expect "like to produce like," seem to border on the extraragant. But the good qualities are there, and the extraordinary samples do occur, and for the sake of illustrating the peculiar nature of grades, and for impressing more fully the advantages of recruiting dairies with them, I will make a brief statement of my view of the law of descent which makes the results known to occur, appear reasonable and legitimate.

It is not intended here to elaborate the laws of hereditary descent to any considerable extent, though it would be very interesting and appropriate to show how to improve milking stock, and how to build up new and superior breeds, but space will not allow. Grades have a law unto themselves, and nothing more than my view of that law can be attempted.

It is said that "like produces like," but dairymen find no certain reliance on the milking capacity of heifers raised from extraordinary milkers they happen to get into their herds. There is a a higher probability of good milkers from such cows than from poor ones, but they do not always follow even when the sire is from a good cow. The reason for this uncertainty, 
very likely, is because the milking capacity of the dam is only accidental, and not a fixed characteristic.

The oft quoted adage, "like produces like," has a significance beyond visible qualities. It takes in also, constitutional qualities. Two animals unlike in this respect, though alike in all others, will not stamp the same peculiarities upon their progeny. The first appearance of a characteristic does not fix it permanently in the constitution of the individual, or, in other words, in the blood, and not being fixed, it is easily lost when circumstances do not contribute to its continuance.

By continuing it through successive generations it becomes permanent, and the longer and more frequently it is transmitted the better it is established in the blood, and the more difficult is it to be bred out or dropped out by a loss of vigor or prepotency in the parents. Qualities recently acquired are easily dropped by a want of vigor in the breeding animals. When the health and vital force are full to overflowing, personal peculiarities are most perfectly transmitted, let them be what they may. The individual then transmits himself as he is. The perfection with which the progenitor transmits himself under such conditions is so complete, that even a scar on the parent has been known to reappear in the offspring. But let the vital force wane, and the characteristics which have been last acquired, and which are of course the least fixed, will fail to appear in the descendant. And as the vigor of the progenitor fails, the characteristics disappear one after another in the reverse order in which they have been assumed, and according to the extent of the depression of vital power, and the progeny "takes back," or in other 
words, inherits only those elements which have been the longest or most firmly fixed in the blood of the parent. Hence, when a combination of favorable circumstances develop an extraordinary milking animal from common stock, the extraordinary capacity for milking often fails to reappear in her descendants, because, while she is breeding, her vitality is apt to be too much reduced by her large flow of milk. Because of the debilitating influence of a large milk production, the transmission of extraordinary milking qualities is more difficult than many, or, indeed, most others. On this account there is a constant tendency to depreciation in milking stock, and the breeder of dairy stock should therefore study to guard against it.

The law of transmission here touched upon is of immense importance to the breeder of blooded stock, but it is not to impress it upon his mind that it is here introduced. It is rather to impress it upon the practical dairyman, whose business is the production of milk rather than raising stock, that he may make it available for filling up the steady waste of his herd, with profitable milking animals, and to make the application more explicit, another feature in hereditary descent may be alluded to.

In his address before the last convention of the American Dairymen's Association, Prof. L. Wetherell said:

"Breeding from a bull and cow of similar typethe progeny will be like, and of a higher degree: qualities are thus perpetuated and intensified in the offspring. Take a Shorthorn bull and represent his hereditary power by roo: put this bull to a cow of totally different hereditary power, say equal to 60 : the offspring would be reduced to roo minus $6 \circ$, equal 
to 40: suppose the offspring to be a bull, both sire and offspring may appear equally perfect in form and general character-the hereditary transmission being as much greater in the former sire, as the proportion of Io0 to 40 ; hence, the former would be, and is, much more valuable for breeding purposes than the latter. By breeding animals of similar type, the offspring will be likely to possess the same characteristics, with a greater power of hereditary transmission of this character or these characteristics. On the other hand, animals of opposite characters, mutually weaken each other's influence, and the offspring possesses the power of a hereditary transmission in a reduced degree."

This is a clear and compact statement of the law by which the tendency to strengthen hereditary transmission is increased by coupling animals of similar type, and the reduction of hereditary transmission by coupling animals of opposite characteristics.

The milking breeds noticed, though the best in the country, are not perfect, nor, on the whole, growing better. There is no breed so perfect that inferior animals do not, every now and then, crop out. The very high price which herd book animals can now be sold for, causes everything to be raised. No one will make veal of a calf for which he can obtain ten or twenty times as much as it is worth for that purpose. Hence good, bad and indifferent, are raised and sold, and somebody gets the poor animals to breed from. Besides this, breeders are all the time breeding away from milk, some for color, some for shape, some for growth, and others for fat and flesh, \&c. But notwithstanding the drawback from raising everything and from turning away from milk to other points, the fixedness of the milk producing tendency from its 
long succession of transmissions in the past may be turned to good advantage by the milk producer.

Peculiar characteristics as readily descend through male as female ancestors, hence milking tendencies descend as readily through bulls as cows, and they are made use of to transmit the best milking capacity of the breeds to which they respectively belong.

When by crossing with animals of opposite characters, prepotency is weakened, that weakness is felt first, and most effectually, in the characceristics which were the latest acquired by the ancestors of the individuals making the cross. If, for instance, a peculiar color was bied into a variety of cattle later than a peculiar form, in crossing with opposite characters, color would be most likely to disappear, or be affected sooner than form. So where a tendency to take on flesh and fat has been acquired on top of deep milking qualities, the beef making tendency gives place to the earlier and more firmly fixed habit of milking. The effect of this law of descent is ever cropping out in crossing thorough bred bulls on the native cows. The milking breeds in which deep milking has been fixed by transmission through a long series of generations, and which more recently have been bred toward other points, the later characteristics are lost in crossing, and the descendant takes back to the older established milking blood, and hence it is common to get better milkers from grades than was shown in the immediate ancestors on either side. This law is well illustrated in "Old Creamer," a grade Ayrshire, belonging to S. D. Hungerford of Adams, N. Y., which gare 302 pounds of milk in three days, and in the two Jersey grades of Joseph Percival, of Waterville, Maine, whose milk made 9i5 pounds of butter in a year, after 
enough of it was sold to make it 50 pounds more. But nowhere does this law find better confirmation than in the use of Shorthorn bulls with native stock The leading characteristics of the modern Snorthorn are later acquisitions than a tendency to milk. All history concurs in making the production of milk the characteristic of the original Shorthorn cow. The extraordinary tendency to flesh and fat, and the fine form of the Short horns of to-day, are the work of modern breeders and have taken the place of a tendency to milk.

In crossing with natives the modern Shorthorns, in which the capacity for milk has run low, the later acquisitions give way and drop. out and the progeny takes back, and the orignal form of the early short horn and their tendency to milk revives. It is on account of the inherent tendency to milk, that short horn bulls, even where that tendency has been well bred out, are so notorious for producing good milkers when crossed with the native cow. As crossing with opposite characteristics impairs prepotency, grade bulls are more liable to fail in transmitting their individual characteristics than thorough breds. When all circumstances are favorable they may transmit themselves, but as their prepotency is more easily affected by unfavorable conditions, the result of their breeding is not very reliable, and hence it is safer in raising grades for milkers to resort to thorough bred males for sires. When this is done, there is no way in which the milk producer can so readily, cheaply and safely supply himself with superior milkers, as by raising grades from his best cows out of bulls of the breed or breeds best adapted to his use.

At the present time, thorough breds and grades 
which are accounted as such, are supposed to constitute about ten per cent. of the cows which make up the dairies in the United States. The rest are from the common stock of the country.' Though the average of this stock is inferior to that of the stock just treated of, it contains some splendid specimens of good milkers. The average annual yield of milk from this 90 per cent. of natives, will fall below rather than above, three times their live weight.

Until thoughts of progress and improvement are impressed upon the minds of more dairymen than they are now, filling up the annual depreciation of herds will continue to be made from the common cattle, as they are now and have always been. This calls for skill in selecting, for which there is a wide range, and makes the study of the external indications of milking quality a necessity. 


\section{SELECTING DAIRY STOCK.}

There is no one thing on which the success of a dairyman depends more than on the selection of the cows which are to compose his herd. There is no profit in keeping poor ones. The steadily increasing price of land brings the cost of keeping so high that poor milkers often fail to pay for the provender they consume. The money made by dairying is all made from good cows, and skill in selecting is therefore a matter of great consequence.

To illustrate the difference in profit between a good cow and a poor one, let us suppose a case. Take a cow of any given weight, say r,000 pounds, and suppose it costs in hay, grain and pasture $\$ 30$ a year to support her body, and five dollar's worth of extra feed to produce milk for making 300 pounds of cheese, the net value of which is ten cents a pound.

Take another cow of the same weight and it will cost the same to support her a year. But suppose she can convert \$10 worth of extra feed into milk that will make 600 pounds of cheese.

Though the first cow has manufactured each dollar's worth of extra food into six dollars worth of cheese, the profits on the.small quantity she has manufactured will not pay for the keeping. "While the second cow, by converting a larger quantity of food into cheese, has paid her keeping and lett a handsome margin. 
A comparison of results will stand thus:

Cow No. I. -Dr. to support one year................. \$\$30

"6 to extra feed for producing milk........ 5

\$35

Cr. by 300 pounds of cheese at $\$ 10 . . . . . . \quad 30$

Loss........................... 5

Cow No. 2.-Dr. to support one year.............. \$30

" to extra feed for milk.............. Io

$\$ 40$

Cr. by 600 pounds of cheese at $\$ 10 . . . \ldots .60$

Profit......................... $\overline{\$ 20}$

These supposed figures are close approximations to actual facts which exist in thousands of dairies. In fact there are few large herds that do not contain cows differing about as much. A dairyman in Herkimer having a dairy of forty cows, which as a herd was accounted a good one, selected five of his best cows and five of his poorest, and measured their milk through the season. The five best averaged 554 gallons each, and the five poorest 243 each. The milk of the whole herd averaged I I $1 / 2$ cents per gallon, making the income of each of the better cows $\$ 63.7 \mathrm{~J}$, and of the poorer ones $\$ 27.95$ - a sum less than the cost of keeping, which he estimated at $\$ 30.5 \circ$. This case was not deemed an exceptional one. Its parallel could have been found in almost any dairy of equal size. To avoid similar defects, a wise selection of stock is evidently essential to prosperity, and every one should study how to do it. It is believed that the best and surest way to secure good cows is to raise them from good milking stock. But a large proportion of dairymen, for one reason or another, prefer to fill up vacancies, which are ever occurring, by purchasing. 
It requires frequent additions to a dairy to keep its numbers good. The milking period of dairy cows averages only ten years, from which it follows that ten per cent. must be renewed annually, and when allowance is also made for losses by accident and disease, and the rejection of such,animals as prove inferior, it will require eleven per cent. or more to sustain the yearly diminution. In the aggregate this makes a large traffic, and it demands a ready appreciation of the merits of the animals with which it is proposed to supply the deficiency.

How much such a knowledge may avail, an instance within our personal knowledge will show. A. L. Fish, of Winfield, N. Y., by a skillful selection of superior milkers, averaged for a series of years over 800 pounds of cheese to a cow in a seasnn. His cows averaged, when feed was the best, 32 quarts of milk each per day, and in one season he made over 900 pounds to the cow.

The merits of different breeds have been sufficiently discussed, and it will suffice here to say that there is no single breed which will answer all the requirements of every dairyman, nor one in which the milking qualities are so well established that one can, by resorting to it, rely on getting a desirable animal without being a judge of milking qualities.

The Ayrshires are more uniformly large milkers, probably, than any other breed, but defective specimens occur among them, making selections necessary to ensure excellence.

The Alderneys excel as generally in richness and color as the Ayrshires do in quantity, but they are not infallible.

It would be difficult to find a larger flow than is 
sometimes obtained from the Shorthorns, but as a breed they are unequal. The rich milk of the Devons is also uneven. The Dutch cow, or Holstein, more recently introduced, promises well both for quantity and quality, but like all the rest, needs to be carefully selectech to secure a first-class milker. No larger yield or richer milk is found anywhere than has been obtained from the native cows, but they, like the short horns, are uneven. The famous Oaks cow, one of the most extraordinary cows of her time, having made $467 \mathrm{I} / 4$ pounds of butter in a year, was a native. The cow Kaatskill, that made about as much, and the Vermont cow, that made 504 pounds of butter in a year, were natives. We have had in our own dairy natives that have made a pound of butter from $123 / 4$ pounds of milk, and on the other hand, some that have required 44 pounds of milk to one of butter. The extremes in quantity are as great, sometimes running down to an amount more befitting a sheep than a cow. We have, as a rule, found grades to be better milkers than either side of the ancestors from which they have descended.

Crosses between thorough breds are also frequently improvements upon the original stock. The extraordinary dairy of Mr. Fish, mentioned before, was made up of grades and crosses, most of them crosses between Ayrshires and a milking strain of Shorthorns.

The large annual demand for dairy cattle must be supplied from any and all sources that are available. The selections, however, must come mostly from the native stock. Culling from different sources, and from animals of such unequal merit, calls for the readiest skill in judging of the external signs of milking qualities, 
There are certain external indications of the capacity for producing milk which are as apparent from an inspection of the cow as are the signs of strength and speed in the horse. In old dairy districts, where the owners are in the habit of filling up their herds annually by purchase, they soon become so expert as seldom to be deceived.

To write out all the marks that are relied upon as showing merit and demerit, would be difficult. They are best learned by practice and close observation. But some of the leading points may be stated that will be of some service in determining some of the wider differences.

A great deal has been said and written in regard to the appearance of good milkers, and a multitude of irrelevant and nonsensical signs have been laid before the public, which have tended rather to confuse and mislead than to guide and enlighten the inexperienced. A sign which has no connection with the thing it claims to signify is always worse than useless, as it is just as likely to lead wrong as right, and detracts from more intelligent indications. What important connection is there between a large flow of milk and a "Roman nose," or " a hollow head;" a long head or a short one; a crumpled horn or a straight one, or one that tapers evenly or unevenly; or a straight leg, or a slim tail; or a peculiarly shaped ear or dewlap; or whether the eye-lids are well divided, or much or little wrinkled? Yet these and a score of other signs equally irrelevant are ever and anon circulating through the press to guide, or rather mislead, the inexperienced purchaser.

The reader will see for himself how the following points are connected with milk production, and by 
attentive observation will soon learn to make them of practical utility.

Milk is a female product, and its production may reasonably be expected to be more or less affected, if the organization varies much from the characteristics peculiar to the sex. First of all, see that the animal has a feminine appearance-a cowy look. The next thing to be looked after, is the digestive apparatus, particularly the stomach and bowels. A large and strong boiler is not more essential to the power of an engine, than a large and vigorous stomach is to the production of milk. A cow cannot make milk out of nothing. If she gives a large flow, she must eat and digest a large amount of food to make it from, and she must have a stomach equal to the task; one that has capacity to hold and power to digest enough to manufacture the milk out of.

When the digestive organs are relatively larger than the other viscera, they give depth and breadth to the abdomen, and a somewhat wedge-shaped form-the body tapering forward. An inclination to this structure may be seen in the illustration of the Ayrshire cow in the chapter on breeds.

The large stomach and bowels here indicated mark a diathesis in which the fluids abound-a condition, as will readily be understood, very essential to a large flow of milk; and the broad hips, and the depth and breadth of the lumbar region, indicate a large development and flow of blood, and vital influence to all the parts surrounding and connected with the milk-producing vessels. Gaunt cows are small milkers.

A good constitution is important. This may be judged of by the lustre of the hair and the brilliancy of the eyes and horns. Constitution depends mostly 
upon the heart and lungs, the size of which may be determined by the depth and breadth of the thorax. They should have a good development, enough to secure health and vigor, but the lungs, in particular, should not be excessively large. When very large, they burn up, by increased respiration, the fat-forming material. By the extraordinary energy they create, they induce unusual exercise and motion, which make a rapid waste of tissue and a rapid assimilation to repair it, and thus divert nutriment from producing milk. If too small, the animal may be an excellent milker while she lives, but will be feeble and shortlived.

The capacity of the lungs corresponds with the size of the apertures through which they are filled. Large open nostrils indicate large lungs, and vice versa. In the same way, the indications of the mouth correspond with the size of the stomach. (See the large mouth and large strong hips of the illustration of Jersey cow.)

The chine is regarded as an index to milking capacity. When it is double, it denotes breadth of vertebræ which correspond to the broad open structure which is favorable to a large flow.

It is an accompaniment of broad hips, and these in turn denote a large cavity which is essential to good milkers.

The milk mirror, or escutcheon of Guenon, is one of the leading indications of milking capacity. It consists of the peculiar appearance of the hair on the udder.

Looking at the hind part of the cow, as shown in the accompanying illustration, more or less of the hair which covers the udder and adjacent parts, will be seen, to turn upward or outward. This reversed hair forms the so-called escutcheon. If the space 
occupied by the upturned hair, especially the lower part of it, is very large and broad, so that it extends far outward on to the thighs, it is regarded as indicating a large flow of milk. (See illustration on page 59.). If the upper part of it is broad and smooth, it is regarded as favorable to a prolonged flow. If the reversed hair is narrow in its lower part, the flow is supposed to be small; if it is narrow and irregular in its upper part, it is unfavorable to a prolonged flow. The manner in which the inverted hair connects with the hair adjacent, is supposed to have significance. A gradual blending rather than abrupt connection is preferred.

The connection of the escutcheon (or scutcheon) with the flow of milk is accounted for by Magne, who says, that the hair turns in the direction in which the arteries ramify, and that the reversed hair on the udder and adjacent parts indicates the termination of the arteries, which supply the udder with blood. When these arteries are large, they are not confined to the udder, but extend down through it and upward and outward, ramifying on the skin beyond the udder, giving the hair the peculiar appearance which distinguishes it from the rest of the surface. If the arteries supplying the udder with blood are very small, they are not likely to extend much beyond the udder and hence form a small escutcheon. Hence, a small escutcheon indicates a feeble supply of blood to the udder, and consequently but litttle material to make milk of, and hence a small flow of milk.

Guenon studied and explained these marks only as they appear on the hind part of the bag, and the marks noticed by him were supposed to apply to the whole udder. This could not well be true. Each quarter of 


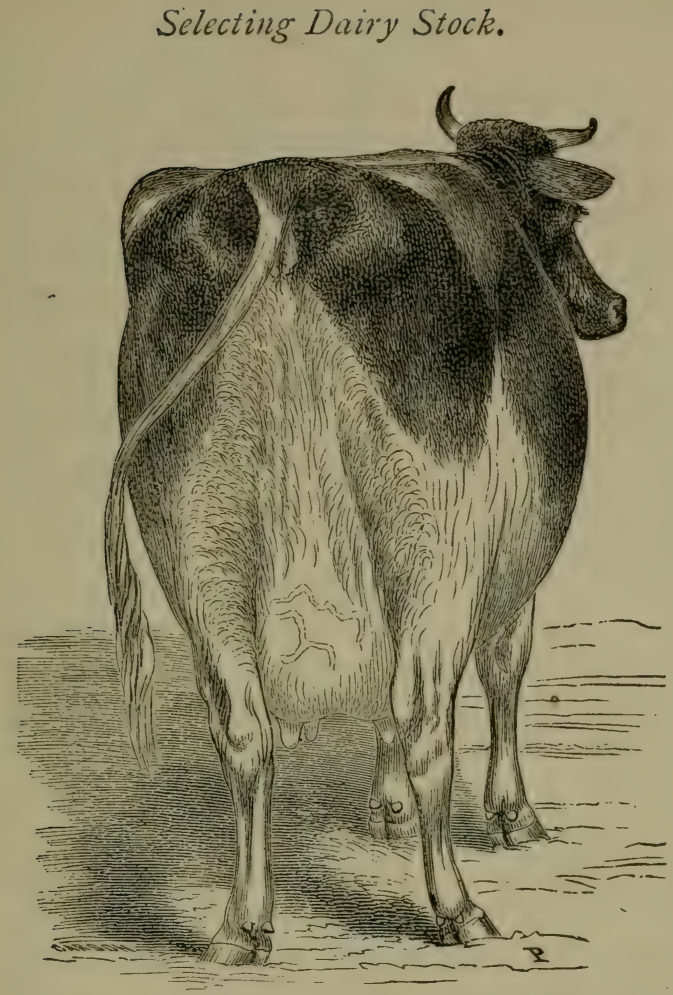

the udder is supplied with blood by a distinct and separate arterial branch, and they may, and often do, vary cunsiderably in size in the respective quarters of the bag. Those supplying the two hind quarters of the bag are usually larger than those which supply the front part, but sometimes the reverse is true, in which case the marks on the back part of the bag would not be a correct indication of the front part, and so with other inequalities. Each quarter of the bag has an escutcheon for itself, made by the ramifications of the arterial branch supplying it with blood, 
and which serves as an index only to that division of the udder. These mirrors blend in the middle and appear as one, but the outside of the reversed hair varies for each quarter according to the size of the arterial branch by which it is supported. Cornelius Baldwin, of Nelson, Ohio, who has studied milk marks very closely, gives as much significance to the mirror on the front part of the bag as that on the hind part. If there is more escutcheon on one side or one quarter of the bag, it indicates a flow from that side or quarter corresponding to the excess of the development.

The size of the escutcheon is regarded as the measure of the quantity of blood supplied to the milk-producing vessels, and are evidence of their capability of elaborating milk. In the same way, the reins take up the blood and carry it back in the milk veins, which pass through the bag and along the belly, and enter the body through one or more holes on their way to the heart. "The size of these milk veins and the holes where they enter the body vary with the escutcheon, and like it give cridence of the quantity of venous blood passing away from and through the udder, and they have the same significance with reference to quantity, as the supply of arterial blood and the size of the escutcheon.

But none of these indications, taken singly, is an infallible evidence of large yield. They must be considered together. A large escutcheon and milk veins, coupled with a small stomach, would be marked down at least one-half of what they might otherwise signify; and a large digestive apparatus, coupled with small milk veins and escutcheon, should be marked down in the same way. Keeping the leading indications 
in view, observation will soon enable one to make close estimates.

Soft, fine hair, is by many regarded as an evidence of richness, and oftener than otherwise it proves true; but some cows that give the very richest milk have hair that is not so very fine and soft. The appearance of the skin is another guide. A clear white, or pale skin, is an evidence, either that yellow fat is not formed, or if formed, the peculiarities of the animal are such that it is used up in supporting respiration. When it is so abundant as to lodge in the pores of the skin and give it a yellow color, it may be expected to appear also in the milk and give it the same color. High color and richness seldom fail to go together, hence a yellow skin becomes an evidence of rich milk; but it sometimes happens that the skin is of such a hue that the yellow fat does not affect its color-in such a case, appearance of the skin has no significance. One of the best indications to the richness of milk is the appearance of the inside of the ear.' If that is yellow and sheds a yellow dandruff, rich yellow milk is very sure to accompany. The same is true in regard to the twist.

The fat of animals is stored in a net work of cells, called cellular tissue, and an abundance of these cells is coupled with a tendency to form fat wherewith to fill them. When a cow is in milk, the fat formed is carried away in the milk, making it rich. Hence, where this tissue abounds, rich milk may be expected. When dry, the cow having it fattens rapidly. The supply of cellular tissue may be known by feeling the skin. When it is plentiful it forms a sort of cushion under the skin, giving it a soft and mellow feeling. When it is wanting, the skin feels hard, and the hand, 
when resting on the animal, feels very much as if resting on the bare bones. A soft velvety feeling of the skin on the rump and ribs, is a strong indication of adipose tissue in abundance, which promotes ready fatting and rich milk.

For reasons explained under the description of the udder, a bottle-shaped bag is farorable to richness of milk.

What breed of cows is best depends on where and what they are wanted for. If a single cow or a few cows are wanted to furnish milk and butter for family use, there is nothing better than the Alderney. Their milk and butter are exceedingly delicious. If one lives near a city or large village, and wishes to sell butter fresh from the churn, nothing would find a more ready market or stand up better under the heat of summer than Jersey butter. But if the object were to sell milk by the quart, a poorer choice could hardly be made than to select the Alderney cow, unless a price could be obtained proportionate to the quality of the milk. If the purpose were to make cheese, or butter and cheese from the same milk, then nothing is equal to the Ayrshire, especially on hilly farms. If to milk awhile and then convert into beef should be what the purchaser wants, the Shorthorn or Holstein would be preferable. The Devons and the natives may also be preferred for special purposes. There is no single breed of cows which will best suit every locality and requirement. The cow which will come the nearest to filling all demands is, in my opinion, the Ayrshire, but she is not best everywhere. The Holstein or Dutch cattle, not so long nor so extensively tested, are finding great favor where beef in addition to milk for cheese is desired. Not all the 
importations of thorough bred stock, I have reason to believe, have been made up of the best animals. The great difference in the qualities of the animals would make it hazardous to order cows without some personal knowledge of the cows or their breeder.

Generally, large breeds are preferred where there is an abundance of food easy of access, as in the valleys of rivers, the plains of the west, or the rich rolling pastures of the Kentucky. blue grass region. They are also well adapted to the less severe hills of the Eastern and Middle States. The smaller breeds have the preference in all hilly regions, and in all situations where much locomotion is required to procure food. While adapting the kind of stock to his location, the dairyman should not omit to procure animals whose former habits and fare have been as nearly as possible like those they are to receive at his hands. The less change in the habits of milch cows the better. In changing places, where there is a wide change in their treatment and mode of living, it takes a long time for adult cows to become used to their new situation. For this reason, cows which are bought in to fill up dairies, often fail for a whole season to give their accustomed mess, and sometimes for the second and even the third. On this account there is a decided advantage in raising stock on the farm with which to replace the failing and worn out members of the flock. The cows which are raised on the farm are worth onequarter more than those of the same natural capacity which have. to endure a long journey and a change of food and habits, to be placed in the dairy.

Having described what a cow should be, I close this subject with offering a sample of a faulty cow, with which I have been favored by Mr. C. Baldwin, of 
Ohio. It shows better than words can describe, just what a cow should not be. This cow in the flush of . feed and in her fullest flow, gave 18 pounds per day of very poor milk.

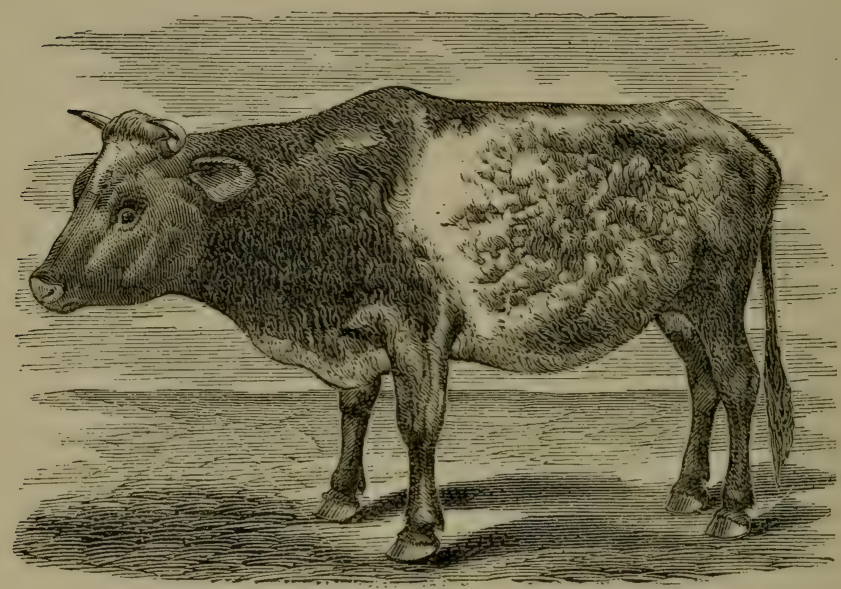




\section{F00D FOR DAIRY STOCK}

The question of food for dairy cattle is a wide one. It involves not only the discussion of the qualities and effects of the various kinds of food in use, but also their relative values and cost. It requires a knowledge of the different qualities in food suitable for dairy and other stock respectively, and of the special requirements of the cows when simply feeding, when being fattened, and when giving milk or breeding, or both at the same time; also, whether the cow is exposed to heat or cold, and what is the condition in which the feed is to be given. In short, it calls up the whole question of cattle food in all its bearings, and reaches out with such wide ramifications, that nothing short of a plethoric octavo could do anything like justice to the subject. For an elementary work like this, nothing more than brief outlines can be attempted.

The cost and economical use of food for the dairy determines more than any other outlay the measure of success. The cost of stock, labor, apparatus and buildings, is not very different in the several localities in which dairy husbandry is, or can be carried on; and the condensedness in bulk and value of butter and cheese and the ease of handling the packages, make the cost of transportation so light as to put dairymen all over the continent nearly on a 
level with each other, so far as freight charges are concerned. But in the cost of food there is great variance. The widest difference in this respect is found in the price of dairy farms. If one farm costs \$150 per acre, as in central New York, and another costs $\$ 50$ an acre, and it takes three acres to keep a cow a year, reckoning interest at six per cent., the annual interest on the land to keep a single cow, will, in one case be $\$ 27$, and in the other $\$ 9$. This makes $\$ 18$ difference in the cost of supplying a year's food, and the profit ought to be large to carry it.

This annual difference in the cost of keeping, if all other circumstances were equal, would more than pay the cost of transporting the products of a season across the continent and back again. It would give the producer in any part of the West or Canada the advantage in the markets of the Atlantic seaboard.

The cost of procuring food for his herd is the heaviest expense the dairyman has to encounter, and its production and economical use need to be closely studied and managed with skill, or the balance is liable to get on the wrong side of his account, especially upon the high priced lands of the older states. The difference in the price of land East and West, is a powerful reason in favor of an extension of dairying westward.

Not only its cost, but its quality must be closely studied, "because every variation affects the quality of the milk. Cattle food has been the subject of a great deal of discussion, and much light has been thrown upon it, but there are very many important points yet unsettled, which science and practical observation are striving unitedly to solve. When they agree upon any point it may be considered settlẹd. It is curious 
to note their points of agreement and divergence, and the progress they respectively make. Science would move or rest on rigid logic. Practical men, struggling with hard labor and limited means, are keenly alive to every opening for loss or gain, and are controlled by these results, and though they sometimes form opinions wide of the mark and prejudicial to their own welfare, it is interesting to see how very often their experience and intelligent observation lead them to uniform and sound conclusions, even in advance of science. Ask a hundred dairymen what is the best food for cows in milk, and with one accord they will all answer "grass," which means young grass as it is grazed from the turf. With this answer science accords, and we consider it settled.

Nothing excites such a liberal secretion of delicious milk as grass. Nothing better contributes to the health and general welfare of the herd than to roam free in the open air upon clean pastures, eating and drinking, moving and resting when they will. More food and more milk, may perhaps be obtained from a given area of ground, by some other way than by grazing, but nothing can surpass grass in the excellence of its products, and on lands of moderate price, the almost universal practice of dairymen argues that it is, all things considered, the cheapest as well as the best. In considering food for the dairy, we shall assume that for all ordinary cases, grass ought to be used as long as it can be obtained, and when no longer available, then such food as comes nearest to it.

We will begin with grass in the spring and follow through the year to grass again. Divergent practices appean at the outset. It is the practice of some to keep their cows yarded and not allowed to taste grass 
till it is grown high enough for them to fill themselves readily, and to subsist on it entirely. Others allow them the range of the pasture, or a part of it, and let them change gradually from hay to grass as the latter comes slowly forward. There are advantages and disadvantages in both these practices. It may be urged on one side that feed will hold out better to keep the herd from it till there is a "full bite," and that by tasting grass cows lose their appetite for hay and will not eat enough to keep up their flesh and strength, all of which is true. On the other side, it may be said that it is better for cows, or any other stock, to change gradually from dry feed to green, and that the season for dry food, always too long, is stretched to its utmost by shutting cows from the early grass, which is also true. A, sudden and radical change of food for either man or beast is always attended with ill consequences. The condition of the stomach and bowels, and the quality of the gastric juices, adapt themselves to the nature of the food used. To break up an established order of things, deranges all the operations of the system and impairs its functions. In turning cows suddenly and wholly upon grass, they are usually made sick for several days, and their milk is so much affected as to work badly in the cheese-vat for a week or more. Diarrhœa sets in, they become weak, and the loss of flesh by scouring is often greater than that occasioned by a loss of appetite for hay. It is the general prackice with the best dairymen to give their cows early the range of at least, a part of, their pasture. We have always found it better, taking the season through, to make the change from hay to ograss a gradual one, and to prevent any tendency to falling away by extra feed. There is also the advantage, in 
turning out early, of having the first tufts of grass eaten off and utilizing the space they occupy, instead of leaving them unused to cumber the ground during the whole season.

But, if from scanty pasturing or any other cause, a dairyman determines to shut his cows entirely from grass till feed is abundant, he may abate the ill effects of a too long season of foddering, and prepare his cows for a diet of grass, by feeding some kind of green food-as beets, carrots, mangolds, turnips or potatoes. By baiting the herd an hour or so at a time each day, for a few days, and by closing up the foddering season with early cut hay and some green food, the cows may be so well prepared for grass that they will not be much affected by the change, though they may not be turned out till quite late; but a small quantity of good hay will be relished by cows a long time after they have been turned to grass, and it should be fed as long as they will eat it, for it will keep them from scouring, and promote a healthy digestion.

Salt ought at all times to enter into the food of the dairy cow, and it should be kept where she can partake of it ad libitum. It enters largely into the mineral elements of the milk, and as these elements are in scanty proportion in young grass, it is most needed in . the early part of summer. Both the quantity and quality of milk are considerably affected by withholding salt till the cows get hungry for it. Cows in the season of lactation require more salt than at other times, and those that give the most milk require the most of it. In some experiments in June it was found that by letting the cows go without salt five days, they fell off in their milk two per cent. in quantity, and seven per cent. in quality, making a loss of nine per 
cent. on the cheese, which was at once restored by supplying salt again. While cows are at grass, salt should be given every day, and in May and June it is well to give it twice a day.

We may now pass on to midsummer with the remark that while grass is used it should be abundant, so that the herd can fill themselves readily and rest and ruminate.

It is not believed to be the best plan to depend entirely on grazing through the whole season. To do this, it would be necessary to reduce the stock so low as to have a large surplus of feed in June and July, otherwise there would be a deficiency in midsummer. Grass that gets very much ahead of the stock, is liable to waste by tramping down, and to lose its value by becoming dry and woody.

It may be said of the long-leaved grasses, the older they are, the poorer the butter and cheese made from them. This remark will not, however, apply to all forage plants.

But it is desirable to make the grazing season as long as we can, and it may be prolonged by sowing different varieties of grass, the mixture including such as will come forward in regular succession of time. Orchard grass is one of the earliest, and is an excellent one to graze off with in the spring, and red clover with its long roots reaching down to moist earth will $_{\mathbf{c}}$ hold on late, while timothy, June grass, and red-top, fill up the space between, and are ready to revive when the dry season is past.

The length of the grazing season will depend very much on the character of the soil-whether it is dry or moist. It is desirable to have the pasture, or part of it, at least, located on loamy soil that will retain 
moisture and keep the feed green. It is thought to pay best to stock so as not to have a large surplus of feed at the approach of the dry season, and to carry the herd through the drought partly on grass and partly by soiling.

Where food is in great abundance at little or no cost, as on some of the commons of the west, soiling is of less account. Soiling grows in importance with the price of land. But it is important anywhere that cows are liable to shrink in their milk from drought or scanty or stale feed.

For soiling, fodder corn is generally used, and if there is occasion for soiling before corn is fit to use, winter rye and green oats will furnish it by coming forward early.

There is much diversity of opinion in regard to the fitness of sowed corn for soiling, some regarding it as nearly worthless, while others prize it highly. It has certainly given very different results on different farms. But this difference is not the fault of the corn, nor of the farms on which it is grown. It is due to the faulty manner of growing and feeding it.

Botanically, corn and grass belong to the same family of plants. Physiologically, corn and grass are quite different. The greatest per centage of cheesy matter and butter appear in the earliest stages of the growth of grass; they are then most highly colored and most aromatic. Steadily, as the grass-plant in" creases in height and age to prepare for seed bearing, the per centage of these valuable properties begins to diminish and the color to grow paler; the starch, sugar and gum prepare for, and begin to change into, woody fibre, and the aroma steadily wastes away. In the growth of corn it is different. Its valuable pro- 
perties-its casein, butter, sugar and aromä-deficient at first, steadily improve in quality and increase in per centage till the flowering begins, and it is not well to feed it much before that time. Those who have condemned it have fed it too young, or have sown it so thick that its aliment was not developed. When too thickly planted, its stems and leaves are soft and pale, its juices thin and poor, and the effect is a growth somewhat like a potato-vine in a cellar. If sown thin, or in drills, so that the air and light and heat of the sun can reach it, and not fed till nearly its full size, it is a valuable soiling plant, and is fed with satisfactory results.

Fodder corn when fed as it comes from the field, fresh and green, contains too much water to produce the best results. Cows will relish it better and eat more of it, and give more and richer milk, if it is wilted and partially dried before feeding. Hon. Harris Lewis, of Frankfort, Herkimer Co., N. Y., who has largely practiced soiling with grass, finds that grass also produces better results if wilted before it is fed, and that both grass and corn, when fed wet or even unwilted, should be followed by a light feed of good dry hay to absorb their extra moisture before digestion.

In its best estate, fodder corn is deficient in fleshforming material, and should not be fed alone. Grass or wheat-bran, or some food richer in albuminoids, should always be used with it to produce the best * effect.

In respect to valuable properties, lucern is far ahead of corn, being quite rich in albuminoids. Lucern is an excellent soiling plant, and yields a very large crop, on soils adapted to its growth. It requires 
a light, deep, rich soil, and one that is clean and free from weeds. Its growth is rapid and its deep roots strike so far down into the earth as to enable it to reach moisture in the most severe droughts. Its abundant nutrition, its large and rapid growth, its perennial roots that save the necessity of annual seeding and culture, and its ability to flourish in soils liable to suffer from extreme drought, make it a valuable soiling plant for special localities. I cannot speak of it from experience, but it is doubtful whether it is as well adapted for the general purpose of soiling as some other plants. Mr. Lewis tried it on the alluvial flats of the Mohawk and on the loamy uplands of his farm, but fell back upon orchard grass, as being, all things considered, the most profitable.

The two varieties of red clover, large and small, are extensively used both for soiling and grazing. The points which give them preference with dairymen are, the large amount of nutritious feed they yield, the rapidity with which their growth is renewed, their ability to endure drought by reason of their long fusiform roots, and their well known action as fertilizers. More butter and cheese can be made from a given area of clover than of grass, but the quality of neither will be as good as when made from grass.

It is a question that must be settled by local circumstances, whether the smaller and better product is more or less profitable than a larger and inferior one. Clover, in its green and succulent state, especially when the growth is young and very rank, carries in its sap a property that modifies the flavor and quality of both butter and cheese. This property, whatever it may be, is often carried into milk in such quantity, when clover is young and fresh, as to produce taint in 
the milk and floating curds, and is perhaps identical with the cause of hoven. But this peculiarity farles away as the plant approaches flowering, and, like the poison in parsnips, is destroyed by drying, or even wilting. Wilted, dried, or even steamed clover, produces more of the peculiarities of its fresh condition, and in this way may be used with good advantage as a soiling plant. The wilting, or partial drying, should never be omitted.

The prevailing practice among the best dairymen of New York and New England, is to commence soiling with green rye, clover, orchard grass, green oats, or fodder corn, before the grass has become niuch scanted, so that the herd shall at first depend about equally on grazing and soiling. In this way, no shock is felt in the feeding, and no shrinking in the milk occurs except the natural decrease by distance from the time of coming in. Thus the herd is carried steadily along till relieved by an increased growth from fall rains, if perchance, they come.

Whatever course is taken by the farmer, snme provision must be made for keeping up the flow when grass first fails. If this is not done, diminished milk and milk products must be expected the remainder of the seasun. After a cow is well along in the milking season, and especially if she is with calf, as she is very likely to be in August, if she is allowed to fall away in her milk, she cannot by any after feeding be brought up to give as much as she would have given had the flow been kept up all along. High feeding will then stimulate the growth of the fotus, and the cow will run to flesh rather than milk. Earlier in the season, especially for a few weeks after coming in, the activity of the milk glands is such that they will rob the blood 
of the cow of what is necessary to supply her daily waste, and she will grow poor under their action if she is not abundantly fed. But later in the season those glands abate their activity, and the increasing vigor of the cow and her growing foctus, make the strongest draught upon her nutrition, and if there is any deficiency, it will be felt in the milk. Hence the great necessity of never slacking in the supply of feed after the middle of the summer.

If the fall feed comes in well and is abundant, extra feeding may not be required during the fall; but usually some succulent food, as foddier corn, pumpkins, apples or roots, will be required to keep the milk from dropping down too fast. In the absence of any such feed, wheat or rye bran will be found an excellent substitute. It is about as good as soiling at any time, and is more convenient to feed. If not very much dried of their milk, five or six pounds of the bran per day for each cow, wet and thrown on to some coarse fodder, will make a pound of milk or over, for every pound of bran, and the milk will more than pay the cost of the bran and labor of feeding. Bran is excellent food for cows at any time when extra food is required. We have generally been able to get from it more milk than from an equal cost of any other ground feed. It is better suited to warm weather than meal. As the weather becomes cool, if cows are at all thin, meal may be profitably added. At any rate feed enough of some kind should be given to keep up both milk and strength all the fall. One of the worst errors a dairyman ever commits, is to let a cow go into winter quarters drooping.

If the herd has been properly cared for while grazing, the flow of milk will be considerable upon com- 
ing to the stable for winter quarters, and it is advisable to keep it up as well as possible. The idea conveyed by the phrases, "a cow is a cow," and "it costs as much to keep a poor cow as it does a good one," is now discarded by intelligent dairymen. A good cow needs more food than a poor one, and the more milk she gives, the more food she requires. But it will not pay the farmer, who is short of fodder, to dry up his cows eariy to save keeping. He will lose money in the end by doing so. A cow that is coming in the first of April may be milked till the first of February, if she is well kept. At the ordinary prices of keeping and of butter, she will make butter enough from the beginning of foddering to the first of February, to pay the whole cost of wintering, with the cost of all the extra feed counted in, and she will lose nothing in flesh or vigor by doing sn. If the supply of food is insufficient, milking so late would be detrimental, as it would tend to debilitate the cow. It pays best to feed and milk liberally. Hay alone, especially if cut after it is in blossom, will not be sufficient. When not in milk, a cow can get along well on good hay alone; but she cannot eat and digest enough to support herself and keep up a good yield of milk-either her flesh or her milk will fail. Some richer feed should be mixed with it. But if hay is cut early, before it is in bloom, and well cured, it will do well alone. The difference between early hay and late cut hay, is not generally appreciated. The later hay is cut, the less is the per centage of flesh forming elements, the lighter colored its butter, and the more slowly does it digest. Grass cut a week before it is in blossom, and grass cut a week after it is out of blossom, are very different for feeding purposes. The later cut hay will contain 
about 40 pounds in a hundred that will be made available for food, the fatty matter will be pale, and it will take six hours to digest a meal of it. The early cut hay, on the other hand, will contain about 55 pounds of available matter in every too pounds weight, which will be in better proportion and better color, and will digest in four hours as well as the other will in six. Horses and mules digest late cut hay very well, especially the mules; but, if eaten in a dry state, it is not well adapted to the bovine stomach, and they fail to digest it thoroughly. This is proved by the fact that cattle will live and maintain themselves on a smaller amount of nutriment when given in green food, which is easy to digest, than they can if given in dry hay well matured.

The following extract from the address of Dr. James Law, of Cornell University, delivered before the American Dairymen's Association, in January, 1870 , is in point:

"A bullock may be kept in fair condition on 120 pounds of turnips daily, but could not be so supported on eight or fine pounds of Timothy hay, though, as judged by their relative amounts of proximate principles, their nutritive value should be nearly the same. Again, cattle which are fed in Scotland on turnips and uncut wheat or oat straw, occasionally make as much as two pounds increase of weight daily, on a diet of 180 pounds Swedish turnips and five pounds of straw per day, yet no one would expect this daily increase on a diet of 20 pounds of hay per diem, which would be a fair nutritive equivalent, as judged by its chemical constituents, and, moreover, is greatly superior to it in those fat producing principles which are especially required in the feeding ox. The 
difference in result is unquestionably due to the abundance of water in the turnips in intinate union with their nutritive constituents, and which renders them more easily assimilated. The plentiful supply of liquid to the blood and tissues not only favors the destructive and reparatory changes in those, but maintains in full activity the various secreting organs, counteracting costiveness, suppressed, concentrated and irritating urine, inspissated bile, and the like. The same result follows in all cases when this fincly divided and watery food is supplied; and however the condition may have been brought about, whether by cooking, macerating, germinating, or otherwise, other things being equal, the progress made in growth, in fattening, or in the yield of milk, testifies to the enhanced value of food in this particular condition."

Dairymen in the older dairy districts, are every year cutting their food for winter a little earlier. In central New York, hay is cut twenty days earlier than it was twenty years ago.

But the reader is probably ready to ask, if it is advisable to milk cows up to within eight or ten weeks of coming in again, and common hay is not good enough to keep them on without extra feed in some form, what is to be done with the coarse fodder, cornstalks, straw, \&c.? Must it be thrown away? All the fodder that is grown on the farm can be profitably fed to the dairy if properly used. Before speaking of its use, however, a word in regard to the nature and purposes of food may not be amiss.

The food of animals is not one homogeneous mass or single composition. It is composed of several distinct parts, each of which performs a distinct part of the economy of life, and cannot be substituted for any 
other. One kind of food, having a definite composition, builds up flesh and restores its waste, and exists in several different forms, and is known under different names, as albumen, fibrin, caseine, gluten, \&c. They are all included under, and are designated by the terms, albuminoids, or flesh-forming food. Another kind supplies the material from which are generated animal heat and force. This kind of food is made up of fats and oils, starch, gum, sugar, \&c., and are called supporters of respiration, or heat-producing food. Besides these, water and certain minerals, as soda, lime, phosphorus, iron, \&c., enter into the composition of the bodies of animals, the latter chiefly to build up the bones. As the minerals, excepting salt, are usually in sufficient supply in all kinds of food they need not be considered here. What we wish to call the attention of the reader to, is the fact that the albuminoids and heat-producing foods must sustain certain relations to each other, and be supplied in certain relative proportions according to the condition and circumstances of the animals. If a cow is not in milk she may not need any more albuminoids in cold than in warm weather; but she would need more heatproducing food to keep her warm. In the summer, for every pound of flesh-forming food she uses, she will require three pounds of heat-producing food, and in the winter, five or six pounds; a cow can live well on food in such proportions if she is doing nothing but living. Twenty-five pounds of hay per day would give her two pounds of flesh-forming and ten or eleven for producing heat, and this would supply her necessities. But it would not support her and a flow of milk too, in which albuminoids are in much greater proportion (two to five). Hence the necessity of some 
other food to go with it to furnish the albuminoids for the milk. A few pounds of meal, or bran, or early. cut hay, or oil-cake (in all of which albuminoids largely exist), will supply just what is needed.

In a similar way we can use the corn stalks and straw. In corn stalks, for example, albuminoids and supporters of respiration are as I to $I_{3}$, the former being deficient; in pea and bean meal, in which are about 25 pounds of the former to 50 pounds of the latter in a hundred weight, we have the means of balancing the elements of food so that the excess of starch and sugar in one, and of flesh-forming elements in the other, shall be economized to the best advantage, nothing being lost. Straw may be made use of in the same way. The flesh-forming and respirative elements of food in it are in the relation of about I to I5, supposing the grain to be ripe when the straw is cut. Different kinds of straw, of course, vary in value, and the value of each will vary with the time of cutting. If the grain is in the dough stage when cut; the relation of the two kinds of food will be about as I to Io. Coarse fodder generally abounds in heat-producing food, and is deficient in flesh-forming matter, and it is therefore best fed when the cows are not in milk. With 15 pounds of straw or stalks cut and wet, a few pounds of bran or meal (say 4 pounds of bran and I pound of pea meal) mixed with it, will keep a common sized native cow in good condition, if she has the benefit of a comfortable stable. Larger cows, and those that are exposed to the cold, will require more. With a little more ground feed added, this same diet may be given to cows in milk. All the coarse fodder a dairyman has occasion to raise may thus be used in wintering his 
stock, and at a less cost, the fodder and grain being counted together, than he can winter them on hay.

We copy from the table of Wolff \& Knop, as quoted by S: W. Johnson, the nutritive and heat-producing values of some of the different kinds of winter food in common use. It may be of some advantage in ariapting the different values to each other. They are arranged in the order of their flesh-forming material:

\begin{tabular}{|c|c|c|c|}
\hline & Albuminoids. & $\begin{array}{c}\text { Starch, } \\
\text { Sugar, Gum, } \\
\text { \&c. } \\
\end{array}$ & Fat. \\
\hline Oil Cake................... & 28.3 & $4 \mathrm{I} .3$ & 10.0 \\
\hline 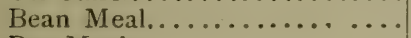 & $25 \cdot 5$ & $45 \cdot 5$ & 2.0 \\
\hline Pea Meal.................. & 22.4 & 52.3 & 2.5 \\
\hline Alsike Clover in blossom..... & I5.3 & $29 \cdot 2$ & $3 \cdot 3$ \\
\hline White Clover in blossom...... & 14.9 & $34 \cdot 3$ & 3.5 \\
\hline Rye Bean.................. & I $4 \cdot 5$ & 53.5 & 3.5 \\
\hline Lucern in blossom........... & 14.4 & 22.5 & 2.5 \\
\hline 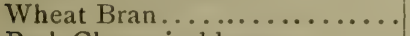 & 14.0 & 50.0 & 3.8 \\
\hline Red Clover in blossom....... & 13.4 & 29.9 & 3.2 \\
\hline 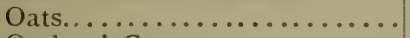 & I2.0 & 60.9 & 6.0 \\
\hline Orchard Grass.............. & II. 6 & 40.7 & 2.7 \\
\hline 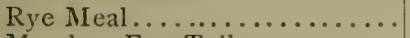 & II.C & 69.2 & 2.0 \\
\hline Meadow Fox Tail........... & Io. 6 & 39.5 & 2.5 \\
\hline 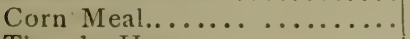 & IO.0 & 68.0 & 7.0 \\
\hline Timothy Hay.............. & $9 \cdot 7$ & 48.8 & 3.0 \\
\hline 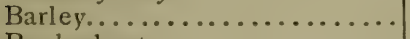 & 9.5 & 66.6 & 2.5 \\
\hline Buckwheat................ & 9.0 & 59.6 & 2.5 \\
\hline Common Hay.............. & 8.2 & $4 I .3$ & 2.0 \\
\hline 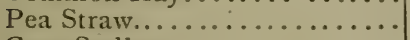 & 6.5 & 35.2 & 2.0 \\
\hline 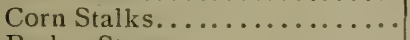 & 3.0 & 39.0 & I. I \\
\hline 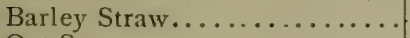 & 3.0 & 32.7 & 1.4 \\
\hline 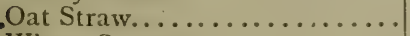 & 2.5 & .38 .2 & 2.0 \\
\hline Wheat Straw ............. & 2.0 & 30.2 & I 5 \\
\hline 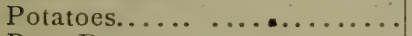 & 2.0 & 21.0 & 0.3 \\
\hline 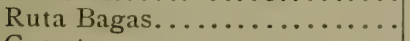 & I. 6 & $9 \cdot 3$ & O. I \\
\hline 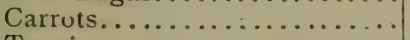 & I. 5 & 10.8 & 0.2 \\
\hline 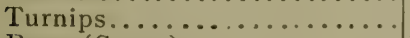 & I. I & $5 \cdot \mathrm{I}$ & O.I \\
\hline Beets (Sugar)............. & 0.8 & I 5.4 & O. I \\
\hline
\end{tabular}

As a part of the heat-producing food must be fat, it has been placed in a separate column.

There are so many circumstances that vary the quantity of food required for the daily use of a cow, 
that no precise figures can be set down as representing the exact amount of the different elements necessary for her to subsist upon, but the following may be regarded as approximatively correct for a cow weighing 800 pounds when not in milk. Her daily food should contain at least-albuminoids, I $1 / 2$ pounds; starch, sugar, \&c., 8 to 10 pounds; fat, $1 / 2$ pound. With a large flow of milk the albuminoids would need to be doubled, the starch, \&c., increased onehalf, and the fat doubled. From this it may be seen how to proportion the several kinds of food to adapt them to each other, so as to use them with economy. If the food is to be used dry, an allowance of onefourth should be made for imperfect digestion. If cooked or steamed the digestion will be perfect and the whole amount may be counted. This amount will be required for cattle provided with warm and comfortable stables and kindly cared for. If they have no other protection than an open yard or shed, one-half more should be added to the quantity named. This may seem a large allowance, but experiments made at the barn of the writer, and tested by actual weights, have demonstrated this difference between comfort and exposure, and the experience of hundreds of others have corroborated it.

In the early settlement of the western world, barns were built everywhere by siding up a frame with boards not fully seasoned, which shrank in course of time, leaving cracks between them half an inch or more wide. It was customary to arrange stabies for the cows on one side of the barn, with their heads pointing toward the floor in the centre, the side next the floor not being boarded except at the bottom, to make a manger. The air streaming through the cracks 
in the side of the barn, carried the air warmed by the heat radiating from the bodies of the cattle, past their heads into the middle of the barn, and rising up, it went out through the cracks above. The cows were kept in a current of cold air but little different from being out of doors. As these primitive barns have been replaced by new ones with sides boarded with matched stuff, and with the exception of means for rentilation, the stables tightly boarded all round, so as to save all the warmth given off from the animals, it has been the uniform testimony of each farmer, as he placed his cows in his new and warm stables, that he required but two-thirds of the hay to keep his cows that he did before. Among the numerous farmers we have heard speak of their experience with such barns, there never has been any less estimate of the saring of food effected. I commend their experience to the consideration of the reader, and submit whether the first item in the économy of winter food for the dairy, is not the comfortable housing of the herd?

Supposing the cows to have been so well provided for as to have arrived near the milking season, with flesh and strength unabated, preparation for spring may be entered upon by a moderate increase of feed, two or three weeks before the cows are expected to "come in." This is necessary to increase their vigor to sustain them in the severity of approaching labor, and supply the rapid growth of the foctus. Some kind of grain should be used for this purpose. Corn is often used, but any other of the cereals is better. Corn is a little too heating for this period. Some food richer in albuminoids should be used, a mixture of different kinds of grain in which oats form a prominent item, has proved very satisfactory in the author's 
experience. But nothing fed at this critical season of the year has ever proved so efficient in good results as green and succulent food-beets, turnips, potatoes, carrots, apples, cabbage, ruta-bagas, \&c., all of which have seemed to serve the same purpose. They improve the general health of the animal, they are easily digested and assimilated, they increase the volume of the blood, making it thinner, and its circulation into the minute vessels more complete and even, and thereby aid most effectually in the relaxation of tissues and expansion of parts so necessary at this particular time. Where roots have been given two or three weeks in advance, labor has been easier and sooner recovered from, and the flow of milk has been larger than when they have not been used. Whether it will pay to raise roots to feed through the entire winter as a substitute for hay, may be a question, but that they contribute to the general health of the animals at any time when fed in reasonable quantities, is not doubted. Though good at any time, they have a special utility in the spring. They not only prepare the cow for an easier labor, but they prepare the whole system for an easy and gradual change from foddering to grazing, so that no shock is felt. They cleanse the blood, and put the milk-glands not only, but the entire glandular system, in perfect working order, and thus extend their influence through the whole summer. When cows come in during the foddering season, there is nothing that will so well prepare them for a bountiful return during the whole remaining period of lactation, as a moderate use of green food while the foddering lasts. For feeding at such a time, it pays its cost many times over, let the question of profit at other times be answered as it may. 
In the early part of the season the active state of the milk-glands will enable a cow to carry off in her milk all the nutriment she can digest above what she can assimilate. If there is any profit in milking at this season, it is in making her digest all she can. To this end she should not only be supplied with all she can eat of food rich in the elements of milk, but her dry food should be selected from such materials as will digest most easily and rapidly. The propriety of providing early cut hay for feeding at this time, will suggest itself, as its easy digestion and its richer and better nutrition, have already been explained, and need not be dwelt upon now. Of course no skillful feeder will select late cut hay, or ripe stalks, or straw, for cows in milk in the spring. But sometimes necessity compels their use. Though not the most profitable food, they may serve a valuable purpose to carry a herd along to grass, and if skillfully compounded with meal, will give fair results. 


\section{CONDITION OF FOOD FOR BOVINE DIGES- TION.}

The condition in which food is offered to dairy stock is sometimes a matter of no little importance. This remark will indeed apply to all stock, but from the peculiar construction of their digestive apparatus, it often has a special significance with respect to ruminants. The digestive apparatus of ruminants is peculiar, and food is handled by it in a different way from what it is in the stomachs of non-ruminants, and for that reason ruminants may be affected by the condition of food where non-ruminants would not be. A brief statement of the borine stomach, will help to understand how it acts upon the food received, and how food affects it.

The cow and other ruminants have a compound stomach containing four apartments. When coarse food, like grass, is eaten, it is only partially masticated at first, and, upon being swallowed. it is passed into the first stomach or paunch. This is the largest division and is about equal to the other three. It serves as a receptacle to hold the coarse half-ground food, till the animal has leisure to remasticate. From the first stomach, it is gradually worked intc the second, which is only an appendage of the first, lying close to the esophagus, and separated from the main part of the paunch by a partial diaphragm in the inside of the 
paunch that reaches in only a little way, and makes only a partial separation between the two divisions. From the outside appearance one would hardly sus. pect the second stomach to be a distinct division of the first. In the second division, the food is rolled into pellets, and by a spasmodie motion thrown back to the mouth. When remasticated, instead of going into the first stomach, as it did at first, it now goes into the third, or manifold, as it is sometimes called. This is a nearly round body attached to the branching termination of the esophagus. It passes directly from the third into the fourth stomach, and the work of digestion is so far advanced that the labor of this division is quickly and perfectly performed. The fourth stomach is designed to receive food only in the plastic condition it assumes in passing through the other three divisions, with the added influence of remastication. It is not calculated to take in, like the first stomach, food in a coarse, fibrous state, unfermented, unsoftened, and unprepared by the partial digestion of the other divisions. The food of the entire bovine race, when taken in its natural condition, as grown in the forest or the field, always takes the course here described. The lower end of the meat-pipe branches out at its connection with the stomach, so that it can communicate with any of the first three divisions; and to aid and insure the passage of the partially masticated food into the proper receptacle, the termination of the meat-pipe at its connection with the first stomach is lined with papillæ, bent like card teeth, the action of which helps work the coarse food along to the place it should go. In their domesticated state, cattle do not always take their food in the coarse condition in which their digestive apparatus indicates it 
was designed to be received. It is desirable to feed them grain and other feed that is pulverized even finer than their remastication would make it. In this condition the papillæ cannot grasp it to haul it along into the rumen, and through a passage way between the ends of the folds in the third stomach it passes directly into the fourth. Perhaps the will of the animal may have something to do with the direction the food takes. But certain it is that very fine food, like corn meal, when fed alone, goes directly into the fourth stomach, missing the other three, and the preparation for digestion they were calculated to give it. This I have repeatedly demonstrated, as any one else may do, by feeding meal to animals that were to be slaughtered immediately, and searching for it as soon as the stomach could be reached.

There may be some exceptions to this rule, as seems to have been recently demonstrated. First, when the stomach is entirely empty, meal, when fed alone, may either voluntarily or involuntarily go into the first stomach. L. W. Miller, of Stockton, N. Y., after feeding on an exclusive meal diet for a week, found the meal, apparently a mixture of each feeding, in the first and fourth stomachs, but the great bulk of it in the first. Second, A. W. Cheever, of the Nerv England Farmer, fed a beef cow meal just before slaughtering, and found the meal all snugly stowed in the first stomach or paunch, where only coarse food usually goes. Others report finding meal divided when taken alone, a part of it going into the first and a part disappearing in the third division. In I $85^{8}-9$, the author made a dozen or more experiments in feeding meal and other food with various degrees of fineness, just before slaughtering, and in every instance found the 
fine food in the fourth stomach and the coarse food in the first. In some instances where food having different degrees of fineness was swallowed together, a separation was made, the coarse going into the first and the fine passing on to the fourth. For instance, when corn in the ear was fed to yearlings, the pieces of cob and corn, down to a certain degree of fineness, dropped into the paunch, while the finer masticated part went on into the fourth. When an ear of corn was wrapped with a wisp of green hay, so that the hay and corn were ground together, the meal finely masticated adhered to the hay and all went into the paunch together. Feeding corn in the ear worked differently with cattle of different ages. When fed to cows ten or twelve years old nearly all the corn passed directly to the fourth stomach, only the whole kernels and large fragments stopping in the first, and often whole grains passed by the first and lodged in the fourth. In yearlings and two-year.olds, a much finer grade of mastication was caught in the rumen, so that the corn was most of it lodged there.

About 1862, Prof. E. W. Stewart, of Lake View, without any knowledge of the experiments just related, for they had not then been published, made some eight experiments in a similar way, using various kinds of fine food, with similar results, the fine food in every case going to the fourth stomach, and showing that, as a general rule, fine food is not deposited in the rumen when fed alone. How numerous the exceptions are, must be determined by further observations, and also, what causes the exceptions, whether they are controlled by the will of the cow, or whether in individual cases the structure of the digestive apparatus, by reason of domestication, varies so that without any special effort of the 
animal, fine food in one case passes by the rumen and in another drops into it. And equally undetermined is the way in which fine food passes the third stomach, whether the manifolds fail to take up food comminuted to a certain degree, or whether by an effort of the will it passes through between the folds, while their action is suspended. The structure of the third division of the ruminants is so constructed that it would not, from inspection, seem probable that anything would be carried directly through it, but certain it is that food does, in certain cases, go direct from the mouth to the true or fourth stomach.

The ruminant stomach is a complex organ and its action is so complicated as to be difficult to trace with exactness, so that its ways are not well known, and hence it is sometimes found doing what we would little suspect.

From the peculiar structure of their stomachs the ruminants' mode of feeding is generally different from that of other animals. The non-ruminant herbivora take their food slowly and grind it well, because they can do nothing further to aid digestion after it is swallowed. The horse for instance, requires an hour to masticate properly five pounds of hay. A cow will eat the same in less than half the time and with fewer strokes of the jaw. This is characteristic of ruminants generally.

They partially grind or crush their food and swallow it into a receptacle suited to such food, but which could be dispensed with if the food was all tine when swallowed, and hence the inference that it is neither absolutely necessary nor natural for food already fine to go there. The coarse food to which this receptacle points as the kind on which the cow was intended to 
live, is more difficult of digestion than food more concentrated and minutely divided, hence special provision is made for reducing such food. From the membranes forming the receptacle into which it is first received, is poured a fluid slightly acid, and charged with a yeast which produces a gentle fermentation, which is the beginning of digestion. By an unequal but regular contraction and relaxation of fibers in the muscular walls of the reservoir, the whole mass is stirred up, kept in motion, mixed, warmed, softened and prepared in the best possible manner for easy, rapid and perfect mastication. In this condition, with digestion begun, it goes back through the second stomach to the mouth to finish the comminution begun when first swallowed. This done, it goes back into the stomach, but this time it goes into another division (3d stomach) filled with pendant folds, between which it is rubbed and triturated and pressed till much of the aliment is separated, and the whole so changed that when it passes hence to the fourth or true stomach, the work of stomach digestion is much more easily and perfectly completed than it would be had not this preparation been made by the other parts of the digestive apparatus.

While this compound arrangement of stomachs enhances the power of digestion as a whole, it is probable, from certain physiological reasons, that the fourth stomach is not, when acting alone, as powerful as the single stomach of the non-ruminants, of which it is a proper representation. Though the appendages to the fourth or true stomach were evidently designed for coarse and not for fine food like meal, yet they can be made available for facilitating and perfecting the digestion of finely ground food. It has been already 
remarked that when meal alone is fed to cows it goes, as a rule, directly to the fourth stomach. To prevent this and ensure its passage into the rumen, wet the coarse food, whether cut or long, and mix the meal with it. It is better to cut the fodder, but it may be used long. By adhering to the wet fodder it is carried along with it into the rumen. The feed for this purpose should be ground as fine as possible.

When it is desired to feed largely with ground feed there is quite an advantage in feeding in this way. The meal digests the easier for the preparation it has received in the rumen, and consequently more can be digested in a given time. In feeding cows for milk it is desirable to induce the largest digestion possible, as the more food used the more milk. There is a limit to profitable meal feeding, and this limit is readily determined by the effect upon the health. When more is fed than can be digested the indigested meal will produce scouring, but so long as it is perfectly digested no such result will occur. A short trial will show that more ground feed can he given without producing scouring, by mixing the feed with some coarse fodder, than when it is fed alone. If the quantity of fine food to be fed is small, the difference will not be very marked. A good way to feed meal is to mix it with sliced or pulped roots. Such has been the author's experience in meal feeding.

The same reasons which have just been used apply to cooking food to hasten digestion. All food which digests slowly or imperfectly is benefited by being cooked or steamed. More food will be consumed in a given time and more nutriment obtained, and hence the more milk, or the more flesh and fat, will come from it. 
Rapid and perfect digestion are all important in feeding cows in milk. No animal can fatten rapidly or give much milk on food which the stomach has to labor with long and hard. To illustrate: straw and roots are quite similar in the proportions of their nutriment, but a pound of straw contains more than twice as much as a pound of roots. A cow can barely digest straw enough to keep the wheels of life going at a slow rate. She could neither fatten if she was dry, nor give milk without growing poor. But because she can digest ten times as many pounds of roots as she can straw, she can consume enough to support herself and have a surplus left for producing fat or milk. .

Unless it is cooked it does not pay to feed straw, or other late cut feed, to cows in milk, because they cannot consume enough of it to allow of any profit, and the slow and imperfect manner in which eommon hay digests, is an objection to using it to the extent many dairymen do as the main food for the dairy. It is often a boast that cows have all the hay they can eat, but it is a boast which does not speak well for the largest returns. Hay will not allow of the best results in milk production. Dried grass will do very well; but common hay would require an amount burthensome for a cow to carry, an amount beyond the capacity of her stomach, to yield the material for a good flow of milk without drawing on her store of flesh to produce it. The more I study the food of milch cows, the more am I inclined to limit the quantity of hay to the smallest amount which will afford a comfortable distention of the stomach, and make up the rest of the ration with food richer and more rapidly digested. It is the best way to get large and paying returns. 
Green and succulent food is best for milch cows, but the succulence of food should not be in excess. Food containing more than about 70 per cent. of water, will produce more milk by evaporating the water in excess of that quantity. Green fodder corn, for instance, which contains from 80 to 85 per cent. of water, will produce more milk by evaporating to to 15 per cent. of its moisture. Another item to regard in the selection of food for milk production, is that the digestible elements of the food should contain fleshforming and respiratory matter in the same relative proportions, or as near as may be, as they exist in milk. If there is an excess of either, it will be fed at a loss; if a deficiency of either, the quantity will diminish. Where proper proportions do not exist they may be regulated by mixing different feeds. Thus fodder corn has an excess of respiratory matter; clover of flesh forming; by mixing the two both are fed more profitably. In grasses these elements are pretty well balanced, so they are in wheat and rye bran and various other foods. So far as milk is concerned, an excess of albuminoids occasions less loss than an excess of starch, sugar, and fat, and a deficiency of albuminoids will also occasion the greater loss. The quantity of milk varies pretty nearly with the supply of flesh producing food when other circumstances are equal.

Water is an important article in the diet of any kind of stock. If possible, it is more so with dairy stock than with any other kind. It constitutes not only about 70 per cent. of the weight of the entire body, Lut 87 per cent. of the milk secretions. To supply so large an amount of water to the constantly wasting tissues and for the composition of milk, requires free access to it in abundance, at all times, or at compara- 
tively short intervals. In the pasture it is not enough that there is a sluggish poud or a ditch of brackish water, nor that a supply may be had if the animal travels a long distance to reach it. The quality of the water affects the health of the cow and the wholesomeness of her milk secretions. Many impurities will at once show their presence in the diseased condition of the cow and in the deteriorated quality of her flow of milk. There are many organic germs, that enter into the circulation of the blood from bad water and appear in the milk secretions, ready to propagate their kind whenever the conditions are favorable. Whoever partakes of the milk introduces these germs into his or her system, where the conditions may be favorable for their growth, and their multiplication may produce disease of a more or less positive form, often resulting in serere if not fatal fevers. These same germs have a similar effect in the system of the cow. So it is important, not only that the supply of water should be abundant, but that it should be pure-that is, as pure as clean spring or brook water, and fit for the use of man as well as of beast. And the accessibility of water is of no small degree of importance. Cattle will travel long distances to get it, before they will die of thirst, but they will often delay the journey and get excessively thirsty before performing it; in consequence, when they reach the water, they injure themselves by an excessive draught, drinking until they feel not only uncomfortable but actually suffer for some time, from a slow fever. This will always happen where the water is not only at the back end of the pasture, but at the back end of a large piece of woods, which contains little for them to eat, and through which and back 
again they must make a special journey every time they drink. If the water is bad when they do reach it, then the injurious effects are doubly aggravated. In winter, cattle do not suffer so much from thirst but they need to drink scarcely less, if they are kept exclusively on dry feed. The purity. of the water is also a matter of importance in winter, and it should not only be abundant, but easily accessible, for cattle will get very thirsty before they will go a long distance, on a cold, stormy or windy day, to get drink. Provision should be made for the weaker animals-that is, the conveniences for getting water should be such that the weaker animals will not be kept long waiting, and possibly deprived altogether of drink. On a severe day, they will soon give up in despair and return to the stable, even though very thirsty, without drinking. Such an occurrence should be carefully guarded against. If they are long kept waiting, they get badly chilled, and if the water they drink is ice cold, the shock to the system is severe and either makes them sick or costs an extra amount of food to supply the consumption of tissue in heating up. Cows giving milk, if thus chilled, will shrink largely in their yield; indeed, even a slight chill, such as caused by leaving the stable and going to a trough in the barnyard to drink, has been observed to make a sensible shrinkage in the mess of milk. It will pay, both in the increased comfort and health of the cow, and in the lessened consumption of food and augmented flow of milk, to make provision for watering milch cows in winter, without chilling them, and if the water which they drink can be tempered to 60 or 70 degrees, it will be an advantage. Of course, every dairyman must be governed by circumstances in 
regard to water, as in other matters, but if he cannot provide all the best facilities and conditions for watering his stock, his aim should be to approximate them as nearly as possible by every reasonable care and expense of time and money. Often, only a little foresight and energy is all that will be needed to provide every requisite. As an illustration of the importance of having water accessible in summer and of the effect of inaccessibility on the flow of milk, I will give a fact in my own experience. When I lived in Herkimer county, my cows ran in a pasture which usually had a good supply of water on the hill or plateau on which they did most of their grazing. Occasionally this water would dry up for a. while, and the cows be compelled to make an extra journey of 60 or 80 rods, into a deep gully to get drink. On every such occasion I at once noticed a shrinkage of fully ten per cent. in their flow of milk, besides a marked deterioration in quality. 


\section{$\therefore$ THE DAIRY BARN.}

A dairy barn should be so constructed as to be conrenient for the herdsman, saving time and labor in the care of stock; it should provide for the comfort and health of the herd; it should afford ample space for storing provender; it should be a comfortable, convenient and cleanly milking barn ; and last, but not least, it should be conveniently arranged for disposing of and protecting the manure.

These points have been well provided for in the plan here illustrated, taken from the barn of Peter Mulks, of Slaterville, N. Y. It is designed for the entire stock of cattle and horses, and for the hay and grain of a farm of 200 acres.

It is 96 feet long by 38 feet wide with 25 feet posts, and has a wing $80 \times 40$, used as a grain barn, carriage house, and stables for horses.

The main part of the building, which is designed for the dairy, is what we wish more particularly to call attention to.

This is located upon a moderate slope, the side and one end resting upon mason work. The building stands with the longest dimensions east and west, with the west and front end, through which it is generally entered, facing the highway. Under the east end is an excavation extending under the building 24 feet and walled up on three sides, the east end being left open. It forms a space 24 feet long by 38 wide and ro or 12 
feet deep, which is used as a manure shed. Under the remainder of the building the ground is levelled up with gravelly loam to the top of the wall, so that the

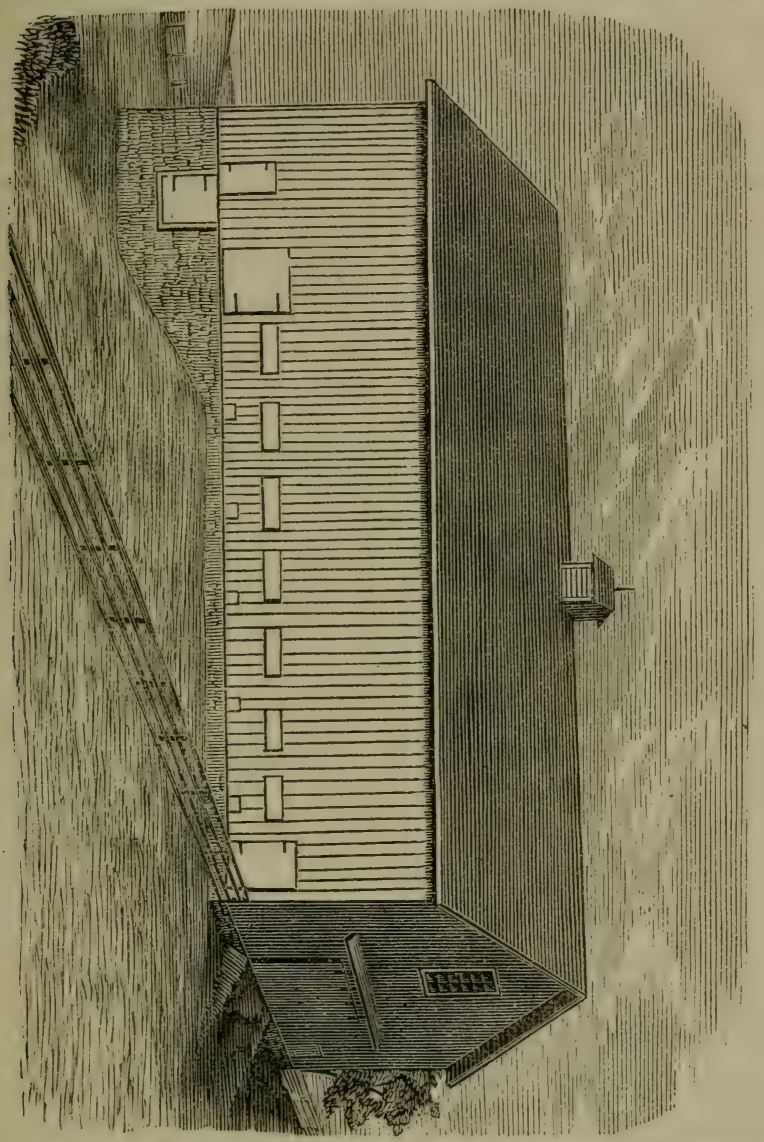

main floor, A, in the centre, lies flat upon the ground instead of on timbers as is usual. The original design embraces a root cellar under a part of this floor. 
The internal arrangements will be understood by referring to the ground plan. The stables occupy 72 feet of the front end of the barn, and are located on each side of the main floor, with the heads of the cows facing each other. Behind them is a floor, B B, five feet wide with an inclination of two inches toward the cows. Next to this is a gutter ro inches wide and 4 deep, made of 2 inch plank, very firm and tight. Next to this is the space, D D, on which the cows stand, sloping two inches toward the gutter. This space of 4 feet and 4 inches from the gutter to the bed piece which holds the stanchion, has no floor. The cows stand on a bed of gravelly loam, which has been pounded down and made firm and smooth. Mr. Mulks regards this as much better and more comfortable for the cattle than a wooden floor.

The stanchions allow three feet to each cow. They are built in the usual way except the mode of fastening, which is very simple and safe. This fastening consists simply of a loop of three-eighths round iron, wide enough to let the ends of the upright pieces pass through it readily, and just long enough to drop over the movable upright and hold it in its place, the other end being dropped into a slot in the permanent upright, where it is made fast by filling up the slot after the loop has been dropped in. (See section of stanchion illustrated in the wing of the ground plan.) The upper end of the movable upright is made slanting, so that the end of the loop slides upon it and falis astride of it when it gets to its place. Though in use several years, a cow has never been known to get loose from this fastening. It is impossible for one to do so, because the loop lies flat on the top of the horizontal piece which holds the uprights, and a cow cannot 
possibly reach it. I have used loops made of No. 6 iron wire, in the same way, which have proved perfectly safe and satisfactory.

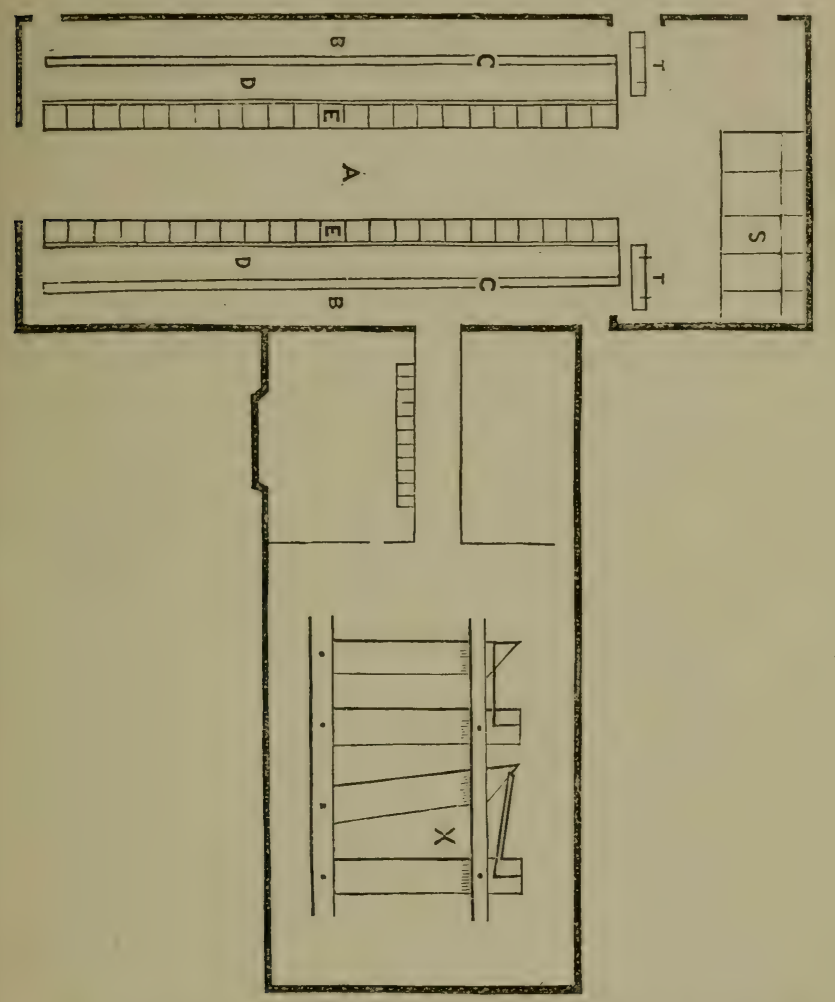

The mangers, E E, are two feet in the clear, with the bottoms raised four inches above the feet of the cow. A separate feed-box is made for each cow. It is formed by boarding up in front 16 or 18 inches, and separating their heads with a partition of two inch plank. The 
part over the manure shed is fitted up with stalls for transient horses and places for keeping calves in the spring, or for absorbents, as may be required.

One of the essential advantages of dairying over other modes of farming is the better means it affords for maintaining and improving the fertility of the farm. The extent to which the manure heap shall contribute to this end depends very much upon the arrangements of the dairy barn for taking care of the manure. If stables are placed in a lean-to on either side of the barn, as is frequently done, and the manure thrown out of windows under the eaves, to be washed by the drippings of a wide roof, half the value of the manure will be lost by the waste of all the liquid excrement of the herd, and very likely, half the strength of the remainder will be steeped out and soaked into the ground where it is not needed, and the bulky remainder finally carried to the field worth only one quarter its original value-a minimum too small to maintain the fertility of the snil. A remedy has been sought in a manure cellar directly under the stable, into which everything is dropped through trap doors directly behind the cows. This makes a complete saving of all the manure, but the fumes from the fermenting mass in the cellar are constantly steaming up through every crevice and opening, and filling the room above with offensive air, unwholesome for the cows to breathe.

All these defects are obviated in the plan before us. The manure shed, instead of being under the stable, is at one end and entirely outside of it, and is effectually shut away from it. It is open on one side so that all the effluvia that arises escapes into the atmosphere, instead of being driven into the apartment 
above. It is at the same time perfectly protected from the weather. The gutter behind the cows and the whole stable inclines a few inches, making it easy to wheel the manure to the shed, where it is dumped through the trap doors, T T. The saving of manure is complete, as all the liquid would find its way to the shed by draining if not otherwise provided for. But bedding and absorbents are always supplied for taking it up and it goes in daily with the solids. Whenever necessary, the gutter is rinsed out and the wash all goes into the shed and is saved. The droppings from the stalls, S, and from the horse stables in the wing, are also daily mixed with that from the cows, improving the condition of both. One is prevented from heating too much and also acts as an absorbent, and the other from being too cold, wet and soggy.

The high posts make the loft a capacious receptacle for fodder. It will easily hold roo tons. The bents are 12 feet distant from each other and divide the whole into eight equal parts. The timbers inside are arranged with a view to unloading with a horse fork, so that no beams are in the way. Beginning at the back side each division is filled separately and the fodder can be taken out separately, if desired. As the filling progresses, a scaffold is laid over the driving floor, A, of plank, the ends of which reach to the scaffolds over the stables and rest on $8 \times 10$ girts reaching from bent to bent.

This, when the barn is filled, forms a complete covering over head, utilizing all the room for storage and making the stables warmer in the winter by preventing a too ready escape of the heat radiating from the cows. With the recent improvements in railway forks, such a barn could be filled by driving up to the front 
end and taking the hay in through elevated doors and carrying it back, wherever desired, on an elevated railway, or the hay could be taken just within the front doors and elevated and carried back from there, easier than to drive in and back out through so long a distance, and save also the labor of moving and replacing the scaffold over the floor.

Bins for holding feed are placed in the front end of the second story. The feed is elevated with a hoisting apparatus, and spouted down as wanted. The feeding and foddering is all done in the barn, and the arrangements for doing it are very convenient.

The milking is also always done in the barn, and for this purpose it is located convenient to the dairy house and dwelling, which are combined. Convenience and comfort in milking are important considerations, and they have been well provided for. It is warm and comfortable in winter. The sides of the barn are boarded up with matched stuff and battened; the doors and windows are all snugly fitted, leaving no gaps for cold winds to rush in; the cows stand upon the ground and the floor lies upon the ground, giving no chance for wintry currents to drive under and crowd up through cracks to reduce the tempcrature inside to a level with that outside. The stables never freeze.

In the summer it is cool and airy. The stables contain 46 stanchions, while the number of cows milked is usually about 30 , so that there is no sweltering heat from cows being crowded together too closely. Ventilation is easy and ample. Besides the admission of air through the doors, there are large wickets in the sides of the barn above and behind the cows, as shown in the elevation, and directly behind each fourth cow 
is a small door 30 inches square, opening down to the stable floor. These little doors are a happy arrangement. While the warm air passes out through the wickets above, the opening of these doors never fails to let in a current of fresh air that strikes directly upon each cow, which is enjoyed alike by the cow and her milker.

The cost of the barn and wing was about $\$ 6,000$. The main barn cost something over half this sum. Parties desiring to build with less expense could somewhat shorten the length of the stables for the number of cows, and build a cheaper manure shed. The wing will not generally be needed for a dairybarn, as the accommodations it affords are usually found in other buildings, which in Mr. M's case had been swept away by fire. A nice and substantial barn, capable of accommodating 30 cows, could now be built for $\$ 3,000$, or probably less.

Some years ago dairy barns were built only for convenience in milking. When this was the main object, it was a very common practice to turn the heads. of the cows out toward the side of the barn, leaving a walk between the side of the barn and the manger. The hind parts of the cows were far enough apart to leave a clean place between, and room enough to travel and carry milk. So long as nothing but a milking barn was required, this arrangement was convenient and well enough. But lately, soiling in the dry part of the season, at least, has become so common, and is now regarded as such a necessity for keeping up an unabated flow of milk, that preparation for feeding green fodder of some kind, to supply the failing grass, must be provided for in the arrangement of the milking barn, where the cows are to be daily 
herded. For this purpose the milking barns of the more modern times are arranged to place the heads of the cows toward each other, and the barn so arranged so as to drive through with a wagon load of fodder and throwing it off on each side. This convenience should never be lost sight of in the erection of a milking barn, whether it is built separately or in connection with other buildings.

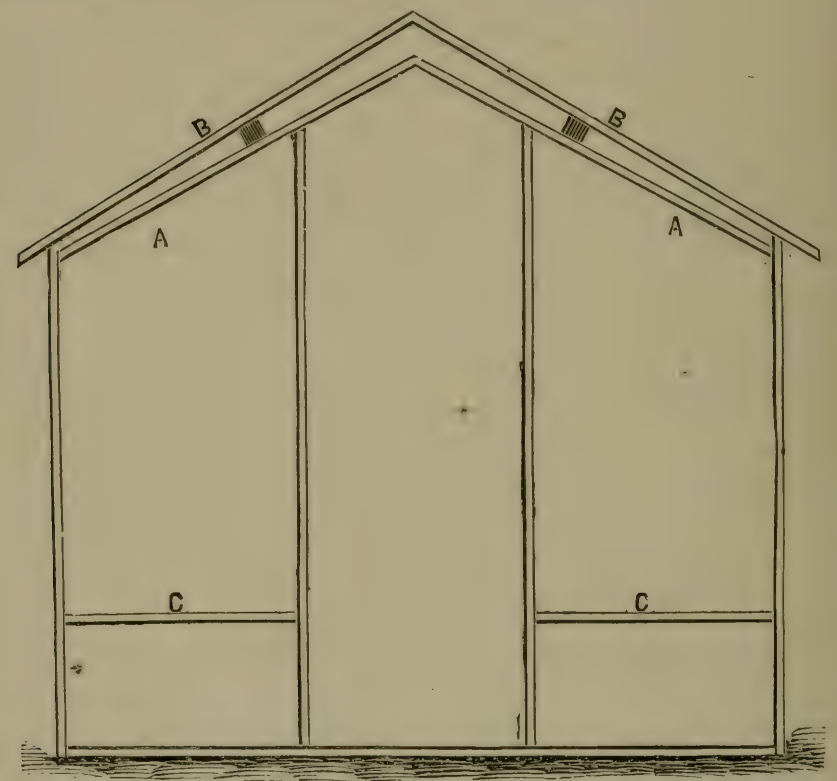

The use of the horse fork is now as much a necessity to the hay barn as the mower is to the meadow, and the frame of the modern dairy-barn should be adapted to its use, by leaving out as many as possible of the inside timbers, and by arranging those which must remain so as not to be in the way. For this purpose, 
Frank Keeler, of Otto, N. Y., President of the Cattaraugus Co. Farmer's Club, makes a very favorable disposition of the interior timbers of dairy barns. The accompanying illustration gives a view of the timbers for one of the middle bents of a barn built by him. For each bent there is a pair of "principal rafters," A A, framed into the outside posts just below the plates. A tenon on the end of the middle pusts passes through them, and they are framed together and pinned at the upper ends. The whole bent is thus tied together so it cannot possibly spread. The true rafters are supported in the middle by a perlin which rests on the principal rafters, as shown at B B. The bents are prevented from spreading by tenons entering the sills, by the girts, C C, and by the "principal rafters," thus making the frame very firm while it leaves the space over head entirely free from any impediment to the fork, nor is there any "big beam," or anything else abore the girts, in the way of passing the horsefork into the spaces between the bents on either side. 


\section{THE OCTAGON BARN.}

Where a single building is desired to answer the purpose of a milking barn and winter stable, a hay and grain barn, a carriage house and horse barn, the octagon barn has some advantages which commend it to the farorable consideration of dairymen, to which it seems proper to call their attention. Its form is compact, and every part of it is easily reached from a single central floor; it affords the most convenient arrangement for the use of the horse fork, as no interior timbers are required for supporting the roof. The roof can be made self-supporting and the space above the scaffolds thus left entirely free of timbers of any kind, thus giving a greater freedom of action for the horse fork than any other form. Next to the circle, it takes less wall and less siding to enclose a given area than any other shape. The difference in the cost of wall, siding, and timber, for building a separate structure for each purpose the farm requires, and furnishing the same room in a single octagon, is about one half. The difference between furnishing it in a single rectangular building and an octagon, is from $1 / 5$ to $T / 4$.

The accompanying illustrations give an elevation and ground plan of a barn of this form, built last season by Prof. E. W. Stewart, of Lake View, Erie Co., N. Y. It is copied from the January number of the Live Stock Journal for 1876 . 
The barn was built to replace four others which had been burned, and was designed to afford all the barn conveniences and storage for carriages and tools required for a farm of $25^{\circ}$ acres.

Its dimensions are 80 feet diameter, 28 feet posts, the sides being each 33 feet and 2 inches long.

To give a gencral idea of an octagon barn, and how to arrange its interior, I cannot do better than to copy from Mr. Stewart's description of the barn here illus. trated :

"This octagon has an outside wall of 265 feet, while the other four barns had an aggregate of $7 \mathrm{I} 6$ feet of outside wall, showing the great economy of this form in expense of wall and siding. If we compare it with a single barn $50 \times 108$, the latter will enclose the same number of square feet and have the same capacity at the same height, but requires fifty-one feet more of outside wall. The rectangular barn will also require many more interior cross beams and posts, which are in the way, besides adding to the expense. The lung rectangle requires, for convenience, two cross floors, which take up more room, and being separated, are less convenient than the single floor through the center of the octagon. The long barn requires posts and purlins to support the roof, which are obstructions in filling with hay and grain, while the octagonal roof of one-third pitch is self-supporting, resting only on the outside plates, and may be safely stretched over a diameter large enough to accommodate a farm of 1,000 acres, or say 150 feet in diameter. The plates perform the office of the bottom chord, and the hip rafters of the top chord, in a truss. The strain on the plates is an endwise pull, and if they are strong cnough to stand the strain of the push at the foot of the rafters, the bottom of the roof cannot spread, and the rafters being properly bridged from the middle to the top, cannot crush, and the whole roof must remain rigidly in place. Its external form being that of an octagonal cone, each side bears equally upon every other side, and it has great strength without any cross ties or beams, requiring no more material or labor than the ordinary roof. The plates are halved together at the corners, and the lips bolted together with four half-inch iron bolts [see fig. 4]; a brace $8 \times 8$ 

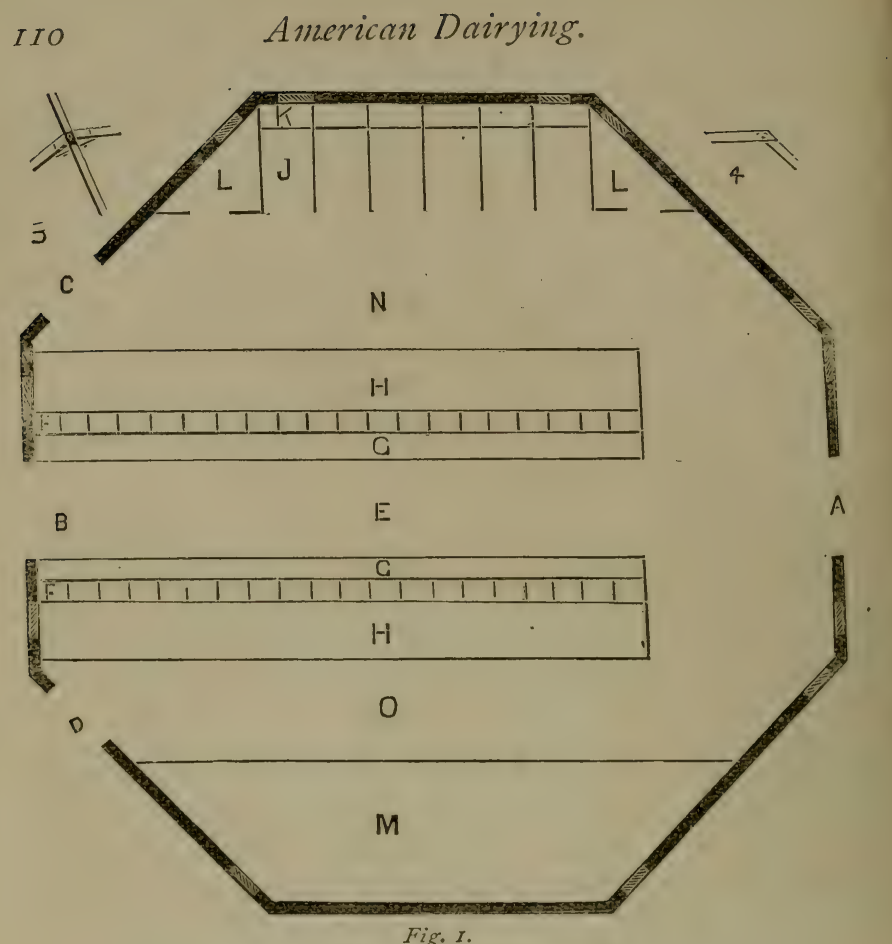

OCTAGON BASEMENT, (NORTH SIDE).

Explanation.-A B C D, doors of basement; E, drive-way through the center; N C, south drive-way for cart to carry out manure; OD, north drive-way ; ter; N C, south drive-way for cart to carry out manure, $\mathrm{M}$, horse mangers ; J, horse stalls ; F, forty cow stalls or stanchions, there should be no separation between these spaces and $\mathrm{H} ; \mathrm{G} \mathrm{G}$, cow mangers; $\mathrm{H} \mathrm{H}$, an open grated platform for cows to stand on, the manure falling through upon a concrete floor below.

inches is fitted across the inside angle of the plate corner, with a three-fourths inch iron bolt through each toe of the brace and through the plate, with an iron plate along the face of the brace taking each bolt, the nut turning down upon this iron plate. Now the hip rafter (T), 6x 12 inches, is cut into the corner of the plate, with a shoulder striking this cross brace, the hip rafter being bolted (with three-fourths inch iron bolt) through the plate into the corner post. [See fig. 3.] Thus the plate corner is made as strong as any other part of the stick. There is a purlin rim 


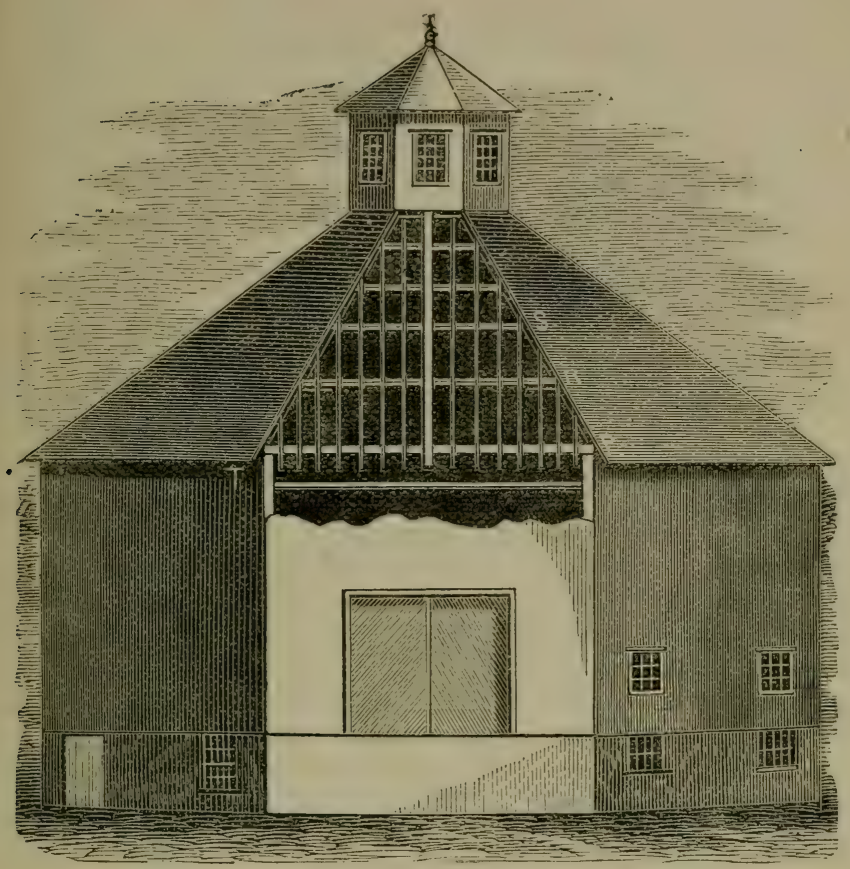

Fig. 2.

OCTAGON BARN, (NORTH ELEVATION).

Explanation.-P, plate; $R$, tie-rod and bridging between rafters; $S$, purlin rim: ' $T$, hip rafters.

(S) of $8 \times 10$ inch timber, put together like the plate rim, bolted under the middle of the hip rafters, which supports the intermediate rafters. The hips may be tied to the intermediates by long rods half way between the plate and the purlin, if deemed necessary from the size of the roof ( $R$ ). The north section of the roof (fig. 2) is represented as uncovered, showing the plate (P), purlin $(\mathrm{S})$, tie-rod $(\mathrm{R})$ and bridging between plate and purlin and the two sets of bridging above purlin, etc. It will be noted that, in this form of roof, the roof-boards act as a powerful tic to hold it all together, each nail holding to the extent of its strength, thus supplementing the strength of the plate-rim or bottom chord. 
It will be seen by fig. 2, that there is a drive-way fifteen feet wide through the center of the principal story from north to south. There is a line of "big beams" on either side of this drive-way, thirteen feet high, across which a scaffold may be thrown to enable us to occupy the high space over this floor. The posts being 28 feet high and roof rising $22 \frac{2}{3}$ feet, the cupola floor is 50 feet abowe the drive-way floor below. The space above these "big beams" is quite clear of any obstruction, and a horse pitching fork may be run at pleasure to any part. The bay for hay on the left side of this floor is 80 feet long, and has an area of 2,030 square feet, and is capable of holding, when filled to the roof, I6o tons of hay. This bay, extending along the floor eighty feet, may be divided into as many parts as required for different qualities of hay, and each part be quite convenient for filling and taking out.

On the right hand side of the floor is a scaffold, eight feet high, having the same area $(2,030$ square feet) for carriages, farm tools and machines below; above this scaffold is-a height of $18 \frac{1}{2}$ feet to the plates-a large space for grain, affording ample room for the separate storage of each kind to the aggregate storage of 2,000 bushels or more. It will be seen that the large space in this barn is all reached and filled from one floor, saving much labor in changing from one floor to another. In our other buildings we had six places for hay, holding less than this one bay, requiring the moving of the horse fork and tackle to six different bays, while in this bay the haying will begin and end, with room to spare.

\section{THE BASEMENT.}

Fig. I shows the basement as we intend to use it, yet there are many different ways in which it may be divided for stock and other purposes.

The drive-way through the basement is from west to east, being the feeding floor between two rows of cattle, with heads turned toward the floor. The floor is $14 \frac{1}{2}$ fect wide, out of which come two rows of mangers $2 \frac{1}{2}$ fcet wide, leaving a space of ro feet for driving a wagon through, or running a car carrying food for the animals. There are places for twenty cows or other cattle on each side, leaving a space of 18 feet at the west end to drive a cart around behind the cattle on either side to carry away the manure and pass out at a side stable door, eight feet wide. The 
horse stalls are arranged on the south side, but may be placed on either of several other sides, or on all. By placing tails to wall and heads on an inner circle, drawn twelve feet from the wall, with feed-box room three feet wide for each horse, with ample room at the rear, sixteen horse stalls may be arranged on southwest, south and southeast sides. But for 200 acre farms, generally. no more than forty head of cattle and six horses would be kept, and for such our ground plan would be most convenient, because it furnishes easy access with a cart, both for supplying fodder and carrying away the manure. On our plan, we have much space on the north, northwest and northeast sides, which may be used for various purposes, such as root cellar, sheep fold for fifty sheep, or for stowing away tools, working wagons and implements.

It will be seen that the basement is not sunk in the earth, but on the north and south sides it is graded up to the floor of the second story, so as to make an easy drive-way into the barn. The base line, as represented on the drawing, is four feet below the general level of the land on the north side, but there is an open channel of water, into which every part is drained, on the south side. The earth on the east and west sides is scraped upon the north and south sides to grade up the drive-ways into second story. The basement is lighted by six windows of twenty lights, $8 \times 12$ glass, and six of ten lights each.

\section{THE OCTAGON ADAPTED TO ALL SIZED FARMS.}

A little examination of this form of barn will not only show its adaptation to large farms, but to all sizes-from the smallest to the largest. A farmer has but to calculate how much room he wants for cattle, how much for horses, how much for sheep, how much for hay and grain, how much for carriages, wagons, tools, or any other purpose, and he can enclose just the number of square feet needed, and with the shortest outside wall: He may be liberal in his allowance of room, for it costs less, in proportion, as the size is increased. Suppose he requires for a fifty acre farm 2,000 square feet of room; this would require a fifty foot octagon, or a $40 \times 52$ rectangle. Now he would require timber forty feet long for the latter, while he could build the octagon with timber for the sills and plates only twenty-two feet long, and this would be the longest timber, unless he wished his posts higher. Each side would be only $202 / 3$ feet, and the wall for the bascment 165 
feet long, whilst the other would be 184 feet long, saving ig feet of wall and siding by the octagon, requiring but eight corner posts, and no intermediates, as the girts would be less than 20 feet long. He would require no interior posts or beams, except those for scaffolds. All the ordinary purlin posts and beams would be saved, and the labor on them. It is easy, also, to see that a few feet added to each side would furnish room for another fifty acres, and so on to any size desired. This form of building, properly understood, would lead farmers to abandon the building of a separate barn for each specific purpose, and to providing for all their necessities under one roof."

The octagon of Mr. S., which I had the satisfaction of inspecting last fall, is a model of simplicity of structure, of strength and durability, of convenience and cheapness, all combined with architectural taste.

Economy in cost of erecting, in time and labor of attendants, and the comfort and health of the stock to be cared for, has been, as it should be, considered in every feature from cupola to foundation. In the examination of this building I was as forcibly impressed with the economy and skill in the construction of the basement walls, as in the superstructure which rests upon them.

Walls which are cheap, strong and durable, and non-conductors of heat and moisture, are important to the dairy farmer, as foundations and for basements to farm buildings and factories. They are in such requisition that I trust $I$ cannot do a better service than to close these remarks on dairy structures with Mr. Stewart's account of the economy and mode of constructing concrete walls for farm buildings:

CONCRETE WALL.

"The advantages of this mode of building walls are not sufficiently known, for when fully understood this wall must come into more general use. In many parts of the country suitable stone is not to be had, and, where stone is plenty, this mode of 
using them is far preferable to the ordinary way of building a wall. The concrete, which would build a wall alone, may be used to cement the stone together, and thus save the cement which would occupy the space of the stone. In many parts of the country, small flat stones are thrown out by the plow and need to be gotten off the field. These will work into the concrete wall and make an excellent job. They will have a firm bcaring upon each other and thus render the wall strong before it sets hard. Care should be taken not to let stones come quite to the surface of the wall, but cover their edges with concrete. Concrete is more porous than stone and will not conduct heat and cold like stone. A concrete wall will show no frost on the inside in winter, is drier and cooler in summer, and warmer in winter, than stones, and, therefore, it is well not to let the stone come within three-fourths inch of the outside. You can use any kind of cobble or irregular hard stone in this kind of wall, but it may be built of clear sand and gravel, the gravel being large or small, and stone may be mixed with the sand and gravel.

\section{WATER-LIME, CONCRETE FOR FOUNDATIONS.}

If there is moisture to come to the wall, water-lime must be used, and it is well to carry two or three feet above the ground with concrete. The place should also be excavated one or two feet bcyond the proposed wall, so as to leave an air-space on the outside, giving the wall a chance to dry and become hard. If, in any case, you go into the slate rock, which is always full of seams charged with moisture, you must not allow the concrete to be built against this rock, for the moisture in the rock coming into the thin mortar will cause the milk of lime to run out and leave an infinite number of fine pores through which water will run; but if no water is allowed to come to it while drying, it will be water and air tight. It is also well to have a drain cut lower than the bottom of the wall on the outside, to carry off any water that might otherwise come against it, which will render the basement dry.

\section{PROPORTIONS OF WATER-LIME CONCRETE.}

If you have only sand to use, mix five parts with one of waterlime, thoroughly, while dry ; then wet into a thin mortar and use immediately. But if you also have gravel, mix the sand and 
water-lime, four to one, then mix into this five or six of gravel, make into thin mortar and use at once. This will make a concrete of about nine to one. If you also have stones to lay with it, put these stone into the boxes and cover with this mortar, and all the stone you put in will save so much mortar and make your wall stronger while new. If you use only sand and stone, then mix the water-lime five to one, lay the stone with it. The way is to put a larer of an inch of mortar in the bottom and then a layer of stone, then of mortar and so on, letting the mortar come over the edge of the stone.

PROPORTIONS OF QUICK-LIME CONCRETE.

If only a basement wall is built, you may use water-lime for it all; or when you get so far above the ground that moisture will not affect it, you may use quick-lime, which is cheaper, and goes farther. If you live near a lime-kiln, it will be cheaper to get the fine air-slacked lime about the kiln, which will answer just as well, if you estimate only the fine lime and not the small stones in it. In mixing this concrete, take ten of sand and one of lime, slaking the lime thin before you mix in the sand; now mix in ten or twelve parts of gravel, fine and coarse, and use this as a mortar to make the wall or lay the stone. Mix it all well together, and then wheel in a barrow and shovel into the wallboxes. The sand and lime will fill all the spaces between the gravel and the stone, if you have any stone, cementing all together. The quick-lime may be mixed some time before using, as the mortar is all the better for it; but it does not set so quick as water-lime, and must have more time between layers. But a quick-lime concrete is more porous, and, consequently, drier and cooler in summer and warmer in winter. The proportions will vary according to the strength of the lime.

\section{CONSTRUCTING THE BOXES FOR THE WALL.}

Having determined the place and excavated for the wall, construct the boxes as follows: Take $3 \times+$ scantling for the standards, a little longer than the wall is high; place these on each side of the proposed wall, as far apart as the thickness of the wall and the thickness of the plank for the boxes. The plank should be fourteen inches wide, one and one-half inches thick, and of a length to accommodate the wall. If the wall is thirty-two feet 
long, then sixteen feet plank will be the right length. These standards would thus be placed fifteen inches apart; placing the plank inside the standards would leave twelve inches for the wall. These standards are held the proper distance at the bottom by nailing a thin piece of board across under the lower end, and the tops fastened with a cross-piece. The wall is built over these pieces at the bottom, and they afe left in the wall. The standards are plumbed, and made fast by braces outside. Now, it will be seen that these plank can be moved up on the inside of the standards as fast as the wall goes up. The plank on the outside of the wall will, of course, be longer than those on the inside by the thickness of the wall. The door frames will have jams as wide as the wall is thick, and will make standards for that place. There will be a pair of standards at each end of the plank; but the pair in the middle of the wall will hold the ends of both plank. To hold the plank from springing out between the standards, take a piece of narrow hard-wood board, two feet long, bore a tiwo-inch hole at each end having fifteen inches between them; put a strong pin two feet long through these holes some ten inches; now these pins will just fit over the outside of the box plank, and by putting a brace between the upper ends will hold them tight against the plank, preventing their springing out. Two of these clamps will be required for each set of plank sixteen feet long. Now, when the box-plank are placed all around the wall, begin and fill in the concrete mortar and stone, as described; and when you get round, if water-lime is used, you may raise the plank one foot and go around again, raising the wall one foot each day, if you have men enough. You will place the window frames in the boxes when the wall is raised high enough to bring the top of the frame to the top of the proposed wall. The jams and sills of the window-frames will be as wide as the door frames.

\section{COST OF THE CONCRETE WALL.}

The cost of the concrete wall for the basement of the So foot octagon-265 $1 / 3$ feet long, I5 inches thick at the bottom, 12 inches at top, containing 2,535 cubic feet-was $\$ 250$; the items being as follows : water-lime 65 barrels, $\$ 90.35$; lumber for door and window frames and board on top of wall, \$19.34; carpenter work, making window and door frames, fitting and plumbing standards, fitting plank boxes for wall, etc,$\$+r$; getting material and the 
labor of laying the wall, \$cg.3I, or about ten cents per cubic foot. This was the cost of a water-lime concrete, quick-lime costs less. Of course the cost of concrete wall will depend upon the convenience of getting sand, gravel, stone and lime. It would take more lime to build altogether with fine sand, as the fine grains have so much greater surface to be coated with lime, but with sharp sand, one" of water-lime to six of sand, makes a solid wall, great care being taken to mix the sand and lime well together while dry. Mixed in this proportion, it would cost about six cents per cubic foot for the lime, but quick-lime, for the wall above the line of moisture, would cost about half as much. Yet it must be remembered that flat stone usually cost about ten cents per cubic foot, or the full cost of a concrete wall.

In building a concrete wall the labor is very much less, as the help required to tend a mason will build more feet of concrete than the mason and tender both, on the common wall."

The barn and basement cost Mr. S. as follows:

For lumber..................... \$1, I67 I9

For nails, bolts, iron for gutters, hinges, \&c........ I6 I 32

For painting, glazing and n.aterials for same........ ${ }_{3} 3965$

Fot water lime.......................... go 35

For labor, including carpenter work............ 79788

For labor of farm hands, team, and board, estimated... 400 oo

Total........................... \$2,756 39

An octagon of fifty feet diameter with basement walls eight and a half feet high, is estimated by $\mathrm{Mr}$. S. to cost about $\$ 800$. 


\section{REARING CALVES.}

The question of rearing calves, when the milk of the dairy is converted into cheese, is one that frequently agitates the mind of the dairy farmer. The calf cannot be raised on whey alone. What, then, can be added to make it a good and economical substitute for milk?. There is not much left in whey but sugar and mineral matter. The sugar is useful in supporting respiration and making fat, and the mineral is useful in making bone, but there is not much in whey to make flesh. The cheesemaker takes out fourfifths of the flesh-forming matter in milk. Supply this loss with something in a form that can be easily digested, and calves can live on the resulting mixture. A good many things can be substituted for the fleshforming material in milk. The best and most convenient is oil meal; it needs only to be soaked in whey, and it is ready for use. A pound of oil meal a day, dissolved in whey, will be a good allowance for a calf three months old, and $\mathrm{i} 75$ pounds will be enough for six months. This, at $\$ 40$ a ton, will cost $\$ 3.50$.

There are other substitutes-pea meal, bean meal, wheat flour, rye flour, buckwheat flour, fine middlings, or finely ground oat and corn meal, may be used. They should be scalded, to make them easy of digestion and to prevent scouring. They are all good remedies for scouring, when cooked, and are rich in what is required to lay on flesh. Peas and beans are 
about as rich as oil meal, and may be used in the same quantity. They make an excellent substitute for the lost caseine; the flesh-forming matter, which they contain, is in a condition very similar to that of the cheesy matter in milk. They contain so much caseine that, when boiled to a paste, and properly seasoned and cured, they assume a cheesy flavor. If flour or meal is used, the quantity should be double, or a little more than double, that of oil meal, graduating the quantity to the age of the animal, and remembering that scalding is always necessary to make digestion easy and prevent scouring. Scalding the whey counteracts scouring, and improves it for feeding; but the whey must not get too sour. Oil meal is rather laxative; if it becomes too much so, its effects may be counteracted by using flour or meal in the place of a part of the oil meal; whatever is used, should be well cooked, in the form of a thin gruel. Buckwheat flour has been used in this way, with excellent effect. Pea-meal used in the same way, is highly recommended by those who have tried it. Good calves have been raised on bean soup, and also on hay tea. The tea is made by cutting the hay and steeping it in hot water; the soup, by boiling the beans until they become soft enough to mix with water, in the proportion of one pint of beans to two gallons. Calves are sometimes fattened for veal on bean porridge.

The natural food of the calf is milk, which is the most convenient and the least liable to get the calf out of health; but, when it is too costly, calves may be successfully and cheaply raised by using one or several of the foregoing named substitutes, with a little addition of care and trouble. The mode of feeding may be thus stated: Let the calf suck until 
the milk is fit to use; then taper off the use by feeding warm skimmed milk with a little whey, diminishing the milk and increasing the whey, until the milk is dispensed with, which may be done in seven or eight days. If oil meal is used, begin with a spoonful, soaked in hot water and stirred into the whey that is to be used for the day. Increase the oil meal a spoonful at a time, to balance the decrease of skimmed milk. When the milk is done with, use one pound of oil meal per day, dissolved in as much whey, or whey and water, as the calf needs for drink. Feed regularly twice a day, and always warm, until the weather becomes hot, when the temperature of the feed can be dropped a degree or two at a time, until it reaches the temperature of the atmosphere. No sudden changes should be made in the quality or condition of the feed of young calves; they will do better if they are given a clean place and afforded shelter from the scorching sun and beating storm. This will also afford some protection against sudden changes of temperature. Grood bright, early cut hay, should be provided for them as soon as three weeks old, until supplied with green grass, on which they should be gradually accustomed to rely. They should also have access to water, as they may desire, and salt should be supplied to them, either clear or in their food.

Calves raised in this way require more care and attention than when raised on milk, but when they are properly attended to, and fed without pinching or gorging, they may be made at a small cost, to reach as good a growth at six months as if fed on milk, and they will make better cows for the dairy. Heifer calves designed for the dairy should be early accus- 
tomed to the use of herbaceous food for the purpose, of giving expansion and vigor to the rumen or first and largest division of the stomach. Feeding much upon milk and concentrated food does not give so good a development of stomach, nor a power of digestion suited to an after diet of grass, as an early habit of living upon food which has considerable bulk. Hay or grass should, therefore, form as large a part of the diet of the heifer calves as it safely can and keep them growing thriftily. It has been my experience and observation for years, that calves thus raised make better cows than those which have been pampered with milk and much concentrated food.

\section{I L K.}

It is not necessary to waste words in describing the appearance of milk. Every dairyman knows well enough that it is an animal secretion common to all mammalia for the first food of their young. He is also acquainted with its physical qualities, its color, its fluidity, its nutritious and wholesome properties as food for man as well as for the young mammal for which it was by nature especially prepared. While there are many things about milk which are obvious enough, there are many other things which are not so readily apparent, and which require careful observation and attention to become acquainted with. Indeed, the study of milk is a long, and, in many respects, a 
difficult one; it has, so far, proved too difficult not only for the practical man, but even for the most critical observer. There are many things about cow's milk and its production, with which we are all in some respects so familiar, which the most careful students have not yet been able to explain or comprehend. There are so many things in regard to it which are still unknown, that I could not if I would, make a complete account of it.

In this little work I shall attempt nothing more than to point to such facts as have a practical bearing, leaving a more full and minute statement to some other hands, or for some future occasion.

The necessity for a more complete knowledge of milk by the producer, the manufacturer, the scientist and the consumer, is fully appreciated by the writer, and he hopes to go far enough, at least, to awąken an interest that will inspire an enthusiasm to go farther.

That the varied and extensive uses of milk call for an intimate acquaintance with its composition and peculiar qualities by the parties who produce, manufacture, or consume it, must be apparent. Though one may learn to work by imitation, or by following rules which the experience of himself or others may suggest, and meet with tolerable success; yet it must be evident that a full and complete understanding of all that relates to the materials to be dealt with, must give the operator many advantages which he would not otherwise be likely to make available. The better, too. the value of milk is understood, the more extensive will be its consumption, as well as the more perfect its production and manufacture; hence, the dairyman should labor with the double purpose of learning all he can himself and communicating all the knowl- 
edge he can to others, with a view to a deeper interest in the whole community, and a wider consumption of his products.

To the milk producer, the food of his cow is his raw material, and his cows the machines by which it is manufactured into an available or marketable product. To the manufacturer, milk is the raw material, which is to be wrought into a new product for increasing its value or for preservation, by means of his own labor and skill. The producer, therefore, has a lesson to learn in the production and adaptation of his raw material, and in acquainting himself with the nature and habits, and the posssibilities of his living machines, before he reaches the raw material of the manufacturer.

The production of food for the dairy embraces the soil and its management, and its adaptation takes in the varieties of food and their condition, both of which have been previously discussed and cannot be enlarged upon here.

Milk, as an agricultural and commercial product in this country, is derived from the lactiferous glands of the cow, stimulated into activity by sympathy with an active state of the generative organs developed in bringing forth her young. Milk as an animal secretion is not, however, always the result of activity of the generative function.

A moderate milk secretion may be induced in the mammary glands by manipulating them without any reference to reproduction, and before pregnancy occurs. This has many times happened with heifers by the frequent sucking of young calves, but it never occurs in quantity sufficient for prufitable production, and hence need not be specially considered. 
The milk of all animals is similarly constituted, being in every species composed of the same class of elements but in different proportions. The great bulk of them all is water. The solids in all are alike made up of supporters of respiration-fat and sugar; of flesh and tissue forming material-caseine and albumen, and of such mineral matters as enter into the bony structure.

The following table of Henry \& Chevellier, quoted by Johnston, shows how these elements vary in some of the different animals:

\begin{tabular}{|c|c|c|c|c|c|}
\hline & WOMAN. & Cow. & Ass. & GOAT. & EIVE. \\
\hline Caseine (albuminoids)... & 1.52 & $4 \cdot 4^{8}$ & $\mathrm{x} .82$ & 4.08 & 450 \\
\hline Butter.................. & 3.55 & 3. 13 & $0.1 \mathrm{I}$ & 3.32 & 420 \\
\hline Milk Sugar. & 6.50 & 4.77 & 6.08 & 5.28 & 5.00 \\
\hline Saline matter.... & 0.45 & 0.60 & 0.34 & $0.5^{8}$ & 0.68 \\
\hline Water............. & 87.98 & 87.02 & 91.68 & 86.80 & 88.62 \\
\hline
\end{tabular}

This table is supposed to show the constituents of milk from the different animals in its average normal condition.

\section{ALBUMINOIDS IN MILK.}

In cow's milk about four-fifths of the flesh-forming material is caseine and one-fifth albumen; the former is coagulable with rennet, the latter is not. The albumen, however, coagulates when heated, if the milk or whey holding it is acid. The relative proportions of caseine and albumen vary greatly with the food and health of the cow. Disease of any kind, especially when of a debilitating character, increases the per cent. of albumen and diminishes that of caseine.

In all febrile diseases the aggregate of albuminoids is increased, and the sugar and fat diminished. This 
increase of albuminoids is occasioned generally by an increase of albumen rather than of caseine. I have not yet found caseine to increase in any case of disease. The largest per cents of caseine have occurred when the animal has been full fed and in the most perfect and vigorous health, and in active habits and in comfortable condition. The per cent. of albumen is then the lowest. Albumen has been found to increase in almost every abnormal condition of the cow. Its increase is not limited to absolute disease, but it occurs in case of temporary pain, worrying, fright, solicitude, grief, or insufficient nutrition, and in all those slight deviations from perfect health which occasion tainted milk, caseine diminishes and albumen increases.

The following analysis will give an illustration of the effect upon the albuminoids of milk by a slight deviation of health. The herd of cows, fourteen in number, from which the milk came, was supported partly by grazing upon a short pasture of timothy and clover, partly by shorts wet with water, and partly by fodder corn-all good food, and enough of it to produce a liberal flow. The circumstances which affected their health were exposure to hot sunshine in a pasture without shade, and drinking water from a pond-hole. The principal cause was the stagnant watcr, but tests, several times repeated, proved that the effects were aggravated by hot sunshine. The following analysis made August 1 Sth, 1873 , is similar to several others made about the same time:

ONE HUNDRED PARTS OF MILK GAVE

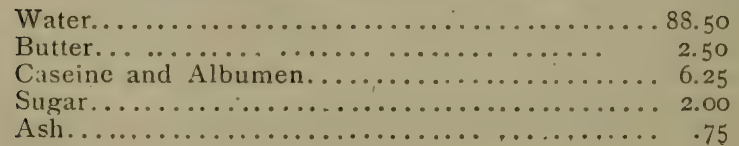


At that season of the year, with such food as these cows were using, their milk, if in perfect health, should show in roo parts :

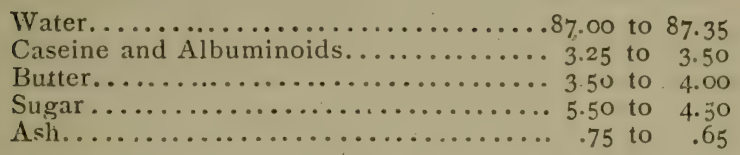

The great disproportion between the albuminoids and the butter and sugar in the milk of the affected cows, is a common result where fever and debility exist, as they did in this case, though the owner had not even suspected that his cows were at all affected.

Notwithstanding the very large amount of caseine and albumen when weighed together, samples of the milk when curdled with rennet gave no extra results in curd, and the whey when scalded with a little vinegar showed an abundance of albumen, indicating that the unusual per cent. of nitrogenous matter was albumen rather than caseine.

In a state of perfect health the variations in the albuminous matter in milk do not appear to be very great. The quantity of the milk, more than the per cent. of the nitrogenous matter, is affected when such matter is largely fed. But variations in the nitrogenous elements of the food affect the per cent. of such elements in milk within certain limits.

In conditions of perfect health, and especially in the early part of the milking season, the caseine in milk, as well as other nitrogenous matter, is in a state of complete solution and colorless, and with the sugar and mineral matter, is in chemical union with the aqueous portion of the milk. In the latter stages of milk giving, and in cases of inflammatory disease, I 
have found the caseine in a solid form in very minute and irregular shaped atoms, whose presence gires a deeper opacity to the milk. These atoms are sometimes so abundant as to settle to the bottom of the vessel in which milk stands for several hours.

\section{FATS IN MILK.}

The fats in milk are in a solid state, and are the only solid matter usually found in milk; they exist in the form of very minute globular atoms and are known as butter globules. These butter globules, or

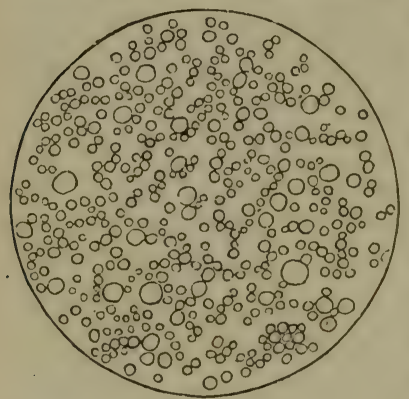

Fig. I2. as they are by some called the milk globules, are suspended in the liquid mass and float about in it freely, whitening every part with their presence. They ordinarily appear round, or egg-shaped in form, but in size they are very unequal, varying from $\frac{1}{1500}$ down to $\frac{1}{4000}$ of an inch in diameter.

When viewed under a microscope with a magnifying power of 300 diameters, newly drawn milk has the appearance represented in the annexed figure.

Upon the structure and treatment of these infinitessimal bodies, depend the dairyman's success in buttermaking, and it is therefore important that he should be as familiar with them as possible. A clear knowledge of a few leading facts in regard to them will be found more efficient in leading to desired results, than the haphazard labors and blind imitations of rules made by parties ignorant of the structure and pro- 
perties of the things they are handling, though the operators may boast of long years of experience.

Examining milk with a strong magnifier we discover that globules of fatty matter, of unequal dimensions, float mechanically in the watery mass, and further investigation has shown that these little bodies, minute as they are, are made up of atoms of several kinds of fats, in a state of combination with a little nitrogenous matter and water, the whole enclosed in a very thin pellicle of membraneous material. If the reader can imagine that the little circles which he sees in figure I2, are sectional views of the milk globules, they being divided through the center as one would cut an apple in halves with a knife, the black lines that indicate their circumference will represent a section of the pellicles or sacks, and the interior will represent the fats which they enclose. Now, let him bear in mind that the little atoms of fatty matter, thus enclosed, are composed of white and yellow fats, and several varieties of volatile oils, all mingled together, and that the real diameter of the circles is only a three-hundredth part of their size as represented in the above figure, and he will have something near a correct view of the size and structure of these little globules, which play such an important part in dairy husbandry, and which contribute so largely to the luxuries of the table, in all the civilized countries of the world.

The fatty matter which enters into the composition of these butter globules consists of four varieties. The hardest of them is stearine, which when separated, is a hard, white, flaky appearing fat. The second in consistency is palmatine, which resembles palm oil; nost of the coloring matter in butter is connected with this fat. The third is called oleine, from its thin, 
oily consistency. The fourth consists of essential oils of the food of the cow, and which, probably, are as numerous as the varieties of food she consumes. These constitute the fats of which butter is made. Their origin is not perfectly clear; they are all ultimately derived from the food of the cow, but how much of them is derived direetly from the food, and how much is elaborated in the body of the animal out of other elements of food, is not well established. Their characteristics change with the condition and quality of food, and with the constitutional peculiarities of cows. The fats from different cows living on the same food, are often quite unlike, and in the same cow, they change their color and their density with the variations in the food as to age, succulence, and abundance and scarcity of fats in it. Young food generally gives a higher flavor and color to them, than that which is mature or approaching maturity.

When in combination the specific gravity of the whole is about 940 , water being 1,000 . The several fats when separated, have not any fixed standard of specific gravity. The essential oils which enter into the composition of the globules, is of course, very light; the solid fats vary very much in their gravity. They are usually heavier in the following order: stearine, palmatine, olcine, but I have seen this order reversed.

Besides the fats and oils enclosed in the globular bodies described, the liquid mass of the milk is charged with numerous oils, so light and volatile as to escape easily by exposure to the air, or by raising the temperature of the milk. These give flavor to the milk and its products, and act an important part in the digestion of the milk when used as food, and also 
in varying the butter and cheese made from the milk that contains them. Among these volatile oils, is the one imparting the animal odor. They consist of essential oils in the food of the cow, which have not entered into the combination of fat in the globules, but remain loosely mingled with the milk.

\section{SUGAR OF MILK.}

The most weighty element in the dry solids of normal milk is sugar; it constitutes about $\frac{5}{13}$ of their weight. When separated and clarified it is perfectly white and forms into very hard crystals, much harder than those of cane or maple sugar. It is harder than any of the vegetable sugars and has less saccharine flavor.

The sugar of milk is remarkable for its very low sweetening power and for its stability. It is said when pure to undergo no change neither in a crystalline or liquid state; but as it exists in milk it is very susceptible to change, more so, probably, than any other element in milk; by absorbing oxygen it is with great rapidity and ease converted into lactic acid and is thus the cause of the sourness of milk. The rapid changes in milk and its unstable character, are due to the ease with which this sugar ferments. In Switzerland it is largely separated for commercial purposes, but in this country it is not separated, but goes as food for swine.

\section{SALINE CONSTITUENTS OF MILK.}

Like all the other solids in milk the saline constituents are very variable, ranging from two-tenths to one per cent. of its weight, the average being about seventy 
to seventy-five hundredths of one per cent. The most prominent ingredient in the ash of milk is phosphate of lime. This constitutes about one-half of the whole ash. The next largest is chloride of potassium, which amounts to about one-fourth of the ash, so that threefourths of the ash of milk, or thereabouts, are made up of these two minerals.

A cow giving 4,000 pounds of milk a year, exhausts the soil of twenty-eight to thirty pounds of mineral matter, one-half of which is phosphate of lime, and one-fourth chloride of potassium. The rest of the ash is made up of soda and chloride of sodium and the sulphates of iron and magnesia.

Prof. Jas. F. W. Johnston quotes from Haidlen two analyses of the ash of milk, which will show how milk production exhausts the soil and how to restore the exhausted minerals. The analyses are as follows:

THE ASH OF I,OOO LBS. GIVES

Phosphate of lime...................... 1bs.

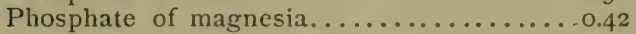

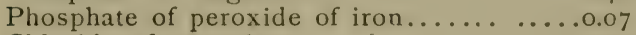

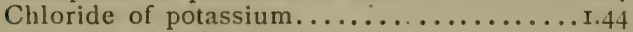

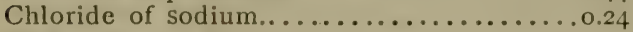

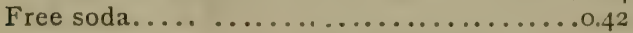

2.

3.44 lbs.

o 64 “"

007

1.83

0.34

0.45

\section{MILK SECRETION.}

As the form of a tool is indicative of the purpose it was made to serve, so the anatomical structure of an organ in an animal body affords an evidence of the function it was made to execute. The study of the udder therefore is one of the most direct and efficient means of studying the way in which the secretion of milk is effected. I shall not assume the task of unraveling all the mysteries of milk secretion, but having given some attention to the structure of the 
udder, I shall venture a few observations descriptive of that organ, in hopes that what has proved very interesting to me, may at least afford something of interest to others.

The extraordinary development of the mammary glands upon the domestic cow, is to a large extent, the work of art, since nature furnished only enough with which to elaborate food for the offspring. As art does not always use precisely the same means, it does not always lead in precisely the same direction with its developments. The irregularity of art shows itself in the development of the bovine udder. It is not always uniform, externally nor internally. It is not only different upon different breeds of cows, but it varies in different individuals of the same breed, and the corresponding parts of the same udder are not always uniform.

For the sake of giving actuality to the description, I will describe an udder taken from a choice six year old cow, four weeks from the time of calving, and in as good a condition as it could well be for examination.

Considered as a whole it was made up of four distinct glands or lobes, one for each teat, bound together by membraneous tissue, and covered by a pouch of skin in which it seemed to be suspended, and to which it was snugly bound by the same kind of tissue which attached the lobes together, and also by nerves, blood vessels, and minute tubes and tendons. While membraneous tissue surrounds the whole, each lobe has an envelope of its own, which is attached to the others where it comes in contact with them.

An arterial branch of considerable size entered each Iobe, and also several smaller ones, the origin of which was not traced, by which each quarter was sup- 
plied with blood. So far as traced, the arterial branches were neither uniform in size nor in their mode of division nor subdivision. There was an evident difference in the quantity of blood supplied to each quarter of the udder, and especially between the front and back lobes, and also between the two back

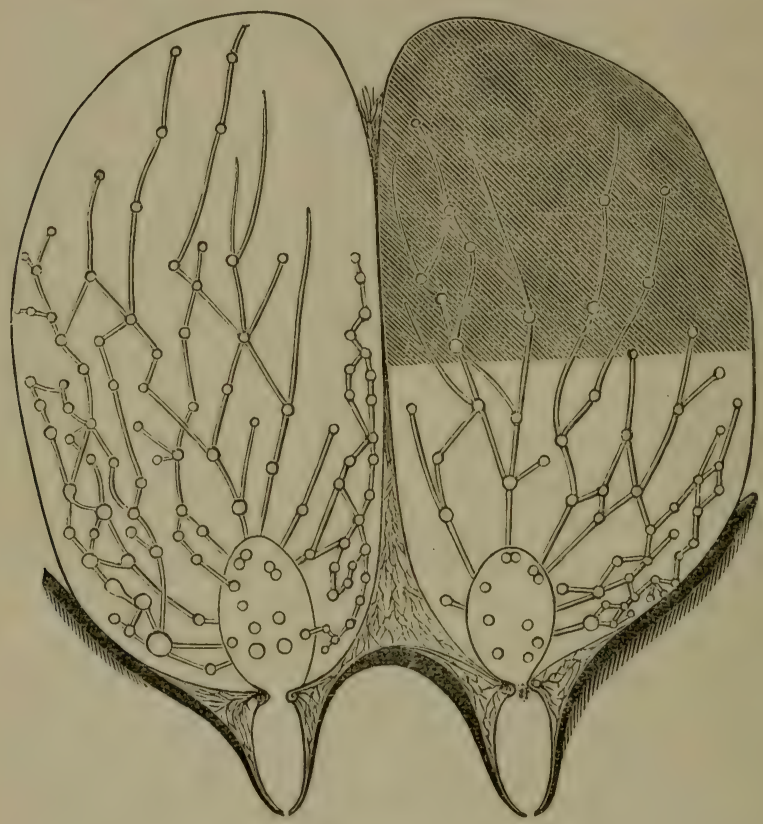

Fig. 13.

lobes. But few observations were made upon the venous system of this specimen. The lactiferous vessels" were more carefully observed. In each quarter of the udder these were entirely separated from each other, and in each were differently arranged. 
Beginning at the lower end of the teats we have an aperture closed by an elastic band. Proceeding up the teat, we have in it a cavity enlarged in the middle, when injected, as seen in figure 13. At the top of three of the teats there was a diaphragm separating the cavity in each teat from a little larger cavity above it, with a hole in the middle of the diaphragm about the size of a pea. The cavities above the teats answered as little reservoirs for holding milk. That over the right hand teat, when distended, was about the size and shape of a turkey's egg with the large end down. Those of the front teats were the size and form of a hen's egg. Over the left hind teat the diaphragm was wanting, and the cavity above opened directly into that of the teat as shown in figure $\mathrm{I} 4$.

From the little reservoirs at the top of the teats were tubes running in different directions through each gland, which were frequently cut off by still smaller reservoirs distributed all through each gland, as indicated in fig. I2. These little reservoirs were more abundant, and larger in the lower and outer

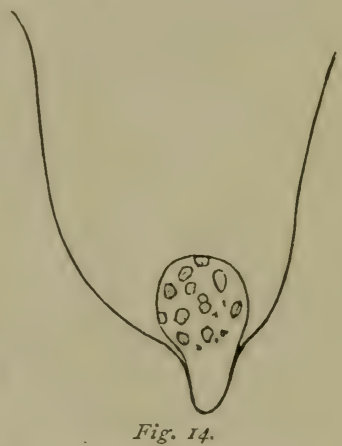
parts of each lobe, diminishing in size and frequency as they rose toward the upper part. They varied in size from a hickory nut to a pin head. There was but a single one the size of a hickory nut, the majority of them were of the size of beans or peas and so down, till they disappeared in the upper part of the udder.

The tubes which connect the reservoirs were, some of them, larger in the middle than toward the ends, 
and by connecting with different reservoirs, anastomosed like blood vessels. At each end of the tubes, where they enter and where they leave the reservoirs, is a diaphragm similar to those at the top of the teats, which stretches over a part of each end of the tube, leaving, as over the teats, a hole in the middle. The diaphragms at the top of the teats and at the ends of the lactiferous tubes are all alike made by an extension of the mucous membrane lining the inside of the tube. Where it doubles over to form the edge of the aperture, it encloses a small cord which swells out the folds a little, giving the appearance of a hem running around the edge of the aperture. The contraction of this cord closes the aperture. It is a very delicate thread. It is made up, not of fleshy fibers like ordinary muscle, but of very fine elastic fiber-like spiders' webs, so fine that five hundred of them were judged to form one of these little threads. In the center of the udder and between the four glands is a large and strong tendon leading from the abdominal muscles and passing down between the four glands or lobes, where it soon divides up into branches like the brush of broom corn, which again divides and subdivides till the threads become too fine to follow with the unaided eye.

These ramifications connect with the little cords just described and which appear to be terminations of the filaments of the tendon passing around the apertures in opposite directions, so that when the cow contracts the abdominal muscles by drawing up her abdomen as she always does when she holds up her milk, she pulls on these ramifications and closes all the apertures with one effort, and prevents the milk from flowing. It is in this way that cows 
hold up their milk at will. When the abdominal muscles are contracted the tubes begin to close, first in the upper part of the bag where the apertures in the diaphragms at the ends of the tubes are very small; a more vigorous effort closes the larger ones below, the last ones to close because the largest are those at the upper end of the teats. It requires a powerful effort to draw these so tight that milk will not pass through them, but when much disturbed, there are but few cows which are not able to close them perfectly.

The minute filaments of this central tendon have attachments elsewhere than in the fibrous cords. They fasten all through the udder and in the skin, so that in holding back her milk, the whole udder is contracted and held firmly. These filamentary divisions were so extremely fine and difficult to trace that they could only be followed by dissolving away the soft parts with an acid.

In each quarter of the udder the system of tubes were found to divide and subdivide each in a different way, so that when dissected out they were as unlike as the divisions and subdivisions of the branches of so many different trees. They all alike start from, or empty into, the reservoirs over the teats, but the number of tubes starting out were in each case different and differently located. Twenty-three tubes led out of the reservoir at the top of one hind teat, and seventeen out of the other; twenty-one started from over one forward teat, from the other side the number was less and differently arranged, showing an independent and special action in each division so far as secretions were concerned.

The bulk of the udder is made up of a mass of cells and vascular membranes, through which the lactiferous 


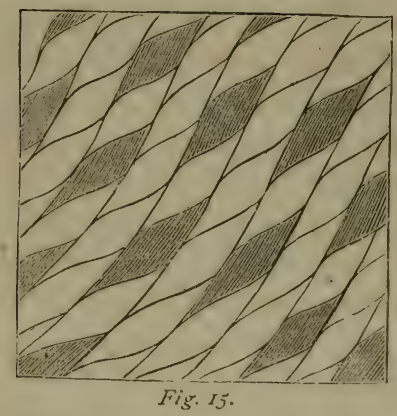

tubes penetrate. In the upper part of the glands where the structure was less disturbed with reservoirs than below, the arrangement into lobules was quite regular as in figure ${ }^{5}$, which gives a magnified view.

Into these lobules the lactiferous tubes ramify with

great minuteness to take up the milk which the glands secrete. Magnifying one of these lobulated divisions till the ultimate follicles could be seen, we have a view as seen in figure 16 . The follicles are covered with a membrane, the cells appearing upon the inside of it from which they seemed to emanate. The investigations and opinions advanced by Dr. E. L. Sturtevant, of Mass., have been very fully sustained in these examinations of the ultimate follicles which at twenty-eight days from the time the cow came in were in the best possible condition for studying. The gland cells, as he suggests,

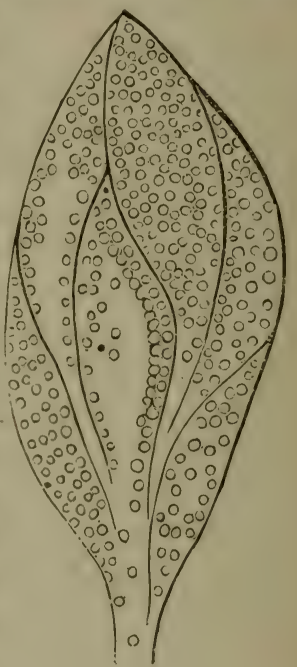

Fig. 16 . appear to start out of the inside of the membrane like blisters, whose contents are fat. Others follow behind them in succession, crowding them along, till the first formed separate and are shed off like leaves in autumn, or as sucking teeth give place to those which come after them. 
The liberated cells, completely enveloping a speck of fat, find their way out of the follicle through the vascular membrane which connects it with the minute terminations of the lactiferous tubes, where by the aid of the liquid part of the milk they are worked along through the system of tubes and reservoirs, till they pass out at the teat in the form of what are differently known as milk globules, cream globules, fat globules, and butter globules.

When not filled with secretions the interior cavities of the follicles collapse and make the substance of the gland appear like a solid mass, but when cut into thin slices and highly magnified, it appears extremely vascular and exposes a great extent of surface. It then appears like a net work, or sieve, through which liquids could pass with great freedom. The secretion of the liquid portion of the milk evidently proceeds very slowly, but the yast extent of surfaces it has to exude from, enables the udder, as a whole, to collect considerable quantities in a given time

That the milk globules were once gland cells, is corroborated, first, by the fact that they have the same size; this was demonstrated by Dr. Sturtevant by actual measurement. Second, they have the same form; when viewing them under circumstances which would exhibit their exact form, I have found them to be alike, neither of them being exactly round. Third, the covering of the globule is a membrane, and not caseine, as many have supposed; that it is a membrane is shown by the fact, that when treated with nitrate of silver the globules give the same reaction which is given by other membranes, embracing fat, (suet,) turning them to straw color. Caseine, when treated with nitrate of silver gives a 
different reaction ${ }_{2}$ turning black. Fourth, while it has been supposed by some, that specks of fat when floating in the liquid milk in which albumen and caseine are in solution, become coated over with solidified caseine and thus derive their delicate covering, others have supposed that the minute particles of fat become incisted while in the blood vessels, and that they áre secreted from the blood ready formed. The fact that milk globules sometimes exist without containing any fat is a sufficient refutation of both of these theories. I have found that instances occur in which a part of the milk globules contained only serum so attenuated, that when dried down, the walls of the pellicle enclosing it would collapse and appear perfectly flattened, while others retained their rounded form, showing them to be filled with fat. In an extreme case the milk of a cow which would not make butter, had part of its globules filled with fat so that they remained round when dried, others with various degrees of depression, but fully one-half appeared to contain no fat at all, as they were perfectly flattened by drying. In several cases the pellicles covering the serum became adherent and shrunk and tore apart in

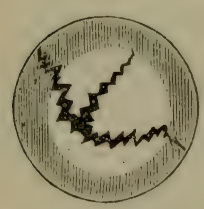

Fig. $I 7$. the middle from the edges sticking to the glass, showing various fractures. An enlarged view of one of these fractures is shown in figure $\mathrm{I} 7$.

By examining milk with the early morning sun and turning the reflector so that the globules would cast no shadow, I have been able to use a stronger light and get better views than I could with the mid.day light. Under this mode of inspecting, several cases have been met with in which a part of the globules showed no fat, while 
others showed to be part full, and the great bulk of them entirely full of fat. Though the gland cells of the udder are generally filled with fat, it would seem a very easy matter for some of them, under peculiar circumstances, to form without fat, and hence account for the occurrence of fatless globules in milk if the cells at length become globules, and it would be difficult to account for them in any other way.

\section{COLUSTRUM.}

In the latter part of the period of gestation, by reason of a sympathetic influence exerted upon the udder, the blood vessels leading to and from it begin to enlarge, and the circulation in it to become more active, and assimilation more rapid, its whole structure becomes increased in size, and its vessels engorged with blood. The result of this unusual activity is increased heat, and presently the formation of gland cells. These begin to form in the follicles, to the sides of which they remain attached, as in A, fig. I8.

At birth, or a little before, the liquid part of milk begins to be secreted, holding sugar, caseine, albumen, and

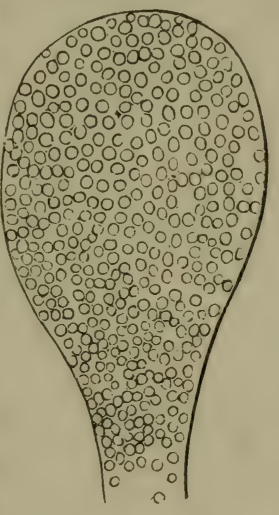

$B$

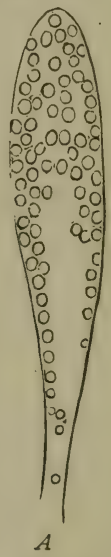

Fig. I8. A certain mineral matters in solution, and to accumulate in the udder, when the gland cells begin to shed off, sparingly in heifers, but more freely in older cows. At first the cells appear to break off very fre- 
quently in clusters, peeling off some of the membrane of the follicle with them, as shown in figures 19 and 20, which are fac similes of the first milking of the cow whose udder has just been described. They were drawn by the aid of a camera and accurately engraved; they show some large and many irregular pieces of membrane, with more or less cells attached, which,

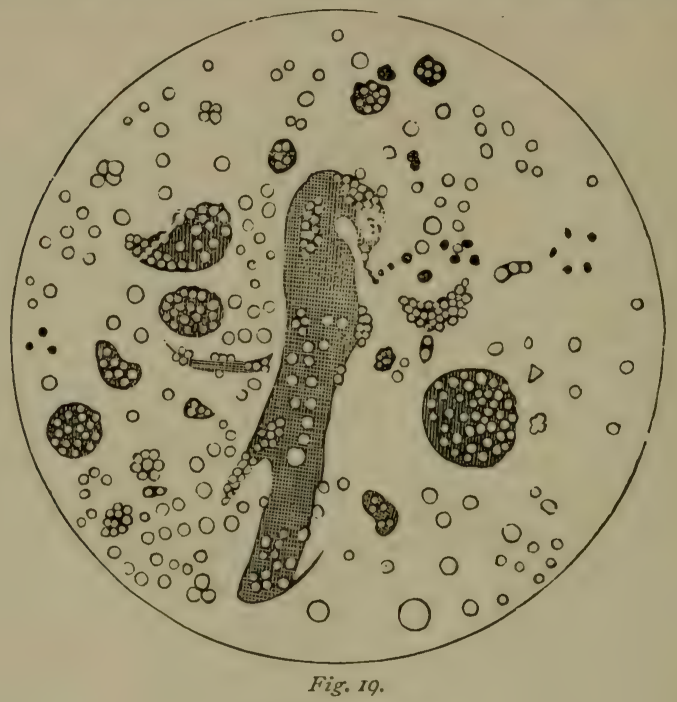

COLUSTRUM.

from the feverish condition of the bag at that season, sloughed off with the cells before they fully became milk globules. As the inflammation abates and the action becomes more regular, the membrane disappears, and the cells only are mingled in the milk. When these clusters no longer appear, the milk is considered fit for human use, or for manufacture into butter or cheese. Some dairymen are in the habit of 
saving the fifth milking; it is sometimes good, but oftener not. I give an illustration of the fifth milking of this cow. fig. $2 \mathrm{r}$, which seemed to be full as well as cows generally are at this time, in which specks of colustrum are seen. It often requires five or six, or more days, before they entirely disappear, according to the health of the cow and the extent of inflammation in

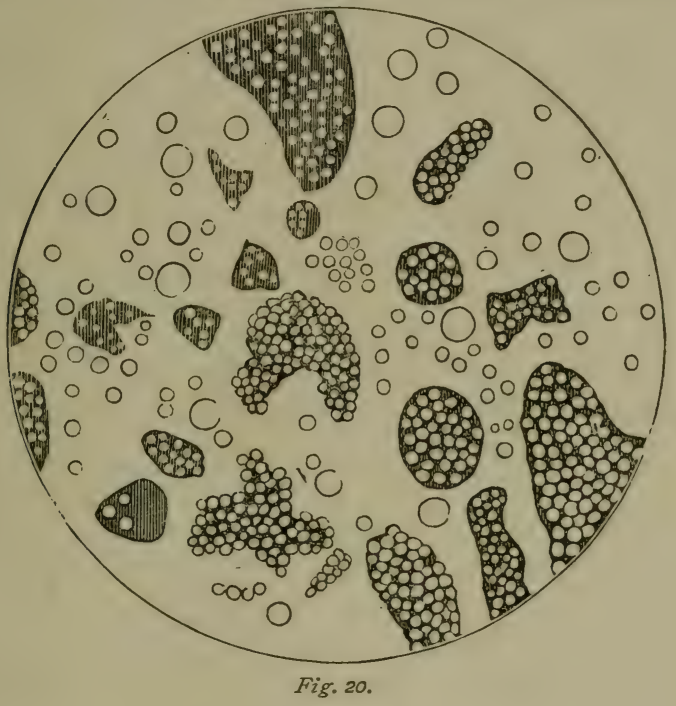

- COLUSTRUM.

the udder. When the milk will boil without curding, it may be regarded as fit for use. This is an efficient and convenient test of fitness for use.

The analyses of colustrum vary very widely in their per cents of fat as twell as other elements These differences are doubtless owing more to the particular condition of the udder at the time of coming in, than to any other cause. 
The treatment of the cow, at and previous to the birth of her offsping, has very much to do with the condition of her udder and the quality of her first milk. There can hardly be a doubt that an abundance of fat in the blood, stimulates the formation and multiplication of gland cclls, and hence milk globules, and that a paucity of fat diminishes the extent of their

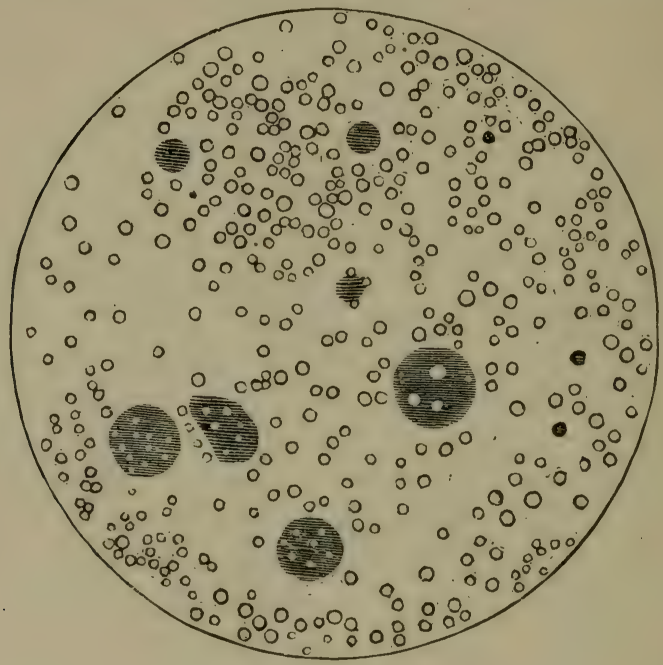

Fig. 21 .

FIFTH MILKING.

formation. It has been my observation for years, that where cows are fed chiefly on unstimulating and fleshforming food before coming in, such as clover hay, pea meal, bran or shorts, the bag remains pliable and soft, and if the milk is drawn out in season, there is not 'a very wide difference between the first milk and that which comes afterward. But if corn meal, oil meal, cotton seed meal, or other food, very rich in fat, 
enters freely into the diet of cows before calving, their bags swell up to a very large size and are hard and inflamed, the follicles become distended as in B, figure I 8 , because of the greatly increased number of cells which the rich food has stimulated while they are still adhering, and they become hard and inflamed, and it is difficult to reduce the inflammation afterward; the colustrum is high colored and thick, and full of cells with pieces of membrane attached, and they continuc in the milk for a long time. It is not very uncommon for cases of garget, which ruin a part or the whole of the udder, to follow high feeding with food too rich in fat, before cows come in, especially in young heifers.

The feed before coming in should be generous and nutritious, but it should abound in flesh-forming rather than in fat-forming elements. Early cut clover is one of the best things I have fed at such times, and corn meal and oil meal have proved the most dangerous. After cows have been in milk awhile and their bags have become reduced, corn meal and similar food may be fed with altogether different results. The fat then goes rapidly into the milk, avoiding the accumulation of cells in the udder and the inflammation which would otherwise follow. Previous to birth the same food would accumulate fat in the gland cells, swelling out and crowding the follicles as at $\mathrm{B}$, in figure $\mathrm{I} 8$, because at this time the cells, though forming rapialy, are not shed.

\section{CHANGES IY THE QUALITY OF MILK.}

Colustrum is the result, in part, of inflammation in the udder, and may occur at any time during the milking season, but is less likely to occur in the later than in the earlier stages of giving milk. When after 
parturition the inflammation has died away and the globules float singly and freely in the milk, it may then be said to have assumed its normal condition; but the quality of milk does not remain stationary, it is constantly varying from the time a cow comes in till the milk ceases to flow. At first, or so long as the quantity continues to increase, as it usually does for a few weeks after coming in, the per cent. of water increases, and that of cream and caseine diminishes, though the aggregate products are, by reason of the increased quantity, constantly enlarging. When the flow begins to diminish, the quality begins to improve, and it continues to grow richer till near the close of the milking season, when it again begins to depreciate, when the cow dries up before coming in again. The globules vary in size, diminishing as the distance from the time of calving increases, or rather as the amount of secretion diminishes, for if by an abundance of rich food the flow can be kept up, the globules may retain their size.

The quality of milk varies with the quality and supply of food; if it is very succulent the water increases in the milk, but the increase of water cannot go beyond a certain limit, 90.5 water and 9.5 solids is the extreme limit I have met with by succulence and moisture in the food. On the other hand, by the use of food rich in the elements of milk and other circum. stances favorable, the extreme limit in the opposite direction has been 81.5 water and 18.5 solids. The former occurred in June, with a feed of grass and brewer's grains, the latter in the fall with after feed and meal.

The aggregate results of cheese and butter factories demnnstrate this rule on a large scale. When cows 
come in in the spring, the product, whether butter or cheese, from $\mathrm{r}, 000$ pounds of milk, varies during the season, as indicated by the following tables which are the result of different factories in different years:

Two factories, reported in I868, by Asahel Burnham, of Sinclearville, Chautauqua Co., N. Y.

\begin{tabular}{|c|c|c|c|}
\hline - I868. & MILK. & CHEESE. & $\begin{array}{l}\text { NO. LBS. MILK } \\
\text { FOR } \\
\text { I OF CHEESE. }\end{array}$ \\
\hline 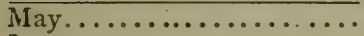 & 227,276 & 24,058 & 9.44 \\
\hline 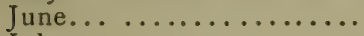 & 481,648 & 49,919 & 9.65 \\
\hline July................... & 529,406 & 50444 & I0. 49 \\
\hline August....... $\ldots . .$. & 398,285 & 39,903 & $9.9^{8}$ \\
\hline September............... & 232,840 & 26,762 & 8.70 \\
\hline October............... & 100,132 & I $2,48 \mathrm{I}$ & 8.02 \\
\hline
\end{tabular}

\begin{tabular}{|c|c|c|c|}
\hline I868. & MILK. & CHEESE. & $\begin{array}{c}\text { NO. LBS. MILK } \\
\text { FOR } \\
\text { I OF CHEESE. }\end{array}$ \\
\hline 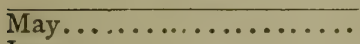 & $3 \mathrm{II}, \mathrm{IOI}$ & $32,55 \mathrm{I}$ & 9.55 \\
\hline 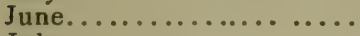 & 616.791 & 63,867 & 9.66 \\
\hline July.................. & $633, \mathrm{OS} 2$ & 60,712 & 10.42 \\
\hline 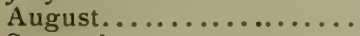 & $472.6 \mathrm{Ng}$ & 47,769 & 9. 9 \\
\hline September.............. & 323.603 & 37,333 & 8.72 \\
\hline 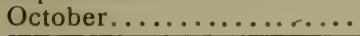 & I26,895 & 16,116 & 786 \\
\hline
\end{tabular}

Cold Spring Factory, Whitewater, Wis., in 1870 , reported by $\mathrm{R}$. Wheeler.

\begin{tabular}{|c|c|c|c|}
\hline 1870. & $\begin{array}{c}\text { NO. LISS. } \\
\text { MILK } \\
\text { RE':EIVED. }\end{array}$ & $\begin{array}{l}\text { NO. LBS. } \\
\text { CHEESE } \\
\text { MADE. }\end{array}$ & $\begin{array}{l}\text { NO. LBS. MILK } \\
\text { TO I LB. } \\
\text { CHEESE. }\end{array}$ \\
\hline 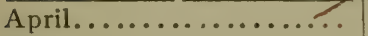 & $8,8 I I$ & 850 & I0.36 \\
\hline 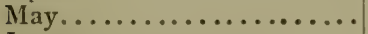 & 53,417 & 5,650 & $9 \cdot 45$ \\
\hline 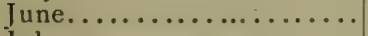 & 75.010 & $7.740^{\circ}$ & 9.69 \\
\hline 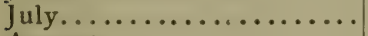 & 79,251 & 7,960 & 9.95 \\
\hline 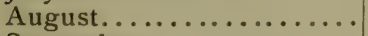 & 70,788 & 7.164 & 9.88 \\
\hline 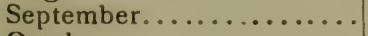 & $59, I_{3}$ & 6,127 & 964 \\
\hline 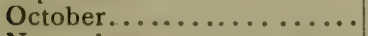 & 41,237 & 5,032 & 8.29 \\
\hline November............... & 4,297 & 588 & $7 \cdot 30$ \\
\hline
\end{tabular}


Brook's Creamery, Little Valley, Cattaraugus Co., N. Y. for I871, reported in the Live Stock. Journal:

\begin{tabular}{|c|c|c|c|}
\hline I 87 I. & $\begin{array}{l}\text { LBS. } \\
\text { MILK. }\end{array}$ & $\begin{array}{l}\text { LBS. OF } \\
\text { PRUDUCT. }\end{array}$ & $\begin{array}{l}\text { LBL. OF MILK } \\
\text { FOR I OF } \\
\text { PROICT. }\end{array}$ \\
\hline 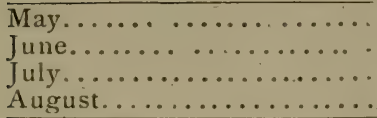 & $\begin{array}{l}I 06,43 I \\
298,263 \\
261,652 \\
168,948\end{array}$ & $\begin{array}{l}11,124 \\
32399 \\
27,567 \\
17,584\end{array}$ & $\begin{array}{l}9.567 \\
9.206 \\
9.960 \\
9.609\end{array}$ \\
\hline
\end{tabular}

The Sulphur Spring Factory, Lowville, Lewis Co., N. Y., as reported by C. L. Sheldon, for $187 \mathrm{I}$, shows the following in the different months:

\begin{tabular}{|c|c|c|c|}
\hline I87I. & $\begin{array}{l}\text { Ll3S. } \\
\text { MILK. }\end{array}$ & $\begin{array}{c}\text { I.BS. } \\
\text { CHEESE. }\end{array}$ & $\begin{array}{l}\text { LBS. MI'KFOR } \\
\text { I LB. CURED } \\
\text { CHEESE. }\end{array}$ \\
\hline 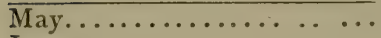 & 245,790 & 25,466 & $9.65 I$ \\
\hline 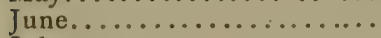 & 390,796 & $39,78+$ & 9.822 \\
\hline July....... & $328 ; 994$ & $3 J, 935$ & $10.30 \mathrm{I}$ \\
\hline August..... & 227,396 & 22,408 & I0. 147 \\
\hline September... & I 75,590 & I9,954 & 9.215 \\
\hline 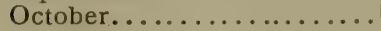 & I 32, I 4 I & 15,466 & 8.543 \\
\hline
\end{tabular}

The factory of J. D. Ires, in Norway, N. Y., as reported by B. B. Moon, maker, for $\mathrm{i} 87^{2}$

\begin{tabular}{|c|c|c|c|c|}
\hline I872. & $\left|\begin{array}{c}\text { POUNDS } \\
\text { OF } \\
\text { MILK. }\end{array}\right|$ & $\mid \begin{array}{c}\text { POUNIOS } \\
\text { OF } \\
\text { CHEESE. }\end{array}$ & $\begin{array}{l}\text { LBS. MILI } \\
\text { TO I LB. } \\
\text { CHEFSE. }\end{array}$ & - \\
\hline March.......... & 32,479 & 2,668 & II. 73 & Skim milk. \\
\hline April........... & $123.6 \mathrm{II}$ & I I , 288 & 10.95 & One mess skimmed. \\
\hline May............ & 306,737 & $3 I, 493$ & 9.42 & Whole milk. \\
\hline June............ & 502,910 & 52,256 & 9.63 & do \\
\hline July............. & 477,246 & 48, I 26 & $9.9 \mathrm{I}$ & do \\
\hline August.......... & 396,862 & $4 \mathrm{~T}, 620$ & 953 & do \\
\hline September....... & 340,339 & 37,890 & $8.9^{3}$ & do \\
\hline Uct. to Nov. 9...: & 305,026 & 36.184 & 8.52 & One mess sliimmed. \\
\hline Nov. Io to Dec. I 4 & 52,017 & 6,404 & 8. 12 & do do \\
\hline
\end{tabular}

The variations of milk through the season are different, according to the condition and feed of the cows. The milk of cows having insufficient food or 
of poor quality, not only give less milk, but what they do give is poorer in quality than the milk of cows well fed. The difference in quality caused by difference in feed, is much wider than dairymen are apt to suspect, and it often amounts to great injustice in the division of the proceeds of factories.

In testing the milk of the different patrons of a fictory by curding equal weights of their milk, and drying and weighing the curd, I have found the milk from one dairy to make 27 per cent. more curd than the same quantity of milk from another dairy delivered the same day, both being sound and pure.

Ten to fifteen per cent. in the value of milk for cheese making is a very common difference in the latter part of the season, a difference due wholly to quality and supply of feed. The wide variations which occur from this cause should be more carefully studied by dairymen, and some more exact mode of apportioning the proceeds of factories be devised. The least injury done to the patrons by way of watering milk or skimming, or saving out strippings, will receive the most prompt attention and punishment, whenever detected, and a most watchful care is always on the alert to guard against unjust loss in any of these ways; but one patron may bring milk which will make fifteen per cent. less cheese than that of another, and yet they divide equally and without complaint or suspicion of anything wrong. If the present inequality in the value of milk, especially for cheesemaking were fully understood, it would not long be tolerated. The remedy is easy as will be shown in another place.

Other circumstances than those of feed affect the quality of milk; pregnancy is one of these circum- 
stances. Of two cows giving milk alike at the start and continuing alike in respect to food and other conditions, except that one becomes pregnant and the other not, the one becoming with calf will soon begin to fail in the quality of her milk as compared with the farrow cow, and the further advanced in the period of gestation, the wider will be the difference in their milk. The milk of spayed cows is least affected by distance from the time of coming in. But whatever may be the situation of the cow, her milk will fail after a time. In a few exceptional cases, cows continue to give milk continually for a series of years, whether breeding or not.

The milk producing function is brought into activity from an extraordinary amount of blood driven into the udder by an enlargement of the arteries leading to it, the enlargement being occasioned by a sympathetic influence from the active state of the reproductive organs. The increased size of the arteries being due to certain conditions, it is reasonable to expect that when the conditions have ceased to exist, the arteries would gradually fall back to their former size and activity, or nearly so, and this they do unless means are used to prolong their expansion and activity. As time advances, the stimulus being removed, the arteries by degrees diminish in size, and the supply of blood to the udder becomes less and less, till finally, it falls back to its normal standard, and the flow of milk keeps pace with this influx of blood, and the cow dries of her milk when the extra influx ceases.

But the contraction of the arteries leading to the udder is in a measure under the control of the dairyman; he can retard or hasten it at will. By causing the milk to be frequently removed from the udder he 
creates, as it were, a vacuum into which the pressure of blood in the arteries drives forward the newly forming milk to fill. The reaction of pressure in the milk tubes upon the arteries which supply the blood from which to elaborate milk to fill them when exhausted, is both direct and large. So directly are the milk tubes and arteries connected, that by injecting onequarter of an udder with water and subjecting it to strong hydrostatic pressure, I have been able to drive water through the milk tubes into the arteries so rapidly as to make it drip in a stream from the main artery supplying that quarter of the bag with blowd. The direct effect of relieving or not relieving the milk tubes of their contents is to hasten or retard the passage of blood toward the udder, keeping up their expansion by an active passage of blood in one case, and allowing of contraction in the other, by retarding the motion and diminishing the quantity of blood passing through them.

Frequent, perfect, and regular milking is, therefore, a very efficient means of promoting the flow of milk and preventing change in its quality, for so long as a large flow can be maintained so long will it maintain its earlier characteristics.

The secretion of milk has a tendency to diminish the volume of blood by drawing both upon its liquid and solid elements. To keep up a flow of milk, this draft must be supplied by furnishing enough to restore the steady waste. A failure to do this for any considerable time, is not only to decrease the yield of misk during the lack of food, but to invite a hurried contraction of the blood vessels connected with the udder. These once reduced, there is no enlarging them again till the occasion of another birth, and the supply of 
blood for making milk will be diminished to their reduced capacity, keeping down the flow permanently and shortening the time of its final cessation.

Immense losses are sustained every year by dairymen from not comprehending this fact with sufficient clearness. A lack of fecd in the midsummer drought where shrinking has already begun, hurries the shrinking along; lasting several weeks, the reduction becomes permanent, and must remain the rest of the season. No after feeding can restore the former activity of the glands, for the vessels supplying them with blood have become reduced. The great value of soiling, when grass fails, lies in keeping up and prolonging the action of the mammary glands. The dairyman who appreciates this will never let lis milch cows lack for food or drink.

An instance will illustrate the effect of a defective supply of food upon the milk-secreting vessels. In visiting the farm of the Hon. Ifarris Lewis, in the fall of I $S_{73}$, I found his cows, after the severe drought of that summer, giving an arerage of twenty-two pounds of milk a day; his heifers and farrow cows giving thirteen pounds a day, and his other cows twenty-four pounds each. Though the rains had come and the grass had revived, the average at the factories around him, where soiling had not been adopted, was thirteen pounds to the cow-just equal to Mr. L.'s heifers and farrow cows. The soiling more than paid for the cost in the dry season, and in the fall the large yield gave larger profits. But many dairymen complained that year that their cows did not pay for their keeping. The reader may possibly see why.

Variations in the quality of milk during the main part of the milking season are gradual, and for the 
most part can only be noticed by comparing milk at periods remote from each otlier. When such comparisons are made it will be found that the liquid part of the milk becomes less and less transparent, till toward the close of a long period of milk-giving, it becomes only translucent, and more or less of the caseine becomes solid and remains in minute particles

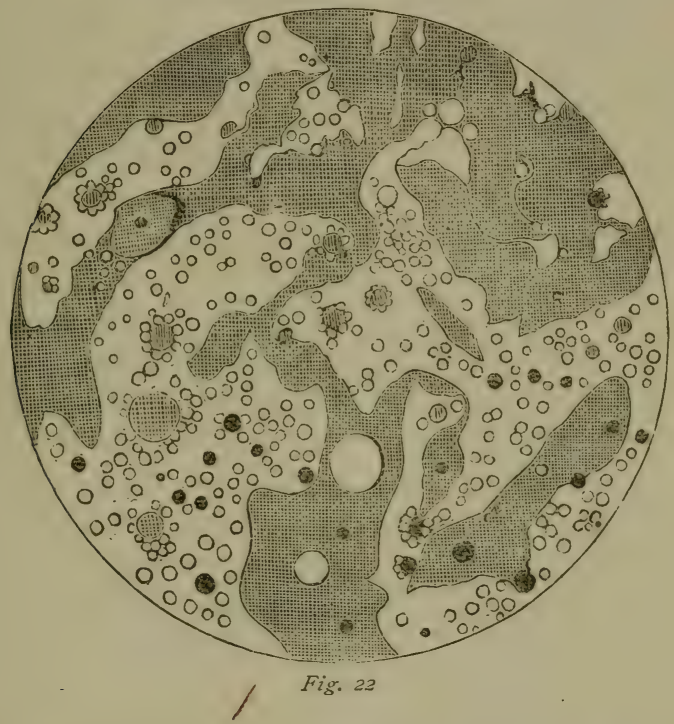

suspended in the liquid like milk globules, but which upon standing, tend downward instead of upward. Opacity is also increased by a change in the condition of the fats and sugar. A part of the fats and probably the sugar, appear as glycerides, preventing the formation of the butter. At this time it assumes a somewhat gelatinous appearance, and something of an elastic consistency, so that it does not spread well 
upon the glass, but draws itself up into bunches, as in figure 22, which is a view of milk near the time of drying up, and which would not make butter. The globules were scanty and very small. Though perfectly sweet when freshly drawn, it contained many particles of solid caseine, and was full of cloudy streaks, more or less dark, but not so dark as the figure indicates.

The quality of milk is affected by the frequency or remoteness of the times of milking. In trials of milking once, twice, three times and five times a day, the most frequent milking gave the richest milk. Milking every twelve hours, gave $12 \mathrm{I} / 2$ per cent. cream; milking once in three hours, gave $171 / 2$ per cent.

The difference in the quality which may sometimes be observed between the morning's and evening's mess, is chiefly due to unequal distance of time between milking-the milk being richer at night when the days are short, and richer in the morning when the nights are short. When the times between milkings are equal, the yield and quality have proved to be similar. A difference sometimes occurs where cows are more comfortable and quiet during the night than during the day, or the reverse, as when suffering by cold in winter, or by flies in summer, when more and richer milk follows the greater comfort.

There is a well known difference between the first and last part of a milking. This is generally but erroneously supposed to be due to the rising of the richer part of the milk to the top of the udder; but no such circumstance could occur. All the motion milk is susceptible of in the udder, is from the follicles forward towards the teats. It can not possibly move from the teats backward toward the follicles or ramification of the lactiferous tubes. As has been already mentioned 
the ends of the milk tubes, where they connect with the little reservoirs, are capped with diaphragms. These, except at milking time, are kept constantly closed, so that milk, as it comes from the extremities of the tubes, can only pass into the reservoirs with which they connect, by being pushed along by the milk that is forming behind it. The theory, therefore, that cream rises in the udder must be entirely fallacious. It is confuted also by the fact that woman's milk, in this respect, exhibits the same peculiarity as cow's milk, the last being the richest; but if the cream could rise in the gland the last ought to be the poorest.

The difference between the first and last part of a milking must have some other origin than that of the separation of the cream by rising.

In the udder which has been described, the gland cells in the upper part were larger than those in the lower part, indicating that the richest part of the milk was secreted there, and as this would naturally be the last to come out, it would seem to account, in part at least, for the greater richness of the last part of the milking; but as no other udder has, that I am aware of, been examined with reference to this difference in its cells, it would be unsafe to make a general inference from this one case, though it is quite likely a general fact.

Again, milk loses in quality by absorption while lying in the udder. That milk loses considerable from this cause, is evident from the fact, that when the flow is small it is all taken up in this way. Judging from the rough and jagged appearance of the globules which have lain long in the bag, the cream, especially, appears to suffer, but just to what extent it loses in this way, it is not easy to determine. 
Thirdly, it must be evident that the milk globules, being.solids, would meet with more resistance and make less progress, in passing through fine tubes, whose sides collapse, or lie against each other, than the purely liquid part of the milk would, and hence that they would fall behind the liquid portions of the milk in their journeys toward the teats. The larger globules would meet with more resistance and come forward slower than the smailer ones, and hence come out last, making the last part of a mess the best as well as the richest. Dr. Sturtevant thinks this cause sufficient to account for all the difference between the first and last part of the milking, and it certainly could not fail to make a very wide difference.

\section{MILK AFFECTED BY BREED.}

It is rare, if not impossible, to find two cows in any herd whose milk will be exactly alike. Each animal has a constitution peculiar to itself, and the milk secretion is moulded, in each case, by that constitution. There can be no doubt that all the elements of milk are modified by the constitutional peculiarities of the case, but observations have yet been almost exclusively confined to the fats, and these even have been but little investigated: Cows having similar constitutions give milk similar in quality, hence the milk of a breed has an approximate uniformity in its characteristics. Thus in the milk of Jersey and Deron cows generally, the fat is deeply colored and abundant, and the globules are very large and comparatively uniform in size. Figure 23 is an illustration of average Jersey milk, in which it will be seen that the globules are large with but few small ones. 
Dr. Sturtevant was the first to call attention to the size of butter globules in different breeds, and to him I am indebted for figures 23,24 and 25 .
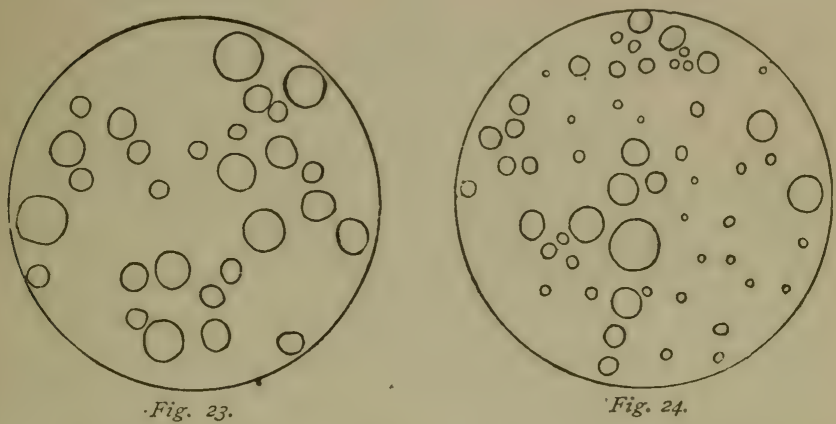

The flavor of Jersey butter is as characteristic as the appearance of its butter globules, and that of the Devons scarcely less so. In the milk of Ayrshire cows the globules are smaller, and in size unequal, a circumstance which is also quite common in the milk of native cows. For view of Ayrshire milk, see figure 24 . For view of Holstein or Dutch milk, see figure 25 , in which the globules are small and remarkably even in size, a striking peculiarity in the milk of the Dutch cow. The butter from this breed of cows has specific qualities;

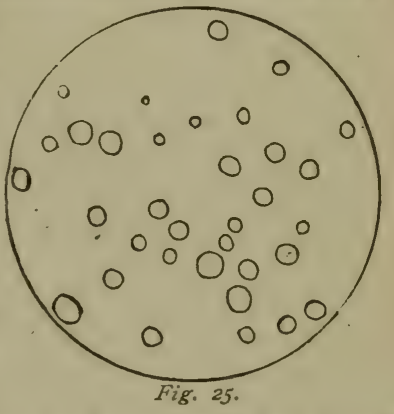
it is neither high flavored nor high colored, but is of good quality and remarkable for its long keeping. The milk of this breed is well stored with fat, and is the richest in cheesy matter of any I have cxamined. 
The milk of Shorthorn cows somewhat resembles that of the Dutch, but the globules are larger and not so uniform in size or quality. The milk of individual cows and of particular strains, varies more in color and flavor

The common stock of the country being derived from the different breeds which have from time to time been imported, by crossing and mixing in every conceivable way, develop in their milk the widest differences. There is no more uniformity in the quality of their milk than there is in the certainty with which individual characteristics are transmitted.

In crossing, there is generally something of the form of the ancestors impressed on the offspring, but the characteristics of milk are less likely to follow. The milk of grades is therefore liable to great uncertainty, but it is more uniform than in the common stock. The effects of cross-breeding upon the quality of milk is sometimes very strange. I have seen the characteristics of the milk of two distinct thorough breeds so completely wiped out by crossing, that none of the peculiarities of either could be recognized.

Every variation in the constitutions of cows varies the quality of their milk, making it a matter of prime importance for every dairy farmer to know all he possibly can in regard to the laws of hereditary descent.

\section{MILKING.}

Milking is an art that requires to be learned as much as any trade. An expert will, at sight, detect an unskillful hand as readily as a farmer would distinguish a want of acquaintance with the use of an axe or a scythe by seeing one attempt to use either of 
these tools. Any one who determines to do so, can milk a cow, or use an axe, or a scythe, after a fashion, but to do either to the best advantage requires skill and experience.

There are three distinct points to be regarded in milking. The first relates to the treatment of the cow, the second to cleanliness, and the third to the manner of extracting the milk.

The manipulations in milking are best learned by practice. But there is philosophy in milking as well as in everything else, and a right and a wrong way of doing it. Because the right way is the best, it should be pointed out and followed. However plain and simple the art of milking a cow may be considered, the particular manner in which it is done may have much to do in modifying the profits of the dairy.

A perusal of the description of the internal structure of the udder, which will be found under the head of "Secretion of Milk," will explain the reason for certain conditions insisted on as essential. Otherwise, they may appear unimportant.

The cow is naturally sluggish in her movements, and should not be hurried out of her natural gait. She should never be driven to the place of milking faster than a walk, and if she has far to go, the walk should be a slow one. Hurrying a cow when she is full and the weather warm, hastens the circulation of her blood, and heats both her blood and her milk. A very little heating of the blood perceptibly affects the milk. It increases its odor as well as raises its temperature, and modifies the butter or cheese made from it. On this account, driving cows with a dog is not to be recommended. We have seen the milk of a dairy numbering over thirty cows perceptibly affected by 
the milk of a single cow driven in haste by a dog. She happened to be out at night and was accidentally left in a lot a hundred and fifty rods distant, when the herd was driven to a barn. Against our protest a dog was sent after her, and she came running to the barn, panting and frightened. In ten or fifteen minutes afterwards she gave about six quarts of milk, instead of ten, and it was hot and odoriferous. It was mixed with the rest of the milk, and, as was then customary, left through the night without any other cooling than it got by stirring. The extra odor of the feverish mess, acting as a ferment in the slowly cooling mass, made its impress upon the milk and curd of the next day. The milk of this cow was not natural till after several milkings. This was an extreme case. Less heating and worrying produces less effect, but never fails to do injury.

Unless the number of cows is very small, and they are all very quict and peaceable, they had better be fastened in a milking barn or shaded stalls, rather than to be milked in an open yard. A large herd requires a yard so large as to give too much chance for dodging, running, hooking, and disturbing each other. It soon becomes trodden up and filthy, especially in moist weather. The practice of milking in open yards is rapidly going out of use, especially in large dairies.

All harsh and violent treatment should be entirely aroided. Pain and fear, worrying and solicitude, are clearly detrimental to milk secretion, and never fail to make the cow hold back a part of her mess, if they occur at the time of milking. Kind and gentle treatment and quietude promote secretion, and are absosolutely essential to drawing all the milk. 
The milker should be careful to avoid every occasion of discomfort to the cow. He should keep her teats sound and healthy by oiling them, if they are inclined to chap or crack; he should also be careful to take hold so as not to pinch a part of them between the ends of his fingers and his hand, and he should see that his finger nails do not, like hawks' claws, do riolence to the teats when pressing them. If any thing occurs to disturb the cow, or make her start or kick, treat her kindly, soothe her with caressing tones, and abate the disturbance as much as possible. Use no harsh language or violence. All severity is sure to make a cow keep back all the milk she can. It not only fails to effect any improvement in the habits of the animal, but does positive injury, and makes matters worse by cultivating a fractious disposition in both cow and milker. The man who cannot govern his temper had bettor let milking alone.

If a cow kicks or is uneasy, it should not be inferred that she is malicious; it is very likely because she is hurt, or in some way made uncomfortable, and the cause of discomfort should be found and removed. When milking is comfortably and properly performed, the cow evidently enjoys the operation. She manifests her pleasure by her quiet and placid demeanor, and often by putting herself in a way to be milked, showing impatience if it is not done when she expects it. Kindness is by far the best agent for regulating the habits of the dairy. All unusual noises, or loud talking and singing, should be avoided, because they excite the cow's attention and prevent relaxation of her udder. A strange dog passing through the yard or barn, has made many a cow hold back a pint of her best milk. Whistling or low singing may have no 
particular effect upon the cow, but they had better be omitted because they retard work. The singing milker is very sure to be behind hand. A slow, quarrelsome, or noisy milker will waste more than his wages and had better be kept away from the cows.

Each milker should have a good stool of his own and when he sits down to milk, should sit snug up to the cow. Getting off at arm's length not only makes awkward and hard work for the milker, but it exposes his every motion to the gaze of the cow, keeps her attention aroused, and gives her the advantage of position if she should feel disposed to use it.

Pail room enough to hold the whole mess should always be within reach of the milker, for, toward the last end of the mildking, he cannot get up and sit down again, and get all the milk. When once begun a cow should not be left till she is finished. The pail being placed safely against catching dirt and spilling, let the work go on silently and as rapidly and quietly as possible, always using both hands. Milk the left hind teat with the right forward one and the right hind one with the left forward, changing teats often enough to relieve the pressure in the different parts of the udder about equally. Hold the left arm firmly toward the right leg of the cow, so as to be able to press it back and protect the pail with the least disturbance, if she should kick or step forward. If the milk is not soon extracted, the last part of the mess will be held back and permanently retained, when the milker probably thinks he has got it all, because it stops coming. A cow should, therefore, be milked quickly as well as quietly. It is natural for her to part with her milk in a few minutes. A calf wll draw a large mess of milk in three minutes, and a 
milker should come as near that time as possible. If the time of milking is much prolonged, she will become impatient and be sure not to "give down" perfectly. The quickest milker gets the most and the best milk, because he gets all the "strippings," which are the richest part. If anything occurs to attract the attention of the cow, near the close of the milking, some of the best milk will be held back till the next milking, when it will have become the poor, blue milk that is first drawn. A double loss ensues from crcry such occurrence, because leaving milk in a cow's bag always tends to diminish secretion.

An hour is long enough to keep the herd confined, and milkers enough should be employed to complete the work in that time. This will require one hand to about ten cows, and that number is about as many as one can safely. milk at a time without danger of injury to the hands of the milker or to the cows. The number had better be less than more. Each milker should have certain cows to milk, and he should milk the same ones every time, and in the same order, so as to divide the time equally. Changing milkers attracts the attention of the cow and excites a little feeling of cautiousness, and she does not "give down" as per" fectly as when always milked by the same person.

When a cow is nearly milked, the hand, as it grasps the teat, should reach up a little above the teat, so as to press the milk down through the valve or contraction at the upper end of it, and every time the milk is pressed out of the teat, the milker should pull down on it, not with a jerk, but gently. When the milk is nearly exhausted from the udder, this pulling down on the teat pulls open the contractions at the junctions of the tubes, and lets the milk run down, and is neces- 
sary to procure all the milk. The omission of this operation leaves a part of the milk in the tubes and is what has made every milking machine a failure.

Regularity is of prime importance. The cows should come slowly and peaceably into the barn yard, but promptly at a certain hour. Five in the morning and five at night are good hours. Some milk at five in the morning and seven at night, but it is not well to divide the time so unequally. Observations have shown that milkings twelve hours apart will give thirty pounds of cheese to the cow in a season, more than when they are ten and fourteen hours apart, and a greater inequality will make more difference still.

So much has been said and written in regard to cleanliness in milking, and it is so obvious that milk which is to be used for, or to be manufactured into human food, should be perfectly clean, that it seems almost superfluous to call attention to the subject. But in spite of all that has been said, filthy practices continue in use. One of these is milking in the rain or when the cow is so wet that the water will run down her sides and drip into the milk pail. The hair and skin of the cow are covered with accumulations of perspiration, and to soak these up and rinse them down her sides into the milk, is as injurious as it is filthy.

Another defect sometimes occurs from not thoroughly cleansing the teats and udder before beginning to milk. A thorough brushing is always necessary to get off the loose hairs and dirt, and if the teats have become otherwise filthy, they should be washed, but not milked till they are dry. A pail of water and a cloth should always be at hand for this purpose. When milking is done in a stable there is sometimes 
a neglect to provide absorbents to soak up liquicl excrement, and to prevent spattering. This is both a violation of cleanliness and wasteful. It can easily be guarded against by the use of straw, sawdust, dried muck, or something of the kind. Still another filthy practice is that of drawing a little milk into the hand and wetting the teats with it before beginning to milk. Some milkers insist that this is not uncleanly; to which it is only necessary to reply that any person whose sense of neatness is so obtuse as not to discover, without argument, that the practice is a filthy one, is unfit either to milk or work about a dairy.

Besides objections on the score of filth, the first milk drawn contains so little cream and so much saline matter, that it makes the surface of the teats, dry and harsh and inclines them to chap. If, after the milking is done, the pail is set aside and the teats wet with some of the very last strippings, that are little else than cream, there would be less objection to the practice.

To mention in detail all the points that offend against cleanliness would be tedious. They must, for the most part, be left to the milker's sense of neatness, which certainly ought to be of an appreciative character. Uncleanly milking is quite too common. If all the milk of which butter and cheese are made could be taken to the dairy-house as undefiled as it exists in the udder, the price of those luxuries would be at once materially advanced.

Drawing all the milk perfectly from the udder at every milking, not only prolongs the flow, but it keeps the bag in good condition. By leaving milk in the bag it becomes crowded and inflamed before the next milking, drying up the milk and injuring the bag. In 
some cases the milk comes down very slowly, and occasionally it is not all drawn out by reason of hard milking. This may be overcome. It is occasioned by a too small hole in the end of the teat, which can be easily enlarged. The following illustration and manner of doing it, copied from a recent number of the N. Y. Tribune, will sufficiently explain how:

Make a small cone-shaped plug of ivory, bone or metal, or even hard wood, well oiled, as large as you can well insert in the end of the teat. By making a head on the large end of the cone, and just above the head a little contraction (as shown in the figure), the plug when inserted in the end of the teat will remain and keep the opening stretched till it will become sufficiently enlarged to milk as easily as you desire. It may be removed at each milking, and when the milking is done it may be inserted again, to remain till the

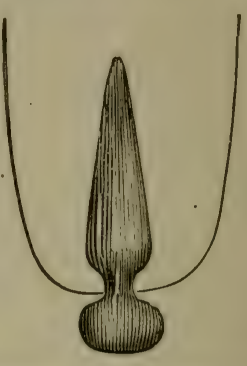
next milking, and so on till the orifice becomes permanently enlarged to the right size. No harm will be done to the teat.

To cultivate a habit of giving down rapidly and fully, fast and careful milking are necessary. Slow milkers seldom get all the milk, and the bag gets out of order in one way or another. Difficult milking is occasionally produced by a contraction of the orifice in the diaphragm which stretches over the top of the teat. The little cord which runs round the edge of the hole, contracts and knots up, closing the hole and making a hard bunch just at the upper end of the teat. Cases of this kind are more numerous than formerly, owing, I have no doubt, to feeding more corn meal and heating food than formerly before parturition. But sometimes it is brought on by too much pulling down on the teats when milking, especially where the 
milk is drawn by "stripping," as it is called, with the thumb and finger, $i . c$., the teat is held between the thumb and finger tight enough to keep the milk from flowing back, while they slide down the teat and crowd the milk out. This constant and severe pulling on the teat irritates the diaphragm and cord, and makes them pull up and occasion the bunch described, just above the teat. When this contraction has been carried so far as to make the bunch feel hard, there is no relaxation to it afterward. It has so proved in my experience. It can be remedied by cutting the cord and diaphragm to make the hole larger. It requires a considerable incision to prevent growing right up again. It does no harm to the udder to make the cut quite large. It is best done by inserting a flattened tube as large as can be crowded into the teat, and after pushing it up to the bunch, make the incision by passing a blade through the tube, then turning at right angles and cutting again. It is best done when the bag is full of milk.

\section{SOURING AND OTHER CHANGES IN MILK.}

Milk, it is well known, is an unstable compound. It is constantly undergoing changes from the time it is formed in the lacteal glands until it is manufactured or consumed. The moment it is secreted by the milk glands, and passed into the tube of the udder, it is attacked by thousands of busy absorbents, that begin at once to suck up and carry away, into the general circulation, the nutrient properties it contains. Milk twelve hours in the udder is a very different thing from milk when first secreted. Exposed to the action of the absorbents that line the milk tubes, it steadily 
loses, as it passes along, a portion of its fat, its albuminoids, its sugar and water, and, probably, also a portion of its saline ingredients.

When relieved from the action of absorbents within the udder and brought into contact with the air, other agencies begin at once to act upon it, inducing the changes which afterward occur. Unstable as milk appears to be, it does not perish from anything in the nature of its own elements, but is destroyed by influ ences foreign to its own necessary composition.

If milk is drawn from the udder without being exposed to the air and sealed up tight, it neither sours nor taints, provided it is healthy and sound when it is drawn. But if exposed to the air it sours and decays.

If a can of fruit or milk, which has been safely preserved for an indefinite time, is opened so that its contents are exposed to the air, it will soon sour and spoil, showing that the agency which does the work of destruction is conveyed to the fruit or milk by the air. This observation, which must be familiar to. every dairyman, demonstrates that there is nothing in the nature or composition of the milk or fruit itself which causes it to change or decay, but that the cause existed only in the atmosphere through which it is conveyed to the milk or fruit.

It is what the air contains and not the air itself, that destroys the milk or fruit in this case, for if a long tube filled with cotton be connected with the contents of the can, so that the air which will be admitted to it shall be filtered of whatever foreign matter it may contain, the contents of the can remain sound indefinitely, the same as when perfectly sealed.

Milk absorbs from the atmosphere the seeds of a fungus plant, which grow and multiply and fill it with 
their presence, and produce the souring. The seeds of the fungus that are concerned in the process of souring are very small, and are always floating in the air unseen and unsuspected. When developed they are of considerable size, so that they are readily seen with a magnifier of moderate power. They are shown at the bottom of the annexed figure, as they appear under a microscope with a magnifying power of $\mathrm{x}, 000^{\circ}$ diameters.

They have a distinct cylindrical form, and are known as arthrococcus, or jointed cells. Cold checks their growth, but never kills them. They are not injured at all by freezing and thawing, or wetting and drying. Nothing but heat kills them. One of these cells, adhering to the sides of a milk pan, or in a crevice, may be dried in the most thorough manner pos. sible, and lie there for a week, a month, or even a year, without injuring it in

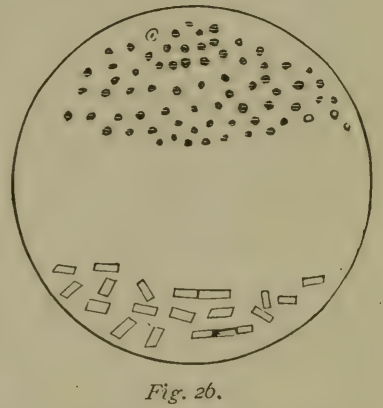
the least. The moment it is moistened with warm milk, it swells up and springs into active growth, and in a short time its progeny may be counted by the million. Premature souring of the milk is the result. They grow most efficiently at blood heat, and nothing short of boiling heat is sure to kill them.

A few destructive agencies get into milk through the body of the cow. One of these is represented by the dots in the upper part of figure 26 . They are called Micrococcus cells. They are exceedingly minute, and everywhere abundant. Thcir influence tends to pro- 
duce decomposition. They are also active agents in digestion, and in the coagulation of milk, and in putrefaction. They do no particular injury to milk, unless kept too long, when they produce offensive putrefaction. They are killed with boiling heat. It is to kill these destructive agents, that we scald green fruit; and we seal it up air tight, while hot, to shut them àway from it. They may be killed in milk in the same manner, and if they are effectually shut out by sealing up air tight while hot, milk or sweet cream, as we have found by experience, will keep just as well as canned fruit, and for precisely the same reason.

There is nothing, therefore, in the necessary composition of milk which makes it sour or putrefy; that it is always matter foreign to itself which destroys it, must be evident from the fact that when all foreign agencies within it are killed by scalding, and those outside of it kept away by excluding the air from it, sweet milk will remain unchanged for time indefinite. Milk which has been thus kept sweet for a year or more, will sour in two days at 60 degrees, by simply letting common air come in contact with it. It is an opinion by no means uncommon among dairymen that milk spoils of its own accord, so to speak, and that it is of necessity short lived. But this, as we see, is an error, and the sooner it is discarded the better. The ready infection it takes from the air in which it may be placed, ought to be better appreciated. If the fact that the short lived tendency of milk was occasioned, not because its composition necessarily impels it to destruction, but simply because it affords such a fertile field for developing and multiplying the minute seeds of fungus plants which are floating in the atmosphere, was more clearly impressed upon the minds of 
all those who hare the care of milk, they would be more cautious than they now seem to be, in regard to the quality of air which they allow to come in contact with it. It requires no long exposure to the air for milk to take an infection that will cause it to sour. A moment's contact is usually enough. The germs of acidity multiply in milk with such astonishing rapidity, that a very few are all that is necessary to set the work a going.

The influence of the air upon milk is not confined to the absorption of the spores which produce acidity; spores of every other kind are taken in as well. Nor does the absorptive power of milk end with absorbing living germs; it takes in odors as freely as infectious germs. It is a fact which cannot be too strongly impressed upon the mind of every one connected with the care of milk, or the manufacture of milk products, that milk takes in every odor as well as the seeds of every ferment that blows over its surface.

This absorbent power is not peculiar to milk alone. It belongs in common to all liquids. Water, placed in a cellar containing decaying regetation, soon tastes and smells of the decay, and becomes unwholesome to use. But milk, being full of oily matter and holding albuminoids and sugar in solution, offers to every species of ferment just what is most desirable for it to flourish in. Every odor that comes in contact with milk is grasped and taken in at once, and its grasp is never slackened. Once taken in, it is there permanently, and the seeds of every ferment that touches its surface find such a fertile soil to flourish in that they spring at once into vigorous growth, and multiply and quickly "leaven the whole lump." The London Milk Journal cites instances where milk that had stood a 
short time in the presence of persons sick with typhoid fever, or been handled by parties before fully recovered from the small pox, spread these diseases as effectually as if the persons themselves had been present. Scarlatina, measles and other contagious diseases have been spread in the same way. The peculiar smell of a cellar is indelibly impressed upon all the butter made from the milk standing in it.' A few puffs from a pipe or a cigar will scent all the milk in the room, and a smoking lamp will soon do the same. A pail of milk standing ten minutes where it will take the scent of a strong smelling stable, or any other offensive odor, will imbibe a taint that will never leave it. A maker of gilt-edged butter objects to cooling warm milk in the room where his milk stands for the cream to rise, because he says the odor escaping from the new milk, while cooling, is taken in by the other milk, and

- retained to the injury of his butter. This may seem like descending to little things, but it must be remembered that it is the sum of such little things that determines whether the products of the dairy are to be sold at cost or below, or as a high priced luxury. If milk is to be converted into an article of the latter class, it must be handled and kept in clean and sweet vessels, and must stand in pure fresh air, such as would be desirable and healthy for people to breathe.

Many other changes than those enumerated, occur in the milk room. The souring process once begun, continues till the sugar is converted into acid. The whey begins to separate from the thickened milk and the vinous fermentation sets in, slowly forming alcohol, which takes up the volatile oils, and the strong acid ferment preys upon the solid fats, to the detriment of the quality and quantity of the butter. If still per- 
mitted to stand, the alcohol is converted into vinegar, aggravating results. While these changes are going on, the micrococcus cells will be slowly decomposing the cheesy matter, and carrying it on to putrefaction.

These are some of the changes which are ever progressing under the eye of the dairyman, and he who can most successfully direct and control them is the one who reaps the best reward.

\section{SPONTANEOUS COAGULATION.}

It has happened every now and then, in cheese factory practice, that milk has been found to coagulate without the presence of any sensible acidity. Well authenticated cases of this kind have occasionally appeared in the agricultural papers, and they have also been mentioned by dairymen at their meetings for public discussion. Their occurrence has been the occasion of surprise, and a good deal of wonder as to the cause of such a phenomenon, but no light has been shed upon the subject further than to find that there is always something the matter with the milk so affected.

During all the hot weather of the season of ${ }_{1} S_{73}$, cases of this kind were of frequent occurrence in the milk with which the city of Rochester was supplied. The city was furnished by numerous small dealers who brought milk in their wagons once a day, their farms being from three to five miles distant. Some of the dealers reported no trouble from any unusual thickening, while others said their milk somerimes curdled before they could get it to their customers, without being sour to the taste, and when it was delivered apparently sound, customers now and then complained that it loppered while sweet. From our own observa- 
tions of the keeping qualities of milk brought to the city, and from inquiries made of those who used it, it appeared that the peculiarity complained of was much more extensive than even the milkmen themselves supposed; and that milk in which souring did not appear much sooner than is usual, often became thick upon an unusually slight developmeut of acidity. One milkman stated his experience substantially as follows: He lived three miles from the city, and delivered milk only in the morning; his night's milk was strained into his carrying cans, which were placed in tubs of water where they stood all night with the covers partly open; the morning's milk was also cooled in the same way, but of course was not kept long enough to cool so thoroughly as the night's milk. He stated further, that he furnished a considerable number of families with pure morning's milk, for the use of infant children. The milk for each family was put in a separate can, suited to its amount, the cans for this purpose varying from one quart to six. These little cans were also set in tubs of cold water and cooled with the rest of the morning's milk.

The premature thickening always arose with the morning's milk, and oftener with the small cans than with the larger ones. With the night's milk, there was no trouble. It kept longer than the morning's milk, and was therefore dealt out last. His experience was similar to that of many others, and represented a considerable share of the milk brought to the west half of the city.

Cheese makers in different factories have reported to me several cases in which milk standing in a large body in the manufacturing vats through the night 
has been found in the morning to be more or less coagulated and yet perfectly sweet. The curds thus formed have been warmed and cut, treated in the usual way and made into cheese which did not appear, when cured, materially different from cheese made with the use of rennet. There was no indication of acidity in the working of the curd or in the curing of the cheese more than is usual in the curd of siveet milk coagulated with rennet. I have met with a good many cases of this kind of spontaneous coagulation in which the tendency to acidity was not greater than is usual. In one case, milk as soon as drawn was put into a closely covered can and after being carried in a wagon for half an hour curdled in a few minutes upon being warmed to ninety degrees. This sample was not only perfectly neutral when it coagulated, but the curd and whey remained neutral six hours before they would respond to an acid test.

The causes which brought about these seemingly strange results are neither new nor very materially different from those which produce ordinary coagulation.

Milk is composed of water, caseine or cheesy matter, albumen, sugar and certain mineral matters, all joined in a chemical union. Butter is an outsider, so far as this chemical partnership is concerned, for it is only mechanically mixed, or suspended in this liquid combination. The caseine is what becomes curd when it separates from the other members of the partnership. It is attached to the rest of its companions by a very feeble affinity and becomes detached from them easily. A slight change in the mineral matter by the action of an acid, or in the sugar by the action of yeast, is sufficient to break off its connection 
with the compound, when it becomes a solid instead of a liquid, and appears as we see curd in cheesemaking and in loppered milk. A shock of electricity may, by changing the elective affinity of some one of the elements, produce the same result.

When milk is left standing exposed to the air, two varieties of yeast are active in producing the coagulum. There is in milk, as has been before explained, when it comes from the cow, a very small quantity of yeast, similar to that in rennet. This multiplies, and would, in time, become sufficient to curdle the milk alone. Besides this, there is the lactic yeast, that is concerned in the souring, which falls into it abundantly from the air, that would also produce congulation, if it acted alone. But the two act together and produce a coagulum sooner than either would acting by itself. The lactic yeast produces the greater effect, but that the curding of the milk is helped along and hastened by the aid of the former, may be known by scalding the new milk, when the yeast, born with the milk, will be killed, and the coagulation will come from the souring alone, but about one-third more time will be required to effect it. It is a fact which must have been noticed by almost every one who has the care of milk, that it does not always coagulate with the same degree of sourness, which may be accounted for by the varying quantity of yeast similar to that in rennet. The influence of the ferment in new milk varies, according to the treatment of the milk and the health of the cow from which it is taken.

If new milk is covered up, so as to prevent the odor from escaping, it will very much facilitate the action of the rennet yeast. Agitation also helps it along. The health of the cow varies the quantity, to start 
with. Any circumstance which produces a feverish condition in the animal will increase the coagulating agent in her milk in proportion to the amount of fever. The feverishness produced by eating too much or improper food ; by drinking stagnant water; by worrying with dogs, or by exposure to a hot sun, will so increase the rennet yeast as to make the milk coagulate upon the first approach of acidity or even before, when without this extraordinary amount, a deeper souring would need to be developed before curding would result. These are general principles that relate to the action of milk everywhere, and are worthy the careful attention of all cuncerned in any way in the production or handling of milk. They cover the cause of the premature thickening of the Rochester milk, and that in the factories. Several samples of this spontaneously coagulating milk have been analyzed and in every instance, a lack of butter and sugar and an excess of albuminoids was found, indicating a feverish condition in the cow. One of these analyses is given on a preceding page, in which the albuminoids were six and a half per cent., while the sugar was only two and the butter two and a quarter per cent. Such proportions only occur in a disturbed state of health. The cause of the tendency to premature coagulation in this sample was traced to stagnant water. Some of the dairymen around Rochester, who have not running streams on their farms, have supplied the defect with what are termed "pond-holes." A large cavity is excavated in some low place, which fills with water in the spring and remains through the season. The sides are made sloping, so that the cows can easily get down to the water to drink. In hot days, they love to wade into the water and stand there to protect their legs 


\section{I78 American Dairying.}

from the flies. Of course the water gets full of filth, and becomes green and putrid, and full of miasmatic matter that would make any person sick to drink it. How any one, with common sense, could for a moment suppose that such water would make good milk and promote healthfulness in his cows, is not easy to imagine. It may be better than no water in a case of extreme emergency, but it is certainly unfit for the use of anything but the lowest forms of animal existence. The milk which curdled so soon came from cows which drank from such a pond in August. No wonder that they were not in good health and that their milk was abnormal. Yet this milk was daily distributed through the city to feed children when the records of mortality were swelled with cases of cholera morbus, cholera infantum, typhoid and chill fever, and such other diseases as that kind of water is liable to produce

\section{MICROSCOPIC EXAMINATION OF MILK.}

The examination of milk with a magnifying giass, serves a purpose in dairy practice which is of no small account. It enables us to distinguish between healthy and diseased milk.

In all the examples of diseased milk, and illustrations of diseased milk met with, the pellicles of the milk globules have appeared viscid and adhesive, as seen in the following illustrations where the circles appear in clusters, leaving spaces between them nearly vacant.

Figure 27 represents a sample of slightly tainted milk, made so by a little fever in the cow.

One of the very first effects of disease is to begin to decompose and soften the coats of the globules, rend- 
ering them adherent. This effect appears long before the cow exhibits any signs of disease-at least any that would be likely to attract the notice of the ordinary observer. In more advanced stages, the globules become broken down and destroyed, and assume a variety of new appearances.

Figure 28 represents a sample of milk tainted by
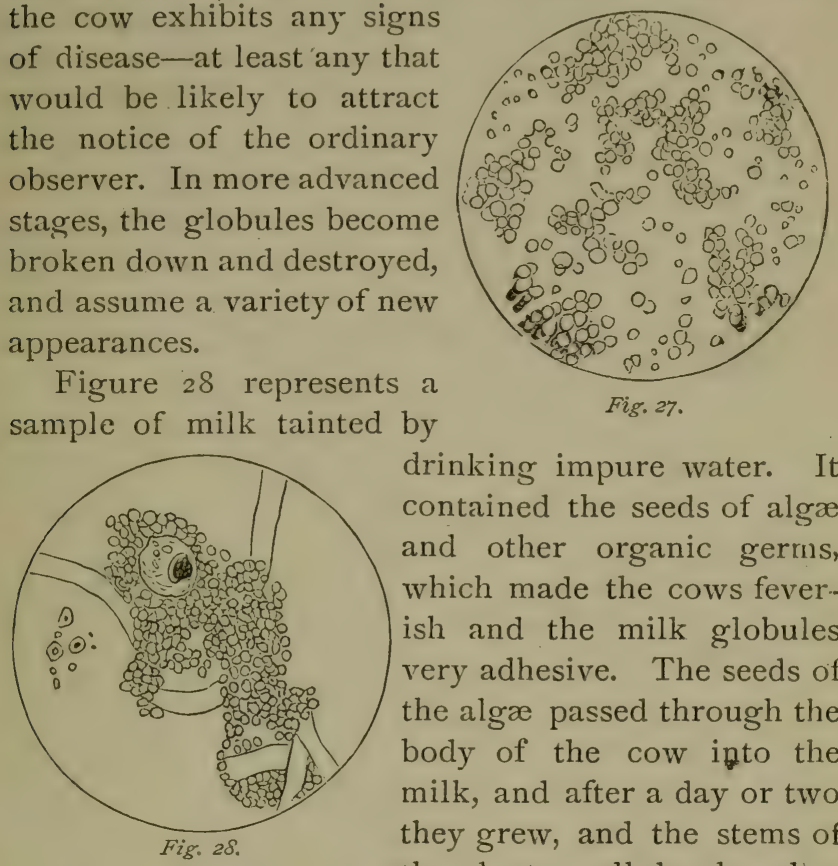

drinking impure water. It contained the seeds of algæ and other organic germs, which made the cows feverish and the milk globules very adhesive. The seeds of the algæ passed through the body of the cow into the milk, and after a day or two they grew, and the stems of the plants, well developed as in the illustration, were seen in the milk. A large germ of another kind lays bare on the adhering globules, and at the left of the figure may be seen some smaller ones of still another variety, and also a few blood cells, having a dark centre. This illustration was obtained from drawings made by Professor Law, of Cornell University, who examined the tainted milk.

Figure 29 exhibits an aggravated case of diseased milk. It was drawn from a sick cow in a distillery stable in Williamsburg, at the time of the notorious 
swill milk exposition in the city of New York, in

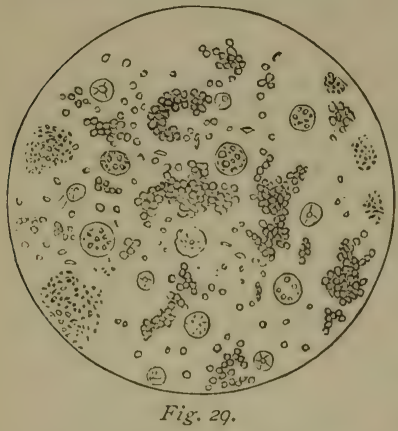
I 858 or 1859 . The view is taken from a microscopic representation made by Dr. S. R. Percy, of New York city, as it appears in the annual report of the N. Y. State Medical Society, for I 860 .

The cow had very high fever and inflammation of the bowels. The milk was scanty and blue. Under the microscope, it showed the milk globules cohering, and also little bunches of them broken down and decaying.

From the first two samples of tainted milk, butter could be made, though it would churn with a good deal of difficulty. From the last, butter could not be derived, though it should be churned a week, but they would all work into cheese, though a less amount would be produced than if the milk were sound.

Other and more detrimental agencies, in the form of organic germs, sometimes get into milk through the food and drink, or the breath of the cows. Figure 30 shows some that got into the milk through bad water, which the cows drank. They consist of two species of microscopic algæ, often called "frog spittle." They were not seen in the milk when

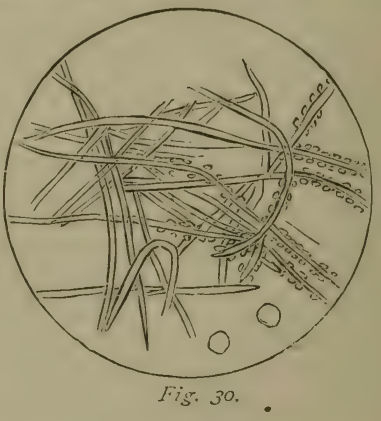
first drawn; but, after standing a while, they grew 
from the seeds contained in the milk, and developed into visible plants. They affected the health of the cows, producing slight fever, and the milk had all the peculiarities of what factory men call "tainted milk."

Figure $3 \mathrm{I}$ is a view of milk which contains a plant resembling what is known commonly as frog-spittlea green, stringy-looking plant which grows in stagnant or very slowly moving water. In the lot where

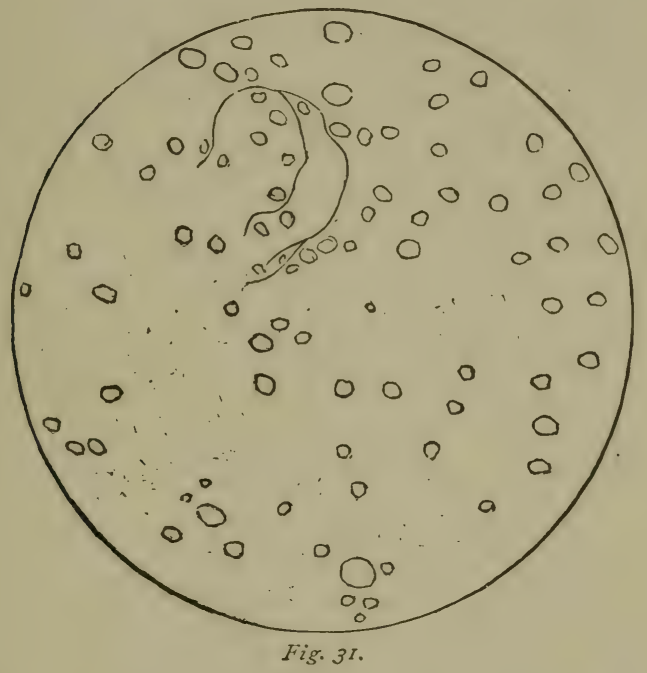

the cows fed was a sluggish stream with stagnant eddies extending out some distance from the brook, and these eddies were green with the frog spittle (algx). From drinking this stagnant water the microscopic species here exhibited was taken into the stomach of the cow and passed through the blood vessels into the milk, where it developed and grew in the manner seen. It could have got into the milk in 
no other way. It is but a diminutive thing, its whole length being only $\frac{1}{400}$ of an inch, and its diameter less than that of a spider's web, but it is enough to show the excretory power of the milk gland which cast the seed out of the blood.

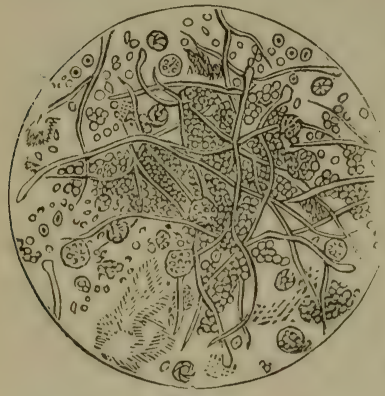

Fig. 32.

Figure 32 shows what came in'by feeding distillers' slops. It is another sample of the same kind of milk illustrated by figure 29. The growth was made in 24 hours, the milk being closely corked. The organisms were in immense numbers. Every drop of milk contained from 5,000 to 10,000 of the full grown plants.

\section{EFEECT OF TREATMENT.}

The influence of mental and physical treatment received by cows has a decided influence in changing the character of the secretion, and upon its keeping quality afterward. The bovine is not unlike the human mother in this respect. Starvation or brutal treatment, worrying or fright, changes the composition of milk so much as to sicken the nursing offspring, and in extreme cases it amounts to an absolute poison. These effects are of common occurrence with nursing mothers, and occasionally brutal severity and fright affect a cow so much as to sicken the calf which sucks her milk. In all such cases, milk spoils very rapidly, and its composition is changed. But little fat is formed in it, and sugar and caseine almost entirely disappear. Their place is supplied with an imperfect secretion 
of albumen. In the earlier stages of the milking season these influences do not appear to be so potent as at a greater distance from the time of coming in, but the effect is always visible. Milk is not only the most healthy and perfect, but keeps best when the cow is well fed and healthy and quiet.

\section{THE ODOR OF NEW MILK-ANIMAL ODOR.}

All who have been accustomed to handle or use milk when first drawn from the cow, are aware that it has an odor peculiar to it, at that stage, but which soon passes away if the milk is thinly spread out and exposed to the air. There are many people who cannot use new milk at all till after this peculiar odor has passed off. It is not only disagreeable to some, but produces nausea and other disturbing effects upon health. To others it is not particularly unpleasant, and a few like it. Children often relish milk when new and warm, and it seldom does them any harm on account of its being new, if the milk has come from a healthy animal. But milk is different before and after the smell, peculiar to it when first drawn, has passed off, and its effect as a food is also varied.

The milk of all mammalia, so far as I am aware, exhibits similar phenomena. The milk of each gives off an odor while new and warm that does not belong to it afterward, and in each case the odor resembles the mingled smell of the breath and insensible perspiration of the animal from which it has been derived. Thus the new milk of the cow smells so much like her insensible perspiration that it is often spoken of as a "cowy odor." The milk of the sheep, goat, horse and human, sustain similar relations. 
Previous to the adoption of butter and cheese factories, the apparently evanescent odor of new milk had attracted but little attention. Its existence had simply been recognized, and so far as dairymen were concerned, little else was thought of it. But when it became necessary, or at least convenient, to transport milk to factories in covered vessels, and to move it while fresh and warm, this odor was soon found to be a disturbing element. When milk was put into closely covered vessels, which, on account of convenience in handling, could not be filled full, and carried a mile or more to the factory, the space in the upper part of the vessels not occupied with milk would invariably be filled with a smell of new milk, which seemed to have accumulated till it became so strong as to be effensive. Upon uncovering the can, (the ressel in which it was carried,) the offensive accumulation of odor was at once dispersed, and the farmer supposed that to be the end of it; but results in the factory proved differently. It soon became evident that the odor had not departed from it, but had actually increased. When received into the factory, and heid in large vats containing several hundred gallons in a body, though exposed to the open air and cooled down to 60 or 70 degrees, it still hung to the milk, and its presence affected the cheese, making it porous and spongy, and giving it a strong flavor. The further fact soon became apparent that it varied in intensity with the varying circumstances which affected the cows. In hot and sultry weather, when the heat of the sun was oppressive and water scarce and poor, and especially when the mercury stood close to 90 in the shade, the odor became intense and offensive, and the effect upon the cheese was greatly aggravated. When- 
ever cheese was made from milk emitting much of this strong smell the curds became soft and spongy, and instead of shrinking and scttling to the bottom of the rat, as usual, they were puffed and swelled, and so much distended with gas as to float on the whey like cork on water.

By cooling and salting, the curds were worked down to a firmer consistency, but when pressed into cheese the difficulty reappeared. The cheeses would huff up like loares of bread and be, for a time, about as porous. As soon as they began to cure they gave off offensive gases and soon went to decay. The whey and the curd while it lay in the vat, emitted foul odors which increased in intensity as the work went on. This state of things became quite general, and at times was almost co-extensive with the existence of cheese factories. As the weather became cooler, and water purer and fresher, the milk gradually became better, and the offensive odor died away. This peculiarity in the state of milk comes and goes with every season, and often many times in the same season. Milk of this character is now managed with so much more skill than formerly, that the disastrous effects upon the cheese are to a large extent avoided. But the fact is now generally recognized by dairymen connected with factories, and especially by manufacturers, that milk fresh from the cow does not make as good cheese as it does after it has stood till the animal odor has escaped, and that, however much the method of working milk, that has.from any cause become affected with odor, has been improved, the cheese made from it is never equal in flavor or keeping to that made from milk not so affected.

- The influence of animal odor upon butter is as 
deleterious as upon cheese. If the odor of new milk is carried into cream and thence worked into butter, as it often is by cooling new milk too low and ton suddenly, the butter has a modified flavor in consequence. The fine aromatic and clear and delicious taste of the olein and its essential oils, which are developed in butter from milk free from such odor, are obscured and modificd so much as not to be recognized, and a strong and indistinct flavor, as if something foreign and impure had been mingled with the butter, takes the place of the naturally agreeable taste.

In like manner, butter made from milk which has become affected with odor from a feverish condition of the cows, or from carrying closely covered, takes on an unnatural, strong and unpleasant taste and a greasy appearance, unless the odor is removed before the cream is raised.

The appearance of these new phenomena in the handling and working of milk, brought into use a new set of terms. As the odor, which had formerly been supposed to belong only to new milk while warm, began to increase from the influence of weather, food, treatment, and the new modes of manipulating milk, and to become intense, it smelled so much like the perspiration and breath of cows as to show an unmistakable animal origin; and hence it has become - generally known as "animal odor," and this phrase is now in general use among dairymen in the United States, to indicate this peculiar odor of milk in all its stages. When it becomes very intense, it often savors so much of the odors of putrefactive fermentation as to lead to the supposition that actual decomposition of the milk has begun; and hence milk in this advanced stage is said to be tainted, though its condition is in 
fact quite different from that of other animal matter when we speak of it as tainted. But the apparent analıgy of the two cases has brought the phrase "tainted milk" into extensive and familiar use; and owing to the fact that curds from this kind of milk usually rise to the surface of the whey, the phrases "tainted milk," and "floating curds," have become correlative terms, and the latter has had about as wide an application as the former, which is now by common consent used to signify milk from which any strong odor is emitted. The three phrases "animal odor," "tainted milk" and "floating curds," have thus each become technical terms and assumed a permanent place in the dairy literature of the country.

To the outsider it may seem like a waste of words to occupy time in talking about the smell of a thing, but to the American dairyman, the phrase "animal odor," is one of dreadful significance. It reminds him of a bitter enemy, one which, however much he may affect to despise, he dare not ignore. It refers him back to losses incurred, which may be estimated by millions, from a perishable inclination and other defects it has given to his cheese. He recognizes in it the most active agent in the destruction of his butter, and oftener than anything else, the cause of that cry which has become to him disheartening and dreadful, from the frequency with which it is applied to his goods, of "off flavor." However trifling the odor emanating from milk may seem, it really strikes back to a cause of defect in both butter and cheese, than which, none is more potent. If, from ignorance of its power, it has not been appreciated in times past, the introduction of the factory system has revealed its might and made a terrible display of its destructive 
energy. Dairymen now are aware that there is something in it that needs looking after. It is now beginning to attract the attention it deserves. At the fireside of dairymen, at social knots, at the conventions so often held in the interest of their vocation, " animal odor" and "tainted milk," are never-ending themes of discussion.

Just what animal odor is, or what it is derived from, has not been well understood either by practical men or scientists, though many have been the speculations in regard to it, and multifarious have been the devices to dispose of it and counteract its effects.

By some it has been supposed to be the proper and legitimate smell of warm milk. To this it may be objected that the same cow's milk even, does not at all times have the same odor when warm, while, under some circumstances, it disappears entirely while warm, and under others, it increases as the temperature falls. Others have supposed it to be the result of the peculiar warmth of the animal body, and great pains have been taken to get the "animal heat," as it is called, out of the milk. This supposition has found a great many adherents, and many cling to it still. A wider mistake could hardly have been made, nor a more baseless theory be imagined.

In the first place, there is no difference between animal heat and any other. All heat, whether generated in the animal body or out of it, is the same. There is but one kind of heat, from whatever source derived. This fact is too well known to need demonstration.

In the second place, heat and odor are entirely distinct from each other. The former is only a condition of a thing, while the latter is a thing of itself - a sub- 
stance it must be, to be appreciated. How idle then to suppose that warmth generated in the body of a cow should give rise to any particular kind of odor. Yet the number of dairymen who still persist in using "animal heat" and "animal odor" as synonymous terms, or in considering the former as the cause of the latter, is legion.

A simple experiment will illustrate how untenable both of the preceding suppositions are. Upon an occasion, which accidentally occurred, when my cows were giving milk strong with animal odor, I made a small filter containing pulverized charcoal and passed the milk through it as soon as drawn. Upon emerging from the filter at a temperature of 90 degrees, it was perfectly delicious, both in taste and smell. Though retaining nearly all its animal heat, it had lost all its animal odor. By continuing the use of the filter, the coal soon became saturated with the odor, giving unmistakable evidences of its presence, and showing that animal odor, or the odor peculiar to new milk, does not belong to the milk itself, since it can be separated from it, leaving the milk free from any such smell-the milk in the meantime being unchanged.

In attempting to account for the strong odor which nccurs in hot sultry weather, it has been assumed by some, that a putrefactive change begins in the milk the moment it is discharged from the udder, and in some cases, even before it leaves that organ. If this supposition were true, ammonia or nitrogen, in some form, should be given off. But tests have shown that no nitrogen escapes in any form, either combined or free, from what is known as tainted milk. The discharges have been carbonic acid gas mingled with the peculiar odor. 
That no change of the character supposed occurs in milk under the circumstances described, is erident from the fact that milk freed from odor by heating a little above blood heat, even after it has been pretty badly tainted, throws up a very nice sweet cream and makes excellent butter, and the further fact that such milk so heated afterwards makes delicious and pure flavored cheese that will keep and hold its flavor as long as milk that has not been tainted. These facts amount to a demonstration, inasmuch as it would be altogether impossible to make a nice flavored and long keeping cheese out of milk in a state of actual putrefaction. Hence it becomes necessary to look for the basis of animal odor in some other direction.

Having observed that this peculiar odor escapes more rapidly as the temperature rises, and more slowly as it falls, till ceasing to escape at all, it remains permanently in the milk, the writer at first regarded it as a gas emanating from the waste matter of the body, especially, as under different circumstances its odor corresponded to that of excretory matter. At low temperatures, it appeared to assume a liquid form, for though it ceased to give off any odor, its presence was made manifest by a flavor corresponding to the odor.

Prof. Caldwell, of Cornell University, suggested that its behavior was that of a very vulatile oil, rather than of a gas.

To test this suggestion, a sample of milk in which odor had purposely been allowed to accumulate was distilled and a small quantity of a clear limpid oil, with a slightly yellow tinge, was obtained. At 35 degrees (F.) it was as fluid as water and emitted no odor, but upon warming a little, it quickly assumed 
an aeriform condition and disappeared with an intense smell of new milk-the genuine animal odor.

A few experiments demonstrating that the odor in question is an extremely volatile oil, the next query was, how does the oil get into the milk? If the odor disappeared upon cooling and exposing to the air, and never reappeared, the inference would be that it was a secretion of the milk glands, the same as the fatty matters in butter. The investigator might at least be satisfied with referring it to such an origin. But the formation of the oil does not stop with the discharge of the milk from the udder. It continues to form out of the udder the same as in it, if the milk is kept warm. As the temperature of the milk falls, it forms more and more slowly till it ceases entirely. It only fails to become intense because being open to the air it escapes. Cover milk closely and keep it warm, and the odor will soon become as strong and even stronger than in new milk. Nor is its formation confined to the udder or the milk. The same odor appears to be all the time escaping in all the excretions of the bodythe breath, the liquid and solid fæces, and profusely in the perspiration. The odors in these different cases vary a litule from that in new milk as well as from each other, and the odor from milk in different circumstances differs in the same way. The milk of a cow smells differently when she is quiet from what it does when she is worried; differently when she is feverish from what it does when she is not; and odor formed in the udder is different from that formed out of the udder when the milk is closely covered; yet its general characteristics are so analagous as to be unmistakably the same thing. The samples of oil obtained by distilling milk under these different cir- 
cumstances cannot, while liquid, be distinguished from each other, and they all alike fly off in vapor upon being warmed, but in taking on an ethereal condition each gives off exactly the same odor as the milk it was derived from.

Again, the milk of a single cow, if feverish, would soon bring a 600 gallon vat full of good milk into the same condition as itself, if it is kept warm. The milk of a half dozen or more feverish cows would, to be sure, do it sooner than one. But the fact that a small mess of milk tainted with any modification of animal odor will infect a large mass, is a fact well known and is a point to be noted. Another significant fact is, that after milk has been boiled, no odor will accumulate in it when closely covered, showing that the cause of the odor is destroyed by heat.

Since the oil on which animal odor depends multiplies independently of the animal body, being formed in milk as well after as before it leaves the udder; since its formation increases and diminishes with the rise and fall of the temperature of milk, till the ultimate cause is quieted with cold or remored with heat; and since a small mess of affected milk spreads its peculiar characteristics through a large mass with great rapidity, obeying all the laws of a ferment, it is deemed a safe conclusion to infer that the peculiar odor of new milk, and what is generally known among dairymen as animal odor and taint in milk, are produced by a volatile oil formed in the milk by the action of a peculiar yeast, which is present in a greater or less degree according to the circumstances under which it is produced. As in other cases of fermentation, the yeast or ferment, which is the active cause of change and new products, has been found to consist of living 
organic germs; so in this case, it may fairly be inferred, from the close analogy in action and results, that the growth and multiplication of organic germs are the cause from which the peculiar odors of milk are derived.

The circumstances which contribute to an increase of odor in milk, before it is drawn, are very numerous. They are in general such as disturb the health or heat the blood of the cow, and these disturbances may consist of mental as well as physical treatment. The following may be specified as among the most common causes: Oppressive heat of the sun-especially in sultry weather, and when scanty feed occasions too much exposure of the cows to fill themselves. Taint in milk is very apt to increase and diminish with the rise and fall of mercury in the thermometer-a circumstance which shows that in this latitude cows need protection from the hot sun in summer as well as from the cold winds in winter. Stagnant water-this is a very prominent and efficient cause in producing an increase of odor. Scarcity of water-when cuws lack a full supply of water, or when it is not convenient of access, the odor of milk is very soon affected. So also with dogging cows, driving fast, or too long journeys, or in any way worrying them. A slow pace and short journeys for cows in hot weather are required for good milk. Worrying or in any way heating the blood, viulent usage, pain, uneasiness, fright, solicitude, sore teats, garget, cow-pox, being in heat, any disease, and especially such as produces feverishness; breathing bad air, as tie odor from carrion or the air of foul and close stables, or of a filthy barn yard; gorging, as when cows break into forbidden enclosures or are fed with more food of any kind than they can digest; feeding 
improper food, or food in a state of decay or highlyt fermented, as the refuse of the dairy in a stale condition; the slops of the distillery and brewery; decayed grass which has lain on the ground during the winter; coarse and sour grass, grown on swampy places or in low moist ground; rank green clover in the early stages of its growth; eating strong scented or medicinal food; going too long without milking; suddenly checking perspiration by exposure to cold or wet.

The principal causes which produce bad odors in milk, before it is taken from the cow, and which afterwards become the cause of taint, are oppressive heat and stagnant water.

Of the causes which increase the odor in milk after it is drawn, the principal one is keeping the warm milk closely covered, so that the odor which was in it when it was drawn, and that which afterward forms, cannot escape.

Another very efficient cause is defective cleansing of dairy utensils. Another, cooling too rapidly, or not soon.enough, or not low enough; exposing the cans containing milk to the hot sun while in transit; exposing milk to foul odors at the farm yard and at the factory; keeping milk in large masses without sufficient stirring, and various other similar defects in the care of milk, contribute to augment the development of odor. Though it is no easy task to keep clear of all these causes of injury, it is necessary to do so in order to have perfect milk.

Again, when dairymen appreciate that the cause of the odoriferous oil in milk is a ferment, it will be as easily wiped out as the oil itself. The laws which control the propagation and destruction of ferments are well known. They originate from seeds as distinct 
as the seeds of grain, and are like them in some respects, but more than equal them in tenacity of life. The seeds of the cereals retain their vitality under great exposure and severe treatment while they remain dry seeds, but the moment they germinate, they are easily perilled; their strong hold on life is gone. A little exposure to heat or cold, wet or drought, or to a little violence, and they become extinct at once. So with the seeds of ferments, while they remain spores they retain their vitality under almost any vicissitude, but the moment they become developed into growing fungi, their destruction, like that of sprouted grain, is very easy. Though they require oxygen in the composition of their food, they cannot endure it on their surfaces. Though they require warmth to develop, they can bear but a certain amount of it. The ferments which flourish so luxuriantly in milk can only do so when protected from the attack of oxygen by a liquid envelope. The mushrooms that spring up under cover of the dark and dampness of night to wilt before the light and dryer atmosphere of day, are more tenacious of life than the germs which constitute the ferments in milk; they perish instanter when exposed to a little too much heat, or to the corroding influence of the oxygen in the air.

One of the most effectual barriers now in the way of further improvement in factory cheese making, lies in carrying milk warm and closely confined to the factory. The objectionable odor is developed in the journey to the factory. Milk, in which a strong taint is liable to develop, appears, when first drawn, scarccly different from sound milk. It would be difficult to dis. tinguish them, yet when it arrives at the factory the affected milk is so full of odor as to become offensive. 
To avoid this increase of odor on its way to the factory, is the most important point, next to avoiding the original cause in the care of the cow. Having discovered that the odor is simply a very volatile oil that is all the time forming and escaping at common temperatures, three ways of counteracting it suggest themselves. One is to cool so low as to prevent the action of the ferment by which it is formed. This will stop its increase, but it will retard the escape of what is already in the milk, and if cooled low enough will condense it into a liquid, and give an animal flavor instead of an animal odor. A second way is to give it a free chance for escaping. It will then pass away .without help as it is formed, leaving the milk in its original purity. A third way is to hurry its exit by heating, and if occasion requires raising the heat so high as to destroy the fermeut and remove the cause entirely.

In discussing the subject of the so-called animal odor in milk, it has been deemed appropriate to speak thus fully-first, because the investigations in regard to its nature and origin will be new to many readers; second, because the multiplicity of views in regard to it among dairymen seems to demand a definite solution and explanation so clear and full that it could be understood and appreciated by all; and thirdly, because the important part it plays in modifying the quality of butter and cheese, require that it should, if possible, be well enough known to be controlled and counteracted.

The discovery of this new oil in milk, and its mode of development in the bodies of animals, has a significance wider than its application to the dairy interest. Its identification with odors in the perspiration 
and breath; its formation outside of the body of the cow as well as inside, show that its origin is independent of the vital functions of the animal, and its mode of development being in such strict accordance with the action of ferments, as to leave no doubt that it is the product of the development of organic germs. All this points to the conclusion that extensive changes take place in the bodies of the bovine race under the influence of a ferment, which has yet proved too minute for discovery; for this odor, and consequently the production of the oil it is derived from, is not confined to the body of the cow. It exists in the bodies of the entire bovine species. In the horse there is the same accordance between the odors of its new milk and the perspiration and breath of the species, establishing an identity in the cause of their origin in the equine race with that in the bovine. In all the mammals we are acquainted with, similar phenomena may be discovered, which, by analogy, show further that the peculiar odor in the perspiration of animals generally is due to an oil, the same as in the cow and other known mammals, and that this oil has the same volatility and a similar origin. The formation of an oil on such an extensive scale in the bodies of animals, which assumes an ethereal form below blood heat, indicates a specific purpose in nature, and naturally raises a query as to what that purpose is - whether, indeed, this attenuated condition is not a necessary one for the most easy assinilation or utilization of the elements of food in the bodies of animals, and, while small portions of it are escaping in perspiration, breath and fæces, whether much larger portions are not being employed in the economy of animal life. Considering the fact that the digestion of milk with rennet, and, by 
analogy, other digestion is carried on by the agency of organic germs, the questions are raised whether other changes carried on in the animal body, which are supposed to be the result of the vital functions of the animal, may not be due to a similar agency; whether the influence of the vital force in animal bodies is not in fact confined to much narrower limits than we have been accustomed to ascribe to it; and whether it is not itself controlled to a large extent by infinitesimal lives acting within the animal organism.

\section{. BUTTER MAKING.}

In the dietary of all the civilized nations of the globe, butter holds a high place. With the cultivated and refined it is everywhere recognized as one of the crowning luxuries of a perfect meal. The tables of wealth and refinement are never complete without it. Its absence would create a void that nothing would fill. But it is the perfect article that takes this strong hold of the appetites of men. The imperfect article is despised. Nothing could be more indicative of the esteem in which the extremes are held than the terms used to designate them - " gilt edged" and "grease." Commercially, it assumes large proportions. It is an article of extensive traffic and interests everybody, 
for every family either makes or buys it. An article in such general use and general esteem ought to be so well understood as to insure, in all respects, perfection in its manufacture, so that nothing but a perfect article would ever be sent from any farmer's home. 'There is the greater necessity for this, since its commercial value depends upon the extent to which the palate is pleased. But experience does not run in this direction. Perfection is the exception instead of the rule, and it is not very strange that it is so, for the art of buttermaking is an intricate operation. Its success depends upon a succession of little acts, each one of which is liable, when not performed aright, to alter the whole character of the production. The correct performance of all these little acts involves an acquaintance with the properties of milk which the present extent of practical and scientific knowledge renders it difficult to acquire. We will notice in detail some of these little acts.

\section{VESSELS FOR SETTING MILK.}

There are three varieties of vessels extensively used for containing milk while the cream is rising, and each has its advocates.

The small tin pan, holding eight or ten quarts, which, until a few years since, held sway almost without rival, is still largely in use. Its form is tuo familiar to need any description. It has answered the purpose well, and some of the finest butter known, is still made from milk set in these pans. They have some advantages over any other vessel in use; they cool the milk readily without the use of water; they are light and easy to handle and cleanse; their small size adapts them to situations where no other kind would suit; 
they are conveniently stored away when not in use, and are cheap and durable. An improvement in the manufacture of these pans has enhanced their value. They are now made without seams by pressing sheetiron into the proper form and then tinning it heavily afterwards. Thus made, they are more durable and very easy to clean, there being no crevices for sour milk to lodge in. They are better adapted to small dairies than large ones, as in a dairy of much size, the large number required, necessitates an immense amount of handling to cleanse and put in place, and to fill and empty.

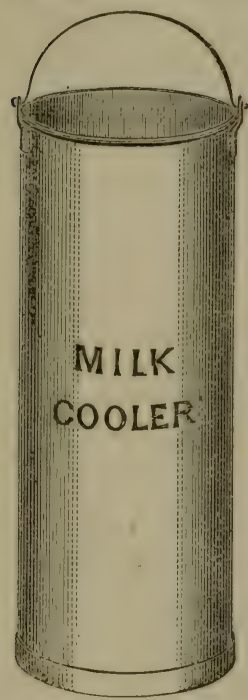

Fig. 33.

To obviate this large amount of labor, and as many believe, to improve the quality of butter, deep pails are used where pools of cool water can be had to set them in, to prevent the milk from remaining warm too long. They are made of sheets of tin $24 \times 20$ inches, and are usually 19 inches high, and nearly eight inches in diameter. The merits of this mode of setting milk consist in cooling large masses of milk quickly and in requiring less room and less labor than the small pans.

Another form of vessel for setting milk, which has gained considerable reputation, is the large square or rectangular pan. There are several varieties of this pan in use, some of which vary but little from each other. The main points as well as the points of difference, will be understood by a brief description. 
The one first introduced contains a large rectangular pan within another, with a space of half an inch or so between them to admit water. They are made of very heavy tin, and not more than six or eight inches deep, and of a size suited to the amount of milk they are desired to hold. The outer pan may rest upon a frame, or a table, as preferred, and the inner one hangs upon its edges, is movable and can be taken off at pleasure, to wash or repair, if there is occasion. A small stream of water is led by a pipe into one corner of the lower pan, and after filling the space between the two, is made to pass out at the opposite corner.

Another pan is made with two bottoms, one-half inch apart, with water-tight divisions extending nearly across the pan lengthwise and at alternate ends butting against the end of the pan, thus forming a channel that compels the water, which is let into the space between the bottoms at one corner, to flow back and forth across the pan lengthwise, till it is let out at the other corner on the same end where it enters. The discharge orifice is raised above the bottom, so as to keep the space always full, and the inlet is higher than the discharge to give the water head. The ingress and egress of water is regulated by faucets, and a faucet is also placed at one end of the pan to draw off all the water between the bottoms when desired. The pan is one solid structure, there being no inside pan to lift out as in the one first described. It is designed to rest on a table made with a top of matched boards to kcep the warm air of the room from the bottom of the pan.

Another style of pan has straight sides and ends and a rounded bottom, making it easy to clean; another is arranged so as to set one above the other to save 
room in the dairy; another has its sides made of iron with the inside lined with porcelain, a very favorable feature for cleansing the vessel and keeping milk sweet; still another has compartments in the interior adapting them to holding variable quantities of milk, see figure 34. All the varieties of this sort of pan would make a very long list. They have one feature common to them all, viz.: A pan within a pan and

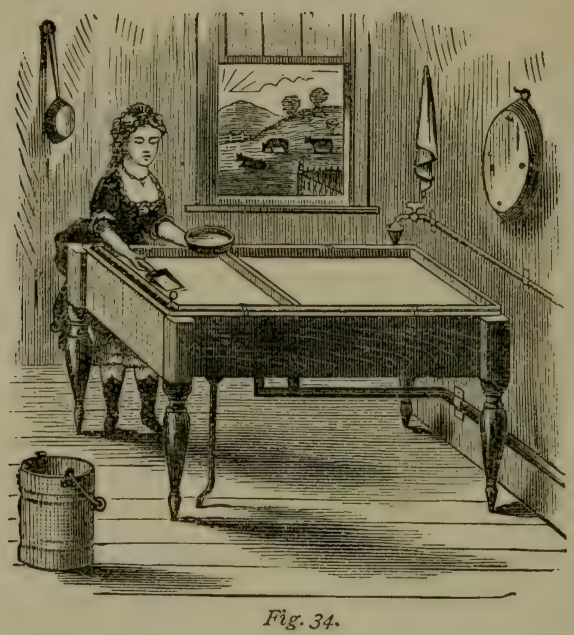

water between them. Recently, for creamery use, pans involving this principle are made of very large size, in which the outer envelope is made of wood, the whole resembling a large vat for manufacturing cheese. They are designed to use large quantities of water for rapidly cooling large messes of milk. In some factories a third pan is employed which is suspended within the one containing the milk. Its edges rest upon the top of the milk pan and its bottom goes 


\section{Butter Making.}

down nearly to the milk. This third pan is filled with cold running water, to aid in cooling the milk by cooling the air above it. By elevating these large pans so that milk can be spouted from them to the manufacturing vats, they are exceedingly convenient for creamery use, and have proved very successful in turning out a fine quality of butter, but in the creameries where I have been able to get the statistics the yield has not been satisfactory, but I can see no good reason why, if properly arranged, the quantity should not also prove satisfactory.

In attempting to set forth the effects of the different methods of setting milk, we have a multitude of difficulties to encounter. Successful butter making depends upon proper attention to a great many details which are liable to be varied singly or in combination. It thus often becomes almust impossible for the operator to determine with precision how much this or that variation has affected his butter, and even whether the effect has been for good or for evil. The vessel for setting milk is but one of these items which may be greatly varied by attendant circumstances. The form and size of vessel to be preferred should have reference to accompanying conditions.

\section{CREAM.}

Butter is the aggregated fat of milk which is first known as cream. Pure cream consists of the globules in milk which rise to the surface on standing. These globules, as has already been observed, are composed principally of three varieties of fatty matter-stearine, palmatine and oleine, enclosed in a membraneous pellicle. Butter is formed from them by removing the pellicle and collecting the fat into a mass. Occasion- 
ally, particles of fat are mingled with them which have no pellicle. This is especially true with respect to the lighter fats which are derived from the essential oils in the food of the cow. The naked fat appears in very minute particles. Water also enters more or less into the composition of the milk globules, apparently taking the place of a part of the fat. I have recently, as before observed, found globules in which the fat was entirely displaced with water. As the composition of cream is variable, there is a corresponding variation in the specific gravity of different samples. It varies, acccording to different authorities, from I,024.4 by Berzelius, down to $9 S_{3}$ by Sturtevant. The actual difference in the gravity of different samples of cream I apprehend is less than is generally estimated, the samples being varied by the amount of milk taken with the cream. Taken from grass fed milk in June, the cream being very carefully separated from the milk, the pure cream had a gravity of 985 , water being $\mathrm{r}, 000$; this is the lowest determination I have made. - I have never met with a sample of sweet cream which I can recall as being heavier than water. Sour cream will often sink in water because of the coagulated caseine which adheres to it, but when sweet cream is placed in distilled water the caseine sinks and the cream rises. Hence, I infer that though the great majority of authorities agree in putting the specific gravity of cream greater than that of water; the higher gravity is due to an imperfect separating of cream from the milk. That this was so in the extraordinary gravity ascribed to it by Berzelius, is evident from the fact that the cream so estimated produced only $4^{\mathrm{T}} / 2$ per cent. of butter, while the residue gave $3 \frac{1}{2}$ per cent. of caseine and 92 per cent. of whey. 
Such a resuit could not be obtained without having mixcd with the cream a large amount of milk. Pure cream ought to yield 20 per cent. of butter. I have obtained from it 25 per cent., and it sometimes yields more.

It must not be understood from this remark that cream is all supposed to be alike in respect to gravity or value, for neither is true. The cream from the milk of different cows varies both in gravity and value, and even in the milk of the same they are varied considerably by the effect of feed. A cow in April, while in the barn, and fed on hay and wheat bran, gave milk in which the cream differed so little from the rest of the milk, that no distinct line between milk and cream could be observed after standing twenty-four hours in a graduated glass ten inches deep. The cream appeared to diminish from the top to the bottom of the glass by a gradation nearly uniform. About one-fourth of the way from the top down was a confused change in the shading, showing the cream to be thicker above than below, but the diminution of opacity downward showed considerable cream below. A milk so very rich as to show 25 per cent of cream, and still cream to spare below that, seemed a remarkable instance of richness and to be worthy of analysis, but I was much disappointed to find in a total of dry solids of 13 per cent. less than 4 per cent. fat. The milk of this cow was watched and the diminution of the per cent. of cream with a change of feed noted. In June, when fully established on a diet of grass, the cream had dwindled to 12 per cent., and its line of separation became distinct. An analysis showed a slight falling off in solids and a trifling increase in fat. The changes noted in the milk of this cow are interesting as indi- 
cating the possible change upon the gravity of cream by the influence of feed, and the unreliability of the volume of cream as an absolute guide to value, and may help to throw some light upon the variable specific gravities ascribed to cream. The April cream was evidently largely composed of milk, because its gravity being so near that of the milk itself, it did not crowd itself to the surface to displace the milk that was mingled with it. In June, the globules were better filled and the fat in them was lighter, and they pushed themselves (so to speak) with more force to the surface, displacing the milk and forming a compact coat of cream with a deep color. The former must have weighed heavily; the latter light.

Cream from the milk of different cows and from different brceds of cows is liable to similar variations. The bulk of cream, however; affords a strong probable evidence of the butter product in the milk, but not an absolute one. The opacity of the cream is often as good an index of value as bulk.

\section{RAISING CREAM.}

From time immemorial, cream has been separated from the other parts of milk for the purpose of making butter, yet the best method of effecting the separation is far from being settled.

Opposite practices, in many particulars, are advocated and adopted. A beginner in butter making is always confused with the contradictory notions of old practitioners; and these differences of opinion and practice are likely to continue till the operators assemble and compare practices and products, and settle differences by discussion. 
In the present unsettled state of opinion and modes of operating, an appeal to general principles becomes necessary. The statement of a few leading facts will help us very mich in deciding what is, and what is not, proper.

The first prominent fact in the separation of cream from milk is, that it rises by reason of its having a less specific gravity than the milk with which it is mingled.

The average specific gravity of milk is about $\mathrm{I}, 030$. The difference between this and 985 brings the cream to the surface; it is so little that the cream makes haste very slowly. The globules never all come to the surface. Other circumstances being the same, the largest ones rise soonest, as they are specifically lighter and in rising meet with less resistance in proportion to bulk than the smaller ones. Many of these never make a start toward the surface at all. Neither do the larger ones always rise, some of them settle instead of rising. In placing in a glass tube sixteen inches long, milk on which the cream appeared to rise perfectly, leaving a blue skim-milk, and letting it stand twenty-four hours, and then drawing milk from the bottom of the tube, globules of good size $\frac{1}{2000}$ of an inch in diameter) appeared mingled with the smaller ones. As globules of unequal size remained at the bottom, it is evident they did so because of a difference in their composition which made them specifically heavier. Those remaining at the bottom of a deep vessel appear less opaque than those which rise to the surface, those rising first, being the most opaque. Analyses of skim-milk show that about one-eighth of the fatty matter in milk never gets to the surface.

The smaller the globules, the slower they rise; and some of them dwindle down to such minuteness that 
they would not rise through three inches in a week, if the milk could be kept sweet that length of time. Cream will continue to rise till the milk gets thick, be that time short or long. The best part rises first. If milk is skimmed every twelve hours, and the cream of each period churned separately, the product of the first period will be the highest flavored and the highest colored, and the color, quantity and flavor of each successive skimming will diminish to the last, but the keeping qualities will grow better. The fourth and fifth skimmings will be quite pale and insipid. Where a high flavored article is desired, it is not advisable to continue the process of creaming too long. What will rise in forty-eight hours, at sixty degrees, on milk four inches deep, is all that it is generally profitable to separate. What comes up after that is so white and tasteless as to do more injury, by depressing the flavor and color, than it can do good by increasing quantity.

The second essential point is the fact that fats expand and contract more with heat and cold than water, and more than the other elements of milk. The difference in specific gravity between milk and cream is varied by the circumstance of temperature. It is greatest when hot, and least when cold, and this fact materially affects the rising of the cream.

As fat, of which cream is chiefly composed, swells more with heat and shrinks more with cold than water, of which milk is chiefly composed, it is evident that, if other circumstances are alike, crean will rise better in a high temperature than in a low one, since the fat in cream, by swelling more with heat, will be relatively lighter when both milk and cream are warm than when both are cold-the temperature in both cases neither rising nor falling, but standing without 
change. Most people seem to have the opinion that milk must be cooled to make the cream rise fast, and that the colder they can get it, the faster the cream wili rise. The fact is exactly the reverse when the temperature is stationary. The colder the milk, the slower the cream rises, because there is less difference between the specific gravity of the cream and milk, and because the milk is more dense and offers more obstruction to the motion of the cream globules. It does not rise as fast at 60 as at 160 degrees. In butter making the waste of butyraceous matter is confined almost wholly to the minutest particles of cream. These rise with great difficulty and very slowly. Those who make butter from whey often heat the whey to I 70 degrees, when the difference in specific gravity between the fat in the cream and the water in the whey becomes so great, that the cream all rises to the top in a short time. By cooling to 60 degrees, five or six times as much time is required to effect the same result.

In noting the difference of expansion in water and fat, by varying the temperature, the fat in rising from 60 to 130 degrees, swelled, as near as I could determine by graduated tubes, twice as much as water by the same increase of temperature. Water expands unequally by an equal increase of heat according as the increase is made at a high temperature or a low one. Water rising from 40 to 50 degrees swells only one-tenth as much as when rising from so to 90 degrees, and in cooling, of course the same law is followed in the shrinkage. In falling from a high temperature to a low one, the water in the milk shrinking little and the fat much, the specific gravities come nearer alike, and hence the fat rises more slowly at low temperatures 
than at high ones, when the temperature is unvarying. Water is a better conductor of heat than fat; hence, when the temperature of milk varies either up or down, the water in the milk feels the effect of heat or cold a little sooner than the fat in the cream does; therefore, the cream is always a little behind the water in swelling with heat or shrinking with cold-thus climinishing the difference between the specific gravity of the milk and cream when the temperature is rising, and increasing it when the temperature is falling. The difference between the specific gravities of milk and cream, when both have the same temperature, is but little. It is barely enough to give a sluggish motion to the cream. Where the difference in gravities is so very small, a slight increase or decrease is sensitively felt, and the careful observer will have no difficulty in noting the retarded ascent of cream in a rising temperature, or its hurried ascent in a falling one. The fact of a hurried rising of cream in a falling temperature of milk has great significance in butter dairying; but, though always open for recognition in every butter making establishment, whether corporate or private, it has failed of being recognized both by dairymen and dairy writers-perhaps because they have had their minds intently bent on some ideal temperature or depth, as the sine qua non.

A fourth consideration is depth; other circumstances being equal it must be evident that it will take cream less time to rise through a thin structure of milk than a thick one-less time to rise through three inches than twelve. But depth involves temperature and makes the question of depth a complicated one, It cennot be consistantly considered alone, for there is no particular depth at which, under all circumstances, 
cream rises better than at every other temperature; and of temperature it may be also said, that there is no particular temperature at which under all circumstances cream rises better than at every other temperature. Depth and temperature are somewhat correlative; in practice they affect each other, and they should be considered in connection. Further experiments are necessary to note all the facts which result from the combined influence of these two circumstances, but a little explanation may help to show how these general statements are connected with deep and shallow setting. If two vessels of milk at $80^{\circ}$ and of the same depth and quality, are set in a room which has an eren temperature of $50^{\circ}$-one being cooled to $50^{\circ}$ before setting and the other not - the vessel which is cooled will not throw up cream so rapidly nor so perfectly as the one which is not cooled before setting, because the former will receive no benefit from an increased difference between the specific gravities of the milk and cream by reason of a falling temperature. If, after the cooled milk has stood at $50^{\circ}$ until the cream ceases to rise, it is warmed and then set again in a room at $50^{\circ}$, or if, without warming, it is set in a colder room, more cream will rise because of the falling temperature that will in either case follow. The same results would be obtained, but in a feebler degree, if the milk which was not cooled before setting were treated in the same way, provided it was set shallow, say two inches deep, in the first place. Milk set shallow in a cold room will not throw up its cream so perfectly as when set in a warm room, because when shallow it drops to the temperature of the room before the cream is all up, and having ceased to derive any benefit from a decreasing temperature, it will not 
now throw up its cream with sufficient force to bring the heavier particles to the surface. Bearing in mind that the warmer milk is kept, up to a certain point, the sooner it spoils, $65^{\circ}$ is a high temperature to set milk in; yet, milk set two inches deep at $65^{\circ}$ will throw up its cream quickly and perfectly when it would not do so if set at $50^{\circ}$, because the milk will very soon fall to the standard of the room and cease to derive any advantage from a falling temperature. As cream rises more rapidly in a high temperature than in a low one, it will, at two inches depth, in a temperature of $65^{\circ}$, come up fast enough to rise perfectly before souring begins. If we should set warm milk in vessels six inches deep, in a room at $65^{\circ}$, it would take the cream so much longer to come up through that increased depth, and it would remain warm so much longer that the milk would spoil before it had all risen. But let the deep vessel be placed in a cold room, say $50^{\circ}$, and the result will be altogether different. Unlike the shallow' milk in the cool room, the increase of depth and bulk will so much prolong the time of cooling that the cream will all, or very nearly all, rise before the milk has dropped to the temperature of the room. We can now see how the arguments of the advocates of deep and shallow setting are derived. An experimenter having observed a fact like the last, in which the cream is perfectly raised in a deep ressel, declares in favor of deep setting as the best and only sure way to get all the cream; and another one, having set milk two inches deep at $65^{\circ}$, and accomplished the same result, takes position on the other side and becomes an advocate of shallow setting under all circumstances. Each haring weighed but half the facts, his arguments cover but half the ground. 
Had both investigated more thoroughly, they might have been agreed in the position that all the cream can be obtained by either deep or shallow setting, if there is a proper adaptation of conditions; and they might go farther, and lay it down as a rule, that the warmer the room in which milk is set, the less should be its depth, and the cooler it is, the greater may be the depth. By having the foregoing general statements well grounded in the mind, and keeping in distinct remembrance the relation between tempcrature and depth, especially the important effect of a falling temperature, any one can, with a little experience, be successful in raising cream perfectly at any temperature from $40^{\circ}$ to $70^{\circ}$. It will become clear that, though certain temperatures are desirable, they are not absolutely necessary to obtaining all the cream. There is a great deal of talk about an even temperature for raising cream, and so far as the dairy room is concerned, it is desirable that it should be uniform, because it gives regularity to all the operations of the dairy and aids in securing uniform results, but so far as the single fact of raising the cream is concerned, it is better that the milk should not be kept at any one particular degree, but at a temperature steadily falling as long as possible. It is an inportant item in heating milk before setting it, that it gives a wider range of temperature for it to fall through. Low cooling contributes to the same result, at the other end of the scale; but it is necessary to observe that, in using low temperatures, the depth and bulk of milk should be graduated to the warmth, so that the rising of the cream shall not be arrested by too soon bringing the temperature of the milk to a stand still. If the cooling is sufficiently rapid to prevent the milk from 
souring before the cream is all up, the slower the cooling the better, as the benefit of a falling temperature will be more fully availed of. This is one reason why cooling milk in cold air is better than cooling in cold water; the water being a better conductor than the air, brings the temperature to a stand still too soon. But, at the beginning, the rapid cooling will throw up cream faster than slow cooling, but the slow cooling produces the best results in the end.

The greater the number of degrees of temperature through which milk falls while the cream is rising, the more perfectly does it come up, other circumstances being equal. Milk cooled from $80^{\circ}$ to $60^{\circ}$ in twelve hours will not throw up its cream so rapidly nor so perfectly as when falling from $80^{\circ}$ down to $40^{\circ}$ in the same time. Facts like this have often been noticed and a wrong inference drawn from them. It is supposed because cooling to $40^{\circ}$, instead of $60^{\circ}$, makes the most butter, that cream rises better the lower the temperature. But this inference is unwarranted and untrue, for if a mess of milk is divided and one-half cooled to $60^{\circ}$ and the other to $40^{\circ}$ before the cream is allowed to rise, and kept at those tem peratures respect. ively, the cream will rise more rapidly and perfectly on the half cooled only to 60 degrees. This fact may be easily verified by experiment, and the general principle confirmed that cream rises better at high temperatures than at low ones when the temperature is unvarying. The other experiment will prove a very satisfactory demonstration of the fact in regard to the influence of raising cream while the temperature is depressing. Particular attention is called to these general facts, because some experimenters who are regarded as authorities, have fallen into the error just 
alluded to. In effecting a separation between milk and cream, the influence of a falling temperature is so efficient and has been so long and so entirely overlooked, that it deserves a more extended notice than can here be given, but what has been said may be sufficient to direct attention to it. The practices in Sweden and the experiments of Tisserand and others, in cooling to low temperatures, which are just now going the rounds of the agricultural press in this country as evidence that cold favors the rising of cream, are obviously the result of a falling temperature rather than a loze one, per se.

Another important fact that affects the separation of cream, is the growth of minute organic germs in the milk, which, up to a certain point, is greater the higher the temperature.

There are thousands of germs in all milk exposed to the air, that are ready to start up and grow whenever the milk is warm enough for them to do so, and by their presence, hinder the upward passage of the cream globules. The sour milk cells, are the principal obstructions in the way of the rising of cream; they begin to form long before the milk begins to appear thick. The growth of other germs do injury by altering the flavor.

Organic germs are prevented from interfering with the rising of cream, either by retarding their growth by cooling the milk, or killing them by heating.

\section{SKIMMING.}

The time at which skimming should be done and the best mode of doing it, are also subject to modification by circumstances. The most general rule is to 
skim when the milk first begins to be sensibly sour. When milk is to be used only for butter making and is set in broad vessels with little depth, the rule of fitness for skimming is a certain consistency of the cream. When the cream becomes so thick that it will not flow back behind the finger as it is passed through it, it is time to skim. If the vessels are very deep and the temperature very low, this rule will not be applicable, for the cream will remain soft and flowing for a loug time after it is all up. Milk which is cooled down much below $50^{\circ}$ while the cream is rising, remains sweet almost indefinitely. On such milk the cream continues to rise as long as it is swect, but after sixty or serenty hours the quantity is almost inperceptible, and the quality so poor as to detract from the value of the butter more than will be added by increased quantity. The judgment of the operator must be the final appeal in all such cases. The sooner it is taken off after it is all up the better. There is no advantage in keeping cream standing exposed to the air longer than is necessary for it to rise.

In my early dairy experience a skimmer was the only implement made use of for removing cream from milk, but with me it has long since been laid by as neither convenient nor appropriate for the purpose. The impression once generally prevailed, and does to some extent still, that the cream should be separated as completely as possible from the milk before churning. But this is not best-the butter is better and more of it is obtained by churning a portion of the milk with the cream. The cream and the milk taken with it, should constitute one-quarter of the milk. To churn less than this tends to injure the grain of the butter, by having too mach butter in proportion to the 
liquid in the churn. The butter suffers by friction with a small amount of liquid in churning, which is obviated with more liquid. On this account some of the best modern butter makers churn the whole milk; but I do not regard this as necessary. Since it is desirable to have some milk go with the cream, a skimmer is not the best instrument to remove it with. In its place I use a broad and shallow tin scoop resembling a dust pan or a curd scoop, which I pass under the cream so as to take in the top of the milk with it. The top of the milk often contains considerable butter which this mode of skimming saves, but which is lost in using a skimmer, and not unfrequently some of the thinner cream also. In deep setting cream should always be dipped off.

\section{PREPARING CREAM FOR CHURNING.}

From the time it begins to rise, cream is all the time changing till it is at last consumed by the products of the fermentation which goes on in the milk, if left standing long enough. Ripeness is the term used to indicate the degree of advancement in this changing. The principal circumstance which affects the ripening of cream is temperature; the cooler it is the slower it ripens and vice versa. To produce the best result for general use and the largest yield, the cream to be operated on should have a certain degree of ripeness which is indicated by a moderate sourness, and it should all be equally advanced. If some of it is sweet and some of it sour, or parts of it are of unequal sourness, the unlike parts will not churn in the same time and a part of the butter will be left back in the buttermilk. If a churning is to be composed of 
cream skimmed at different times, the different messes should be well mixed and stand together twelve hours at sixty degrees. If it is colder, it should stand longer, as the changes are slower and it will take a longer time for it all to assume the same condition. If it is warmer than sixty degrees, less than twelve hours will make it all alike. Unless there is some special reason for churning immediately, it is better to let cream stand twelve hours before churning than to churn as soon as it is skimmed, for it is generally not all ripe alike when skimmed, though all taken off of one vessel. The upper part which is exposed to the air and light, generally ripens faster than the under side, if the air has humidity enough to keep the top soft, and it will require time after skimming and mixing to make it all assume the same condition. If the air is so dry as to dry the top of the cream, it will require time for it to soak up soft again. When the circumstances are such that neither of these conditions occur, there is no objection to churning as snon as skimmed, if enough for a churning is skimmed at a time. It is not well to keep cream very long after removing it from the milk. Butter makers often lose by keeping it too long. Cream changes faster than milk. It both sours and decays sooner than milk under the same circumstances. This makes it necessary to keep the cream jar cooler than the milk, if it must be kept, but it is better and safer to churn often. If there is not enough for a churning of the cream alone, it is better to add milk and let the churning go on, rather than keep the cream beyond the proper time.

If the temperature of the cream is to be changed before churning it should be done gradually. The best way to do it is to place it in a tin vessel and surround 
it with water, either cold or warm, according as the temperature is to be lowered or raised.

\section{FLECKS IN CREAM.}

White specks in butter come from different causes. There are at least two causes which seem to produce. this result: one is dried cream, but it is very seldom that dried cream produces the specks, for, if cream is dry when churned, unless the butter comes very quickly, churning long enough to bring the butter will dash the dried lumps to pieces. They will become soft and mingle with the buttermilk, and of course, no longer remain in lumps. But sometimes that may not occur; they may not be so broken up but that particles of cream stuck together will appear. The usual cause of flecks in butter is the coagulation of drops of milk by the action of germs in them. In the fall, when the cows are being dried off, and the milk remains some time in the cow's bag, specks are very likely to appear. If a glass vessel that can be looked through is used, flecks may often be seen developing in the bottom. The growing germs will curdle a little milk and by the fermentation which centers around that spot, gas will be formed in the fleck and it will become lighter than the milk and work its way up to the top, where it will be found in the cream. At another time, it will develop in the cream. The germ will coagulate a little bit of milk and remain there; and when churned, the lump of curd will not be broken to pieces. If such milk is scalded the white specks will not appear.

These specks are sometimes developed by the action of air and light. I have taken two pans 
of milk from the same mess and set them side by side; one pan would have the specks in it, and the other would not. I was at first a little puzzled to account for this; but after a while, I found that the light, which shone into a window, struck one pan and developed the germs, thus making the specks. - The development was not so rapid in the other pan, because it was in the shade, so the specks did not appear. I have had them appear in one cow's milk and not in another's, when the milk of both cows was placed just alike, and subjected to the same influences, in every particular. Specks of dried cream may not injure the quality of the butter materially, but when the condition's of milk or cream are such as to develop flecks by coagulating specks of milk, I do not think as good butter can be made. The specks in butter may be dried cream, but they are oftener floating curd, made by the development of germs in the milk. A current of air will in a very short time produce flecks; it will ripen the germs that lie on the top of the cream, so that little specks will very soon form and be seen floating on the surface. It will bring other germs into the same condition, just as one apple rotting in a barrel will make half a dozen others rot around it. Those which form down in the milk are composed almost entirely of curd, the atoms of which are bound firmly together probably by the mycelium of the fungus which has occasioned their formation. Those which form in the cream are partly curd, but largely cream which do not break to pieces by the action of the churn. Some butter makers after the cream is ready for the churn, strain it to pulverize whatever there may be of flecks from dried cream or any other cause in it. The instrument used for this purpose is a cone-shaped 
strainer, the pointed end of the cone being made of wire gauze, with a band of tin at the broad end as a support. An interior cone of wood is made to rotate over the gauze and crowd the cream through, pulverizing any lumps and grinding flecks or fat to atoms if any there be in the cream. But this is a labor of doubtful utility. If the flecks come from dried cream the difficulty would be sufficiently removed by mixing and stirring the cream and letting it stand awhile before churning. It takes but a very short time for dried cream to soak so soft as not to be distinguished from the rest. If it would not do so, crowding it through the meshes of a wire sieve would not help the matter much. In case there are flecks it would be much better to leave them whole, as they would be much less likely to get mingled with the butter than in their pulverized state. They never churn in either case and their presence in the butter detracts from its good quality and keeping. Flecks usually come from a faulty condition of the milk, and the butter made from such milk should not be mixed with other butter, as it will not keep like butter from sound milk. They may be prevented by scalding the milk in which they occur to $130^{\circ}$, to kill the germs which occasion them. When the milk is very much affected a higher heat will be necessary.

\section{COLORING.}

When butter is very pale its market value is enhanced by coloring it. This should always be done in the cream just before churning, and it is best done with annattoine or some preparation of annatto. No coloring should be added directly to the butter; it would be impossible to incorporate any coloring ma- 
terial evenly with the butter after it has been churned, without injury to the grain of the butter, and I know of no material which could be used that would not injure the butter by direct contact. Some color butter with carrot juice, and a few do so whether it is to bc sold or used at home, because they like the modified flavor given to the butter by the addition of carrot juice. But the great majority of consumers, especially those with cultivated taste, prefer the taste of good butter to that of carrots, and to all such the carrots do a double injury, for they injure the keeping as well as the flavor. The vegetable matter soon decays and works the destruction of the butter by its own decomposition.

Butter makers can prepare their own coloring by dissolving annattoine in potash, using equal weights of potash and annattoine, with water enough to give the strength desired. It is most convenient to make it concentrated. Some add as much sal soda as potash, and think the color is improved by the addition. When annatto is used it should be dissolved in strong ley and boiled, then strained, and when it has settled, the purc liquid turned off from the sediment.

Artificial coloring for butter should always be sparingly used. The added hue is seldom, if ever, quite equal to the natural one, and if it is a little too strong it disfigures by giving an unnatural appearance.

It requires some skill to prepare the coloring, which is only acquired by experience. 'To be sure of having a good article and to avoid the muss which its preparation generally makes, it is better for all small dairies, at least, to buy the small amount they use, ready made. The American preparation of Wells, Richardson \& Co., Burlington, Vt., and that of Nicholson, are 
among the best, and one or the other, or both, are for sale by all dealers in dairy supplies.

\section{CHURNING.}

Before discussing the process of churning and working butter, a brief explanation of what is understood by the grain of butter seems appropriate.

It has already been stated that butter is made up of the fat globules in milk which adhere after having been divested of their delicate membraneous envelopes by churning, and that these little atoms of fat are themselves made up of several varieties of fatty elements, such as stearine, palmatine and oleine. These fatty elements have in each globule not only a definite composition, but also a definite organization, as much so as that assumed by the several parts composing an egg.

When butter can be churned and worked so as to leave the disrobed granules of fat whole, or nearly so, if a piece of it at $60^{\circ}$ or below is broken in two, it will show a clear and distinct fracture like broken cast iron, and when the fracture is viewed with a magnifier, it will show a granular structure. This unbroken and undisturbed condition of the granules of fat, is what constitutes the grain of butter.

In this condition butter has its best flavor and best keeping quality. If the churning, working or handling has been such as to mash and break the granules, the fatty elements composing them become mixed and the oily parts spread and give to the whole a greasy appearance, and the fracture, instead of being distinct like that of cast iron, will be more like a fracture of lard, green putty, or salve. The more the atoms of fat 
are mashed and broken, the more the flavor is depressed and the sooner the butter spnils, just as an egg might be expected to spoil the sooner for having its contents disturbed and mixed up. The difference in the keeping of butter whether the grain is broken or not is very great. When the grain is all right butter may be kept under great disadvantages and almost anywhere. If the grain is spoiled it will hardly keep long under any circumstances, and the flavor is about as much affected as the keeping.

In all the processes, therefore, of making and handling butter, the preservation of the grain should be kept constantly in view, and those methods adopted which will do it the least violence and have the least tendency to make it appear greasy. The right temperature too must be observed, for if too cold when manipulated, the granules will grind against each other and injure by the friction, and if too warm, the grain is spoiled by the too easy mixing of the softened fats.

The object of churning is to divest the milk globules of their delicate membraneous covering without breaking or disturbing the granules of fat within them. This is best done by a force in which motion and pressure are combined. Such a power is much better than motion and friction. Repeated impulses of motion and pressure act upon the entire mass at once and alike. Notion and friction act only upon such particles as the instrument used comes in contact with. Friction wears off the pellicles and does its work unevenly. The larger globules meet with the most friction and hence their pellicles are worn off first. These gather into lumps before the smaller ones become churned, If the churning continues till the smaller ones "come,' 
the larger ones become over churned and greasy by the excessive friction. Pressure operates upon large and small nearly alike, and the globules of different sizes come nearer together and more perfectly, producing more and better butter.

The devices for churning are very numerous. The one most extensively in use in this country is the old dash churn. It is also the hardest to operate; but when properly constructed it does its work in the best manner. To do the best work they should be barrel shaped, having a moderate swell in the middle, and the dasher should be large enough to occupy three-quarters of the area of a horizontal section of the middle of the churn. The dasher should either be a complete circle or have

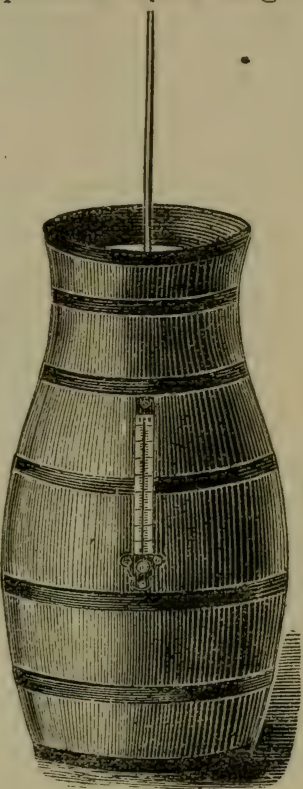

Fig. 35 . the form of figure 36 , the floats or wings being broad and whole instead of being narrow, notched and full of holes, as in figure 37. The large dasher as here figured, will require about once and a half as much power to operate it as the smaller and narrower one with its nutches and holes, but it will give more and better butter and do its work in one-half the time, or in the same time at a few degrees lower temperature. The smaller the dasher the easier it works and the longer time it takes to bring the butter, and the poorer the butter. The more notches and corners and holes it contains, the more friction will it occasion, the more 
will the grain of the butter be injured, and the greater the tendency to become greasy. The most objectionable form of dasher I have met with on account of making the butter greasy, is the system of checks in figure 38 .

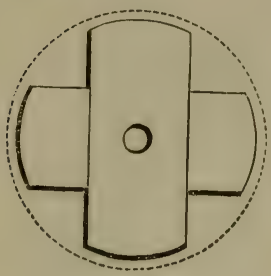

Fig. 36.

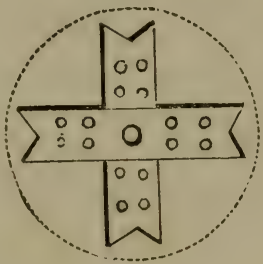

Fig. 37.

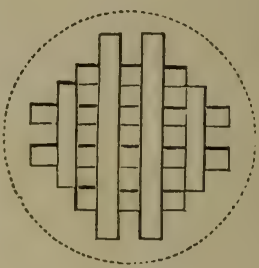

Fig. 38 .

There are other churns which operate essentially upon the same principle as the dash churn, and do their work easier. Among these I may name Bullard's oscillating churn, which has a reciprocating motion, works easily, and produces its effect by caus-

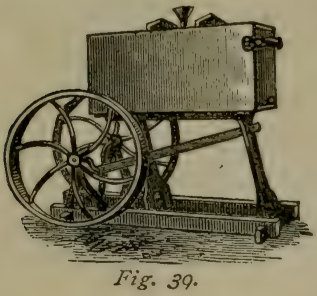
ing the cream to strike the ends of the rectangular box with a thud as it suddenly changes the direction of its motion, producing an effect upon the whole mass of cream equivalent to the stroke of a large dasher in a dash churn. The barrel churn revolving endwise, produces a similar effect; so also the revolving rectangular churns, whether suspended at the middle of opposite sides, or at opposite corners, as in Whipple's rectangular churn. These churns require considerable diameter, two feet or more, to make the cream fall far enough to produce a sufficient concussion in falling from side to side. 


\section{Butter Making.}

Next to the old dash churn, the Blanchard churn is the most popular, a hundred thousand of them are said to be now in use. It is cheap and durable, quickly cleaned and operates easily, and gives general satisfaction to its numerous patrons. It has recently become very popular as a factory churn, large sizes having been made specially for that purpose.

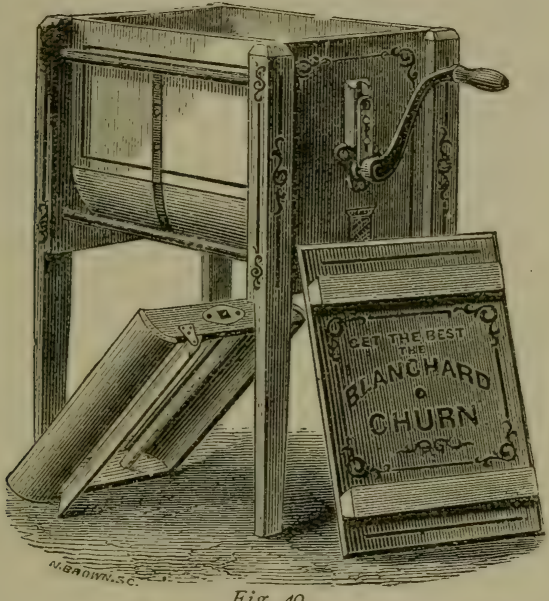

Fig. 40.

BLANCHARD CHURN.

The choice of a churn is sometimes of considerable consequence and sometimes not. When butter is to be made from the milk of Channel Island cows, the Holderness or the Devon, the butter comes so easily that it makes little difference about the kind of churn or whether the cream is sweet or sour. With the milk of the Natives, the Ayrshire, the North Holland and the Shorthorn cow, the case is often quite dif- 
ferent. Their cream generally requires so much churning that the best apparatus to do it with must be selected or injury will be done to it.

The best temperature for churning is generally sixty degrees, but it varies with circumstances. Sour cream not only churns easier, but will come at a lower temperature than sweet, but it should not be too sour. If it is allowed to get very sour the quantity of butter will be diminished and the labor of churning increased, instead of diminished, and perhaps the cream injured so much that the butter will never come. When whole milk is churned it requires to be about four degrees higher than the cream of the same milk, both being in the same condition as to sourness. In the dash churn the temperature of the cream should vary with the size of the dasher. Cream, just a little sour, will churn well at $58^{\circ}$ with a dasher equal to $3 / 4$ of a horizontal section of the churn; if equal to $1 / 2$, it will churn well at $60^{\circ}$ to $61^{\circ}$; if only equal to $\mathrm{I} / 4$, it will require the cream to be $63^{\circ}$ to $64^{\circ}$. Excepting cream from the milk of Jersey cows, and milk of similar quality, sweet cream will require to be about four or five degrees higher than it would if sour, to churn in the same time.

All other circumstances being the same, the amount of churning necessary to bring the butter increases with the distance from the time of calving, or to churn in the same time the temperature requires a slight but gradual rise. This increased labor of churning is occasioned by a gradual decrease in the size of the milk globules. For this reason the milk of farrow cows does not churn well with new milk. Cream from the milk of a cow eighteen months after calving, requires about once and $a$ half the time for 
churning as at one month after calving. The conversion of cream into butter is greatly facilitated by scalding the milk or cream while it is sweet. The scalding may be done when the milk is first drawn, or at any time afterward, provided it is not postponed till souring begins.

Winter churning is often very difficult and sometimes impossible, without the aid of scalding, and the higher the scalding, the easier the cream churns. At other seasons of the year, milk, which is for some reason faulty, often has the labor of churning greatly abridged by scalding nearly to a boiling heat.

At the commencement of churning the operation should be slow till the cream is well mixed, after which the speed may be increased to the uniform rate to which the churn is adapted. But in no case should it be very rapid or do great violence to the cream; a moderate motion makes the best butter. This is especially true when the butter begins to come. If the churning has been rapid before, it should slacken as soon as the butter begins to collect in visible lumps, as it will be more easily affected by the friction of the churn after the lumps form than before.

It is generally customary to collect the butter into a solid mass before leaving the churn-to "gather" it. This is best done by cooling the contents of the churn gradually, as the butter begins to come or show signs of coming, and operating the churn slowly.

Butter gathered in the churn always contains more or less buttermilk, which would soon spoil the butter if not removed. There are two ways of removing it. One is by kneading it in water or brine, and the other by kneading it without water. One is called "washing" and the other "working." The former 
removes it much more readily than the latter. As to which is the better way there are conflicting opinions. Some would not have their butter washed on any account, because they believe the flavor and the keeping of the butter are thereby injured; while others are equally tenacious in the use of water, and believe as firmly that the flavor and keeping are improved by washing.

The flavor of butter which has been washed is different from that which has not been washed. The difference between washed and unwashed butter is analagous to the difference between clarified and unclarified sugar. The former consists of pure saccharine matter, the latter of sugar and some albuminous and flavoring matters which were contained in the juice of the cane mingled with it, which give a flavor in addition to that of the sugar. Brown sugar though less sweet, has more flavor than clarified sugar. When unwashed, there is always a little buttermilk and sugar adhering to the butter that give it a peculiar flavor in addition to that of pure butter, which many people like when it is new. Washing removes all this foreign matter and leaves only the taste of the butter pure and simple. Those who prefer the taste of the butter to the foreign ingredients mixed with it, like the washed butter best.

The assertion is often made, and many people believe, that water washes out the flavor of butter, but it only cleanses the butter of the buttermilk, sugar and milk acid, which may adhere to it, just as clarifying sugar removes from it the foreign matters which modify its true flavor. The flavor of butter consists of fatty matters which do not combine with water at all, and cannot therefore be washed away by it. 
The effect of washing upon the keeping quality of butter depends upon the purity of the water with which the washing is done. If the water contains no foreign matter that will affect the butter, it will keep better for washing the buttermilk out than by working it out. But if the water is hard from the presence of lime, or contains anything that could injure the butter by contact with it, washing becomes an injury instead of a benefit to its keeping. Nothing but the best and purest water should be used about butter. Very hard water is always objectionable. It is not, however, so objectionable as the water from wells, which contain a muddy sediment so full of organic matter as to become tainted. Water standing orer such mud takes in the taint, and if used for washing butter, is sure to injure it for long keeping. There is a good deal of well water, otherwise good, which is rendered entirely unfit for using about butter by reason of sediment at the bottom of the well.

This is frequently the case in dry times when wells get low and the influx small, and the water in them is too slowly changed. I once saw a lot of nice butter spoiled entirely for table use, in twenty-four hours, by being washed with water from a well which was low, and the sediment in its bottom had become affected. It is not a very uncommon occurrence to find water in wells which people do not object to using for culinary purposes, so much affected by sediment as to be detrimental when applied to butter.

For washing butter, brine is better than water alone, especially when the weather is warm and the butter soft. It cools the butter and takes up the buttermilk more readily than fresh water. In many cases it will prevent water from injuring butter that would be 
objectionable if used without the salt. It is perhaps needless to say that the salt used for this purpose should be of the purest kind.

A new practice in manipulating butter in the churn is coming into use among fancy butter makers in New York and New England, by which a saving in labor and an improvement in the quality of butter is effected. As the plan originated with John Higgins, of Speedsville, N. Y., I will describe his method of working: Mr. Higgins uses the dash churn with a large dasher as recommended on a previous page, and churns with a slow stroke, about forty to the minute, till the butter begins to come, at which time the contents of the churn are $59^{\circ}$ or $60^{\circ}$. He then turns in cold water, at two or three short intervals, till the cream rises high enough to prevent the dash from quite clearing it in its upward stroke. The water to inake this increase is made cold enough to reduce the contents of the churn to about $55^{\circ}$. The motion of the dash is slackened to about twenty strokes per minute, and so continued till the whole mass of butter forms in granules of the size of small peas or finer, which it will always do if the temperature is sufficiently low. The granules of butter which are thus formed are very hard and compact, and entirely free from buttermilk in their interior. The advantage of gathering in this granulated form is, that the butter is perfectly freed from buttermilk by rinsing with cold water without any working whatever, thus avoiding entirely the injury usually done to butter by that process. To effect this, Mr. H.'s practice is to dip or skim off the butter in any convenient way and put it into a vessel of water at $54^{\circ}$. A little stirring relieves it of so much of the buttermilk that a second washing cleanses it entirely. It is then laid on 
the butter worker and as soon as the water has drained off it is ready to salt. Six pounds of salt to roo pounds of butter are mixed with the granulated butter by stirring, and a few strokes of the lever bring the whole into a solid mass, which is set away in a cool room six hours, and then receives a light working when it is ready to pack. This method of gathering in a granulated form preserves the grain of the butter in the most perfect condition, and gives to it the highest flavor and the best keeping quality. It has been found that when butter is thus gathered in granules it may, as soon as rinsed, be at once put into vessels in its granulated form, without either working, salting or packing, and the vessel filled with strong brine and closely covered or tightly headed, and that it will in this condition keep unchanged for long periods. Butter made in July and put up in this way, was opened in the following January, and when the brine was rinsed off it was found to be just as fresh and sweet as when it came from the churn. Upon salting and working it into solid form for use upon the table, it had all the freshness and aroma of butter just made. This mode gives the finest gilt edged butter.

\section{WORKING BUTTER.}

The object of working butter is to free it from buttermilk, to mix salt through it evenly, and to make the mass as solid as possible.

The less labor with which these ends can be accomplished, the better for the butter. If well washed in the churn or in a butter bowl, very little working will free it from the water left in by washing; if unwashed, considerable working may be saved by pressing the 
butter with a damp linen or cotton cloth, alternating with the use of the ladle or lever.

There are a great many devices in use for working butter-quite too many to be separately described. Some of them are very excellent and convenient while others are only supposed improvements. For small dairies the common wooden bowl and ladle are in general use, and all things considered, are perhaps the best. For larger dairies, factory and creamery use, the slab and lever make a cheap and excellent worker, and one that is durable and easy to clean. The slab and lever do the work as perfectly as any of the more complicated workers I have examined, and cost the least and last the longest, and hence are in extensive use where large quantities of butter are manufactured. They are made of two inch white oak, maple or birch plank, three to six feet long and two to four feet wide at one end, and half as wide at the other. A thicker plank is often used. It stands on three legs and inclines toward the narrow end so as to drain off the liquid worked out of the butter, which is conducted down the slope by means of a shallow groove on either side of the plank. A loosely fitting standard sets. in a hole at the middle of the lower end of the plank, resting upon a shoulder, and fastened in place by a pin through the end, which reaches down below the plank. Through a hole in this standard one end of the lever is inserted and the other is handled by the operator. The working is best done by pressing upon the butter with the lever which should be four inches through, and which may be square, octagonal, three-cornered, round, or flat on one side and round on the other, to suit the fancy of the workman. The structure of this simple butter 


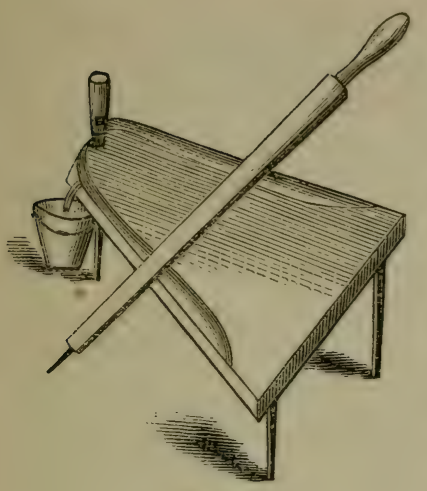

Fig. 41 .

worker, if not already familiar, will be understood by figure 4I.

With whatever machine the butter is worked the working should be done by pressing on the butter, and all rubbing, sliding, or grinding motion most carefully avoided, as it breaks the grain and makes the butter greasy.

The temperature of the butter should be $5^{8^{\circ}}$ to work with the best effect and greatest facility. If more than a few degrees either above or below $5 \delta^{\circ}$, the work will not be so perfectly or so rapidly done, and the grain will be affected, in one case by being too soft and the other too hard. It is a common fault with butter makers to work their butter too much. A watchful attention is necessary to guard against this. Not a stroke of the ladle or lever should be used beyond what is actually needed. Every unnecessary stroke tells on the quality. As soon as ready, the salt should be evenly incorporated, always doing it with the least possible labor, and then the butter set away for six to twelve hours for the salt to dissolve, and then worked again with a light working. Some dairymen are in the habit of working but once and packing as soon as salted. This treatment will not spoil good butter, but when the finest quality is desired and the butter is to be long kept, the practice is not adrisable. When the salt is added to the butter it absorbs the water of composition and leaves the butter a little 
porous. A short second working makes it more solid. A firkin which will hold roo pounds of butter worked once, will hold about 102 pounds of butter worked twice. The second working should be barely enough to press the mass firmly together and get out a part of the brine. To remove all the brine makes it too dry, but not to work out any, leaves too much in and the texture a little spongy.

In selecting salt for use in the dairy, whether for butter or cheese, the purest made should be preferred. A reference to analyses is the most reliable guide for deciding the question of purity. The fancy of manufacturers often leads astray. There are several varieties of salt in use of which one or the other is tenaciously clung to by individual makers, and firmly believed to be better than all others, which in fact is not at all superior to many of the rejected varieties. Among the best rarieties of salt in common use for butter, may be named the Onondaga factory filled salt, the Ashton, Higgin's, Marshall, Dean's, Deakin's, Boston, Worthington, Washington and others, which are all good.

The Ashton has many favorites and is an excellent salt. Recent tests have proved the Onondaga factory filled equal to the best, and as it is generally cleaner than the Ashton, and a good deal cheaper than any of the foreign brands, it is more extensively used than any other, and is increasing in favor with fancy butter and cheese makers. It requires to be ground very fine as it does not dissolve quite so readily as some others.

Where an analysis is not accessible for judging of the purity of salt, a good test can be made by observing its behaviour in damp weather, If, when the weather 
is damp, salt will attract moisture enough from the air to appear wet, it is unfit for putting into butter or cheese. Pure salt remains dry in wet weather. It may stand in a cellar all summer without being sensibly moist. It is the impurities in salt (notably the chloride of calcium) which attract moisture and make it appear wet, hence salt which will vary with every change in the hygrometric condition of the air should be rejected by dairymen as impure and unfit for their use.

In salting butter regard need only be had to seasoning. For this purpose the quality is varied from one ounce down to one-half an ounce to a pound of butter, to suit the taste of different individuals and markets of the country. No increase of salt need ever be added for preserving butter. The smallest amount used for seasoning is always more than enough to do all that salt can do toward preserving butter. Its keeping depends chiefly on other conditions than salting.

When, for long keeping, a stronger antiseptic power is desired than is furnished by the salt used for seasoning, it had better be supplied by saltpetre, rather than by adding more salt to injure the flavor of the butter. For this purpose the salt used for seasoning may be composed of five to eight per cent. of saltpetre, finely pulverised and mingled with it. This will aid in the preservation of the butter without injury to flavor. Some people object to saltpetre, fearing its effect upon health. No well grounded objection can lie against its use on that account, unless an extravagant and needless amount of it is used. In the proportion suggested it is just as wholesome as salt, and 
like salt, enters into the nutrition of different parts of the body.

Sugar, when perfectly pure, has also a strong antiseptic quality when applied to butter, and may be used when it is known that the consumers' taste will be suited with it. But many butter fanciers do not relish the modified taste given by the sugar so well as the taste of the pure butter, and hence its general use would be objectionable.

\section{PACKING BUTTER.}

In packing butter for preservation or for convenience in transporting to market, it is necessary to guard, first, against its receiving any foreign taste or infection from the ressel in which it is packed; second, against contact with the air; third, against the effects of unfavorable temperature, and fourth, against damage and loss by soakage.

For the preservation of butter, metallic packages which would neither act upon, nor be acted upon by butter or anything it contains, would be very desirable, because first, they would avoid all loss and deterioration by soakage, second, they would impart no foreign flavor to their contents, and third, they would afford perfect exclusion from the air. Pure tin answers this demand. It allows of no soakage and is not acted upon by butter, or the water, or salt, or acids it contains, and imparts no flavor to the butter, and is only deficient in protecting against temperature. A wooden envelope would afford this protection. But it is difficult to obtain pure tin, as the tin of commerce is generally more or less alloyed with some other metal which salt or lactic acid will corrode. 
To obviate these difficulties, packages have been made of tin, enclosed with wood and lined with paraffinc, which work very well but are rather expensive.

Enameled cast iron has also been tried which is subject to the same objection as above, and also to being affected by temperature. Various other means have been tried for the safe and convenient conveyance of butter to market, but a package which will not affect the butter nor allow of soakage, and which will be air-tight and not be affected by temperature, and yet be so cheap as to go to the consumer with the butter without being required to be returned, is still a desideratum.

Wooden packages, with all their faults, continue to be the chief means for storing and transporting butter. Most of the trouble which arises from their use is occasioned by a faulty preparation of the wood before using.

Wood in its natural state is so porous as not to prevent access of air to the butter it encloses. It also contains sap which, from being dried down in seasoning, requires a long time to soak out, and gummy products which water fails to remove. If these are not taken out before use, they gradually work out by the agency of the salt in the butter, and injure it. Superheated steam or boiling hot brine will quickly take out of wood whatever of sap or gum it may contain. Brine is within the reach of every dairyman and is the most convenient agent for the general manufacturer.

To do this effectually the package should be soaked with strung brine, made with pure salt, for two or three days; then this brine turned out and boiling hot brine turned in, filling the package to the brim. 
When this has stood till it gets cold, the cask will be fit for use. All of the sap and gum which the salt in the butter can draw out will be removed, and the grain of the wood so filled with salt as to be effectually impervious to air. The heads or covers for packages, require the same treatment as the packages themselves.

For preserving butter for any considerable time and for transporting long distances, firkins or barrel shaped packages which will hold about roo pounds, are the most in use, and if prepared as above directed answer the purpose well. If soaked only in water, or if soaked in cold brine, the sap will not be so fully removed from the wood but what it will soak out into the butter and injure more or less of the part which lies next to the wood. But when prepared as described, the butter next to the wood is just as good as that in the middle of the cask.

The practice of the best dairymen in using firkins is to take out one of the heads and cover the other with salt half an inch to an inch deep. It is then packed nearly full and perfectly solid, so as to have no air spaces at the side of the package, leaving room on the top of the butter to put on a layer of salt equal to that on the bottom head. A circular piece of fine bleached muslin, having a diameter half an inch greater than the top of the butter, is wet with brine and laid over the butter, which should be very even and smooth. Then with a wooden tool shaped like a gouge with a thin edge and with a curvature corresponding to the side of the package, the edge of the muslin is neatly pressed down between the outside of the butter and the cask. The package is then filled with salt and headed, and taken to the cellar or place of keeping, and the end having the 
muslin on, turned down. In the head which was before down, but is now up, a $5 \%$ hole is bored and a saturated brine of pure salt turned onto the head till the space under the head is filled with brine and the top of the head well covered. A plug that will fill the hole is set loosely in it so that if the brine should soak away, that on top of the head will work down and keep the space full, the plug being chiefly useful to exclude light from the butter. When butter which has been well made is thus packed, it will keep a long time in a satisfactory condition. In a dry cellar that was moderately cool, I have known several instances in which butter has been kept through two summers and then put upon the market and sold the same as goods recently made. Butter for long keeping must be well made. If not well made, it will soon deteriorate, no matter how good may be the package that contains it.

Tubs should be as carefully prepared as casks which admit of heading, and unless going into immediate consumption, should be kept covered to exclude light and the top of the butter covered with brine. It is not necessary to have much depth of brine. I have noted the best results when tubs are to stand long, if a cloth is laid over the butter as described for firkins, and covered with salt an inch or so deep. Then just water enough turned on to make a thin coat of brine next to the butter, say one-quarter of an inch deep, leaving a good coat of dry salt above the brine. This affords a better protection to the butter than when the brine covers the salt.

A good many dairymen are now very successfully preserving and transporting butter in rolls. Packages which can be headed are employed. The butter is 
made into cylindrical rolls of the desired size with the ends flattened. Each roll is wrapped with a piece of fine bleached muslin cut to fit it. One head of the cask is removed and a tier of rolls standing on end is placed on the bottom, another tier upon this, and so on till the cask is full. It is then headed and, through a hole in the head, filled with a saturated brine. The hole is then plugged and the butter is ready either for transportation or preservation. The rolls present the butter in a very convenient and desirable shape for retailing. Packing in brine has one important advantage over packing in ice, as is often done in transporting butter in warm weather. After being packed in ice it perishes rapidly upon exposure to the air, while that in brine keeps all the better for having been in the brine.

A great many devices have been made which I have not space to enumerate, for keeping butter and carrying it to market in such a way that it can be placed upon the table in a more convenient and desirable form than is given to it when cut out of a solidly packed tub or firkin. In the most of these devices the butter is made into pound, half pound or quarter pound prints at the dairy, and then arranged on shelves in boxes of various patterns with or without ice. Tin boxes of a size just suited to receive the print in a fine muslin envelope, make a very safe and convenient instrument for preserving the perfect form of the print during its journey to the retailer or consumer. The tins when packed within a wooden box will carry their contents a long way without marring.

The efforts being made to get butter to market in a well preserved and tasty form, are worthy of all encouragement. There is no article of food which 
appears in the general market, whose market value is more affected by its appearance than butter. The neater and more tasty the form in which it can be presented, the greater price will it bring, the better satisfaction will it give, and the more will there be consumed to give a demand for an increased production. Some economical way of packing butter which

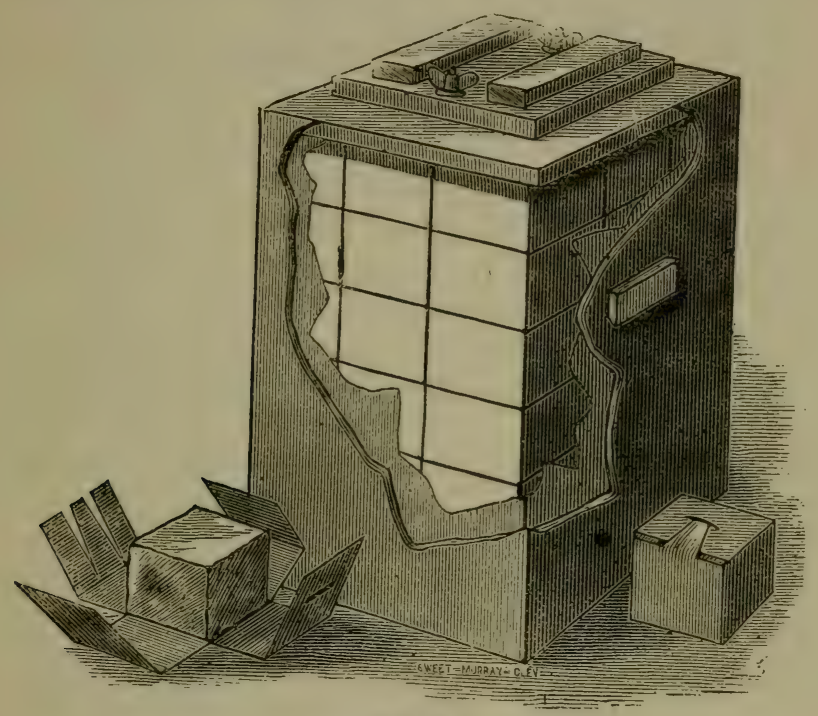

Fig. 42.

will keep it sweet and preserve it in a nice shape for the table on a large scale, and which will be comparatively inexpensive and convenient, is now much demanded in butter dairying. One of the packages which comes as near as any I have met with to answering this demand, is known as the Adams package, of which figure $4^{2}$ is an illustration. The butter is 
molded into cubical blocks weighing just one pound, and each block is encased in a thin envelope of deoderized wood, consisting of two pieces, which are cut in such a way as to hold themselves in place when put on. The blocks thus encased are packed in a box of wood with a metallic lining protected from rusting. The boxes are of three sizes, holding 36,45 and 54 pounds respectively, and each is exactly filled with the cubes it is designed to hold. A little strong brine fills all the interstices between the cubes, entirely excluding air from the butter. A cover, as will be seen, is fastened down with a couple of thumb screws, closing the box air tight. Covered with brine and excluded from the air, and packed so snugly that they cannot move or mar, the parcels are in a position to go or stay at any season or by any mode of conveyance without damage. This mode of packing seems to cover about all the requirements except the necessity of returning packages, and appears to be well adapted to the use of creameries and large dairies, who have occasion to supply distant customers, or those who desire to fetain the package till the contents are consumed. Being kept air tight and under brine there is no deterioration in quality while the contents of the package are being consumed, though several months may elapse while doing it.

When the distance is not too great and when the contents of a package are soon consumed, the return butter pail, figure 43 is in very general use for marketing butter. They are cheap and durable, and convenient to handle, and carry their contents in very good order. They answer the demands of a certain class of dealers and producerś, and will not be likely soon to go out of use. 


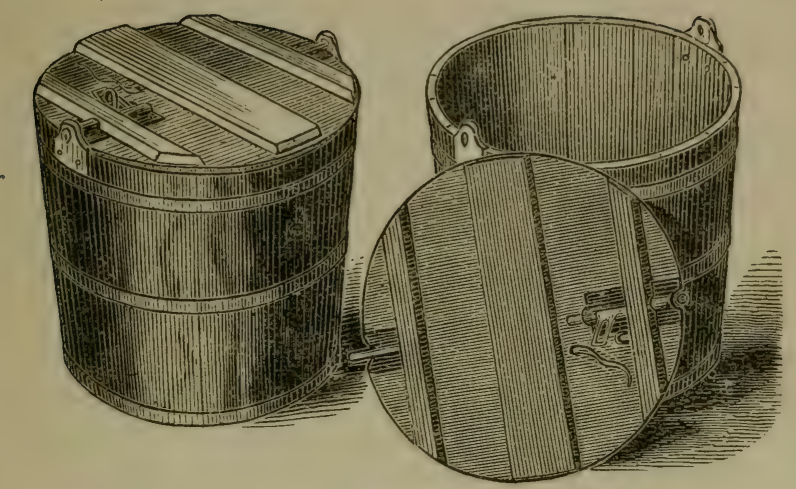

Fig. 43 .

For a smaller class of butter makers, who carry their goods to a near by town as fast as made, the package illustrated in figure 44 , for which, and the preceding illustration, I am indebted to G. B. Weeks, Syracuse, N. Y., is finding much favor. It is known as

CHESEBRO'S DOMESTIC BUTTER JAR.

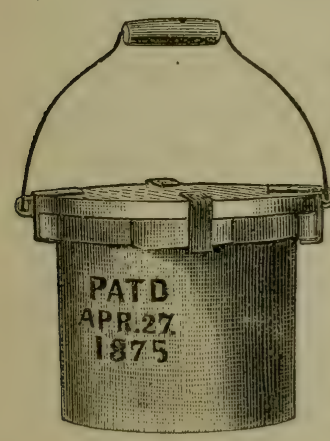

Fig. 44 .

Whenever it can be used with safety, a stone jar has long been recognized as one of the best things known to keep or market butter in. This recent invention is a stone jar with a wooden cover, which by the aid of projections on the jar, and tinned hooks on the cover, screws on the jar with a close fit, very much like the cover of a fruit jar. They are made of different sizes and fitted, as will be seen, with a bail, which makes them convenient to handle, and the projection of the 
wooden cover beyond the sides of the jar protects it against breakages. As the corer screws on air tight and the stone ware is but a poor conductor of heat, the butter carried in them remains a long time without being affected with the heat.

Having given a general account of the philosophy and principles of butter making, it may help to illustrate the subject more fully to give in detail some of the special practices in private butter dairies, butter factories and creameries, respectively. And first, a few words in regard to practices, plans of buildings, and systems of management in

\section{PRIVATE DAIRIES.}

The common error in private dairies is to allow the milk to be too warm in hot weather, and too cold in cold weather. The cream will not rise perfectly in either case, and the resulting butter will be imperfect. The loss sustained in failing to get all the butter that a given quantity of milk is capable of making, is much greater than is generally suspected. Few farmers know how much milk they are taking to make a pound of butter. They seldom weigh or measure, or even guess, at the quantity they are using. From what we have seen, and from facts gathered during a series of years, it appears that 28 to 30 pounds are usually required. Where the facts could be got at, the amount has varied all the way from 44 down to 20 pounds. If the practices in creaming and churning could he suddenly made so perfect as to get all the butter from the milk that it is capable of yielding, every fifth cow could be thrown out of the dairy, and the same quantity as at present obtained. If farmers would 
take a little pains to know more precisely what they are doing, such losses would not be endured.

Creameries and butter factories usually give us precise figures, but even they are not always fortunate in showing the happiest results. In factories which I have visited, the difference in amount required for a pound of butter has run from 22 to 28 pounds, and this difference is due, not so much to the milk, as to the different modes of managing it.

Where small dairies are kept, the conveniences for keeping milk for the cream to rise are often very imperfect. They are either in a cellar where the air is confined and impure, or in an upper room which is not protected against the variations in temperature. To subject milk to the changes of our variable climate whilc the cream is rising, or the butter after it is made, is to spoil the peculiar qualities which constitute it a delicious luxury that will command a high price, and to reduce it to the level of common or inferior goods, which, instead of being sought after, must crowd their way to the hands of the consumer. It will pay every farmer who keeps half a dozen cows to build a milk room that will be proof against the changes of the weather, one from which he can shut out the heat, and that he can warm up with a stove when too cold. It need not necessarily be very large or expensive, but it should be tight enough to guard against both heat and cold.

What has been done will perhaps indicate more forcibly what $c a n$ be done. I know of a dairy house in New York, which was built twenty years ago for thirty cows, which I will briefly describe. An excavation was made at the east end of the farm-house 18 inches deep and 20 feet long by i 8 wide, with the 
north side of the excavation on a line with the north side of the house. This large size was required on account of the use of eight quart pans. This was supplied with a good drain, a floor of flat stones, and surrounded by a double wall three feet high, laid in mortar, with an air tight space between them. On this wall was placed a wooden frame boarded up with tight joints on the outside and plastered inside, leaving an air space between the walls. The windows were double and the ventilation ample, reaching from the flagging to the floor over head. The south end of this room is protected from the rays of the sun by a churn room and shed for a horse-power to do the churning with, and the east side by shade trees set for that purpose. It was a chcap structure, but it was well planned and has answered the end for which it was built. It might, perhaps, have been better if it had been supplied with running water, but it has done very well without it. In the hottest weather the doors are kept closed during the day, and the mercury never rises over sixty-five, hence ice or running water is hardly needed. Soft water from a well that is cool (about $5^{\circ}$ ) is used for washing butter, and is considered sufficient. In cold weather, a small stove prevents the temperature from falling below sixty.

This cheap and unostentatious dairy house has held the milk for many tons of strictly fancy butter, since its erection, and is operating satisfactorily still. Its proprietor has not the advantages which some have who live near large cities and can send in their butter every day, or while fresh and new, and who, perhaps, by the fancy or caprice of some individuals or houses, can get 75 cents or $\$ I$ a pound for goods which, if offered without a name, could not be distinguished 
from hundreds of other samples that sell at no such figures. He is a plain, unassuming farmer, cntirely unknown to fame, and scarcely beyond his own immediate neighborhood, and therefore sells his butter without any prestige or display, simply on its merits. Being made as it is, remote from market and put up in plain firkins for long keeping without the use of any ice or running water, or costly buildings or apparatus, or any display of extraordinary wisdom or skill, but simply by the use of plain practical common sense, I quote the example with no little satisfaction as a complete demonstration that any dairyman, no matter how far inland he may be, nor how plain or unvarnished himself or his premises, if he has the cows and the where-with-all to keep them and a ive!l of good water, has within his reach the means of making gilt edge butter, for all the rest depends on himself. It affords a full refutation of the excuses which men are in the habit of making to themselves for sending to market butter below par instead of above, thinking honestly enough perhaps, that they cannot have a cool, even tempered milk room, or make . the best butter, because they lack ice or running water, and are too far from market to have their goods sell well. This example and others which might be cited, ought to encourage dairymen to aspire to similar excellence, and to assure them that gilt edged butter is confined to no spot.

Of course such butter cannot be made unless every step in the process is taken with care and skill. One wrong practice would be fatal to fancy butter, for a wrong step once taken in butter making can never be recalled nor effaced. Its effects will run through the entire existence of the butter. 
A description of a more modern dairy house and the practices of its proprietor, will serve to further emphasize the possibility and importance of proper facilities for butter making. It is located in Franklin County, N. Y., in the midst of the best butter factories in the county, and is designed for the milk of fifty cows. The room is about 14 by 20 feet, 8 feet high, and located in the center of the north side of the dwelling-house. Its walls are plastered, and its ceiling neatly painted; its light and ventilation comes from a north window. It contains four pans 8 feet long by $3^{1 / 2}$ wide and seven inches deep, and nothing else except the necessary.pipes for the supply and waste of water, and for carrying away the sour milk. This room is kept secure by a lock and key, and no one is allowed to enter it but when it is necessary to the care of the milk. The pans are placed 20 inches apart, with one end standing against a partition that separates the milk room from a hall passing through the house. Through this partition, a little above the end of each pan, is a hole, which is ordinarily kept closed with a plug. By means of a tin receiver and strainer, with a tube attached, the milk, when brought into the hall, is passed through the hole in the wall, and discharged into the pan, the carrier not entering the milk room. This prevents the milkers from carrying any filth into the room, or of polluting the atmosphere by any scent of the barn or milk yard that might attach to their clothes. In this way the air in the milk room is kept in the purest possible condition, and the milk is effectually prevented from absorbing any foreign odor whatever. By following this systematic neatness through all the operations of the dairy, the butter comes out 
at the end of the manufacturing process, with nothing but its own natural flavor. The operations of skimming, churning, salting, working and cooling, are the same as in the factories, except that the cooling in the dairy, which is by water under the pan, is a little slower. This latter circumstance indicates whence the more perfect flavors and larger yield of the butter. The cows of this dairy, when I visited it, were of the same breed as those supplying milk to the factories, had the same kind of pasturage, and noadrantage of soil or location, or other circumstances external to the dairy management; but the butter of this dairy was superior to that of any of the factories, both in its new and in its preserved condition; and while the factories were using 23 pounds of milk for one of butter, this dairy was using only 20.2 pounds. The factory butter was esteemed by some as gilt edged. If so, then this was gilt with finer gold. It was indeed a very choice article. The methods of manufacture pursued in this dairy, though somewhat different from those of private dairies generally, did not vary much from those pursued in the neighboring factories.

\section{A DAIRY SPRING HOUSE.}

The following answer given to a correspondent in North Carolina, through the $N$. Y. Tribune, may meet the wants of some others:

I would build a spring house with the walls double and a good dead air space between them, perfectly tight. For 35 cows, $12 \times 18$ on the ground would do; 8 feet between floors, and a ventilator overhead that could be easily regulated. Light should be admitted near the upper floor, and from a northern exposure. 
A double door would be preferable. I should prefer using large pans, as they save labor and yield more

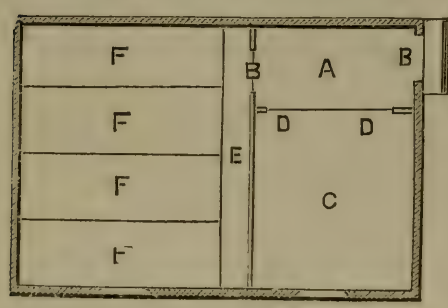

Fig. 45 . butter, but as coolerpails are to be used, I would divide the house by a partition, giving two rooms Ixxi2 and $7 \mathrm{XI}_{2}$ respectively. The pool should be placed at one side of the large room, and be I7 inches deep, and divided into four compartments, so that when a mess of warm milk is put in, it will not warm up the cold milk. The whole pool may occupy 9 feet by 12 , and be made either of cement or plank. The water should be admitted by a pipe with a faucet for each compartment of the pool, so as to regulate the flow of water to secure the right temperature. The other apartment may be used for a churn room. The diagram will show the general idea. A, is the ante-room; $\mathrm{B} \mathrm{B}$, doors; C, churning room; $\mathrm{D}$, folding doors; E, passage to the pools; F F, pools.

A correspondent of the Cincinnati Gazette, gives the following, which is a very good way of constructing a milk room, where shallow setting is used without water or ice:

Lay up a foundation with good hard burnt "bricks, or with stones, a thirteen inch wall. On this set a frame, say of five inch studding. After siding up, ceil on the inside, and fill in with charcoal. Overhead have a flooring and ceiling beneath the joists, putting charcoal between. This is a non-conductor of heat and also a good absorbent of foul air. Have doors on one end and on each side; at least two-thirds the distance back from the door, put windows with sash hung at top, to be hooked up to ceiling. Get wire gauze, paint it, and tack over each window to 
exclude all vermin, "from a cat to a gnat." Now put from four to six inches of good gravel on the floor and pound it till it is solid; then cement this, as you would a cistern, also the side walls. As your frame will not extend in as far as your wall, you can put a shelf on it, say nine inches wide, which will be handy to use for various purposes. Lastly, put a six inch tube of galvanized iron at the rear end, running from within a foot of the ground to two feet above the roof, with a cap on top and an opening on each side equal to the diameter of the tube. Then, with good sweet pans you will have milk and butter that will do to set before a queen. Scrupulous cleanliness is very important; without this, no milk house will make good butter.

The following plans for the construction of apartments suitable for creaming milk are novel and at this time attracting some attention :

Prof. J. Wilkinson, of Baltimore, Md., has developed and patented a plan substantially as follows: He buildș a dairy house of any desired form or size to suit the wants of the dairy, with double walls and floor, making it as near as may be air tight. The house may be partly below ground or wholly above, the former with a location with some inclination is preferred. An air duct is laid in the ground on the elevated side of the incline, roo feet or so in length and deep enough to be out of the reach of influence from frost and sun, and at the end, remote from the dairy, connects the duct with the open air by a tube. The other end opens into the dairy at, or near, the floor. This duct will, of course, fill with air. When the air above ground is warm, it will soon become cool by entering the duct below ground, because the sides of the duct will have the uniform temperature of the earth at that depth, which is about 60 degrees. As it cools it becomes heavy and runs down into the dairy room, which if closed and tight, will be filled with air at $60^{\circ}$, for, as the cold air passes out of the 
duct at the lower end, the warm air follows in at the upper end, and in turn becomes cool and heavy and flows down into the dairy, keeping a constant current passing into the dairy, if there is a sufficient outlet for the cooled air to get 8 ut of the way. When it is desired to stop the flow of cool air, or to lessen it, it is effected by turning a valve in the duct at its entrance into the dairy, and to prevent the room from filling any fuller than is necessary for cooling the milk or its products, a similar duct runs from the opposite side of the room down the incline, and at length discharges its contents upom the surface of the ground. The end of the discharge duct, when it enters the room, terminates in a flexible tube which may be elevated more or less, to vary at pleasure, the height to which the cool air shall rise before it runs out of the room. The cool air will not rise above the mouth of the discharge pipe. When the outside air is colder than the temperature in the ducts, the motion of the air will be reversed. It will rise in the upper duct and go out through the tube $\mathrm{A}$ and follow into the dairy through the lower duct, thus keeping the room at $60^{\circ}$, or as near as may be, the year round.

The sub-earth ducts are made by an excavation like an ordinary underdrain, and at the bottom an $\Lambda$ shaped channel is made with roofing tile by laying the upper edges together and setting the lower ones against the outer edge of the ditch, as represented in figure 46 , which shows a section of the ditch as now made.

The tile and the excavating and filling the ditch will generally cost about $\$ 1$ per rod, making the cost of thus cooling and ventilating a dairy about $\$ 100$. But when it is done it is expected to run itself indefinitely without further cost. 
This system of cooling and airing a dairy has not, that I am aware of, been long enough in use to determine fully by practical tests, the extent of its usefulness, but it looks well theoretically, and some of its results can be easily foretold. First, the air which enters the room through the sub-earth duct will be pure as well as cool. The absorbent properties of earth, it is well known, will deprive it of all noxious gases and odors, and take up its moisture and dust.

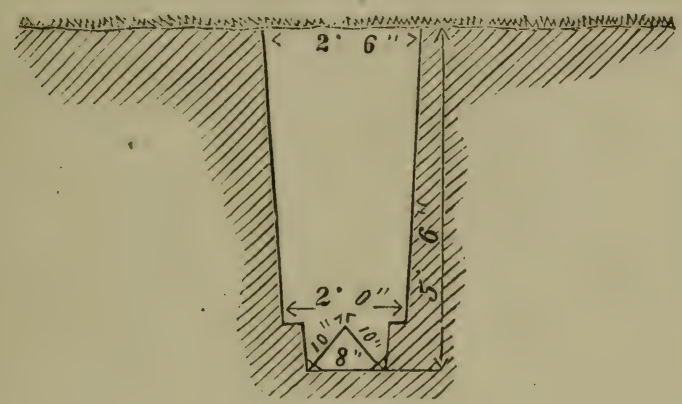

Fig. 46.

Whether the surface of the duct will ever become saturated so that it will cease to absorb the impurities of the air, time must determine. But it is certain that the air, in passing slowly through the duct, cannot fail to fall to the temperature of the earth in which it is imbedded; nor can it fail, for a time at least, to be entirely freed from vapor, dust and odors, by reason both of contact with the earth, and of condensation from its reduced temperature. It allows of cooling milk with air instead of water. It is very much better for butter making to cool milk with cold air than to coul it with cold water. 
When milk becomes colder than the air in the room in which it stands, as is the case when cooled with ice or cold water, it tends by its greater coldness to condense, and take in vapor from the surrounding air, with whatever of impurities that air may contain. But when the air is colder than the milk, the air becomes the recipient, and takes up and holds whatever exhalations may arise from the milk, and hence tends to deoderize it. It must be apparent that it would make a wide difference in the quality of butter, whether, while the cream is rising, the milk is cleansing the air, or the air cleansing the milk.

The system appears to offer great advantages for private dairies and for all occasions where the milk can be spread out so as not to be more than about four inches deep. For very large masses of milk, which require large and deep vessels, it would not seem to be so well adapted. Large bodies of milk require a medium for cooling to have a temperature lower than $60^{\circ}$, and to have a better power of conducting heat than air at $60^{\circ}$, to cool them soon enough to prevent spoiling. For cooling large quantities of milk in deep vessels, ice or cold water becomes necessary. To make the sub-earth duct available in such cases, Prof. W., proposes to connect the ice house with the dairy, and to pass an air duct under the ice, and to arrange it so as to be connected or disconnected at pleasure with the sub-earth duct. When it is desired to have the air in the dairy lower than $60^{\circ}$, by connecting the sub-earth duct with the sub-ice duct, the air may be made to enter the dairy at a very low degree without the trouble of handling the ice, and thus with great ease and advantage cool much larger bodies of milk than could be done with the earth duct alone. 
While in no case, either from fear or favor, will the space in this volume be devoted to puffing patents or condemning them because they are such, when they promise anything useful; and while the author is neither inclined himself to risk much on theory alone till corroborated by practical test, nor to advise others to do so, it has been deemed advisable not to omit a fair and unbiased statement of what may reasonably be expected of this patent, which seems to have enough of merit to challenge public attention, and the same remark will apply to the one which follows, and also to a few others which will be hereafter noticed.

\section{HARDIN'S METHOD.}

Mr. L. S. Hardin, an enterprising dairyman near Louisville, Ky., has adopted and published a plan of creaming milk which, in some of its features is novel and simple, and apparently so feasible as to attract a good deal of favorable notice.

The plan was originally designed for, and is best adapted to farm dairies. It consists of what may be called a cooling cupboard-a box just large enough to hold the milk of the dairy, when put in. deep vessels like common cooler pails. The box is made as near air tight as may be, with closely fitting doors, and high enough to admit the coolers and leave a space over them for an ice shelf. In the bottom of the box is a pan four inches deep which catches the drip from the ice above the milk. An inch space is left on each side of the shelf to give the heat arising from the milk access to the ice, which, slowly melting, drips down upon the covers of the cans and then into the pan at the bottom, in which the water is allowed to rise four 
inches and no morc. The cans are made with a perforated rim at the bottom to allow the water to run under them. Thus the milk, I 6 to 18 inches deep, stands in 4 inches of ice water, with the part above the water

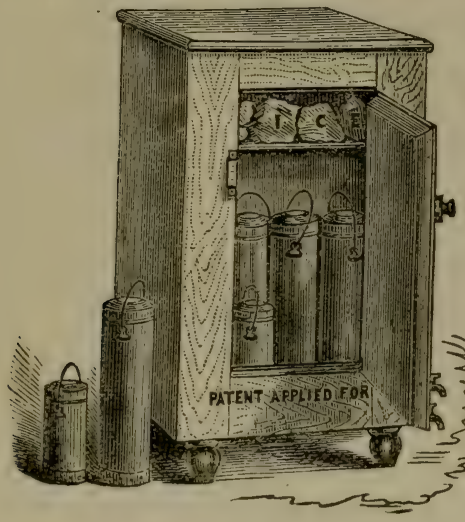

Fig. 47. in air at $49^{\circ}(\mathrm{F})$, or as near as it can be to that degree. See figure 47 . Says Mr. Hardin : "I refuse to give the milk a particle of ventilation from the time it leaves the cow's udder until it is put in the churn. The milk is strained warm from the cows into deep cans and close fitting covers fastened on, and the cans placed immediately in the refrigerator, and the temperature reduced with ice below $50^{\circ}$, and held at a low, even temperature $3^{6}$ hours, when the cream is taken off sweet, and churned immediately at $5 S^{\circ}$ in warm and $63^{\circ}$ in cold weather. Any churn worked at 40 strokes a minute will bring the butter in about 20 minutes."

This plan is known as a modification of the Swedish deep setting. It has some obvious advantages. Ist, It economizes the refrigerating agent to the fullest extent. It is certainly a useless waste of ice or other cooling agent, to cool twenty times as much cubic space as the milk to be cooled occupies. $2 \mathrm{~d}$. It produces cream of uniform ripeness. In setting milk in vessels which cool by ice or water below the temperature of the air in the milk room, the cream ripens 
unequally. The part exposed to the air ripens faster than the lower part which is unexposed and cooler. This unequal ripening is unfavorable to the butter and to perfeet churning. $3 \mathrm{~d}$. It favors the ascent of cream by cooling more intensely at the bottom of the vessel than at the top or sides, thus diminishing currents in the milk. When milk is cooled from the top and sides the cooled milk settles down, making currents which carry some of the cream down with the milk, and thus retard its rising. As the upper and main part of the cans stand in cold air instead of cold water, the cooling in the upper part is slow, ufilizing more fully the effect of a falling temperature. The upper part of the milk, too, being for a time at least, warmer than the lower part, all the cream which comes to the surface stays up, which is an item of some value. 4th. Another favorable circumstance is the great number of degrees through which the milk, while still and free from currents, is made to fall. It can easily be made to drop through a range of $40^{\circ}$, thus widening to the fullest extent the difference between the specific gravities of cream and milk, which, as has been elsewhere shown, favor the rising of cream. Considering simply as a method of raising cream it must be fairly successful, when the cans holding the milk are made sufficiently small. Large bodies of warm milk cannot be cooled with sufficient rapidity by admitting air only on the sides of the vessels, to prevent it from souring before the cream could rise. I should hardly expect that a body of milk of ordinary qualities, ro inches in diameter and 18 inches deep, would cool soon enough to avoid injury before the cream would all reach the surface.

Another peculiarity in Mr. H's. method, is the com- 
plete saving it makes of all the flavoring oils which the milk contains. Some of these oils are always so volatile as to lose strength by standing open to the air, so that something of the very highest flavor which butter is capable of possessing, is liable to escape where milk is spread out very thin for the cream to rise. Mr. Hardin's method of closely covering the milk retains all this aroma in the cream, but in this respect his plan appears a little too economical for general use. It saves all the cowy odor peculiar to new milk, which an abundant experience has proved to be detrimental both to the flavor and keeping of butter.

Mr. H. assumes that milk is perfect when it comes from the cow, or ought to be, and that its defects come by contact with the air, and that the more milk is aired the worse it is for it; and that "animal odor" is a myth that need not be regarded, a position in which he is certainly wrong. That there is something not quite perfect in milk as it comes from the cow, must be evident from the fact that people are often met with who cannot use the best of new milk at all; until after the animal or cowy odor has passed off. It is objectionable to them not only because it is warm, but because of the nauseating flavor and odor it contains. There are many persons who can use milk warm after it has stood awhile, who cannot do so when it is new. There is no class of people who are so particular about having milk in the best possible condition as the managers of condensing factories. Everything that appears at all faulty is rejected, yet milk, while condensing, invariably gives off a strong smell of animal odor at the beginning of the process. Any one bringing his olfactories in contact with the vapors 
pumped from the vacuum pan in a condensing factory for the first twenty minutes, will not question that there is such a thing as animal odor in milk, and that it is a never failing and disagreeable accompaniment of new milk. That there is much less of this odor in some milk than in others, is true. It is also true that there is sometimes so little, that good results are obtained where new milk is cooled so quickly as to retain nearly the whole of it in the milk and cream. And further, it is also true that butter made from milk cooled with the odor all in, may have a better flavor and better keeping quality than some other butter made from milk open to the air, but that all milk, or that milk generally, would make better butter for having the cowy odor retained in it by shutting it from the air while cooling, is a proposition which it will be hard to make dairymen believe who have been accustomed to handle all kinds of milk. But as the adage runs, "the proof of the pudding is in the eating," and if this method, when fairly tried, makes better butter than by leaving the milk open to the air, the proposition of Mr. Hardin must be accepted. That his method will make as much as any other is not difficult to comprehend, but that it will, as a rule, make better butter than setting milk in pure air, such as would be supplied by Prof. Wilkinson's sub-earth duct, will hardly be credited until it can be shown that animal odor is a good thing to have in milk and butter.

Whatever may be the position which the method introduced by Mr. Hardin may finally assume in dairy practice, he deserves a place in the list of progressive dairymen, and is entitled to the thanks of the whole dairy public for the extent of discussion and experi- 
ment which his innovation has provoked, for they must, in the end, result in great good, whether his system survives or not.

The experiments thus far made have not been very decisive, taken as a whole, having sometimes proved better than the open pan system, and sometimes not so good.

Mr. O. C. Blodgett, of Chautauqua, the indefatigable secretary of the Western N. Y. Dairymen's Association, has adepted a very convenient mode of setting milk, which has worked well with him and many others in that county.

He uses shallow pans and sets them in a room above ground, spreading the milk so much in warm weather that it will not be more than two or two and a half inches deep. In cool weather he would increase the depth. His theory is, that while milk spoils the sooner for being warm, the cream also rises faster when it is warm, and the thinner it is the sooner the cream comes to the surface. Hence by adapting the depth to the temperature, and skimming as soon as the milk is distinctly sour, whether it be in 12 or 48 hours, he has succeeded in obtaining very even results amid varying temperatures, and producing an excellent quality of butter. For a short time during the largest flow, two pans are used to hold the milk of one milking-one twice as large as the other. When the milk shrinks to the capacity of the larger pan, the smaller one is laid aside till late fall or winter, when it takes the place of the larger pan.

The pans are made of common tin and set on a cheap frame at a convenient height for working, and are supplied with faucets to run off sour milk or water when washing them. The whole fixtures are inex- 
pensive and labor saving, reducing the dairy work to its minimum. These are excellent features and commend the practice to the attention of dairymen. The greatest objection to it is, that only a skillful operator can manage it, as the conditions of the milk and cream must be all the time varying with the changes of the wenther. I should fear that nothing short of the accomplishments of the distinguished secretary would suffice to keep track of the constantly varying conditions of the milk. It must certainly require more skill and judgment than when milk is subject to an even temperature.

The following plan of constructing an ice house and dairy was recommended in the $N$. Y. Tribune, some three years ago, and has been adopted with good results. The ice house is attached to the dairy room, but is three or four feet higher than the floor of the dairy, making a location on an incline desirable.

The floor of the ice house carries the drip away from the dairy, and under it is a chamber into which cold air from the ice can fall and be held without wasting. The milk room is built with double walls, with charcoal, or some non-conductor filled in between them, and with double floors and windows. The air in a room thus constructed will seldom need any tempering in the latitude of New York. Whenever it is warm enough to require it, a cooling cupboard should he made on the side of the dairy-room next to the ice, inst large enough to hold the milk and cream, and be made as near air tight as possible. The chilled air under the ice is admitted to, or shut off from, this cupboard by a valve, as shown in figure 48 . The use of this cupboard saves cooling the air of a whole room, thus economizing the waste of ice to the greatest 
extent possible, and saves the labor of handling the ice, and at the same time gives the best refrigeration, as it is much better to have milk stand in cold air than cold water. If it is desired to keep butter in hot weather, cold air can be let into a separate apartment

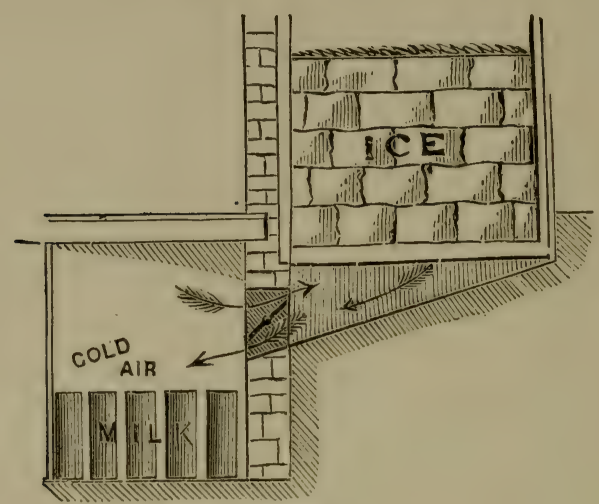

Fig. 48 .

for that purpose. Any kind of vessel for holding the milk can be used, but for the sake of economizing space of cupboard, cooler pails or deep and narrow pans would be preferred. Vessels broad and deep would endanger the safety of the milk by reason of the slow cooling by air. 


\section{BUTTER FACTORIES.}

The butter factory is a modern institution. It is an establishment for making butter from the milk of several herds of cows on an associated plan similar to that on which cheese factories are managed. The milk is brought to the factory twice a day by the dairymen in tin cans the same as are used for cheese factories, and they take back in them the sour milk, which is divided according to the milk delivered. When the factory is owned by a stock company, the company employ hands to manufacture the butter, and generally appoint one of their number to superintend the work and the division or sale of the butter. Sometimes the factory is owned by one man, in which case he makes the butter by the pound, at a price agreed upon, which is usualiy four cents a pound, and the butter is divided pro rata, or sold and the money divicled. The mode of treating the milk is not always the same. In the earlier butter factories the pail and pool system was adopted, in which pails of tin, twenty inches deep and eight inches in diameter, were used to set the milk in. These were placed in pools of water at sixty degrees or below, the temperature of which was kept down by cool spring water, admitted through a faucet to each pool. The pails were filled just full enough to have the milk an inch below the top of the water when the pails were set in the pools, otherwise the top of the 
milk would soụ too soon. The milk was kept stand. ing in the pools till it became slightly sour, which would be from $4 \delta$ to 72 hours, according to the coolness of the water and the weather; the cream was then dipped off and churned, and the butter made in the usual way, using water, horse, or steam power to do the churning. The "pail and pool system" is but little used now in factories which make only butter. This mode has been succeeded by the use of large pans, either deep or shallow, and the factories using them deserve a more particular notice.

In Franklin co., N. Y., butter factories have become so popular as to displace nearly all the cheese factories within their circuit. The butter from these factories has attracted general attention and gained a favorable position in the large markets; hence, there is the more occasion for inspecting them carefully. They are all quite similar in form and size. Compared with cheese factories, they are small, and though plain, they are very'neat structures.

Our cuts, figures 49 and 50 , represent the West Bangor Butter Factory, Franklin county, N. Y. It is $5^{\circ}$ feet long-6o with the porch--by 30 feet wide, with posts about i 8 feet high. The basement, which constitutes the cellar, is laid up with a thick wall of Potsdam sandstone. It has an air space in the iniddle; and the bottom of the cellar is neatly flagged with this sandstone laid in cement. This prevents the development of any underground smell, and keeps the temperature uniform at about $60^{\circ}$. The air in this cellar, when we saw it, was just as pure as that of any upper room. The superstructure is of wood, clapboarded on the outside, and lathed and plastered within.

The lower floor contains a milk room, $30 \times 37$ feet, a 
work room, $22 \times \mathrm{I}_{3}$, and a churn room, $8 \times \mathrm{r}_{3}$, with an engine and wood room attached. The upper story is used as a dwelling by the manufacturer. The milk room contains twelve large pans, measuring $\mathrm{I} 30$ inches in length by $5 \mathrm{I}$ wide and 7 deep, giving them a capacity of 200 gallons, sufincient to hold the milk of roo cows for one milking. Through the middle of the milk room is a track for a hand-car, and the pans are arranged on either side of it, six on a side, 20 inches apart, with one end butting against the outer wall, as seen in the ground plan. Just above the ends of the pans, a water pipe, connected with a good spring, passes along the wall and supplies water at. $48^{\circ}$, for cooling the milk. A little below this is a waste pipe for carrying away the water, as it is discharged from the pan. This apparatus, with the steam pipes overhead, complete the furniture of the room. Nothing else is allowed in it.

Upon a hand-car which passes through the center of the room, is placed a platform scale with a weighing can on it. The milk is brought to the factory in what are called iron-clad cans, and as they arrive are elevated by a hoisting crane and dumped into the can on the scale. When it is full, the car, with all its burden, is rolled along the track between the pans, and the milk is spouted into the pans on either side as desired. The twelve pans in this factory with their fixtures, cost $\$ 700$. An eight horse power boiler supplies an engine with steam for chirning and sawing wood, \&c., and for heating the milk room when necessary. This, with the churns and butter worker, and a few other small things, constitutes the apparatus, which, with the factory building, cost $\$ 3,800$ and is sufficient to accommodate the milk of 300 cows. 


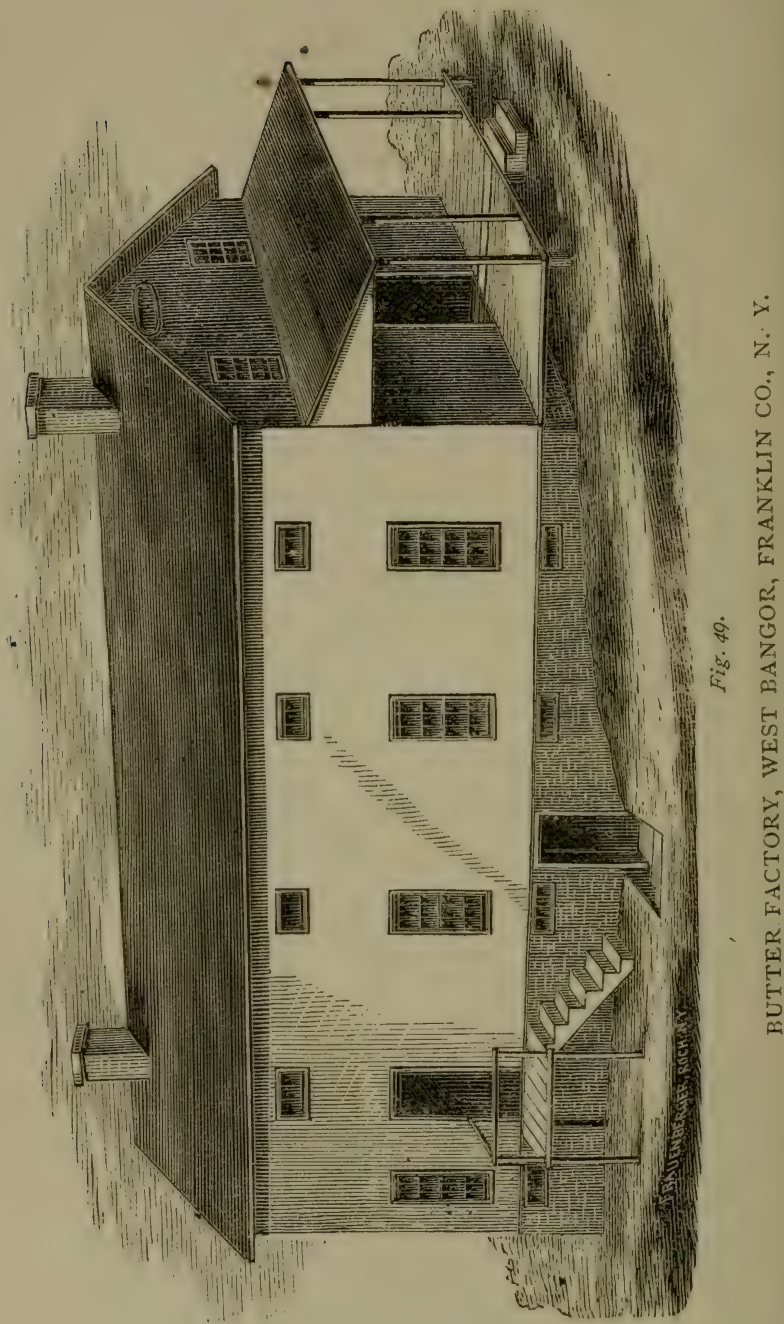


Butter Factories.

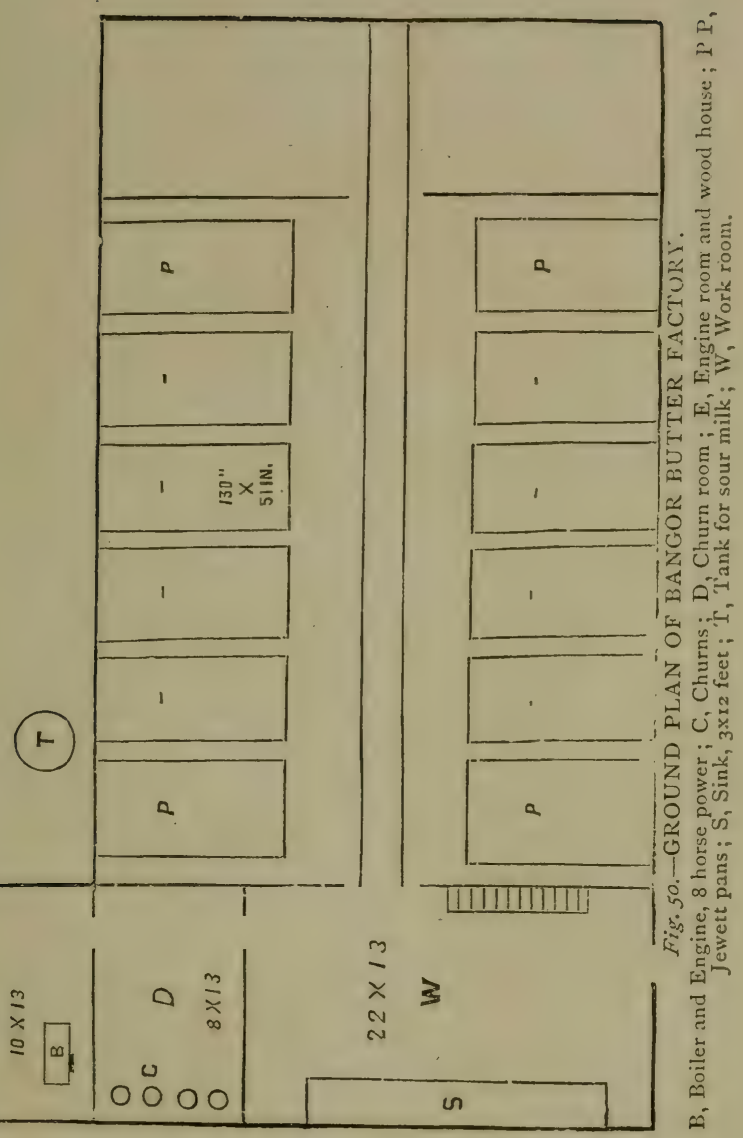


As the milk is delivered to the factories, it is discharged at once into the pans, and as soon as one is filled, the water is let on and the milk is cooled down to $60^{\circ}$ or $62^{\circ}$. As the water which supplies the factory is usually at $50^{\circ}$ or below, it carries off the heat very rapidly, so that the milk is reduced to the desired temperature in from two to three or four hours. The manufacturers all seem to labor under the impression that the animal heat (which they confound with animal odor) should he got out of the inilk in the shortest time possible.

The pan with cold water running under, or around the milk, or both, does this to their satisfaction. It is a little too efficient, as it enables them to cool the milk too rapidly. Except allowing the milk to be brought to the factory in closely covered cans, without previous airing, this rapid cooling is the first essential error, connected with the use of this pan, which attracts our attention. It takes from six to twelve hours, at ordinary summer temperatures, for the animal odor to escape. The objection to sudden cooling is, that it condenses the odor and retains it in the milk and cream. In nearly every factory that we have inspected, where milk was rapidly cooled, we have detected the cowy flavor in the butter. This not only injures the taste of the butter, but very much increases its tendency to become rancid. Such butter loses its fresh flavor so easily that it very soon becomes stale, unless kept all the time below $50^{\circ}$. Even then it has much of the animal flavor and soon depreciates. In one factory which we visited, the water had become scanty and warmed up to $60^{\circ}$. In consequence, it required over six hours to reduce the milk to $62^{\circ}$. The butter made after the water failed was the best in the factory, 
as the manufacturer could readily see when the fact was pointed out.

The importance of distinguishing between animal odor and animal heat, and of getting rid of the odor instead of the heat, is a lesson which the butter makers of the country generally very much need to learn. That the cowy odor in the milk can be condensed and retained, beeoming a flavor instead of an odor, has been too much overlooked. But it is no fault of the large or rectangular pan that the cooling is too rapidly done. It is only necessary to regulate the suppiy of water to cool in any desired time.

In these butter factories the Jewett pan is in use, and it is made an essential point with the manufacturers to keep the air in the milk room at $70^{\circ}$, while the milk in the pans is reduced to $60^{\circ}$ or $62^{\circ}$. This difference between the surrounding air and the milk, has some advantages and some disadvantages. It favors the rapid and perfect separation of the cream. The cooling in these pans begins at the bottom of the pan and works slowly upward, and for some time the cream on the surface and top of the milk will be warmer than the milk below. As the cream approaches the surface and becomes relatively warmer than the milk through which it has passed, it expands and becomes relatively lighter, thus hastening its ascent, and keeping it up when it has reached the surface. The rising of the cream is very rapid in these pans. It was apparently all up in 24 hours.

In the factories where the air was $10^{\circ}$ warmer than the milk, it was very plain to be seen that the cream being exposed to a higher temperature than the under side of it, grew thick, sour, and stale, while the under side of it was yet sweet and thin, After being 
skimmed and kept in large cream pails, I 2 to 24 hours, it would assume a more uniform condition, but it was quite apparent that less difference between the temperature of the milk and surrounding air would make an improvement in the quality of the butter.

The rule for skimming is determined by the thickness of the cream. When the underside of it gets so thick that it will not close over the space made by passing the finger, it is considered fit to skim. It will then not run through the skimmer. If the milk is kept at $62^{\circ}$ it gets thick in 36 hours, if the air in the room is $70^{\circ}$. If the milk is kept at $60^{\circ}$, the cream will require 48 hours to become thick. This rule, so general in these factories, would not apply where the milk is set in deep pails, as the bottom would not become thick before the top would spoil, nor would it apply where the milk and the air in the room were of the same temperature.

Another point in the Franklin county factories, is to take off the cream with the smallest possible amount of milk. This is done to save labor in churning, which it certainly does, but it occasions a loss in the quantity of butter, and also in quality. The upper part of the milk, especially where, as in the Jewett pans, it is five or six inches deep, usually contains butter enough to pay the extra labor of churning, especially where the churning is done by power. It pays to churn one-quarter of the builk of the milk. Some have the impression that the more milk there is churned with the cream, the more cheesy matter there will be in the butter. But this is not so, because where the whole milk is churned there is no more cheesy flavor than when the cream only is churned, and where there is a considerable quantity of liquid 
in the churn, the butter, when it comes, is not so much affected by the friction of the churning as when there is but little liquid, for then the churn crowds more upon the butter and injures the grain.

The skimming is done night and morning, and the cream put into large tin pails, in which it stands until ready to churn. This is done just before the milk comes in to make room for the new milk. As soon as the cream is taken off the sour milk is drained off through a tin pipe into the sour milk tank, by simply pulling a plug which stops a hole in the bottom of the pan. This is the only labor required for disposing of the sour milk. The milk of 100 cows is put in one pan, and in a factory of 300 cows, three pans are filled each night and morning, and of course there are three such pans to skim and wash every night and morning. I noted the time it took two women to skim, run off the milk, wash and scald these three large pans in one of the factorics, getting them ready for receiving milk again, and they did it easily in forty-five minutes. This is a very great reduction of labor over any other method of setting milk.

I cannot do better than to quote from the address of Mr. L. D. Paddock, of Malone, delivered before the American Dairymen's Association at Rome, Jan., I 876 , to give the details of managing the cream, churning: washing, working, salting, and packing butter in the Franklin butter factories. His practice accords well with what I saw in visiting sereral of them:

"The milk is allowed to stand thirty-six. hours, unless it is ready to be skimmed before that time. It must be skimmed at just the right time, and that is, as a general rule, as soon as it becomes sour. It is sometimes the case that the cream cannot be removed at that time without loss. In that case, you must wait until the milk thickens. In taking off the cream we use a large 
skimmer about eight by ten inches square, with a handle, and a low, broad, four-quart pan or dipper with a handle. This rests on the edge of the pan, and when full is emptied into tin pails holding about four gallons, and the cream is then carried into the cellar and set in a vat of cold water, where it is kept at the right temperature by means of ice put into the water from time to time as occasion requires. This is in case your cellar is not cool enough. The sour milk is emptied from the pans through pipes leading to the outside of the building into a large vat, from which it is taken away by the patrons. Cream taken off to-day, for instance, is churned to-morrow morning. We use two sixty gallon barrel churns, and put about twenty gallons of cream into each churn. If you get in too much, it takes a long time for the butter to come. The churns are run at the rate of about thirty revolutions a minute. We start the churning early in the morning, when it is cool, and before the milk begins to arrive. It usually takes about an hour to do the churning, but sometimes longer. As soon as the butter is come in a granulated state, we stop churning, and draw off the buttcrmilk through a sieve, so as not to waste any butter, then pour two or three pailfuls of water into the churn, and give it a few revolutions with the hand so as to rinse it well, then draw off as before, and repeat the operation until the buttermilk is well rinsed out of the butter. The butter is then taken from the churn and put into large, round, wooden trays, and carried into the cellar, where it is weighed and then spread out thin on the butter worker, and salted at the rate of one ounce to the pound-unless otherwise ordered. Some of our customers want but half an ounce to the pound, and some more than an ounce. We use either the best Onondaga factory filled dairy salt, or the Ashton. Most of the factorics I believe work their butter but once and pack as soon as they think it worked enough. At our factory the butter is all worked twice. The first time just enough to work the salt in well. It is then put back into the trays, covered with a clean cloth, and set away until the next morning, when it is worked again, taking care not to let your lever slip or slide on the butter, or to in any way injure the grain of it. Then, as soon as we think the buttermilk all out, it is packed. We generally pack in sixty-pound packages, and the very best that can be obtained. It is then covered with a cloth, and that is covered with salt about half an inch in thickness. If the butter is to be kept long, the 
salt should be moistened just enough to make.a paste, and then pressed down tight all around. Put on a tight fitting cover, and your butter is ready for market.

"It usually takes, on an average, about twenty-three pounds of milk for a pound of butter. That depends, however, very much on whether you are able to control the temperature of your milk. Then your feed has something to do with the quantity of the milk. Some seasons it takes more pounds of milk for a pound of butter than others."

There are now between twenty and thirty of these factories in operation in the vicinity of Malone, the county seat of Franklin county. They have proved a success in many respects. I visited several of them in September, 1873 , and though the butter in all was good, it is but justice to truth and my readers to say, that none of it was "gilt edged."

Some of the little defects which have prevented their reaching the very highest standard have already been pointed out. One of them was cooling the milk before the animal odor could escape, thus condensing it in the milk, whence it mingled with the butter, giving it a peculiar stale flavor and hurrying it on to rancidity. Another defect related to the packing. First, it was nearly all packed with once working, which gave to the texture a lack of solidity. Second, it was nearly all packed in spruce tubs, which were imperfectly prepared. Instead of removing the sap and filling the pores of the wood by soaking with boiling hot brine, they were soaked either with water or cold brine, which left so much sap in the wood that the butter next to the wood soon became affected. The covers of the tubs were not cleansed at all, and being generally made of basswood, soon imparted their odor to the top of the butter. This defect was very distinct. I detected the scent of the basswood, in one instance, 
in the top of a tub of butter which had been covered but a few hours. Basswood is entirely unfit for use about butter.

A difference of ten degrees between the air in a room and that of milk standing in it, the milk being $60^{\circ}$ and the air $70^{\circ}$, is regarded as quite unfavorable for producing the finest quality of butter from such milk, or for securing its greatest longevity. This may require a little explanation. For well known reasons, a pitcher of ice water in a hot day condenses water upon its outside, and because the water inside of it is as cold as the outside of the pitcher, the condensation is as rapid on the surface of the water within it, as upon the outside, though we do not see it because it mingles at once with the water. A vessel containing milk much colder than the air in which it stands, also condenses water upon its sides, and likewise upon the surface of the milk or cream in it. We often see this in butter factories and creameries. The vessels containing the cold milk are seen dripping with condensations; and that they condense equally upon the creanı is evidenced by the fact that the top of the cream is kept moist and soft not only, but often when the cream becomes thick, it is covered with a coat of water, giving its surface a glossy appearance.

When the atmosphere gives up its moisture to the sides of a pitcher, or to the cold water within it, it gives up also its impurities -its foul gases, odors and organic germs. It does this to such an extent as to affect the. taste and wholesomeness of the water in the pitcher in a few hours. Every one who has tasted ice water when it has become warm, will remember how disagreeable it tastes. The water which coridenses on the cream is loaded with impurities, and affects it the same as the 
water in the pitcher, injuring the flavor and the keeping quality of the butter made from it.

Dairymen often notice this moisture on their cream and think it a fortunate circumstance, because it keeps the top of the cream from drying up, and makes it soft. No mistake could be greater. The impurities which attach to the cream from water thus condensed upon it, are fatal to its well being. A piece of meat chilled with ice while exposed to warm air, gathers moisture by condensation, the same as the sides of a cold pitcher, and as it does so, the microscopic germs deposited with the moisture from the air, fasten upon it in such numbers as to ensure its speedy decay. Meat thus treated cannot be preserved without heating it hot enough to kill the germs which occasion the infection. Salt will not save it. So with butter made from cream infected by atmospheric condensations. The minute germs which lodge upon the cream fasten to it, and become mingled with the butter made from it and ensure premature decay, no matter how skillfully it may be treated in other respects.

Another circumstance operated unfavorably upon the flavor of the butter where it had stond long in the cellars. Allusion is made to the practice of covering the top of the butter with a cloth and dry salt. This was very much better than not to cover it with anything. But to prevent butter from growing stale by standing it should be kept from contact with the air. Water enough turned on to the salt to make a brine that would fairly cover the surface of the butter would have done this and kept the top of the butter sound.

These little defects are not noticed with any desire to criticise or find fault with this new system of butter 
making. They are pointed out to prevent others from falling into the same errors, and with the hope that they will be obviated in the factories where they were noticed.

The large pan system has proved one of great advantage to the location it occupies, and its influence is by no means confined to Franklin county. It has reduced the quantity of milk required to make a pound of butter to a lower figure than any other. The great bulk of the milk which is there converted into butter is from native stock, and the average amount for the time the factories run, which is four or five months in the middle of the season, when milk is the poorest, is only about twenty-three pounds. Jersey milk might require less. But $\mathrm{I}$ have met with no instance where, on so large a scale and for so long a time, an equal result has been reached. The butter, if not the very finest quålity that it is possible to make, is certainly excellent, and commands a high price and ready sale in the large markets of the country, running from five to ten cents above the average of dairy butter. The system of factory butter making with the use of large pans, is yet in its infancy, and great advances may safely be predicted of it as time goes along. One of the good things it has accomplished is to economize labor in the manufacture of butter, and to lift a heavy burden from the women folk in the dairy districts. It is worthy of adoption for this alone; but besides this, it pays. The quantity of milk for a pound of butter, and the cost of manufacture, have been so much reduced as to turn the milk to greater profit than when converted into cheese.

Butter factories, as a rule, make better butter than the average private dairies, but they are not yet so far per- 
fected as to equal the best private make. Their goods will not keep as well, nor are they so fine, in any of the associated dairies I have seen, as those met with. in private establishments. There are some obvious reasons for this failure in factories to reach the highest attainable perfection. First, the milk, as now usually conveyed, can hardly be transported the distance generally necessary to reach a factory, without injuring it somewhat for butter making. Second, the mass of milk being made up of different dairies that are liable to differ in quality, some of them will not be as good as the best ; and, third, it is doubtful whether the combination of circumstances at any butter factory are yet quite equal to the best private dairies, though the average of the former is very much above the average of the latter.

\section{CREAMERIES.}

Butter factories and creameries differ in this: the former make only butter; the latter both butter and cheese. The buildings and apparatus for the two purposes are necessarily different. In creamcries, the apparatus for butter making and cheese making must be combined.

Creameries are carried on with two distinct purposes, or modes of operating. The design of one class of creameries is to take off all the cream that can be ubtaincd without actually souring the milk, and 


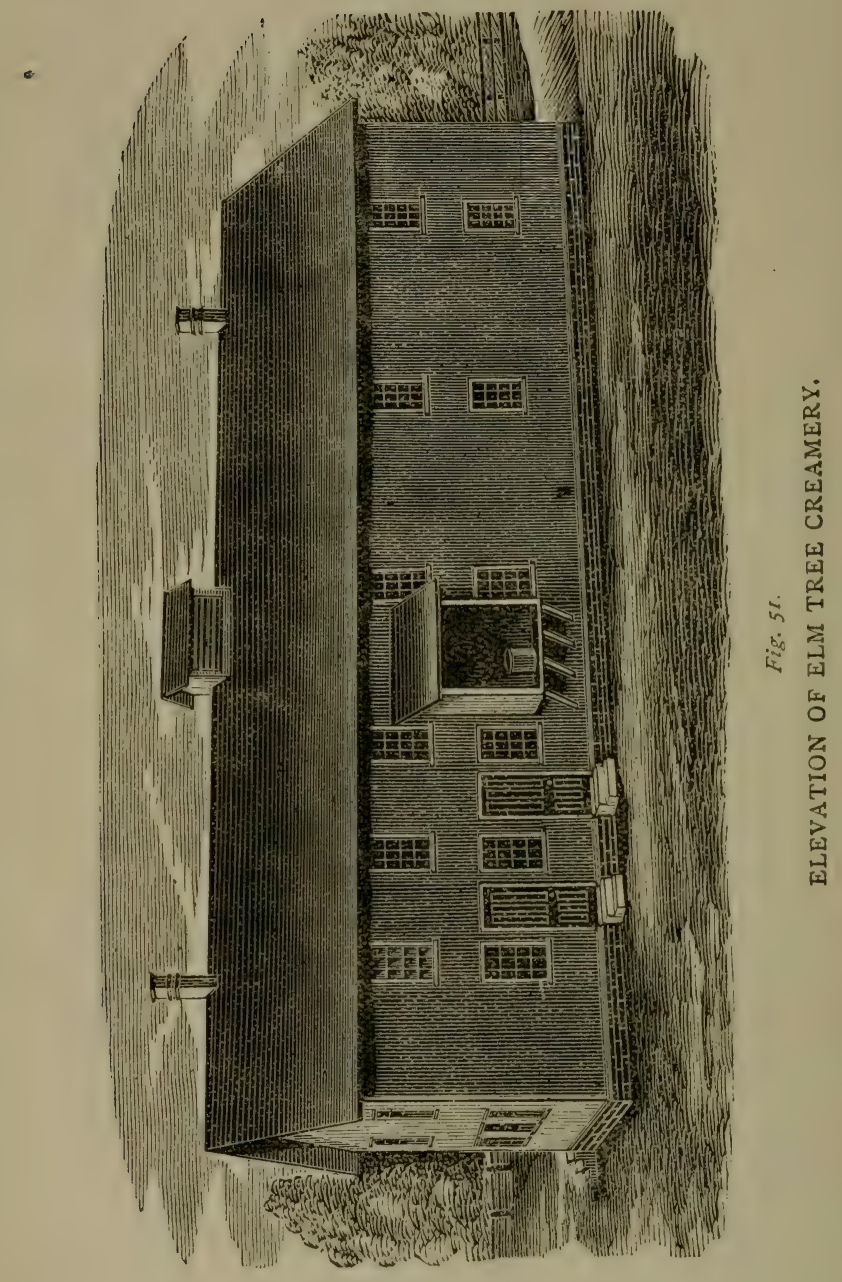


Creameries.
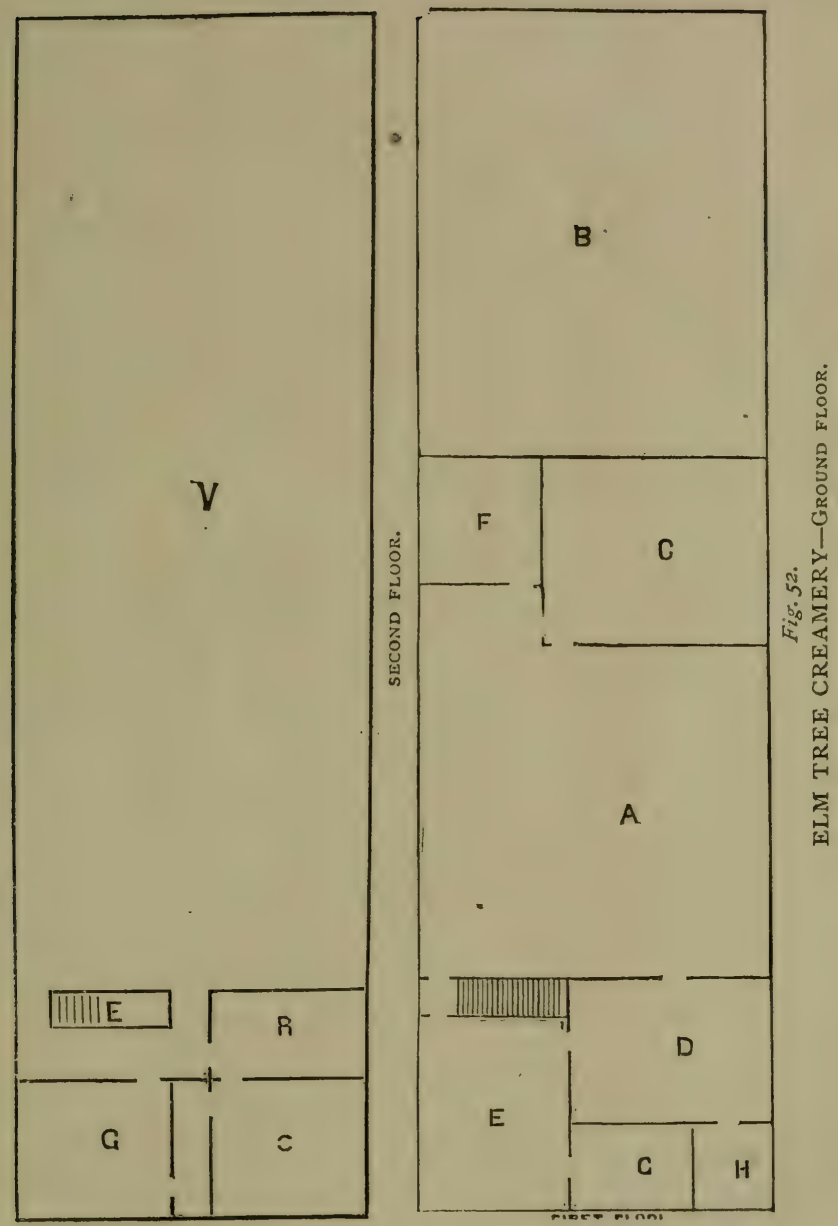
making from the stale milk an inferior quality of skim cheese, with the hope of getting better returns than from feeding it to calves or pigs. In the other class of creameries, the purpose is to take off no more cream than will allow of making a good or at least a fair article of cheese from the skim milk.

Creameries are constructed in a great variety of forms, which are made to vary according to the particular location and the fancy or different purposes of the builders. Perhaps no single plan, however well arranged, would be best under all circumstances. Yet there are certain requirements which run through them all, and which may be described in general terms, and contained in one comprehensive structure.

Most of the creameries are conducted on the "pail and pool" system. The following plans are adapted to this mode of raising cream. The system, however, must soon give way to the better and more laborsaving practice of setting milk in large pans, elevated so as to spout the milk into the manufacturing vats without handling, or to the still more economical mode of setting the milk in the manufacturing vats themselves, thus saving all handling.

The first plan (figures $5^{1}$ and $5^{2}$ ) is that known as the Elm Tree Creamery, located at Triangle, N. Y. It is $28 \times 94$ feet, two stories high, and eight feet between floors.

On the ground floor the letters indicate as follows:

A, Manufacturing room, $28 \times 28$ feet; B, Curing room, $32 \times 28$ feet; C, Pool room, I6xi8 feet; D, Kitchen, I6xiI feet; E, Sitting room, $\mathrm{I}_{5} \mathrm{I}_{4}$ feet ; F, Engine room, Iox 10; G, Bedroom, I0x7 ; $\mathrm{H}$, Pantry, 6x 7 .

Second fluor $-V$, Curing room, $28 \times 76$ feet ; R, Bedroom, $7 \times 13$; G, Bedroom, IIxI3; C, Bedroom, IIxI2; E, Stairway. 
The second plan (fig. 53) is that of the Harrison Creamery, located at Smithville, $N$. Y. It has the-same width as the previous one, but is ten feet shorter, being $28 \times 84$ feet, and the size and location of the rooms are a little changed. Both are calculated for the family of the manufacturer to live in one end of the creamery The second story is similar to that in the first plan, I 2 feet of one end being occupied with bedrooms, and the remainder as a curing room which is $72 \times 28$ feet.

Each of these creameries has, as every creamery should, a good cellar beneath it for storing butter, and each has an eight-horse power boiler and a small engine for churning and doing other work, things very necessary in equipping a creamery. Unless supplied with a plenty of cold spring water, an ice house is also a necessary appendage to a good creamery. As there must always be a constant waste

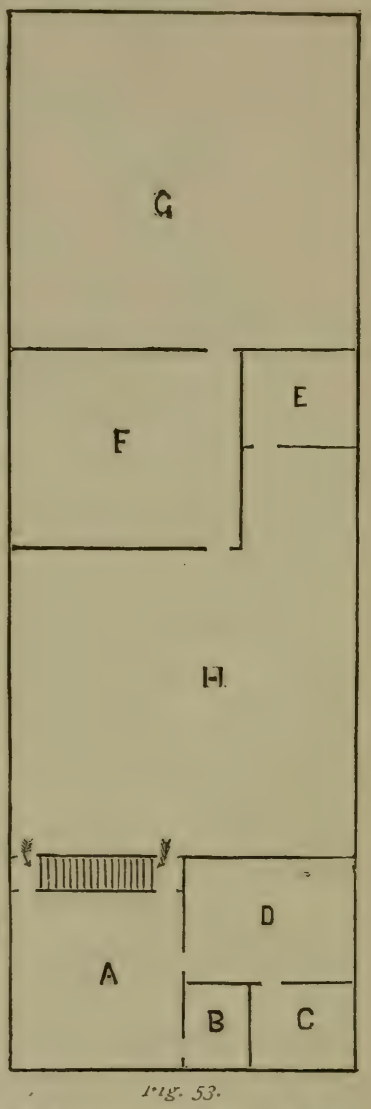

A, Kitchen, $I_{4} \times 1_{5}$ feet ; B, Pantry, $6 \times 7$ feet ; C, Bedroom, $7 \times 8$ feet : $D$, Sitting room, $14 \times 11$ feet ; E, Engine rorm, 8xio feet; F, Pool room, $14 \times 18$ feet; G, Curing room, $28 \times 23$ feet ; II, Manufacturing room.

of water running away from a creamery, and more or less wash and dirty water to be disposed of, a high 
and dry location, which will afford pure air and good drainage, should always bə selected, if possible. It is

- very essential to the production of first class butter that the air in and about the buildings should be dry and free from every taint or musty smell. The building for a creamery need not necessarily be ornamental, though a tasty neatness should always enter into its structure, but it should be substantial and secure against the fluctuations of outside temperature.

The mode of building adopted in the butter factory just described is a good one, and in the end, as cheap as any. The walls should at any rate be double. When coolers are used, the pools to set them in are generally made of plank, and sometimes of cement; but, whatever they are made of, they should be set high enough so that the water can be drained from them at any time desired, and should consist of four or five, the latter number is preferred, separate apartments. When made of wood, the plank are liable to get slimy and the top musty, and require that the water should be drawn off and the vat scrubbed with something like a splint or wire broom, and then rinsed with boiling water or scalded with a jet of steam. Everything about the pools must be kept perfectly fresh and sweet, or the butter will imbibe the scent, if any is allowed to exist.

An incident, which occurred in one of the very best creameries, will illustrate: The water in the pool where the cream was kept, and which was alternately warmed and cooled to temper the cream, was allowed or one occasion to remain unchanged until it began to smell a little old; it was but a slight change from its fresh state, but all the butter tinat was made from the cream standing in the water at the time, assumed 
the same smell and taste, and became permanently injured. Cleansing the pool removed the difficulty.

The pool is divided into a number of apartments, so that there may be one for holding cream, which can have its temperature raised or lowered at pleasure, to keep the cream cold when there is occasion to keep it, or to warm it to temper it fur churning, and others so that each mess may be set in a separate apartment. This is necessary to avoid warming up the water and milk by the introduction of a warm mess into an apartment with one already cooled, which would have an injurious effect on the latter. By having four or five apartments in the pool for milk, each mess is set by itself, and remains undisturbed in temperature until ready to skim.

The cooling may be more or less rapid, as may be desired, according to the volume of the stream of cold water running into the apartment of the pool in which the warm milk is set. If a small stream of water is let in, the warmed water will be very gradually displaced and the cooling slowly done. The process is hastened by admitting a larger stream.

The effects which follow the fast and slow cooling are unlike. - The milk will keep sweet longer with the rapid cooling, but the cream will rise more perfectly, and the butter has been found to be better, when the cooling is done more slowly. The deep cans, nineteen inches high and about eight inches in diameter, before described, are used for setting milk.

The practice at one of the best creameries I know of is as follows: The milk upon arrival is weighed and emptied into a receiving vat. A compartment of the pool is filled with fresh water, which is at $50^{\circ}$. Coolers are filled from the receiving vat as milk arrives, and 
placed in the pool. Water enough is turned on to cool the milk down to $60^{\circ}$ in ten to twelve hours. In warm weather, it is skimmed after standing thirty-six and forty-eight hours. The cream, in coolers, is set in a pool at $65^{\circ}$, where it stands twelve hours and becomes slightly sour. It is then churned in one and a half barrel dash churns, worked by steam. In some factories, a cream vat is used. It is constructed on the same principle as the common cheese vat, and is designed as a storage for cream, in which it can be thoroughly mixed and warmed or cooled, as desired, by steam or water connections.

The skimming in this creamery is the same as in all others when coolers are used. It is done by removing the cream with a conical cup, made of tin, with the pointed end down, and used with a perpendicular handle. When the milk is ready to skim, the pointed end of the cup is pressed down into the cooler until the cream, which is always sufficiently soft to flow, will run over the top of the cup and fill it. It is then lifted out and emptied, and the process repeated until the cream is all dipped off. As the milk and cream rise in the cooler, when the conical cup is pressed down into it, they become somewhat mixed, and a perfect separation of the cream is not made without taking in considerable milk.

In churning, in the creamery referred to, as much cream is put into each churn as can be, and allow the dash, in its upward stroke, to rise above it. The dashers are made large, so as to nearly fill the churn at the top and bottom; and their motion is at first slow, about twenty strokes per minute, until the cream is well mixed, when the motion is increased to 45 or 50 strokes. The temperature observed in churning is 
$5^{\circ}$ to $60^{\circ}$, the cream being cooled down before it is removed from the pool. When the butter bcgins to come, the motion is again retarded, and cold water enough is put in to make the contents of the churn rise a little above the dash, in its upward motion, and reduce the temperature below $58^{\circ}$. The butter comes in a granulated form. The buttermilk is all washed out of the butter, and it receives no working, except to press it together, after the salt has been mixed with the granules. It is generally gathered in the churn in a mass, and washed and worked in the usual way.

In this creamery, through alt the warm weather, the milk stands 36 -and 48 hours before skimming. The milk is then sweet and is made into skim cheese. The cream is soured a little before churning, and the buttermilk of course goes out with the whey, which is fed to pigs and calves.

It is the general practice in creameries which use cooler pails and pools, to get all the butter that can be obtained from the milk and keep it sweet for cheese making. Some churn the cream while sweet, and put the buttermilk in with the skimmilk to make into cheese, others sour it and think the increased quantity of butter they get by souring the cream pays better than the buttermilk does in cheese. In the Speedsville creamery, it was recently found, by repeated trials, that when the cream was churned sweet it took $3^{8}$ pounds of milk for a pound of butter, and when churned sour it required but 28 pounds for one of butter. This rate is a good expression of the difference in results of churning sweet or sour, the cream from the milk of Native, Shorthorn or Ayrshire cows.

Some set the milk 24 and $3^{6}$ hours in hot weather, and occasionally it is set $\mathrm{I} 2$ and 24 hours, but the 
great majority set $3^{6}$ and 48 in summer, and 48 and 60 in cool weather. It is the general practice in creameries to pack in return pails or tubs for immediate market, till the cows become fully accustomed to grass, and after that to pack in firkins for the fall market. But sometimes it is sent off every week all the season.

In these days of close figures upon dairy products, when the cost of production and manufacture run sn nearly parallel to the wholesale price, economy at every point must be observed. The labor of an extra hand in a factory may decide the question whether it shall be run or closed up. Economy of labor in manufacturing is the most prominent item in the difference between making the milk into butter or cheese at the farm, or in factories. For this purpose, the use of large pans, or more properly vats, for setting milk in creamery practice, has of late, been availed of with good effect. In the economy of labor they sustain about the same relation to cooler pails, that the pails do to the small round pans. The vats are made large enough to hold one milking of 100 cows or more, and are elevated so that the skimmilk can be spouted to the manufacturing vats. The labor saved by this method of setting is very great. The skimming and washing of the vats for a given quantity of milk is estimated at one-eighth that required for coolers, and the ratio of labor between handling the coolers and carrying and turning them into the manufacturing vats by hand, and spouting the milk in, is about as twenty to one. A very great amount of labor is also saved by spouting milk from the receiving can to the setting rats, in place of filling coolers and setting them one by one in the pool. In this improvement, the American Dairy and Commercial Company have 
taken the lead. Thcir creamery at Mill Ridge, Oneida county, N. Y., was arranged last year for the use of cooling vats, which worked so well, that they have this year been introduced in several other factories belonging to the company.

In the Mill Ridge creamery the floor of the setting room, which is adjacent to the manufacturing room, is raised above the latter, and vats similar to manufacturing vats are used for setting the milk. The difference in the height of the floors is sufficient to carry the milk from one set of vats to the other. In their creamery at McLean, Tompkins county, N. Y., one of the best conducted creameries in the United States, the manufacturing and setting rooms are on the same floor. The milk is set in large Jewett pans, which are elevated high enough to admit of running milk from them to the manufacturing vats, which are set as low as they will bear for that purpose. The process at this creamery is very satisfactory, and the butter turned out is of very fine quality, and sells at the very top of quotations. From the early grass-fed milk of the present season, one pound of butter was made from 27 pounds of milk, and a little later, one pound from 26 of milk. The cream is churned sour. In other factories, other styles of large pans are being used in - the place of coolers with a degree of satisfaction which indicates that the latter must soon give place to the labor-saving apparatus. Messrs. Whitman \& Burrell, of Little Falls, N. Y., in. their Fink's Basin creamery, economize still further, by using the manufacturing vats for setting milk. The new milk, as received each night and morning, is run directly from the weighing can into a vat, and after being heated to $135^{\circ}$ by turning a jet of steam directly into the milk, 
it is cooled down by passing cold spring water through a coil of tin pipe suspended in the milk just below the depth expected to be occupied by the cream. When the milk has fallen to the temperature of the room or a little below, so that evaporation is checked and the gas and odor has escaped, a close fitting cover, virtually air tight, is set down upon the vat, and the cooling goes on till the milk drops to the temperature of the water passing through the coil, which is below $50^{\circ}$. The cover, which is inexpensive, serves the double purpose of economizing the refrigerating agent, and protecting the milk from any contamination while a vatful is being made into cheese by the side of it. In a recent examination, the cream as compared with that raised in open vats was superior. Its flavor was remarkably pure, sweet and delicious, and was entirely free from the slightly bitter taste which the top of cream acquires by being exposed to the air. The butter it made was strictly gilt edged, and sold, when sent to New York in return pails, for 30 cents, when Orange county was quoted at 25 cents. The cream was churned sweet, and three pounds of butter made from Ioo pounds of milk, and the buttermilk used with the skimmilk in making cheese on the Ellsworth plan. The churning was done with a Blanchard churn, and the butter gathered in the granular form. I note this fact because some butter makers have supposed that butter could not be granulated in that churn.

In the new creamery practice adopted by J. T. Ellsworth, of Barre, Mass., the milk is received into large pans of the variety known as the Empire State pan. By the aid of a heater in an adjacent room and a coil of pipe, hot water is run under the milk and kept circulating till the milk is raised to I 30 to I 40 degrees. 
The hot water is then changed for cold, and kept running till the milk is reduced to $65^{\circ}$ and then left for the cream to rise. As the milk is to be made into cheese, it is skimmed and churned while sweet, the butter gathered in the granular form and otherwise treated in the usual way. It has proved to be very uniform and very nice, having sold the year round for 45 cents a pound in the city of Worcester. I have examined Mr. Ellsworth's butter, and found it to have a remarkably pure and clean flavor, and to be in every respect very fine.

\section{WINTER BUTTER MAKING.}

Within a few years past, a practice of making butter in the winter instead of summer has been gaining ground. This is more especially true in some of the western states. The cows come in during the fall months, so as to be freshly in milk through the winter, and go dry during the heat and drought of the summer. Cows in milk cannot stand the cold as well as when dry, and therefore need very comfortable quarters, but it is easier to protect them against the cold of winter, than against the heat and drought and flies of summer. The store of winter food must be adapted to the situation. Stale fodder, such as late cut hay and ripe cornstalks, will not answer. The food for profitable winter dairying must be early cut, of whatever kind it may be-grass, clover, fodder corn, millet, oats, oats and pease-if cut not later than in blossom, produce nice milk and a very liberal flow. In winter dairying, grain can be fed to better advantage than when the cows are on grass, and roots can be made very serviceable. 
The rield of milk will not be quite as large in the winter as in the summer, but it will be richer, making the annual yield of butter just about the same in one case as the other.

If proper provision is made for taking care of the stock and the milk, it is just as easy to make butter in the winter as in the summer, and in fact, it is less difficult to maintain a proper temperature in the dairy in the winter than in the summer, and it has the advantage of furnishing fresh butter at a time when it usually brings the highest price. Cows for winter use are generally dried off about the first of July, so as to go dry in July and August. But few dairymen in any part of the country follow this practice wholly, but spread the time of manufacturing over the whole year, and have cows coming in during the fall, winter and spring. Often only one-third of the butter product of the year is made in the winter season. The practice is better adapted to warm climates than cold ones, and better in localities subject tơ drought and scanty water in summer than in those which are not.

\section{WHEY BUTTER.}

A few years ago, considerable quantities of whey butter were made, and often formed no inconsiderable item in the revenues of the factory. Latterly, the more careful and improved methods of working, and the largely increased practice of skimming, have very much reduced the production of whey butter. But it is still made in some localities, and a few words in regard to its manufacture may be appropriate.

Two methods are adopted in raising the cream. One is to have vats, similar to manufacturing vats, to set 


\section{Creameries.}

the whey in. These are placed lower than the manufacturing vats, so that the whey will run from one to the other, to save carrying. It is run off as early as practicable, to prevent its becoming too sour, and cooled as quickly as possible down to $60^{\circ}$, and left standing about twenty hours for the cream to rise. It is then skimmed with a tin scoop, as it is apt to be too thin to be taken off perfeetly with a skimmer. The treatment of the cream, the churning and management of the butter, are the same as in inaking butter directly from milk. The whey from 600 gallons of milk yields from two to four pounds of butter, which has a strong flavor and a greasy appearance. It has generally sold for about two-thirds as much as fine butter from milk, and is generally used for conking.

In the other method of raising the cream, the whey is run into vats, the same as in the first instance, and instead of cooling, heating the whey to $170^{\circ}$. The cream rises rapidly and is at once taken off and cared for, and made into butter in the usual way. The yield of butter by the two modes is about equal, but the butter from the heated whey is much the best. 


\section{PRINCIPLES IN CHEESE MAKING.}

In butter making, we only make use of the fats in the milk. In cheese making, we add to the fats its caseine. The elements of butter are already in a condition suitable for food or preservation. The caseine is not. A part of the water and sugar combined with it in the milk, must be separated to secure even a temporary preservation. In effecting this, we convert the caseine into curd, which is insoluble in water, and until it undergoes further change to render it soluble again, is indigestible. See Appendix (a.)

There are two distinct purposes to be kept in view in cheese making. The first is to expel the whey, which contains water, sugar, albumen and mineral matter. This is done by treatment in the vat. The second is to render the caseine soluble by converting it into cheese. This is done principally by the action of rennet.

\section{CHARACTER OF RENNET ACTION.}

The process of cheese making is essentially one of digestion, resulting from the action of gastric juice derived from the stomach of the calf by steeping it. The prominent part which digestion plays in cheese manufacture, first impressed upon the attention of dairy. 
men by Mr. A. Holdridge, of West Burlingtor, N. Y., embodies the fundamental principles of all successful cheese making. The coagulation of milk with rennet is the beginning of the digestive process, and the conversion of the curd into cheese is due to the further action of the rennet enclosed in the coagulum formed by itself.

Milk may be coagulated by other agents than rennet. Alum, alcohol and various acids will accomplish that end, but they fail in the further effect of converting curd into cheese. It is for this reason that no substitute has been found which could successfully take the place of rennet in cheese making.

The changes which are wrought upon milk in making cheese are similar to those which occur in the stomach of a calf in digesting a meal of milk. In the stonach, the milk is first curdled and the whey separated; then the curd, which is first formed into hard lumps, becomes softened on the outside, and takes on the cheesy flavor and odor which we get in the curing room, and a similar texture, becoming friable and tender, and then gradually dissolves into a liquid, when it is ready for assimilation.

In making cheese with rennet, we do the same thing, only the process is slower and less perfectly performed. We use but a small amount of gastric juice to begin with-only about ${ }_{40}^{2} 0$ part as much as the calf, and we work with less warmth. Nor do we intend to digest the curd until it dissolves. We prefer to stop it just before it is ready to dissolve. In this stage, if all conditions have been right, it becomes a very desirable food-a fancy cheese. When curd is thus digested to the verge of solution, it is an easy matter for the human stomach to finish the digestion, 
The steepings of rennets contain ininute globular bodies. Viewed with a microscope, the liquid in which they are soaked appears full of them. We have found by actual count over 1,000 of them in one-five hundredth part of a drop taken from a gallon of water in which a single rennet had been soaked. At this rate, a good rennet would contain some $200,000,000,000$ of them. These minute bodies are living germs that grow and multiply, making the liquid rennet a sea of vegetable life. They constitute the active agency in rennet, as we have proved by finding the strength of liquid rennet to correspond with the number and size of germs it contains; and, second, by filtering them out of the liquid, when the soakings, which were before powerful, became entirely inert. The writer has repeated these experiments so often and so successfully, as to leave no doubt as to the connection of these minute atoms with the active agency of rennet. These germs are the spores or seeds of a variety of blue mould, and are susceptible under favorable circumstances of a wonderfully rapid multiplication. Common yeast is full of analagous germs, and its efficiency depends upon them. It is from their remarkably rapid increase that a "little leaven leavens the whole lump." All yeast has a similar dependence.

The active agency in rennet, being also dependent upon such germs, may be multiplied and carried from batch to batch, the same as the leaven in panary fermentation, and is therefore a true yeast, and should be regarded as such in the principles of cheese making.

\section{EFFECT OF HEAT IN CHEESE MAKING.}

Though but a short time is required for a certain quantity of rennet to curdle a vat full of milk, to 
effect a perfect coagulation is a work of considerable time, and the separation of the whey goes on slowly. Dairymen are in the habit of applying rennet to milk at $80^{\circ}$ to $84^{\circ}$, and at this temperature the digestion goes on tardily. As the warmth rises toward blood heat, the work moves much faster. To continue the contents of the vat at $84^{\circ}$, would require a very long time to advance the curd to the stage necessary to place it in the press and the curing room. To hasten the process and shorten the time of working, heat is applied and the temperature of the mass raised to blood heat. In doing this, skill is required. It is necessary that the whole mass should be heated evenly, or some parts will be advanced more than others, to the detriment of the cheese. To apply warmth evenly, the curd must be cut in fine pieces and the mass constantly stirred, and the heating must be gradual. All this requires work, time and waste, but with our present notions of cheese making it must be done. We could not complete a batch of cheese in a day at $S_{4}^{\circ}$, and hence we must hurry the operations by heating. As the heating of the curd, after it is formed, is done solely for hastening the action of the rennet, in effecting a separation of the whey and ripening the curd, it would seem much more philosophical to apply the rennet to the milk at a higher temperature, which could be quickly reached without detriment to the milk, and thus save the trouble and waste occasioned by cutting and stirring, and the loss of time by heating the curd slowly. It is certainly very important that the contents of the vat should not be allowed to cool while waiting for the curd to form and the whey to separate. But in this respect the practices of dairymen are not very philosophical. It is common for the whey and 
curd to fall several degrees in cool weather while tlie curd is hardening. This should be carefully guarded against by covering the top of the vat. A few do this.

Mr. A. B. Armstrong, of Dorset, Vt., has devised a plan for conveniently raising and lowering a cover to a large vat, so that it can quickly be hoisted up out of the way when it is necessary to work the curd, and be let down again at once, and cover the vat tightly when the curd is not being worked. An illustration of the vat and cover is given on the next page.

In the heating arrangement attached to this vat, $\mathrm{Mr}$. Armstrong has provided for maintaining a uniform temperature in the curd for the whole time necessary for it to remain in the vat. The envelope to the vat, with a sheet iron bottom fitted on water tight, is set on a brick arch, and has a tight cast iron fire box at one end. The heat and smoke go under the whole length of the sheet iron bottom, and then up and out through a pipe. A sheet iron apron is placed a few inches below the bottom of the envelope, to shield it from the direct contact of the fire. Ashes are sifted over the apron, thickly toward the fire box and thinly toward the other end, to equalize and temper the heat. The contents of the milk vat are warmed by warming water in the envelope; and a fire sufficient to warm the milk to the desired degree for setting, will so warm the brick arch and apron and ashes upon it, that when the firebox is closed and the draught stopped, the contents of the vat, if closely covered, will retain an even temperature from six to ten hours, long enough to manufacture cheese, without change of temperature. Experiments have been made in this vat, under the inspection of the writer, in which the milk and curds in the vat, after being warmed up to $9.4^{\circ}$ for setting, 


\section{Checse Making.}

remained in one case six hours and twenty-five minutes, and in another, seven hours and thirty minutes

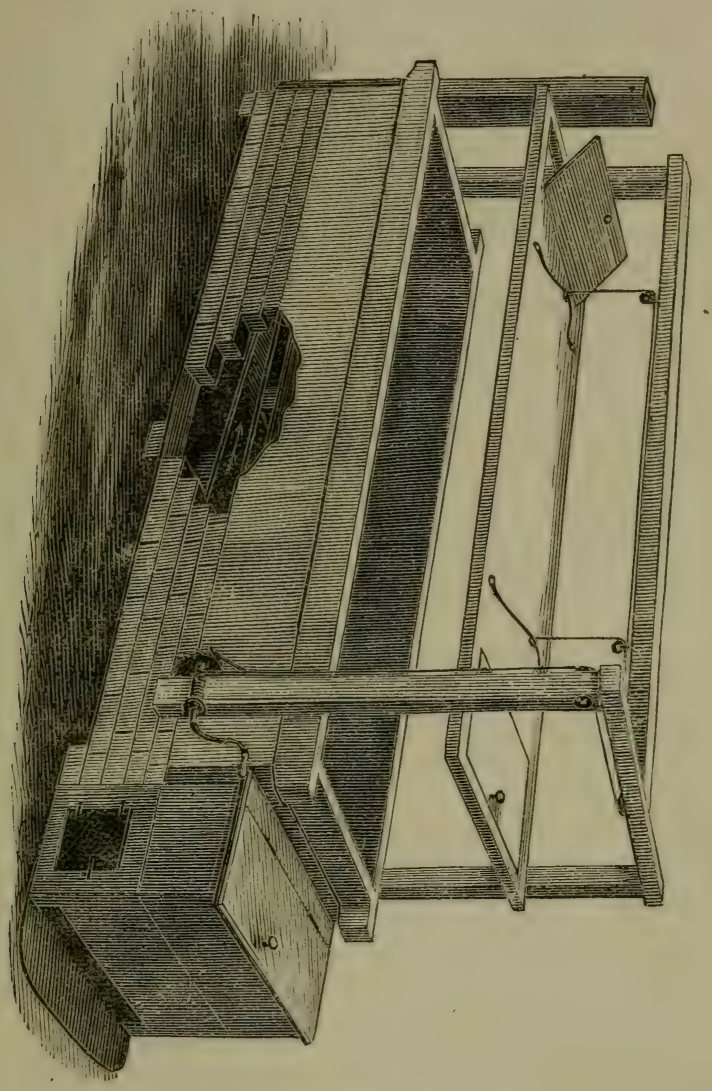

Fig. 54.

without a variation of so much as half a degree. In these experiments, not only was there no change of temperature, but the usual stirring and working of the 
curds were wholly omitted. Nothing more was done to the curd than to cut it lengthwise and crosswise, and let it lie closely covered till it would respond to the hot iron test, when it was salted and put to press. The result was an increased product of fine curd, but from being injured by cold in curing, the cured cheese was only of medium quality. Similar experiments have since been repeated in this vat by other parties, when the weather was mild and curing favorable, in which the cheese proved to be very fine, demonstrating the possibility of successful cheese making without changing temperature, or waste by stirring or handling.

I have spoken thus at length of the Armstrong vat and these experiments, while treating of principles in cheese making, for the purpose of leading some progressive dairyman to make the necessary experiments to reduce to successful practice the possibility they demonstrate.

\section{ACIDITY IN CHEESE MAKING.}

Though the coagulation of milk and the curing of cheese are brought about by the action of rennet, it is not the only agent which acts upon milk in cheese making. Lactic yeast, which gets into milk from the air or other sources, is always present, inducing a tendency to souring. This acidifying agent produces specific effects upon the curd and cheese which are peculiar and powerful. It aids rennet in the coagulation of milk, but counteracts its action in converting curd into cheese, and hence retards the curing process. While lactic acid, like many others, has but little influence upon solid fats, it readily takes up essential oils. Hence the more acid there is developed in cheese making, the more are the light flavoring oils in the 
milk taken up, thus diminishing, according to the strength of the acid, the nutty flavor of the cheese. The fine aromatic flavor of either butter or cheese may be all wiped out by developing a sufficient amount of acid. This fact is worth the attention of all cheese makers who aspire to the production of a choice quality of goods. This ability of lactic and other acids to take up volatile oils, is often of great service in neutralizing excessive animal odor and other objectionable taints and odors in milk.

Though the influence of lactic yeast is always operating in connection with rennet, and the activity of both is increased as blood heat is approached, their relative activity is not always the same. The action of the acid yeast is relatively greater than that of rennet at the higher temperatures used in cheese making, and slower at the lower ones. There is often occasion to take advantage of this peculiarity, and hence it is noticed in connection with the general principles in cheese making.

The success of associated dairying now, unfortunately, depends largely on the use of acid as a controlling agent and corrective. Our practice of making one-half of the milk directly into cheese without expelling the animal odur-our unphilosophical, not to say wicked habit, of carrying milk to factories warm in closely covered vessels, increasing thereby not only the original amount of animal odor, but aggravating cvery taint or infection the milk may chance to possess from the cows having bad food, water, air, health, or treatment-make the use of acid a necessity.

Every taint, from whatever source derived, develops into prominence both while the curd is in the vat and while it is ripening in the curing room, so that, unless 
counteracted, a cheese made of milk containing any taint, grows off flavor as it grows old, and is liable to be condemned for its faults before it is half ripe. Lactic acid neutralizes and hides all the taints which appear in milk, and hence its development in the whey and curds renders it possible to make a marketable cheese, out of milk which would otherwise be condemned.

The cheese made where this necessity exists, must always be at least second quality, for while the acid employed readily takes up illegitimate flavors and odors, it just as readily takes up the legitimate ones, and hence its presence always depresses the delicious flavor which epicures so much admire.

First class cheese can only be made from first class milk, and until our dairymen learn to produce such milk, they will be compelled to make and market second class cheese.

As all the legitimate changes in making and curing cheese are due to the action of rennet, it must be evident that, all other circumstances being the same, the more rennet there is used the more rapid and vigorous will those changes be. Dairymen act upon this principle. Formerly, when cheese was all made in private dairies, it was made to keep, and a small amount of rennet was used. The rennet of a calf was sufficient to curdle the milk of a cow for the whole season. Now, when it is desired to hurry cheese off to market in ten or twenty days, or at most, thirty days from the hoop, it requires two such rennets to curdle the milk of a cow for the same time.

When it is desired to make a cheese for long keeping, but little rennet is used, and its action in the vat is hastened by setting and working at an elevated tem- 
perature. To make cheese curc rapidly, more rennet is used, and a too rapid action in the rat prevented by setting and working at a lower heat.

To make the best cheese, rennet enough must be used to keep the action of the rennet ahead of the tendency to souring; otherwise the curd will have a tendency to become sour and hard, rather than pasty and rich.

The choicest cheeses are set at a pretty low temperature, and with considerable rennet; and they are worked and cured at a low and steady temperature all the way through. This gives the rennet action the advantage of the acid, as it works relatively faster than acid at a low heat; and the large quantity of rennet used does not hurry the action too much. In some of the best, the rennet is applied at about 77 degrees.

This circumstance of getting the rennet action to run ahead of tine development of acidity, enters into the manufacture of all the highly prized cheeses, wherever made; and there is no time when this start can be given so well as before the curd is salted. It is done most effectually by working low, as already described, drawing the whey early and packing the curd in the vat, covering it so that it shall all be warm alike, and letting it lie in that position till it is well matured. Letting the whey run away from it as fast as separated, prevents souring; and it may lie in this situation until all the water has been separated that can be, without leaving the curd too dry.

This is the underlying principle in the cheddering process. There are different ways of reaching the same result-as putting the curd into a hoop and letting it lie unpressed and warm for a day or more before salting it ; pressing fresh and salting afterward, 
by rubbing salt on the outside, \&c., \&c.-in all of which, the ripening process is put ahead by keeping the curd warm and out of the whey for a greater or less time before checking the rennet action by salting. This course not only makes the resulting cheese pasty and rich, but it retains all the aroma of the flavoring oils in the milk.

In the common method of making cheese for shipping, a different course is pursued. The curd and whey are warmed up to $9 \delta^{\circ}$, and the curd is kept in the whey till the acid gets the start of the rennet. The necessity and effect of this treatment have been explained. This makes the cheese dry, firm and compact, instead of mellow and pasty, and enables it to stand the rough treatment of shipping. Rennet enough is used to digest the curd into a rich and nutty paste, but its action is so modified by acid that it becomes too dry and insipid. Our shipping cheese is hardly fancy.

Under the present state of things, a cheese that will stand a voyage of 4,000 miles can hardly be a fancy cheese. In fact, the choicest cheese-that which is the richest and highest flavored-must, like the choicest fruit, be consumed not far from where it is produced.

But a much fancier cheese than we are now producing, one that will stand shipping, can be made. To do this, will require milk to be free from some of the imperfections which arc now quite common; it must be transported to the factories in better ventilated cans; it must be made with less rennet and less acidity; and it must be cured in an even and lower temperature, and in a longer time. While this course will make a product that will equal our present cheese 
in compactness, it will give a richness and high flavor not now attained.

\section{PRESSING CHEESE.}

The object of pressing cheese is to make the particles of curd cohere, make a smooth surface, and expel the whey which adheres to or is mingled with the curd as it goes into the hoop. The idea which some have that, where the whey is not properly separated before the curd goes to press, it can be forced out by hard pressure, is entirely idle. Whey is separated by fermentation, or other changes which occur in the curd. When this is not done, no amount of pressure can remove it. The amount of pressure needed varies with the condition of the curd. If the curd is cold and hard, it must be severe; if soft and warm, but litlle is required.

\section{CURING CHEESE.}

Our curing rooms are not well adapted to producing fine cheese. In the first place, they are too dry. To produce the best results in curing cheese, the room should be moist enough to favor a free development of mold. A rapid evaporation of water from the cheese is induced by a dry atmosphere. Ten tons of new cheese will lose, in a dry curing room, fíty pounds of water per day; this, coming mostly from the surface of the cheeses, makes them too dry to cure well. The surface in such cases never does cure; it dries down into a deep and hard riud of dried curd. This may be some protection to cheese in handling, but it is a loss to the consumer of a portion of the outside of the 
cheese, and a needless loss of weight to the producer, besides doing further injury by preventing the ready escape of gases produced by fermentation within. A basement makes an excellent curing room-especially for cheese in the early stages of curing. But little light and little change of air are needed in curing cheese at the start. Such a room develops mold rapidly, to the injury of the external appearance of the chicese, but it is much better to contend with mold than dry air.

The most obvious defect in the present structure of curing rooms, is their inability to guard against the varying temperatures of the outside air. Fancy cheese cannot be cured in a room in which the mercury rises and falls inside of it and outside of it alike. An approximately even temperature must be maintained, and this should be neither too high nor too low, but should be made to accord with the amount of fat the cheese contains.

The more fat, the cooler may be the room; and the less fat, the warmer may it be. The presence of fat in cheese facilitates the curing process; so that, when cheese is very rich in fat, it may cure at a low temperature, and be fancy when it is done. A cheese poor in fat must be well warmed up to make any reasonable progress, and is always liable to become bitter, in a cool room.

It is neither difficult nor expensive building curing rooms in which a comparatively even temperature can be maintained. The greatest difficulty in the way is, a disposition to do it.

The temperature of a curing room for whole milk cheese should be $65^{\circ}$ to $70^{\circ}$; for part skims, $70^{\circ}$ to $75^{\circ}$; for hard skims and sour cheese, $75^{\circ}$ to $80^{\circ}$. 


\section{CHEESE FACTORIES AND FACTORY MAN- AGEMENT.}

The manufacture of cheese in factories is steadily gaining in favor with dairymen and taking the place of private dairies, and is extending into new territories where cheese has been little made before.

The number of factories in the United States is now supposed to be about 5,000 , and the number is rapidly increasing; but the increase in the sum total of cheese made does not keep pace with the increasing number of cheese factories. The tendency has been within the last few years to build small factories instead of large ones, for convenience in delivering milk.

In the old cheese producing districts, the territory formerly occupied by one large factory, is now frequently divided between several smaller ones, thus multiplying the number of factories without increasing the amount of cheese. Cheese factories have become so numerous and so familiarly known that any description of them seems almost superfluous. I give, however, ground plans of a few representatixe factories, which will show the common structure. 


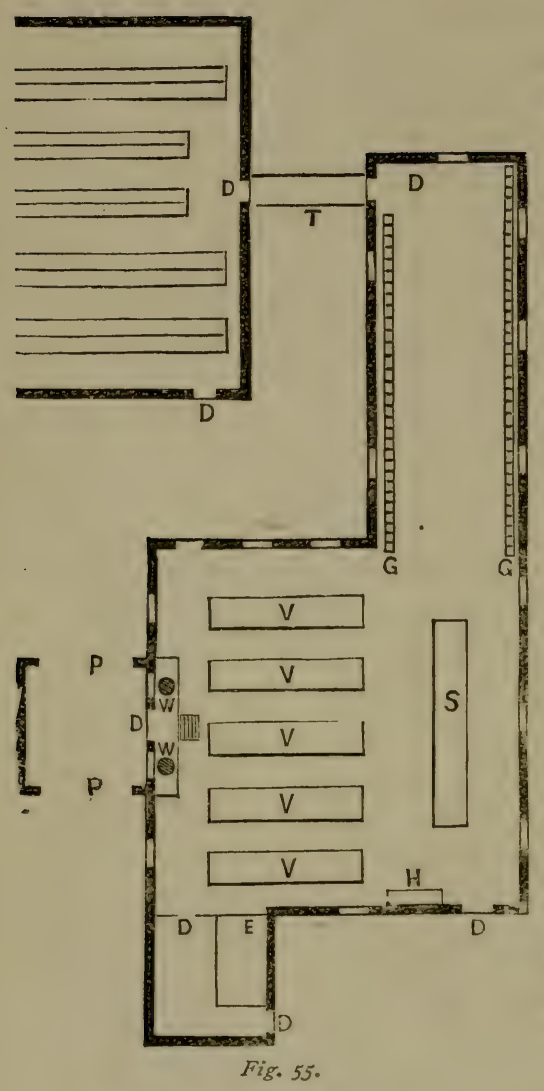

WILLOW GROVE FACTORY.
Figure 55 repre. sents the Willow Grove Factory, which has a capacity for I,000 cows, with a curing room separate from the manufacturing room, so that the cheese while curing shall not be affected by any scent from the make room. * Size of make room, $30 \times 28$; press room, I 4 X 26 ; curing room, $30 \times 100$.

This mode of arranging a factory is more expensive than to have the make room and curing room under the same roof, but it is regarded as favorable to purity of air in the curing room.

D, Doors; G, Presses; S, Curd sink; H. Hot The more comwater; P Drive way; T, Trite from press room to
curing room; V, Vats; W, Weighng can; ; E, En- mon plan is to
Eine.

build two stories high, to have the make room in one end of the lower story and a curing room in the other end and in the upper story. 


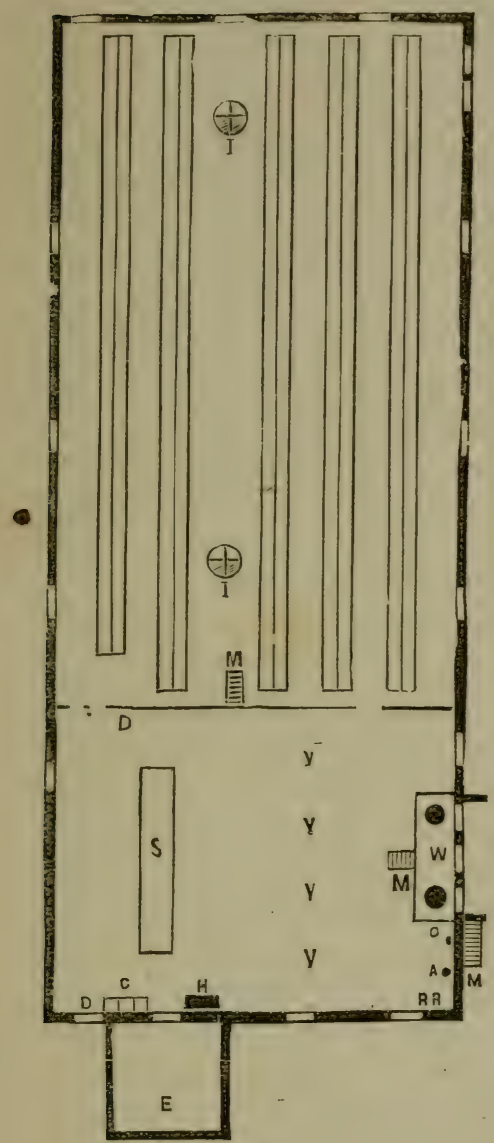

Fig. 56 .

It is the custom in many factories to have the family of the manufacturer live in the factory, and his residence is generally located in the second story over the make room. It is more convenient and pleasant to place his residence in the lower story and in the end most distant from the make room.

Fig. 56 represents the ground plan of a common form of factory without any living rooms. It is $32 \times 100$.

Plans of factories are abundant and easily obtained, and as A, Annatto jar ; O, Salt barrel ; R R, Cold water W, Platform and weighing cans; $M$, Stairs-the one they must vary to secrind story; I, Heating apparatus in curing room; suit different loD, Doors ; V, Vats; S, Curd Sink ; H, Hot water: C, calities and circumstances, it is not necessary to multiply illustra- 
tions. The mode of building will be much more likely to be defective than the form. The site will be determined by the convenience of delivering milk and the water supply, which it is very desirable, should be abundant and cool. Spring water is best, but a well will answer if made large and deep enough to keep cool. If the temperature of the water is too high, it may be cooled with ice, but a well is always objectionable by reason of the labor of pumping. $\Lambda$ cool spring saves this labor and the expense of ice. The amount of water absolutely necessary in a factory is not so very large, if carefully economized, but it is much better to have it plenty. The amount which will run through a three-quarter inch tube under two feet head, would be preferred for every 200 cows.

Buildings for the manufacture of milk, whether to be made into cheese or butter, should be built with special reference to maintaining an even temperature. The cheese factories of the earlier days of the associated system were very defective in this respect. Sided up with inch boards, neither jointed nor matched, but only roughly battened, and often made of lumber not very sound, the air, whether hot or cold, found such ready access that the temperature within doors varied but little from that outside. This, in hot weather, was very unfavorable for the milk which stood in the vats over night, and disastrous to the cheese which had to be cured under such shelter. The necéssity of building a curing room for cheese so as to control the temperature, seems not to have been properly appreciated by the pioneers in the associated system, nor is it properly understood now. What is wanted are walls, floors, and ceilings, through which neither cold nor heat car penetrate, and these are seldom found among the hosts 
of Eastern factories. While in Northern Illinois and Southern Wisconsin, last summer, I saw a considerable number of factories which appeared to me to be a decided improvement over the common style of building in the East. They were very efficient in protecting their apartments against both heat and cold, and were at the same time durable and inexpensive The sills of the buildings were placed upon good walls of mason work and the outer walls studded in the usual way. The studs were set just far enough apart to take on a breadth of ceiling paper and have it break joints on the studs - the paper running from the sill to the plate. Paper was tacked onto the studs both inside and outside, and then covered, on the inside with good planed and matched boards running horizontally, and on the outside with the same running up and down.

This made between the walls a dead air space much more perfect than could possibly be made with wood alone, or by lathing and plastering - the glazed paper being entirely impervious to air. The under side of the joists were ceiled in the same way and the floors were also lined with the ceiling paper. With the doors and windows snugly fitted, a room thus protected could be made to maintain an equable temperature, but little above 60 degrees, through all the hot weather, and could be very easily kept warm in cold weather. I saw cheese curing in these rooms, in hot weather in June, without being at all affected by the severe heat of that season. The rooms were opened during cool nights and closed during the day to shut out the heat, which they did effectually. In creameries, there was no difficulty in keeping butter in a room above ground, though a basement for such use wonld 
be preferred. This mode of building is commended to such as are erecting new factories, and it may often be made useful in repairing and reconstructing old ones.

\section{DELIVERING MILK TO FACTORIES.}

When milk is to be carried to the factory or creamery, it is of course strained into a can. Ordinarily it will be sufficient to leave the can standing open, in a sweet, cool place-always out of the sun or rain-with, perhaps, an occasional stirring to prevent the formation of an air tight covering of cream. Once on the road, of course, the milk will be sufficiently agitated for all practical purposes. And here, as before, neither ventilation nor protection from atmospheric influence should be neglected. There should be a cover to the milk wagon, and the cover of the can should be provided with openings, constructed so as to prevent waste of milk, through which the animal odor can freely escape.

The iron clad can is the one generally used for carrying milk to factories and creameries, and is well adapted for that purpose, with the exception of its having a tight cover and no sufficient provision for ventilation. One of the most objectionable things about the American dairy system, is carrying milk to the factories in cans partly filled and closed with tight covers. If the cans could be filled perfectly full, much of the difficulty would be obviated, as the agitation of the milk would be greatly reduced.

Dairymen seem very slow to learn that the agitation of warm milk developes and increases the odor of new milk when closely covered, yet it is a fact which stares 
Factory Checse Making. $3^{13}$.

most of them in the face every time they deliver milk to a factory. New milk is always injured in its flavor

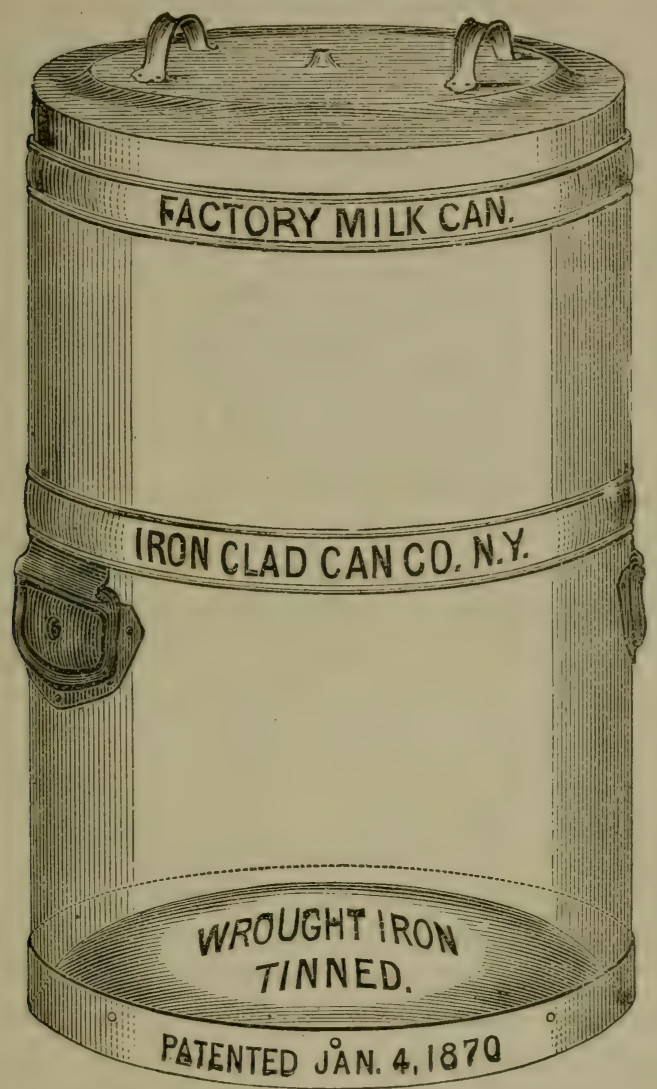

Fig. 57 .

by carrying in a can with straight sides, like the iron clad, when there is room in the top of the can for it to splash from side to side, and no chance is given for 
the accumulating odor to escape. Milk which appears well when it starts from the dairy, appears affected when thus treated, by the time it reaches the factory, even if it has but a short distance to go. A very large share of the milk delivered to cheese factories is injured in being transported, so much as to materially depress the quality of the cheese made from it.

If there is the least thing about milk which is not just right, carrying it closely covered will soon swell the little defect to a very large one. In 1869 , I examined a herd of cows whose milk was affected by breathing the scent of carrion. The milk was carefully examined as it was milked, and when it started for the factory could not be distinguished from perfect milk. The cans were closely covered, and when they had rode in this condition two miles to the factory, the odor had become perfectly nauseating and the milk so injured that the whole vatful with which it was mixed was nearly ruined. A similar result follows whenever cows become a little affected by a hot sun, by worrying a little, or drinking stagnant water, or going without water too long, or by a multitude of other little irregularities which are every now and then occurring, but which would be entirely obviated if the cover of the can were sufficiently open to give the milk free access to the air. With proper ventilation of the carrying cans, tainted milk would be of very rare occurrence, and thousands of dollars would annually be saved in the quality of cheese. For butter making milk is not improved by transporting, but for cheese making, the ride to a factory is a positive advantage, if properly ventilated.

A variety of ways have been devised for ventilating milk cans, but I have seen nothing so cheap and 
cfficient as the device of the author, itlustrated in figure 58 . It is made by cutting a circle out of the center of the cover, and soldering over it a piece of ccarsely perforated tin, or of wire cloth, and giving it a moderate depression in the middle. Around the outside of the wire cloth is soldered a flange of tin two inches high to prerent any milk which may dash through the cloth from wasting.

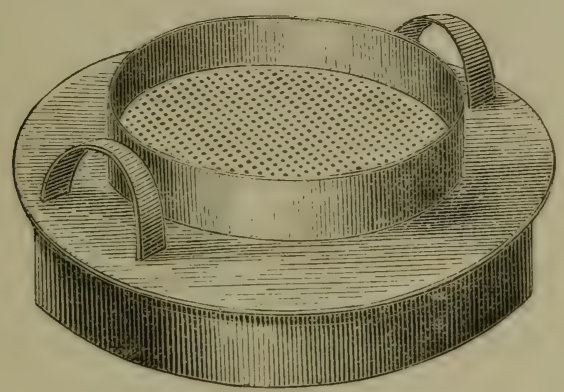

Fig. 58.

The only objection to this mode of ventilating, is a possibility that dust may occasionally fall through it into the milk. It ventilates perfectly. Milk which would injure by riding under a tight cover, will grow better by riding under this, and the farther it rides the better it will be, prorided it stops short of souring or churning to butter. Under it, milk carried to a cheese factory needs no other airing or cooling.

\section{DELIVERING MILK ONCE A DAY.}

With proper facilities for taking care of the milk on the farm, it is quite as well to deliver it once a day as twice. All that is needed is an open shed under 
which the evening's milk can stand during the night, uncovered, and a double set of cans for carrying. The night's milk should occupy all the cans till morning. This will spread it so much that no other cooling will be required than it will receive from the night air, except, perhaps, occasionally in a very warm night. In the morning, one half of the cans may be emptied into the other half, and the cans taken for the morning's milk, which should not be mixed with the night's milk before it reaches the factory.

At the cheese factories, milk is always received by weight instead of measure. Upon arrival at the factory, it is elevated by a wheel or a crane and dumped into a large weighing can which stands on platform scales, high enough to allow of spouting the milk, in an open conductor, to the manufacturing vats as soon as weighed. A very convenient scale for this purpose has been invented by the Buffalo scale works, which has a seven-barred scale beam, on which the milk of seven different patrons can be weighed without emptying the milk can, or stopping to set down the weights.

The milk received at night is run into the manufacturing vats, and cooled by running water under it down to about $70^{\circ}$, and left for the night. By allowing the water to run all night it will get down to about $60^{\circ}$ by morning, and will be in good order.

A few years ago a good deal of stress was laid upon the use of agitators, by the action of which the milk was kept stirred all night, to prevent the cream from rising. They were kept in operation by the power furnished by the waste water used to cool the milk. They are occasionally in use yet. They are so regulated as to act at regular intervals, stirring the milk or 
producing waves on its surface. The effect was to prevent a coat of cream from forming. They could hardly prevent the cream from coming to the surface, but they would prevent it from becoming thick. They left it mingled with the top of the milk. The use of these machines is differently estimated by cheese makers. Some prize them highly and others think them of questionable utility. After one season's use of a good machine I laid it by as not worth the little trouble of keeping it in operation. There was quite as much waste when the agitator was run as when it was not, and sometimes I thought more.

In the morning, the cream which may have been raised during the night, is dipped off (I used a curd scoop) and as the morning's milk is run into the vats, is turned into the strainer and washed through with the warm milk. This, with me, seemed to put the cream in better condition for mixing with the milk, than when it was left in by the agitator. The cream should be taken off' before any of the morning's milk is run in, but it should not be put into. the strainer till near the close of running in the morning's milk, so that it shall be freshly mixed with the milk at the time of applying the rennet.

For furnishing steam and motive power in factories and creameries, for grinding curd, churning, \&c., small portable boilers of different patterns are employed, many of them being built with special reference to dairy use. Prominent among them is the horizontal flue boiler, known as "The Economizer," for an illustration of which I am indebted to Gardner B. Weeks, dealer in dairy apparatus, Syracuse, N.Y. (See figures 59 and 6o.)

This boiler has all the necessary fixtures for con- 


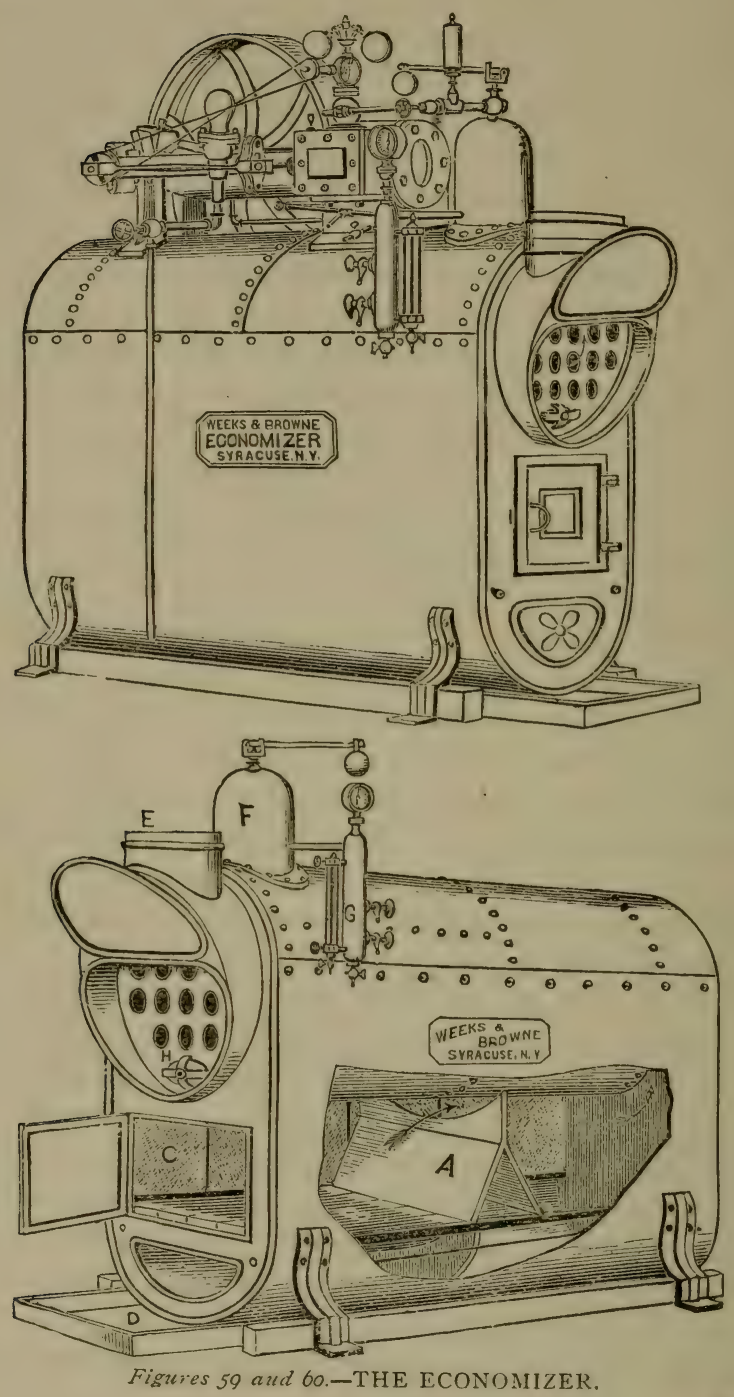


renience and safety, and is ready for use when shipped and is set up without any mason work. The engine attached to it is simple in structure and is easily and safely managed by workmen of ordinary skill, and has an adjustable cut-off for economizing the use of steam. The four-horse power boiler is adapted to a factory of 400 cows, varying the size up or down for a greater or less number.

Messrs. Jones \& Faulkner, of Utica, N.Y., long and prominently known as dealers in dairy apparatus, and to whom I am indebted for various illustrations, also build an excellent boiler and engine for dairy purposes, as also do other parties, but which I have not space to illustrate.

There are different ways for warming milk and heating curds. The agent most generally preferred is dry steam, which must be very carefully distributed to prevent heating different parts of the vat unequally. To secure even heating, some workmen fill the space between the vats with water, and heat the water by discharging steam into it. Others heat the water by a direct application of the fire, and others still do the heating by throwing a jet of steam directly into the milk and whey. I have used all these methods. Throwing the steam directly into the milk or whey to be heated, is the simplest and cheapest way; dry steam between the vats is most convenient; and water heats most evenly and holds heat the longest, but is most clifficult to control.

The vats used in the manufacture of cheese are built nearly alike, all being composed of a tin vat for holding the milk, within a wooden envelope, having a space between the two for steam or water to heat or cool the milk as required. The tin vat is fitted with a 
frame, and handies for holding it in place, or lifting it out at any time desired.

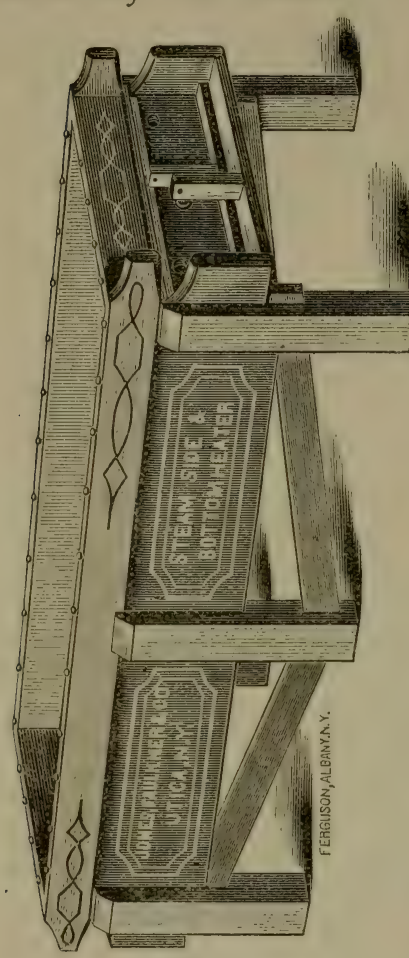

Fig. 6r.

Some are fitted with a heater under them, or attached to one end, making what are called self-heaters. Others are made for heating with water only. The form here illustrated in figure $6 r$ is the one generally used.

If there is more than one vat, the morning's milk, as it arrives, should be divided so as to be mixed half and half with the night's milk. The coloring, if any is used, may be applied at any time after the cream is stirred in. It is only essential that it should be well mixed before the rennet is put in. The rennet should be in readiness and as soon as the milk intended for the vat is all in, it should be added and well stirred to be evenly mixed through the whole mass. The stirring should continue till near the time the coagulation is expected to begin, and then the vat should be closely corered and left for the milk to come to rest before the curd begins to form.

The mode of heating to warm the milk is not essen- 
tial, if only there is left no steam leaking on, nor hot water about the vat, to make an unequal heat in any part of it while the curd is being formed. The temperature of the milk when the rennet is applied varies according to the condition of the milk and the particular mode of making intended to be carried out. When the milk is in a normal condition and cheddar cheese is intended to be made, the rennet is applied, by a majority of makers, at $\delta_{4^{\circ}}$ and enough rennet put in to show signs of curding in ten to fifteen minutes, and to become firm enough to cut in about forty-five minutes.

When the curd has become of the right consistency for cutting, which is determined by its parting with a clean fracture as the finger is passed through it, it is cut with the Young's perpendicular curd knife, both lengthwise and crosswise of the vat, and then with the horizontal knife, which leaves the curd in half inch cubes. It is then left standing till the curd is nicely covered with whey, say fifteen minutes. Then

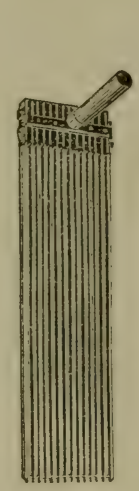

Fig. 62.

PERPENDICULAR KNIFE.

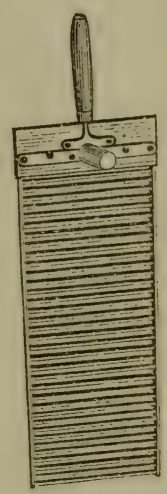

Fig. 63.

HORIZONTAL KNIFE. with the hands, the curd is stirred from the bottom, carefully bringing as much of the bottom as possible to the surface, especially if any part has been missed with the curd knives, so that it may be made fine like the rest, and so that the mass of curd shall be loosened up as much as possible, to be in a condition to heat 
evenly. When this is done the heat is let on and the curd warmed up very gradually, five or six degrees, and gently stirred to keep the curd from packing and therefore heating unevenly. The heat should then be shut off for fifteen or twenty minutes to give time for the lumps of curd to get warmed through, so that the inside of the lumps shall have the same temperature as the outside, but moderate stirring should be continued to prevent packing while the heat is off. As soon as the heat is supposed to have penetrated through the lumps of curd, so that they have the same temperature inside as outside, the heat may be turned on again and the mass raised five or six degrees more in the same way as before, and after another interval, repeated, bringing the whole up to 96 or $9^{S}$ degrees. The stirring at first is best done by hand, afterward, when it begins to harden, it may be stirred with a rake. The whole time of heating should occupy an hour and a half or two hours. The more gradual it is done the better. Up to this point in the process, the practices of manufacturers are very uniform, varying but little from the course here indicated. Beyond this, they differ considerably. The leading features in the different courses pursued deserve attention. The one by which the finest cheese is made is of English origin, and is known as the Cheddar system, and will be first described. The English method is not strictly followed by American manufacturers. It is varied in different ways, but the underlying principle is not lost sight of in the various deviations from the English mode. Mr. S. A. Farrington, of Pennsylvania, who derived his practice directly from English experts, and who is quite successful in making after the Cheddar plan, proceeds as follows, taking the work from the 
time when the heating is done. After the heat is turned off, and the whey and curds, and water under the vat, if any, have assumed a uniform temperature and there is no longer any danger of heating unevenly, the stirring ceases, to let the curd pack on the bottom of the vat and the fine particles, which may be floating in the whey, settle and adhere to the rest. When this has been done, the syphon (fig. $6_{4}$ ) is applied and the whey drawn off, the vat is tipped a little, and the curd heaped up against the sides of the vat and left to drain. If the weather is cool, a little heat is let in and the vat covered to keep the temperature about $98^{\circ}$ In warm weather this will not be required. In this condition the whey is steadily draining out and the curd becoming more firmly packed. As soon as it has become sufficiently adhesive to hold together, say in 15 or 20 minutes, it is cut into chunks

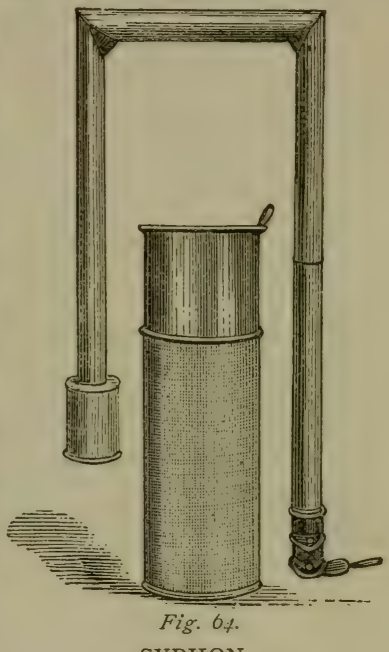

SYPHON. convenient to handle, and turned over, so that all parts shall be affected alike. This is repeated at intervals of twenty or thirty minutes, till the curd is advanced to the proper stage for salting and pressing. This stage is determined by the appearance and smell of the curd. When sufficiently ripened the curd becomes tough and stringy, and when pulled apart, splits instead of breaking, showing a fibrous structure similar to that which may be seen in pulling apart the 
muscular fibers in lean beef when boiled. At this stage, it assumes a distinct and peculiar odor which it is difficult to describe. It has something of the sickening smell of animal odor, but is more like that of the cows' breath than anything else I can compare it with.

As the curd approaches the proper degree of ripeness it is allowed to cuol gradually, so that when it is ground the bits of curd will not so readily adhere again, as they would do if kept near $98^{\circ}$. If the curd mill is operated by hand, it may now be set on the vat, that the curd as ground may fall back into the vat. If the mill is operated by power, the curd is put

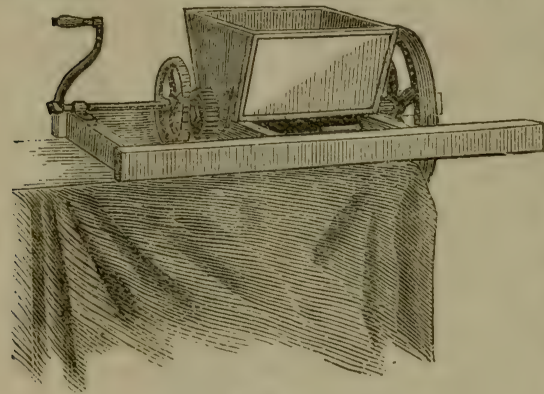

Fig. 65.

CURD-MILL. into a curd sink, and run under the mill and ground fine enough to admit of salting evenly. A curd mill which will cut the curd fine, instead of bruising it to pieces, is preferred, the only object being to make the curd fine for the sake of even salting. Two and a quarter to two and a half pounds of salt to $\mathrm{r}, 0 \mathrm{co}$ pounds of milk is applied, and when cooled to $70^{\circ}$ the curd is put to press. When the milk is all right, this process produces a fancy cheese.

Others let the whey all remain on the curd till it begins to show indications of acidity, then draw off the whey and treat as above, or decide when the curd is ready for the press by the hot iron test. 
It is not necessary, in following out the Cheddar system, to be very precise as to the time the whey is drawn, if only it is done before acidity becomes distinct ; but it may be remarked that, as a general thing, the longer the curd lies in the whey after it is separated, the more the quality of the cheese is depressed, the influence of the whey upon the curd, especially in its later stages, being unfavorable to fine quality.

Another process, which may be denominated the American process, is as follows :

Starting from the point where we began with the Cheddar system - the time when the heating was

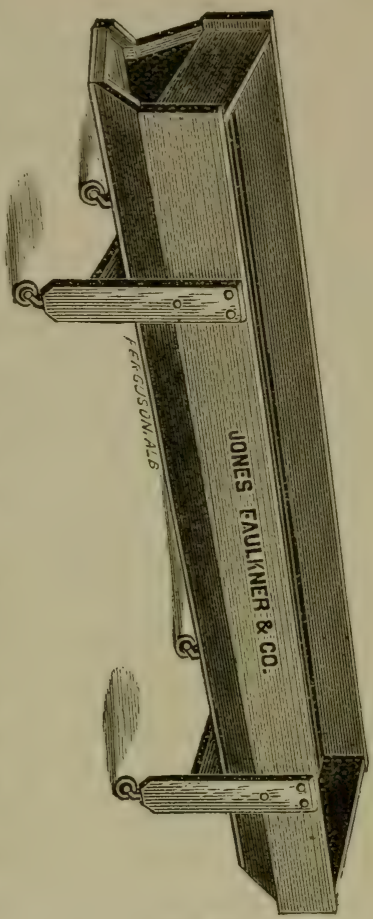

Fig. 66.

CURD SINK ON CASTORS. done-the curd, instead of being allowed to pack, is gently stirred to keep it fine and prevent it from packing. The stirring is kept up and the whey is kept on until the acid becomes distinct. The curd is from time to time tested, and as soon as it will respond to the hot iron test, the whey is drawn, the curd dipped into the sink and carefully stirred enough to prevent its adhering till it is sufficiently drained for salting. It is then salted at the rate of $2 \frac{1}{2}$ to $23 / 4$ 
pounds of salt to I,, 00 pounds of milk, and when cool enough, put to press. This will produce a firm, compact and meaty cheese, of fair flavor and of good ship. ping quality, but in fineness of flavor will be inferior to the Cheddar cheese.

The difference in the working of these two processes is this: In the former-the Cheddar processthe formation of acid is, to a large extent, prevented by removing the whey which contains the acidifying agent-sugar. If, by reason of the little sugar left in the curd, acidity develops while the cheddaring process is going on, it is at once carried away by the whey which is all the time separating and escaping. By this means, the digestive action carried on by the agency of rennet in the curd, goes on unimpeded, as the acid which would counteract its progress, is kept out of its way. By this process, too, the nutty flavor is very completely retained, as there is not sufficient acid developed to neutralize it. By this process of removing the whey early, taints of every variety, as well as acidity, are carried away and prevented from form. ing, leaving the rennet to its own perfect action.

In the other process-that of leaving the whey on and developing a distinct acidity-the strong acid counteracts, to some extent, the activity of the rennet action. This of itself would do no serious injury. What the acid does besides this, is to neutralize every species of taint which may have developed from any cause in the curd and whey, holding them in check, while the rennet; but little impeded by the acid, goes on curing the cheese. The great point in the use of acid is, that it neutralizes all the volatile matters which make taints perceptible. If it stopped at this point, it would be well; but, as before explained, it neu- 
tralizes also the volatile oils on which the nutty flavor of cheese depends, so that the more acid we develop, the less nutty flavor in the cheese.

In the earlier days of associated dairying, it was customary to dip the curd while perfectly sweet, and, without cheddaring or souring, drain, salt, and put to press at once, or as soon as cooled. A similar course is often pursued now. The result is a soft, weak, porous or spongy cheese, which some people like, but which more people do not. In this practice there is no definite rule for determining when the curd is fit for the press. Something can be told by the elasticity with which the lumps of curd spring apart after being squeezed in the hand, or by its squeaking between the teeth; but these are very indefinite guides. The maker has to rely on his judgment or experience, and hence it is rare that the cheese will be alike in any two cases. Cheeses made in this way are very apt to huff and be off flavor, and get out of shape, especiallv in the early part of their curing. The large amount of whey left in the curd often develops a strong acid in the curing room, before cheesing begins, by which the fine flavor of the resulting cheese is always depressed, and not unfrequently occasions leaking. The best reliance for getting a good cheese by this method, is to work very fine and heat pretty high, by which means the whey may be sufficiently worked out to secure meatiness and a fair flavor.

The three processes described may be regarded as the leading ones in the American system of cheese making. The multifarious modes adopted by different dairymen are but modifications of one or the other of these three primary methods. 


\section{WORKING TAINTED MILK.}

Under the phrase "tainted milk" is classed all milk which has any strong smell or taste, particularly that in which strong odors are developed in transporting, handling and manufacturing. The taints which thus develop are the result of unusual ferments, and are to be treated as such. The action of all such ferments accords with the action of rennet, both in the coagulation of milk and in the conversion of curd into cheese. Hence less rennet is needed than in milk not tainted, and less should be used. Tainted milk often coagulates without the addition of any rennet, when entirely sweet, so strong is the coagulating tendency of taint. Curds thus formed, have in several instances been made into marketable cheese without the use of rennet, or any addition whatever to the milk.

As soon as the curd becomes firm, it should be cut fine, and the heat put on at the earliest moment it safely can be, with a view to the earliest separation of the whey possible. After this is done, two courses are open to the operator. One is to keep all the whey on, warming it up as soon as it will be safe, to $9 \delta^{\circ}$ or $100^{\circ}$, - with a view to the early development of a strong acid to neutralize the taint and silence its action; the other is to run off the whey at the very earliest moment practicable after reaching the maximum heat, packing in the vat, and beginning cheddaring at once, with a view to carrying off the taint in the whey

The acid method is the one generally adopted. It is well known that acidity counteracts all the taints which occur in milk, or curd, or cheese, and hence, when they are met with in cheese making, the usual course is to keep all the whey on and under a favorable 
heat for souring, till a sufficient amount of acid is developed to overcome the taint. In extreme cases, where acid cannot be developed fast enough in the whey, sharp vinegar at the rate of a pint to $\mathrm{I}, 000 \mathrm{lbs}$. of milk is added, with excellent effect; or sour whey is used, either sparingly with the rennet, or freely in the warm whey in the vat, to hasten souring. The operator should continue the curd in the warm whey till the acid distinctly predominates over the taint, and he should mark well the difference between the strong odor which becomes manifest in the whey in such cases, just before the acid becomes distinct, or he will fall short of developing acid enough to counteract the taint.

If the hot iron test is made use of to determine when to draw the whey in treating tainted curds with the acid process, the whey should be kept on till the curd, when pulled away from the iron, will spin out into fine long threads. exceeding considerably the length required for ordinary milk. By following out this course, and airing and cooling the curd well, a cheese of good texture and of fair flavor and keeping quality can be made, when the milk is so much affected as to produce a floating curd. The other method-that of getting rid of the taint by getting rid of the whey which contains it-has been for several years carried out successfully by Mr. Farrington, of Pennsylvania, and is done simply by ripening the curd in the vat as exclusively as possible with the Cheddar process, by running off the whey just as soon as the curd will pack. He proceeds upon the theory that the taint is in the whey, and reacts upon the curd, and that by getting rid of the whey, he gets rid of the taint, leaving the curd unhurt and sound. His theory seems to be sup- 
ported by the fact that the cheese he has made in this way, when ready for market, can hardly be distinguished from that made from ordinary milk, though it will not keep so long.

Heating milk which is in any degree tainted to $\mathrm{I}_{3} 0^{\circ}$ purifies it entirely of all offensive odor, and if at once cooled and made into cheese in the usual way, the product will be the same as from milk not so affected.

"An ounce of prevention is worth a pound of cure." It is better to avoid tainted milk than to struggle with its effects. But all dairymen have not learned how to do it, and manufacturers must deal with it in the best way they can.

\section{WORKING SOUR MILK.}

Milk will often respond to au acid test before the presence of acidity will be recognized by tasting. Milk in such a condition, and even after acidity becomes sensible, can be made into good cheese. The course to be pursued is the reverse of that in tainted milk. In tainted milk we have too much rennet action-in stale milk we have too much acid action. In the former we use less rennet than in ordinary milk; in the latter we use more, so as to make the rennet action, at least, equal to that of the lactic yeast. Set at a low temperature $-78^{\circ}$ or $80^{\circ}$ - so that the changes shall not be too rapid by reason of the increased amount of rennet. The curd should be ready to cut in 15 to 20 minutes from the time of applying the rennet, and should be cut fine and worked as rapidly as it well can be. Work low all the way through, being careful not to raise the heat so much as to hurry the curd faster than it can be taken care of. The more acid, the less heat. The 
scalding may run from $90^{\circ}$ down to $80^{\circ}$, or kept at the degree of setting, all the way through, if distinctly sour. It is best to heat just enough to hasten the process as fast as it can be attended to. When it is about to respond to the hot iron test, the curd should be at once dipped, and as soon as drained, salted and put to press warm.

A nother method of treating milk which is nearly or quite sour, is to drain off the whey as fast as formed, for the purpose, as in the case of tainted milk, of getting the acid out of the way and preventing it from affecting the curd. Instead of warming the curd by steam or hol water, under or around the vat, it may be warmed by putting water of the desired temperature directly into the curd. By running this off and adding more warm water, the acid can be nearly all washed out. In other respects it may be treated as in the first method.

By salting while quite warm, the salt strikes through the curd rapidly, and retards the action of the acid, and by excluding it from the air by pressing, it is stopped entirely, while the rennet action goes on without hindrance. In this way good results are secured.

\section{WORKING SKIMMILK CHEESE.}

There is more difficulty in makin巛 good cheese from skimmilk than from milk in any other condition. The action of rennet in digesting milk into cheese is supported largely by the fatty matter in the milk. This is especially true of the lighter fats, for the more volatile oil there can be retained in the curd, the more energetic is the action of the rennet. It is easy enough to coagulate skimmilk, but when the light flavoring 
oils and the principal part of the fatty matter of the milk, are carried off with the cream, the action of the rennet is so much depressed as to make the curing of the curd into cheese very difficult, slow and imperfect. Unless the curing process can be properly effected, the product is worthless for human food. So long as casein retains its curdy condition, it is insoluble in water or weak acids, such as exist in the stomach, and of course indigestible. Coagulated casein becomes soluble by the aid of an alkali, or by the change wrought upon it in the curing process. It is then easily digested, and becomes a nutritious and palatable food.

It is the misfortune of cheese made from skimmilk that it so far fails in the curing process as to retain its curdy nature, and remain insoluble and indigestible, when it is old enough to become cheese. As usually made and cured, much of what is called skim cheese is not entitled to the name of cheese, for it never fully becomes such-it is only dried curd, or partly curd and partly cheese, since the curing, or cheesing process, is but partially completed. To the extent to which it fails in curing, it is insipid and unwholesome, because of being insoluble, it is indigestible. By lying in the stomach long enough to complete the cheesing process, which it will do in time, it can be digested; but by such a detention in the stomach it becomes a source of irritation, and produces constipation-a result which does not occur with well cured cheese, which, on the contrary, is rather a laxative.

Since skim cheese fails in curing, and since it is insipid, worthless and unwholesome to the extent to which it falls short of curing, and remains tough and curdy, instead of being mellow, tender and salvy, the 
operator who attempts its manufacture should employ his utmost skill to stimulate the curing process. To this end, the sweet buttermilk should always be added, and the rennet applied at about $80^{\circ}$, and more rennet used than with unskimmed milk. The curd should be cut fine and worked at a low temperature, the same as when milk is sour, with a view to keeping the digestive action of the rennet ahead of the tendency to souring. Only so much heat should be applied as to keep the work progressing, and if a curd mill is used, the curd may be allowed to pack in the whey; but, if not, the curd must be kept stirred and kept fine, so as to be handled with dispatch when it is ready to dip. As soon as it begins to respond to the hot iron test, dip, drain, and salt expeditiously, or the acid will advance too much, and hurry into the press warm. Use a little more salt than with whole milk, say $1 / 4 \mathrm{lb}$. more to Ioo lbs. of curd, otherwise putrefactive fermentation is liable to take the place of cheesing when full skimming is practiced. If when taken from the press the curing can be done in a room with a nearly uniform temperature of $75^{\circ}$, a wholesome and fairly palatable cheese will result. But if the room is not warm enough, or the temperature is allowed to drop and raise alternately, the cheese will be spoiled in curing. Skim cheeses are much more difficult to cure than those from whole milk. They can not be cured, without being injured, in a room in which the mercury feels all the changes of the outside air.

If a curd mill is used, it is better to follow the Cheddar process, drawing the whey as soon as the curd will pack, and grinding when it will begin to respond to the hot iron test, treating otherwise as above.

Where half skimming is practised, the treatment 
should be between that for full skimming and whole milk cheese.

\section{OLEOMARGARINE CHEESE.}

To remedy the defective curing occasioned by the loss of fatty matter in the cheese from removing the cream, H. O. Freeman, of Sherburne, N. Y., devised the plan of supplying the loss of fat by artificially mixing with the skimmilk, just before adding the rennet, some clean cheap fat, such as rancid butter purified, or oleomargarine derived from beef suet. The latter only is now used. The fat is melted preparatory to mixing, and the milk warmed up to about $94^{\circ}$, and the fat thoroughly mixed. Rennet enough is then applied to coagulate the milk in 8 or io minutes, and the stirring continued till the curd begins to form. Only a part of the fat will be retained in the curd. Enough is added so that the curd will retain $\mathrm{I} / 2 \mathrm{lbs}$. for each roo lbs. of milk; the rest, rising on the whey, is skimmed off and saved for use again. In other respects the curd is worked and pressed in the usual way. The fat enclosed in the curd facilitates the curing, and gives body to the cheese. When skillfully made, the cheeses appear rich and well flavored, and are often mistaken in the market for whole milk cheese. The greatest difficulty in manufacturing is to mix the fat evenly.

\section{THE ELLSWORTH METHOD.}

Another mode of treating skimmilk, first practiced by Mr. John T. Ellsworth, of Barre, Mass., and hence known as the Ellsworth Method, was suggested by the 
author, a few years ago, for the purpose of better utilizing the valuable nitrogenous elements of skimmilk, and has proved very satisfactory. The milk to be made into cheese is heated to $135^{\circ}$ or above, while new and warm, and then cooled to about $60^{\circ}$, and left for the cream to rise, the same as milk not heated, and skimmed when $3^{6}$ or 48 hours old, as is customary in creamery practice. The cream is churned sweet, and a part of the skimmilk is churned either with the cream or separately, and the buttermilk and the churned milk are mixed with the skimmed milk and made into cheese by one or the other of the methods above detailed,-the Cheddar method is preferred. Threc points are gained by this method: first, heating the new milk makes the casein when coagulated softer and easier to cure than when not heated; second, it prevents the buttermilk from imparting that peculiar flavor to the cheese which is imparted to it by the buttermilk of milk not so heated, and it promotes as much as other buttermilk the curing of the cheese; third, the churned milk promotes the curing of the cheese the same as buttermilk, and with all these aids for facilitating the curing process, the operator is able to make a superior skimmilk cheese, and to cure it as rapidly and as perfectly as whole milk cheese.

The large amount of valuable nitrogenous matter in the milk which must be used for our butter supply, and which has heretofore only furnished foad for swine, or been made into a skim cheese, unfit for human food, may, by this method, be fully utilized, by converting it into a palatable and wholesome product, and one which finds a ready sale in the markets.

But, however successful we may be in moulding skimmilk into a fine flavored and digestible cheese, we 
are not able to make a whole milk cheese of it. The nutty flavor and aroma imparted by the flavoring oils which go with the cream, and the richness imparted by the cream itself, cannot be supplied by any mode of manufacture. But we may justly regard it as a matter of much gratification that we are able to transform into a palatable and wholesome food for human use, what was so nearly wasted before.

\section{HAY CHEESE.}

It is desirable to dispose of hay cheese as early as possible to prevent bringing it into competition with better goods. To this end, hay-fed milk should be manufactured to cure as quickly as possible.

To facilitate curing, hay milk, like skim-milk, should be manufactured at a low temperature, and with a large amount of rennet. Curd ripens very much faster while lying warm in the vat, than after it is taken out; and this fact may be taken advantage of when it is desired to hurry the curing of the cheese. By being careful to adapt the temperature of manufacturing to the rennet used, and by digesting the curd as long as possible by cheddaring, or by lying in the whey, the curing process may be pretty well advanced before it goes to press. An extra hour in the vat will ripen the curd as much as several days in the curing room. It requires a good deal of skill to make and cure hay cheese to the best advantage, and when that skill is used, a good cheese and one that will ripen quickly, sell well and prove satisfactory, may be made. But if that skill" is not available, and a poor product-one that is sour, bitter, tough, or curdy, is to go into the market, it would be better 
to suspend cheese-making till grass comes, and make butter through the spring. No one should attempt to make both butter and cheese from the same milk in the spring, when only passable cheese can be made with all the cream worked in.

The curing of early cheese in factories is frequently defective, being too slow, and the heat uneven. The difference in the nature of hay curd and grass curci should be noticed, and the requisite difference in curing made. The casein, or cheesy matter derived from the milk of cows fed on full grown hay, or other well matured fodder, is harder and tougher than that from the milk of cows fed on tender grass, and it requires more curing to break it down and make it salvy and rich. It takes a longer time, and a higher temperature to make it cure with sufficient rapidity. Curd made from grass will cure as fast at 65 degrees, as that from hay at 75 . Ordinarily, 75 to 80 degrees is about the right temperature for hay cheese to ripen in with the best results. It is better to hurry it up as quickly as is compatible with safety. It should not only be kept as warm as it will admit of, but the heat should be unremitting night and day. To keep spring cheese hot during the day, and cold during the night, is to thwart the curing, and make it grow sour and bitter, doing injury to the flavor that no aftertreatment can ever overcome. It is always detrimental to the quality of cheese to be subjected, while curing, to wide variations in temperature, but to spring cheese it is fatal.

It should be remembered that while it is desirable to dispose of hay cheese as soon as may be, it is never good policy to send away green cheese. It is sometimes done in the summer, anticipating that it will 
keep on curing, and be all right by the time it reaches the consumer. It never cures, however, as well in the box as in the curing room. But this practice cannot be safely followed with hay cheese, for the moment it leaves the shelves and gets cold, the curing stops, and the flavor at once begins to depreciate, growing bitter and sour, and otherwise defective. Hay cheese should, therefore, never be allowed to leave the curing room till it is fit to go upon the table.

\section{PRESSING CHEESE.}

Curd for curing into cheese, is molded and pressed into different forms and sizes, as custom, convenience, or the market, dictates. The cylinder form, 8 to ro inches high, and 14 to 15 in diameter, is now generally preferred as being the most convenient for handling and desirable for shipping, but is far from being the most convenient form for presenting to consumers. Thinner and smaller patterns are more eonvenient for cutting. A cheap method of molding and curing cheeses of a size suitable for families to purchase whole, is a desideratum, which when satisfactorily - filled, will increase largely the home consumption of cheese.

In molding curd into cheese, different modes have been, and are still, pursued. Formerly the curd was molded into the desired form in a large cloth placed inside of the hoop, called a press-cloth. When the curd had been pressed long enough to hold together so firmly as to bear handling, the press-cloth was remored, and a clean one applied, and the cheese turned and placed back in the press to complete the pressing. This done, a bandage was applied, and the 
cheese placed in the curing room. Now when presscloths are used, a bandage is applied in the place of the second press-cloth, and the top and bottom of the cheese covered with a circular cloth called a "headcloth" or "cap-cloth," and the pressing then continued till done. By finishing the pressing with the bandage on, the curd is forced into the meshes of the cloth, making a better rind to the cheese, and in every way a better job than when the bandage is applied after the cheese is pressed. In some factories the use of the first press-cloth is avoided by placing a headcloth at the bottom of the hoop, and a ring of rubber, wood, or rope, around the inner edge of the hoop to keep the curd from crowding out under the edge of the hoop, and a similar cloth and ring on the top of the curd, and then applying the follower and pressing till the curd is firm enough to bandage, when the bandage is applied, and the cheese turned, and the pressing finished. It is an objection to this mode of beginning the pressing that, if cooled as much as is desirable before pressing, the surface of the curd does not unite as perfectly when in contact with wood or iron, as when covered with cioth. Hence this practice is limited. The great majority of factorymen now place the bandage inside of the hoop, and fill the curd into the bandage, and thus mold the cheese in the bandage at the beginning of the pressing.

When cheeses are pressed singly, the bandage is placed inside of the hoop, and held there by means of a cylindrical tin form with a flaring band upon one end. The cylindrical part is long enough to reach the bottom of the hoop, and just large enough to fill it. The bandage, except an inch and a half or so of one end, is stretched, over the cylindrical part of this 
form, and the loose end of the bandige turned inside; a cap-cloth is placed over the end of the form, which is then crowded to the bottom of the hnop. The loose end of the bandage is adjusted inward upon the capcloth, and the form filled with curd, which resting upon the inturned end of the bandage holds it in place while the form is withdrawn, leaving the curd, all except the upper part of it, within the bandage.

When the curd has been pressed down so as to hold together, the hoop is removed, the bandage adjusted upon the upper end of the cheese, which is now turned upside down, and power again applied till the pressing is done. When the gang press is used, the bandage is held in place by a metallic band coiled inside of the hoop in such a way as to hold up the upper end of the bandage till the curd is pressed down to a solid form, when the pressure is released, the end of the bandage adjusted, and the power applied again without turning the cheese.

For factories, the single screw press is fast going out of use, and the gang press, of which there are two patterns, (Fraser's and Beach's,) are taking its place.

The time of pressing is usually about 18 hours, and the force applied from two to ten tons, according to the means of escape for whey, and the condition of the curd. Cold curd requires more pressure than warm, aud curds with smooth surfaces, more than those with rough and jagged ones. Curd which has been made fine by slicing, requires more pressure to make the smooth surfaces join firmly, than that which has been broken by hand, or passed through a crushing mill. 
When placed in the curing room, cheese should stand till the surface becomes dry, and then be rubbed with whey butter or some similar grease, to prevent the surface from checking and cracking, and needless shrinkage by a too rapid escape of moisture. If the air in the room is very dry, an occasional greasing will be necessary, or the surface will become too dry. If the air is sufficiently moist, a daily turning and rubbing will only be needed. If too moist, so as to occasion much molding, the air should be changed by ventilation, and if necessary, dried by a fire. Cheese cures so much better in a moist than in a dry atmosphere, it is better to let the air be as moist as it can be, and keep the cheese decent on account of mold. When not made just right, exudations sometimes accumulate on the surface, and make cheese appear rough and uncomely. To remove this, wash and rub occasionally with a weak ley made with water and potash, or by leaching a few wood ashes. The ley will saponify the grease, and soften the exudations, and if strong enough, the rind of the cheese also, and by repeated rubbing, will smooth and polish the surface, and fill up any cracks or checks which may chance to exist, thus guarding against the intrusion of flies. As the cheese-fly is averse to depositing its eggs in alkaline matter, washing the surface of cheeses with ley is the best known protection against that sometimes troublesome insect. When used for this purpose, the ley may be stronger.

As the character of the cheesing process is varied by every variation in temperature and hygrometric condition of the room, it is important that the care taker should use every effort to keep the air in his cheese room even and in the proper condition in 
respect to the temperature and moisture required for properly curing the cheese under his charge. If too hot and dry, sprinkle the floor often. If too cold or damp, build a fire, no matter when the occasion may occur. It is a common occurrence to meet with cheese in the ill-constructed curing rooms of the country, which have had their texture injured, and their flavor made insipid by exposure to an extreme heat, which a frequent sprinkling of water upon the floor would have kept down; and others which, while green, have been made bitter, by being for a few days a little too cold, which might have been easily avoided by building a few fires in the room.

\section{BOXING CHEESE FOR MARKET.}

For protecting cheese properly, the package should be strong, and fit the cheese snugly, but not so snugly that it will not readily come out if turned upside down. Both sides of the cheese should be protected with a scale-board, and loose covers avoided, and the sides trimmed down till the cover will touch the cheese. Very dry boxes absorb moisture from the cheese, and make a difference between factory and city weight. The boxes before receiving the cheese should be made damp enough to prevent this absorption. The cheese will be the better for it, and the boxes will be less liable to get split and broken, than if very dry.

\section{FARM DAIRY CHEESE MAKING.}

Where cheese is made in farm dairies, the single screw press and the self-heating vat will be found most convenient. The buildings and apparatus will 
of course, be reduced in size, but when enough cheese is made upon farms for purposes of marketing, the same general principles and practices will apply which have been described for factories, and need not be again repeated.

For those who make cheese from only a few cows for home use, and are not provided with a complete set of apparatus, a few words may be appropriate.

For making cheese under any circumstances, a few things are absolutely necessary. One must have a vessel large enough to hold the milk. It may be any clean tub, boiler, or kettle. A wooden tub is best, because it will lose the least heat while standing. There must be means for warming, which can be supplied by a cook stove. Rennet for coagulating the milk must be provided and soaked beforehand. A strong hoop for pressing the curd, with a capacity of at least 6 cubic inches for every quart of milk used, and power for pressing equal to at least the weight of a ton. These being provided, warm the milk in any convenient way without burning, to about 84 degrees, and add rennet enough to have it begin to curdle in 15 minutes, and cover the milk to keep it from cooling. The quantity of rennet to use must be found by trial. A good rennet well soaked and rubbed, in time will curdle about 2,000 quarts of milk, but there is so much variation in their strength, that only an approximation to the quantity required, can be made. When the curd has become so hard as to cleave before the finger when passed through it, it should be cut with a blade that will reach to the bottom 'of the vessel, into columns an inch or so square, and then covered again to let the whey separate. After it has stood 15 or 20 minutes, the whey which çan be conveniently removed, 
may be dipped off, and the curd carefully broken with the hands into pieces of the size of chestnuts, or even finer. When this is done, the whey which has been dipped off, or what is better, an equal bulk of water, heated to 150 degrees, may be turned into the curd and stirred enough to make all parts of the curd warm up alike. The curd should be again covered to prevent cooling, and left standing 15 or 20 minutes, or as long as it can be without sticking firmly together, when the whey may be again dipped off, the curd broken up fine again, and more hot whey or water turned on and mixed evenly with the curd by gently stirring, so as not to rile the whey and waste the richness of the curd. Cover the curd again, and repeat the operation till the mass is raised to blood heat. The stirring should be repeated often enough to prevent the pieces of curd from adhering, and the whole covered and left standing for the curd to harden. When it has stood so long as to become hard enough to squeak between the teeth, or spring apart readily when pressed in the hand, or what is better, to respond to the hot iron test, described on a subsequent page, the whey may be at once dipped off, and the curd drained on a strainer-cloth laid over something which will allow the whey to run away steadily, like a large sieve or a basket. When the curd has been stirred till it is freed from whey, and becomes a little cool and the large lumps broken up fine so it will all receive salt about alike, salt at the rate of one ounce for each io quarts of milk. Mix the salt thoroughly through the curd, and then put to press. As soon as the curd is well stuck together so it can be handled safely, remove it from the press, put on a new press cloth, turn the under side up, fold the cloth evenly 
over it, and press again till the press is wanted for the next day's cheese. Upon taking it from the press, let it stand an hour or two till it becomes dry, then rub it over with some soft grease, and turn and rub daily till it is cured, which will be from 30 to 60 days. On small cheese for home use, no bandage will be required. The surface must be greased often enough to keep it from drying and checking. In making small cheese for home use, the press, though desirable, is not an absolute necessity. If a curd is properly made, it will form itself into a cheese of good texture by its own weight. In molding a cheese without pressing, the hoop should be made of perforated tin, so the whey can readily escape, and should have a cover of the same material for its top and bottom, shutting over and outside of the tin like the cover of a pill box, and should be only just about large enough to hold the curd to be molded. A cover is placed upon the lower end of the hoop, the warm curd filled in, and the cover put on the upper end, and set on any level foundation. After standing a few minutes, the hoop is turned quickly upon the other end, the curd slides down and makes a smooth surface, on what was at first the upper end. By turning the hoop a few times while warm, both ends get an even surface, and then, by standing still, the curd will permanently adhere and remain firm when taken from the hoop. To succeed well in molding cheese without pressing, the curd should be taken from the whey a little sooner than otherwise, and be quickly drained and salted and put into the hoop quite warm. Cold curd will not adhere without pressing. 


\section{APPENDIX.}

\section{THE HOT IRON TEST.}

This test is used to determine when curd is sufficiently matured for pressing. It originated in 1845 with L. M. Norton, of Goshen, Conn., who was also the originator of pineapple cheese, and was for many years kept a secret. After a while it became public and is now extensively used, and is the most accurate and reliable guide known for determining the precise stage in the ripening of curd at which it is proper to press it.

To apply the test, have an iron just hot enough to make water simmer when dropped upon it. Make a plug of curd and apply one end of it to the hot iron. If the curd is too immature it will not adhere to the iron; if it is just right it will stick to the iron, and when pulled away will draw out in threads from $1 / 2$ to $3 / 4$ of an inch long. If too far advanced it will string out in very fine and long threads.

\section{TESTING MILK AT FACTORIES.}

As a protection against fraud in diluting or adulterating milk, every factoryman should be provided with a set of graduated glass tubes, which he can daily, or at short intervals, fill with milk from his different patrons, and ouserve and record the per cent. of cream which rises upon the milk in each. So long as the milk of every patron shows a fair proportion of cream, he need not make any further tests. Should the milk of any one show a deficiency of cream, tests should made to determine whether it has been tampered with. To do this take a sample of milk from one or more herds which is known to be pure, and reduce it to the temperature at which the lactometer is made to be used, and note whether the lactometer sinks in it to the point $(\mathrm{P})$, which denotes pure milk. Do the same with the milk which showed a deficiency of cream, and note whether the point on the stem of the lactometer which stood at the surface in pure milk, sinks, or rises above 
the surface of the milk being tested. If the point $\mathrm{P}$ rises above the surface, it may be considered pure, because pure milk which is deficient in cream, is heavicr than pure milk rich in cream. If it sinks below the surface, dilution may be predicted, because it is lighter instead of heavier than pure milk. Now take two per cent. glasses and fill one to the top graduated marks with pure milk, and the other with the suspected milk, and when the cream has fully raised on both, remove it, and insert the lactometer in the skim-milk in each, and note exactly how far it sinks in each, and make a record of the result, for future use, if it should be wanted. If it sinks lower in the suspected milk than in the pure, turn water into the pure milk till the lactometer sinks to the same point it did in the suspected milk, and note the per cent. of water added. The per cent. of water added, will show the per cent. of dilution.

\section{RENNET.}

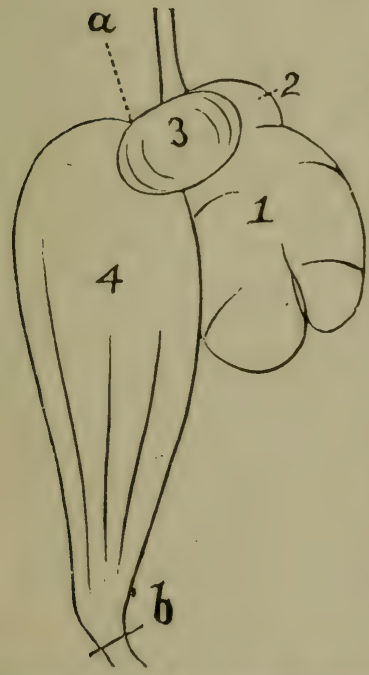

In its general signification, rennet applies to the preserved stomach of any young quadruped. As used by dairymen in the United States, the term signifies the $4^{\text {th }}$ division of the stomach of the sucking calf. If the stomach of any other animal is meant, the name of the animal is added, as pig's rennet, lamb's rennet, \&c. The same word is also used to signify the liquid in which the stomach has been steeped. The 4 th division or part of the stomach used for coagulating milk, is the one next to the small intestines. The points for severing it are indicated by the letters $a-b$.

The coagulating power of rennets varies in strength and quality with the age, health and habits of the animals from which they are taken. They are usually in their best condition when the calve are from five to ten days old, but they do not vary much in strength so long as the calves live entirely on milk. As soon as they begin to live upon solid food, the strength of their stomachs, as rennets, begins to abate. The stomachs of calves five days old are generally preferred by dairymen to those older or younger. To obtain the best rennets, the calves should be allowed to suck 
a moderate meal I 8 or 20 hours before killing. It is a good way to give the last meal at night, and kill the next day near noon. Some let them go 24 hours, and even longer, and the rennets are the stronger for so doing; but in going too long without eating, the stomach becomes inflamed and congested with blood, giving them a dark, reddish appearance, and the disturbed condition thus occasioned, is carried with the steepings of the rennet into the cheese, and affects it unfavorably. The calves should live till the curd from their last meal is nearly dissolved, but no longer. As the curd disappears, the coagulating agent accumulates, not in the juices of the stomach, as might be supposed, but is deposited on the inside of the stomach, forming a delicate coating, faintly flesh colored and very tender, which breaks off in thin, flocculent scales upon slight friction. As this coating contains the concentrated strength of the rennet, it is desirable to preserve as much of it as possible. To this end, the sack, when taken from the animal, should be handled with great care. The contents should be emptied out carefully, sack turned inside out, and any specks of dirt or hairs that may appear on it, picked off. If further cleansing is necessary, it may be wiped with a moist cloth, or very carefully rinsed by laying it in a dish of water and moving it gently. Water should not be poured upon it. When sufficiently cleansed and lightly salted, it is ready for drying, which may be done in any convenient way, so that it shall not waste by dripping, nor injure by tainting. It may be stretched on a crotched limb, or bow of splint, its ends may be tied and inflated, or it may be cut open and laid out on a dry board, which will aid in drying by absorbing its moisture. These modes of preserving are very m:uch better than salting in a pickle, or filling with salt. If exposed to much heat, rennets lose strength quickly. But they are improved by freezing and thawing, and also by age, if kept open to the air. Rennets should not be used the same season they are saved. They are very much better for a year's age if they are kept open to the air so that the strong odor common to green rennets can have time to be carried away. Their strength also increases with age for a season or two at least. When prepared for use, they may be steeped in brine or whey. If in brine, it should be no stronger than is necessary to protect them against tainting, as much salt is detrimental to their action. If the water is not pure, it should be boiled before using. Whey, both sweet and sour, is in common use. It should always be boiled to prevent carrying taints into the cheese, which arc always developing in the whey as now made in factories. Swcet whey has a fine effect upon the cheese, but sour whey is the best preservative, and if decidedly sour, is a better antiseptic than salt. Of whatever liquid is used, two quarts are enough for each rennet. Stone or earthen jars are the best vessels to prepare them in, and the preparation should be carefully covered, as liquid rennet soon loses its strength by exposure to light.

The first strength which soaks from the vells is better than the 
last. It is not only stronger, but it acts more vigorously upon the cream, so that it is better retained in the curd. It is very desirable to distribute the first soakings of the stomach through the whole of the steepings, and to have them of uniform strength from first to last, to secure uniform results in curding. To secure this, two or more jars or casks will be necessary. Three are preferable. Fill a jar or cask with brine or whey, as before directed, and then take as many rennets as would last 15 or 20 days, and cut them open, (some cut them in small pieces), tie them in a sack made of bandage cloth, and put them to soak in advance, for a batch to begin with, stirring and rubbing them every day, or oftener. Upon beginning to use this, put a second batch soaking in a second vessel in the same way, and take the sack from the first vessel and put in with it, marking it so it can be distinguished. As the strength of the second vessel may be different from that of the first, to prevent making any mishap on that account, begin using sume of the second before the first is exhausted, mixing more and more of the second with less of the first. In this way the strength in each jar will be readily known, and no mistake will be made in its use. Upon beginning to use from the second jar, take out the sack that was in the first, and after rinsing its contents, throw them away, fill it with new rennets, put to soak in a third jar, take the other sack from the second jar and put with it, and so continue through the season, always stirring the liquid before using. Careful inspection should be made in selecting rennets, to see that none that are tainted, or in any way objectionable, get into the jars to injure the cheese. All dark colored or strong smelling ones should be avoided. In using the Bavarian rennets, the thick ends made by tying, are often tainted and should be trimmed off, and in American and Irish rennets, the small end of the stomach is often left too long, and becomes objectionable by reason of bad odors and filth, and had better be cut off. The action of the extreme end of the stomach is al ways very feeble, and of questionable utility at any time, and should never be used unless in perfect order. There is no good reason why the active agent in rennet may not be extracted cheaply, and in a state of perfect purity and freedom from the objectionable animal matter which now always goes with it, and in a concentrated state and of uniform strength. Such preparations are now made in Denmark and Switzerland, and must soon be brought into use in this country, but until some enterprising chemist shall discover a cheap method of making an extract that will supply this demand, we must use the native stomach, and I give the best methods of utilising it, till its strength can be furnished in a better form. 


\section{PREPARING COLORING FOR CHEESE AND BUTTER.}

To prepare annattoine, take equal weights of annattoine, pure potash and sal soda, and dissolve each separately in four times its weight of water. When fully dissolved, mix all together and let it stand four or five days for the alkali to cut the annattoine, stirring occasionally. It will then be ready for use. It is best kept in earthen jars. For cheese, $\frac{1}{2}$ pint to $\mathrm{r}, 000$ lbs of milk give a deep golden color. For butter, I tablespoonful to 6 quarts of cream will give a deep color to pale butter. For either cheese or butter, find by trial, exactly the quantity required to produce the desired hue.

\section{TO PREPARE BASKET ANNATTO.}

Make a strong ley by dissolving potash in water, and put in as much annatto as the ley will dissolve. Boil the solution and set by for the sediment to settle. Turn off the pure liquid for use. The sediment may be washed with ley, and the clear liquid used. Find by trial, the amount of liquid required to give the desired color. Basket annatto varies too much to admit of precise directions.

Annatto seed may be prepared in a similar way. The seed should be several times rinsed in ley or hot water to extract ali the coloring.

\section{BOARDS OF TRADE.}

Associated dairying naturally led to associated marketing, where salesmen could become posted as to the market value of their produetions, and thereby obtain better prices than by individual effort; consequently "Boards of Trade," or "Sale Days" became necessary for the protection of the interests of dairymen.

The first effort in this direction was made in 1870 by T. D. Curtis, then editor of the Utica Herald, who advocated the organization of such Boards, in the Herald, and in a paper read before the New York Farmers' Club, December I6th of that year. Mr. C. issued the first call for establishing a local market, in the spring of IS7I. A week subsequent to the call of Mr. C., a similar one was issued at Little Falls, N. Y., calling for an earlier meeting, and at that meeting the first Dairymen's Board of Trade was established, which is now known as the N. Y. State Dairymen's Assoclation and Board of Trade. The call first issued matured a week later, and in obedience to it, was formed the National Dairymen's Club, now known as the Utica Dairymen's Board of Trade. The fruit of this enterprise thus inaugurated 
has resulted in great good to dairymen, and nnmerous institutions of a similar kind have since been established. In view of the importance and rapid multiplication of such Boards, I insert a blank form to aid in their organization :

\section{RULES AND REGULATIONS FOR A BOARD OF TRADE.}

Ist. The payment of $\$ 5$ to the Treasurer shall constitute a membership of the Board of Trade of the______ for one year.

2d. Members only shall be entitled to all the privileges of the salesroom.

3d. There shall be a register kept and a bulletin board arranged in a conspicuous place in the room, for posting telegrams and other information of interest received from other markets, and to which register and board all members shall be entitled to free access. Also all members shall have the privilege of posting upon said register a notice of any dairy or other produce they may have for sale.

4th. There shall be an officer appointed by the Club, whose duty it shall be to prơcure telegrams and other information deemed necessary by the Club for the bulletin board ; to procure and issue tickets of membership ; and to have the general supervision of the Salesroom.

5th. There shall be a Board of Arbitration constituted for the purpose of settling all differences which may arise from time to

- time between buyers and sellers, and it is an express understanding that the decision of such Arbitration Committee shall be final. The said Board of Arbitration shall be chosen and constituted as follows: In case of difference between two parties or interests, the said parties or interests shall each choose one member of the Board, and the two members thus chosen shall select a third, and these three shall constitute the Board of Arbitration, and have appropriate jurisdiction.

6th. All bargains between members made at the Salesroom or elsewhere, verbally or otherwise, shall be considered binding, and a failure of either party to perform his or their part shall be considered sufficient cause for expulsion from the Club and Salesroom.

7 th. For avoiding disputes respecting short weights, it is agreed that where a discrepancy is found in the weights of butter or cheese on arrival in market, a legally appointed weighmaster's certificate of such discrepancy, with expense of certificate attached, shall be considered a standard to settle by.

8 th. It is essential, that each of the foregoing rules be strictly observed by each member of the Club, and any violation of such rules shall be considered a sufficient reason for appointing a committee to look into the facts, and report what action, in their opinion, ought to be taken by the Club to avoid a repetition of the same. 
9th. It is understood that where a factory has more than one salesman, either one or all of said salesmen shall be admitted on presenting the factory's ticket of membership, and that a buyer and his agent may be admitted on one ticket, whether owned by the principal or the agent.

Ioth. It shall be proper for a member of this Board to be accompanied, when admitted to the Salesroom, by a neighbor or friend who is not interested in buying or selling, without additional charge ; but it is understood that this is a matter of courtesy, and any violation of good faith will be deemed a breach of the rules of the Board.

IIth. The price of single admission to the Salesroom, with the privileges of the Board for the day, shall be fifty cents.

I2th. Amendments to these rules and regulations may be made at any regular meeting of the Board, by a majority vote, provided notice of the proposed amendment has been duly given at a previous regular meeting.

\section{LIST OF APPARATUS.}

In response to numerous inquiries by parties contemplating the manufacture of cheese in factories and dairies, I give below a list of the apparatus with prices, as now commonly used in a factory of 400 , and a dairy of 30 cows, from which an approximate estimate of cost for a larger or smaller establishment can be made. The total cost is, of course, liable to vary by reason of change in prices and the introdution of new and improved apparatus, but it is believed that the tables will nevertheless be of value as an approximation to cost of outfit. The prices are for apparatus as now furnished by Gardner B. Weeks, of Syracuse, N. Y. :

\section{COMPLETE OUTFIT FOR A CHEESE FACTORY OF 400 COWS.}

I 3 -Horse Power Boiler, with fittings complete.................\$ $\$ 90$ oo

2600 Gallon Vats, with inside steam pipes, 2t $\$ 85.00 \ldots \ldots \ldots \ldots \ldots \ldots \ldots \ldots \ldots \ldots$. 17000

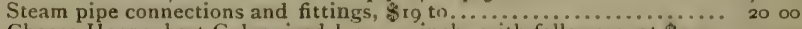
16 Cheese Hoops, best Galvanized Iron, 15 inch. with followers, at $\$ 4.50 .7200$

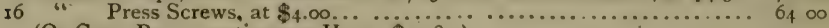

(Or Gang Press, costing per Hoop, $\$$ i $_{4} .83$.)

'Timbers for Press frames can be made by any good mechanic, say..... 2500

Curd Drainers......................................... 1500

I 60 -Gallon Weigh Can, -large faucet ................................ 13 50

I Tin Conductor................................................. 250

I 6os-lb. Fairbank's Scales, with wheels, for weighing milk................ 23 o0

*1 r40-lb. "" " " cheese, \&c....... 16 50

I Curd Knife, $-r_{3}$ Blades, -20 in. long........................... 7 o

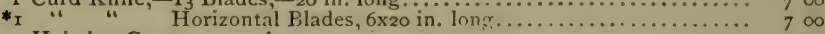

I Hoisting Crane, - complete .................................. I4 oo

I Syphon and large Strainer................................ 350

* tr Bandager - ( Patented)

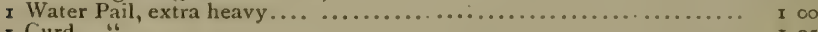

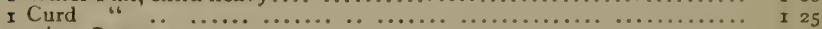

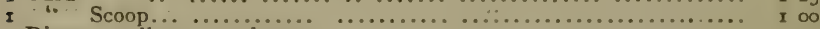

I Dipper-gallon, extra heavy.................................... I o 
I Set Milk-Testing Instruments-comprising 3 Graduated Jars, I Lac-

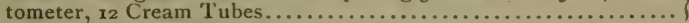

Case Stencil Plate and Brush . . . . . . . . . . . . . . . . . . .

I Factory " " about.....

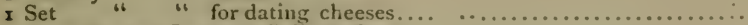

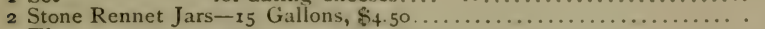

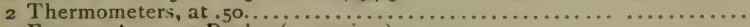

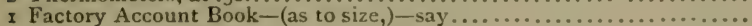

r Rubber Mlop

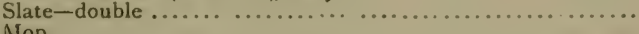

* Floor Funnel

* Curd Mill, double cylinder.

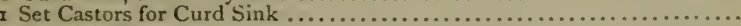

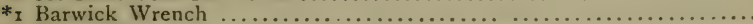

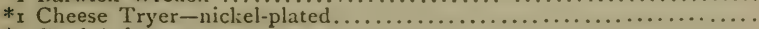

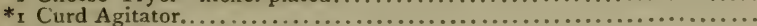

t* I Milk " Austin's (patent).

*I Tinned Cheese Knıfe.

I 00

In case a Factory fitted up as above for making cheese from 400 cows is converted into a Creamery where butter and cheese are made from the same milk, the following articles would be required :

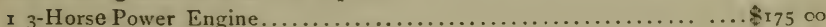

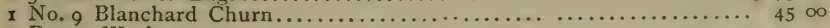

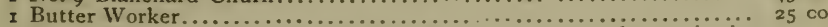

Cooler Pails, -as per time that milk is to set. It may be set in the

Cheese Vats if only for in $_{2}$ or $2+$ hours - at .................. 90

I Butter Mold ..................................... I

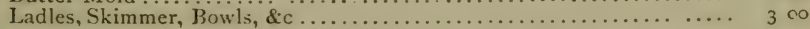

Articles marked with a * may be dispensed with, though very much used.

Articles marked with a + are patented, and the right to use them must be obtained of the owners of the patent.

\section{FIXTURES FOR A CHEESE DAIRY OF 30 COWS}

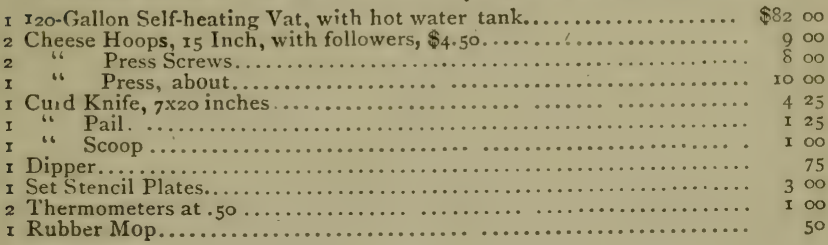

\section{FORM FOR ORGANIZING A DAIRY MANU- FACTURING COMPANY OR ASSOCIATON.}

We, the undersigned, hereby organize ourselves into an association for the manufacture of (Cheese, or Butter, or both, as the case may be,) under the name and style of, (insert name, with P. $\mathrm{O}$. address). It is agreed and understood that the stock of this association shall be divided into (number of shares, at the par valuation of $\$$ per share;) and it is hereby understood and agreed that each shareholder shall contribute his pro rata share of expenses, and receive his pro rata share of all net profits. 
All matters in the construction of the necessary huildings, furnishing them, the hiring of help and the general management, shall be decided by vote of all shareholders present at a regular meeting, or at a special meeting of which all stockholders have been notified, the majority of stockholders represented determining the result. A special meeting shall not be held without at least three days' notice being given by the president to each member, either verbally or by written notice left at his place of business. The officers of this association shall be a President, two Vice-Presidents, a Secretary, a Treasurer, and an Executive Committee of three. The duties of the several officers shall be t'iose usual to such organizations. We also hereby agree to abide by and observe all By-Laws, Rules and Regulations which may hereafter be adopted by a two-thirds vote of this assotiation, at any regular meeting - that is, two-thirds of the shares of stock represented at such meeting cast in the affirmative. For the faithful performance of all which we hereby subscribe our names, this the - day of $\longrightarrow$ - $18-$.

(a) The parts separated in making cheese are shown by the following analyis made in Cornell University under the direction of Prof G. C. Caldwell:

\begin{tabular}{|c|c|c|c|c|c|c|c|}
\hline & I & 2 & 3 & 4 & 5 & 6 & 7 \\
\hline Water. & $3+.18$ & 29.82 & 35.24 & 20.19 & 30.49 & $28.1 \mathrm{I}$ & 4056 \\
\hline Fat.. & 33.92 & 35.80 & 35.68 & 37.24 & 39.25 & 41.03 & 20.53 \\
\hline Ash... & 3.02 & & 2.84 & & 3.00 & 2.68 & 7.05 \\
\hline Protien. & 28.88 & & 26.24 & & 27.26 & 28.18 & 34.86 \\
\hline
\end{tabular}

No. I was a factory cheese three days old, made at North - Bridgewater, N. Y., July, I875. No 2, same five months old. No. 3 was a factory chcese one week old, made by Hon. Wm. A. Johnson, at Collins Centre, N. Y., August, I875. No. 4. same four months old. No 5 was nine months old, made of half Jersey milk, at Winthrop Factory, Maine, Aug. 24th, 1874. No. 6 was well cured and made of all Jersey milk at same factory, Sept. I6th, I875. No. 7, also margarine cheese, six months old, made at McLean, N. Y. 


\section{DF" GET THE BEST." THE BLANCHARD CHURN}

As now offered to the trade and to the practical Dairyman, is the result of over tiventy-five years' experience and experiment. It has been proved, and improved, and $a p$ proved, during the past quarter of a century, and is now unquestionably

\section{The Leading Churn of the Country!}

\section{ONE HUNDRED THOUSAND}

A re now in successful operation. They are for sale in every State and Territory of the Union, and many foreign countries. They always sell the best where they have been used the longest. They combine more desirable qualities than any other Churn now made. No other Churns are made of as good materials, or as faithfully. WE CHALLENGE COMPARISON. They cannot get out of order, because they are so simple. Because they are so simple, and thoroughly made, they are very durable. They have no cogwheels or gearing to wear out or break. They work the butter free from butter-milk in the churn, without any change of dasher, quicker and better than it can be done by hand. They work in the salt in the same way. They are PERFECT AUTOMATIC BUTter MAKERS. Seven Sizes Made.

No. 3-For about 2 gallons of cream..............\$6 oo

No. 4 - " " 4 " "

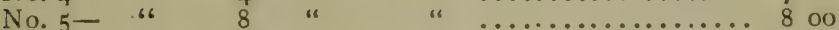

No.6- " 12 " "

No. 7- " I8 " " 8 " $8 \ldots \ldots \ldots \ldots \ldots . .1200$

No. 8 -For from 50 to 75 gallons of cream............ 40 oo

No. 9- " 75 to 150 " " $\ldots \ldots \ldots \ldots \ldots .4500$

Power Pulley for any size Churn................ 250

If they do not give satisfaction, or prove to be as represented, they may be returned to the agent of whom they are purchased, at our expense.

The Factory sizes (Nos. 8 and 9) are found to be exactly what is needed in large Dairies or Factories, where power is used. They have the unqualified commendation of every one who has used them. Send to any dealer in really first-cliss dairy implements for our goods. They all keep them.

We furnish free, on application, our "New Butter Manual," and Descriptive Circulars. Send for them. "Get the Best."

- SOLE MANUFACTURERS,

\section{PORTER BLANCHARD'S SONS,}

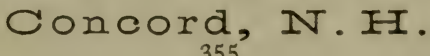




\section{THE}

DAIRY

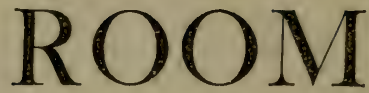

OF THE WORLD,

AND

THE ONLY PERFECT SYSTEM OF COOL.

ING AND VENTILATING AUTOMATIC-

ALLY, AND MAINTAINING THE

SAME TEMPERATURE SUMMER

AND WINTER, WITHOUT

THE USE OF AIR.

PATENTED JANUARY, I876, BY

\section{J. WILKINS0N, Baltimore, Md.}

Send 25 Cents and Stamp for full description. Address, until November next, J. WILKINSON, Chief Superintendent of the Agricultural Department International Exhibition, Philadelphia, Pa.

\section{BUTDICK'S}

\section{SELF-LOADING HAY WAGON.}

THIS MACHINE is warranted to load one ton of hay in two 1 minutes, and drops it out upon the barn floer, or heside the: stack, without stopping the team, only to hook a chain. Price $\$ 200$. Price of wagon without any machine $\$ 100$.

Address, H. P. HURDCK, Amed, Allegany Co.s N.X. 


\section{WHITMAN \& BURRELL, Little Falls, N.Y.}

Sind for complete Illustrated Circular of all Apparatus and Furnishings for

\section{CHEESE AND BUTTER FACTORIES!}

New Method of Manufacture Given.

General Agents for the Celebrated Blanchard Churn, French Burr-Stone Grist Mills, \&c.

We manufacture largely CHEESE-BOX HOOPS, Rims and Heading, and ship in bundles ready to make up into CHEESEBOXES, TOBACCO DRUMS, \&c.

\section{Economizer Improved Boiler \& Engine.}

The Only BoIler for Dairymen and Farmers.

IHighest award of the Committee on Boilers for Cheese Factory purposes, at the American Dairymen's Convention, a very large assemblage, at Rome, to the ECONOMIzFr, over all others on exhibition. The best Portable Steam Engine in market. Boiler all wrought iron. Every part made upon honor. All bearing parts made to take up wear. Engine warranted of best iron and steel. Nothing cheap but price. Fire passes underneath boiler to the back, thence through the flues and up the stack.

PrICES. - Three-horse Power, \$350; Four-horse Power, \$400; Five-horse Power, \$450; Eight-horse Power, \$575.
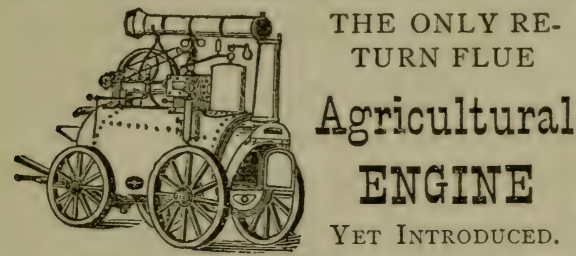

YET INTRODUCED.

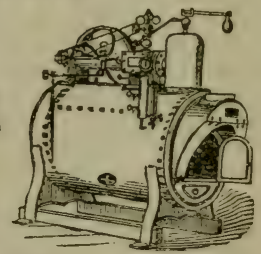

COMPLETE WITH SPARK ARRESTER.

[Refer to page 107 in Report on Factory Apparatus, in Annual Report of American Dairymen's Association, for IS76.]

HIGHEST PREMIUMIS at twenty-two important Fairs and Expositions, including American Institute test of three months'73 and ' 74 -for PORTABLE BOILERS AND ENGINES.

It is the most economical yeT POWERfUL Agricultural Engine in the market. It has No Fire Tile to Shake Loose or get broken. The Fire is Right in the Center oe the Water iTSELF-ALL THE HEAT is UTILIZED. It can not scale up, and will last a life-time. There can be no possibility of sparks, for the fire goes to the rear end, then back to the front through the return flues, so that all sparks are entirely consumed. examination will convince any party of its great superiority.

D EvERY ARTICLE OF OUR MANUFACTURE FULLY GUARANTEED. 


\section{PERFECTED BUTTER COLOR.}

WTE TAKE PLEASURE in offering to the Dairymen of America this preparation, as the perfect result of our long continued experiments in the preparation of an Artificial color for their use.

In our Perfected Butter Color, we have succeeded in combining the bright yellow coloring principle of the Dandelion blossom with the previously well known "Golden Extract," thereby securing a bright golden tint, so exactly like the highest grade of June butter, that wo expert can detect it, even by actual comparison of the artificial with the natural color.

We claim for it every point wanted in a PERFECT Butter color, viz:

Ist PERFECT COLOR. The butter never turns to a reddish tinge, but always keeps its bright golden color.

2d. PERFECT FREEDOM FROM ANY TASTE OR SMELL, that can be imparted to the butter.

3d. PERFECT KEEPING QUALITIES. It does not mold, sour, or spoil in any manner. Heat or cold have no effect upon it. It has a decided tendency to preserve butter, whereas butter colored with carrots, annatto, etc., will often spoil or turn to a dull reddish tint.

4th. PERFECT ECONOMY IN USE. It requires no labor, as it is a fluid that is put with the cream into the chnrn. It is cheaper than any other coloring, being put up in three sizes, selling at 25 cents, 50 cents and $\$ 1.00$, which color respectively 300,750 and 2.000 pounds of butter. We warrant it to add at least five cents per pound to the value of white butter, a return of one dollar for every cent it costs.

\section{IMPORTANT PROPOSITION.}

In order to give every one an opportunity to give this color a trial, we will send samples sufficient to color 50 pounds, post paid, to any address, on receipt of ten cents. Address,

WELLS, RICHARDSON \& CO., Burlington, Vt.

\section{WELLS, RICHARDSON \& CO.'S}

\section{GOLDEN EXTRACT of ANNATTO.}

A liquid extract of Annatto, pure, brilliant, permanent, economical. The best color for cheese, far surpassing in Strength, Purity, Quality and durability of Color and Cheapness, any product, liquid or otherwise, ever offered to Dairymen.

Its strength is extraordinary-one gallon giving a good color to 20,000 lbs. of cheese, or more. The color is uniform, and permanent, and just that bright shade best adapted to the English market It is cheaper for cheese makers than any other coloring. Send for circulars giving full particulars. 


\section{THE AMERICAN DAIRY SALT COMPANY,}

SOLE MANUFACTURERS OF THE

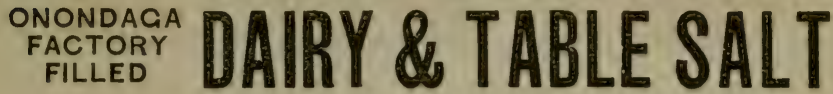

\section{AT SYRACUSTE, IN Y.,}

Respectfully call the attention of Dairymen and others to the quality of the Salt now being mantfactured by them. Having for many years past been engaged in perfecting the various processes for the manufacture of this Salt, and by adopting the best modes and machinery for the purpose, they ficl warranted in saying to the consumer that the article now produced is sup trior to any other, either of foreign or domestic production. The following is a curret. analysis of our Salt, and also of the celebrated Ashton's English Salt, made Ly Chas. A. Goessmann, Ph. D., Professor of Chemistry in the MIassachusetts Agricultural College at Amherst, Mass.:

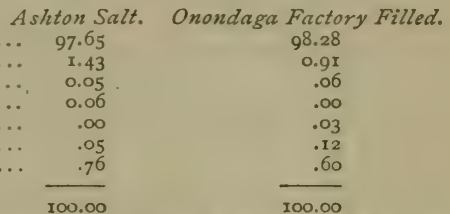

Sulphate of Lime.....................

Sulphate of Magnesia.............. 0.05

Chloride of Magnesia................ 0.06

Sulphate of Soda....................... .

Insoluble matter................... .05

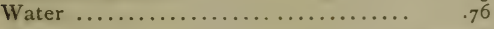

I00.00

Circulars in regard to various tests made with this Salt in comparison with the best foreign article, also certificates from a large number of the best dairies in this State as to its quality, may be had on application to J. IV. BARKER, Secretary, Syracuse, N.Y., to whom orders for Salt may also be addressed. It is also for sale by Agents of the Company in principal Western Lake Ports; by KOBT. GEER, No. rog Pier, Altrany, N.Y., and by Salt Dealers generally throughout the State of New York. Inquire for ONONDAGA FACTURY FILLED DAIRY SALT.

THOS. MoLloy, Treas.

J. WV. BARKER, Pres't and Sec'y,

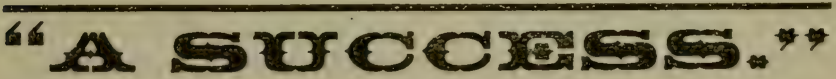

(See Prof. ARNold's Opinion, page 257.)

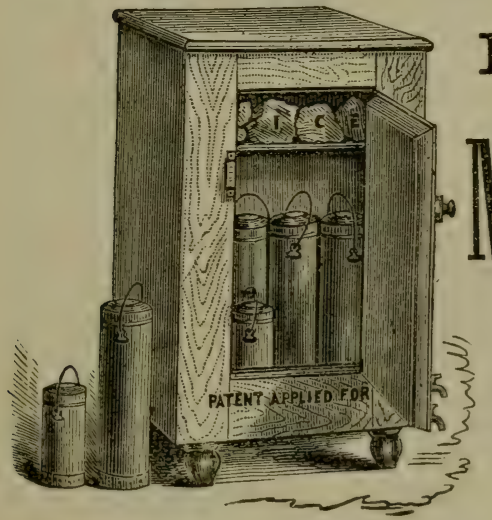

HARDIN'S

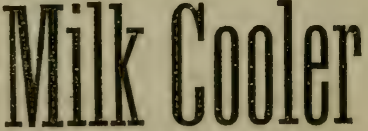

CIRCULARS FREE.

Address,

L S. HARDIN,

Louisville, $K y$. 


\section{Adams' Patent Butter Case,}

\section{NORRIS \& BRO., Proprietors,}

3I Prospect St., - CLEVELAND, O.

For price, terms, or other information in regard to this Butter Package, address as follows:

For New York and Eastern States-

LEWIS T. HAWLEY, Syracuse, N. Y.

Hon. HARRIS LEWIS, FRANKFORT, N.Y.

For Illinois and Iowa-

C. C. BUELL, Rock Falls, IlL.

And for all other States and Territories, the Proprietors. ORDERS FUR

CHOICE TABLE BUTTER,

Packed in these Cases, promptly filled and shipped to any part of the world with safety.

NORRIS \& BRO., Proprietors.

CHARLES MILLAR \& SON,
Cheese \& Buttel-MaKing' A ppalatuS,
Combining all the Latest Improvements. DeAlers in
Cheese Factory d Dairy Fumishing Goods,
Send for Illustrated Circular and Price List.
I27 \& r29 GENESEE STREET, UTICA, N. Y.
SLAVE," is the best in America.

MIDDAUGH'S MILK TESTER.

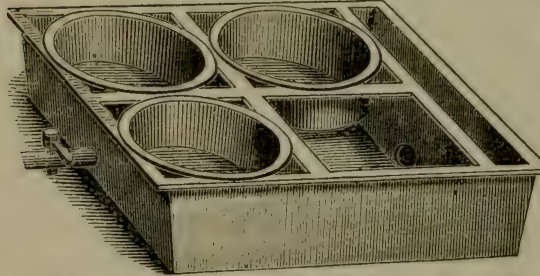

Instruments and Rights to use sold by

This is an instrument for testing the value and quality of milk It will tell if milk has been skimmed, watered, or taken from a cow that has garget or any other disease that will affect the quality of the milk. It is simple in construction and operation, and is rapidly going into use in the best Butter and Cheese Factories in the country.

ALVIN MIDDAUGH, Friendship, N. Y.

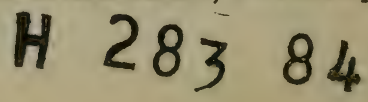




\section{,}



$0 \gamma_{2},-\infty x-1$

$A^{\circ}=x_{0}$

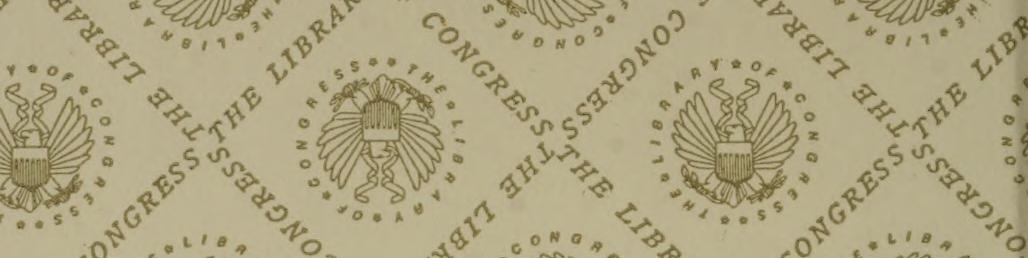
100

40

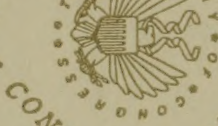

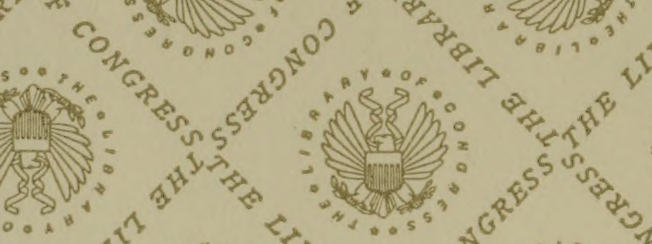

of

年,

40

(1)

ast $\cdots$

10

$c^{0}+\cdots \cdots$

(35)

(a)

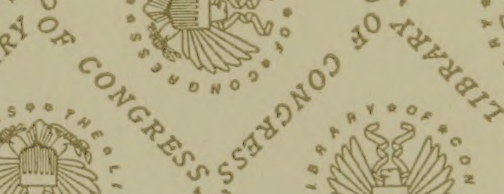

in

, $30.0,2$

$\rightarrow \frac{6}{6}$

- 5 40 के

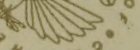

$5^{2}$

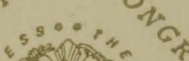


: Dat

- $100^{\circ}$

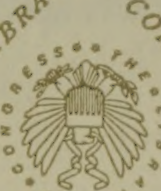

ap

8. $=$

"s

- हो $100^{\circ}$

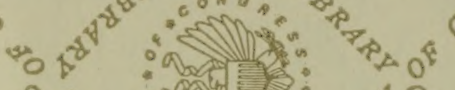

$\left.\mathrm{C}^{2}+1,8\right)^{2}$

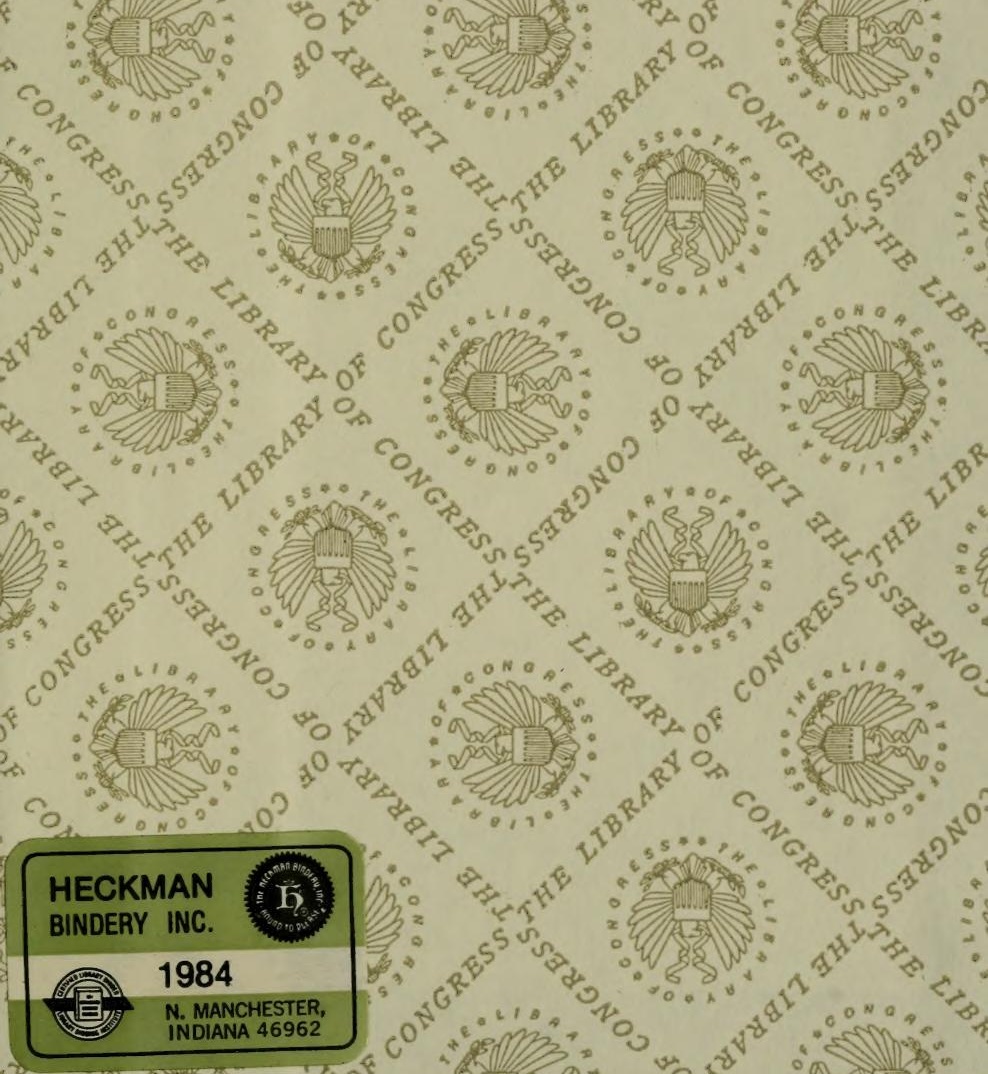

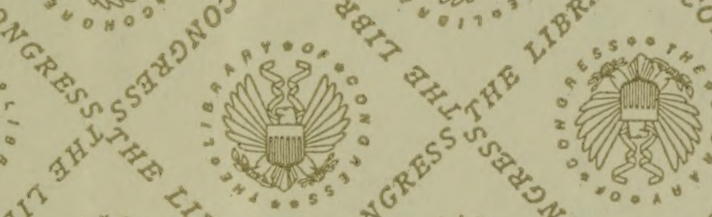




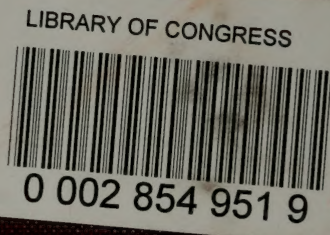

